\title{
Multigrid Methods for Anisotropic Heterogeneous Material Simulation in Dry and Elasto-Hydrodynamically Lubricated Contacts
}

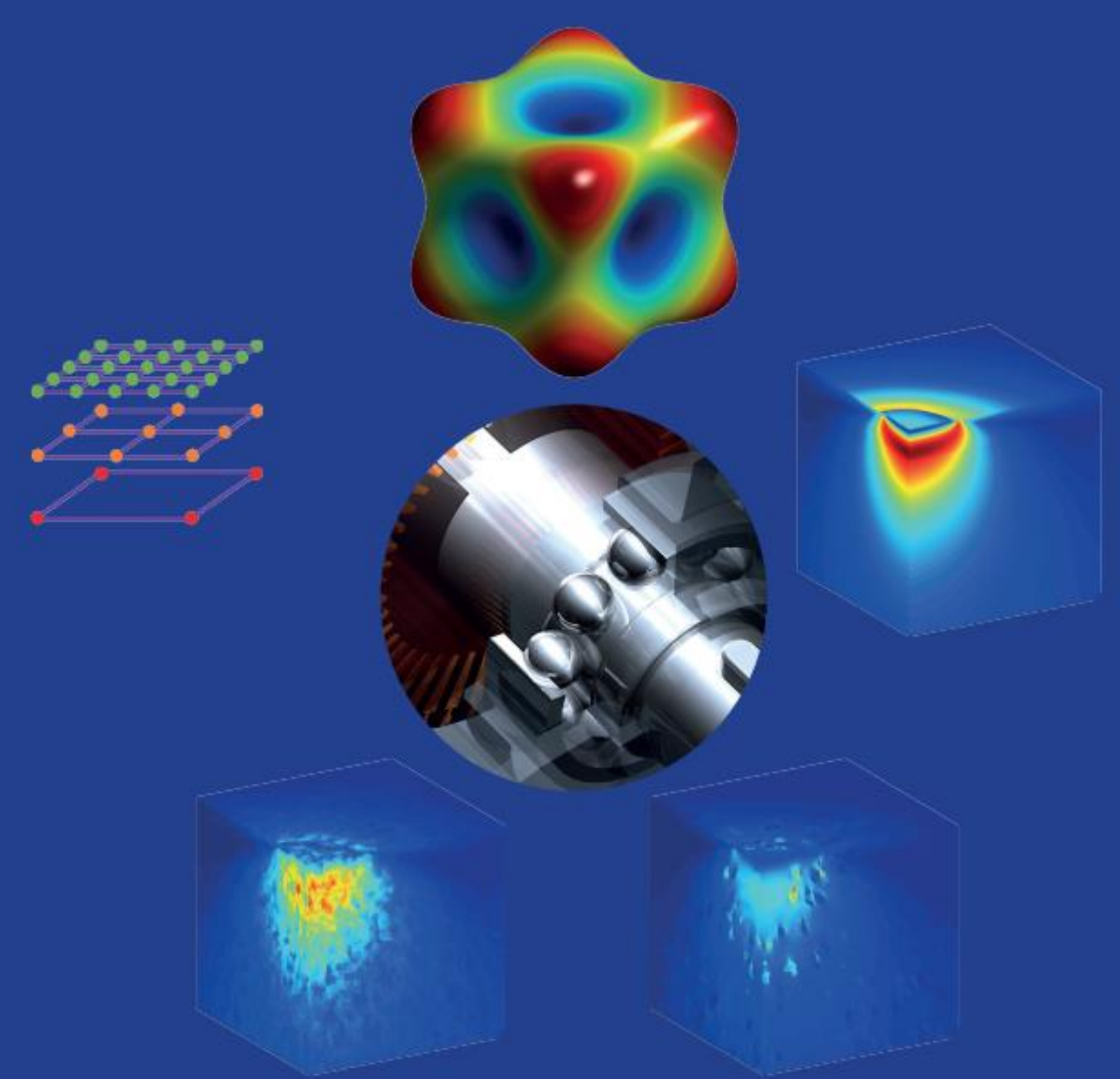

Binbin Zhang 


\section{MULTIGRID METHODS FOR ANISOTROPIC HETEROGENEOUS MATERIAL SIMULATION IN DRY AND ELASTO- HYDRODYNAMICALLY LUBRICATED CONTACTS}

Binbin Zhang 



\title{
MULTIGRID METHODS FOR ANISOTROPIC HETEROGENEOUS MATERIAL SIMULATION IN DRY AND ELASTO- HYDRODYNAMICALLY LUBRICATED CONTACTS
}

\author{
DISSERTATION \\ to obtain \\ the degree of doctor at the Universiteit Twente, \\ on the authority of the rector magnificus, \\ Prof.dr. T.T.M. Palstra, \\ on account of the decision of the Doctorate Board \\ to be publicly defended \\ on Thursday 27 August 2020 at 12.45 hrs
}

by

\section{Binbin Zhang}

born on 29 November 1988

in DongYing, China 
This dissertation has been approved by:

Supervisor

Prof. dr.ir. C.H. Venner

Cover design: $\quad$ Binbin Zhang

Printed by:

IPSKAMP

Lay-out:

Binbin Zhang

ISBN:

978-90-365-5040-6

DOI:

$10.3990 / 1.9789036550406$

(C) 2020 Binbin Zhang, The Netherlands. All rights reserved. No parts of this thesis may be reproduced, stored in a retrieval system or transmitted in any form or by any means without permission of the author. Alle rechten voorbehouden. Niets uit deze uitgave mag worden vermenigvuldigd, in enige vorm of op enige wijze, zonder voorafgaande schriftelijke toestemming van de auteur. 


\section{Graduation Committee:}

Chairman / secretary Prof.dr.ir. H.F.J.M. Koopman

Supervisor:

Prof.dr.ir. C.H. Venner

Committee Members

Prof.dr.ir. A.H. van den Boogaard

Prof.dr.rer.-nat. S. Luding

Prof. dr.ir. A.A. Lubrecht

Prof. dr-ing. G. Poll

Dr. A. Félix Quiñonez 



\section{Abstract}

In view of the need for sustainable development, energy losses at any scale in machines and processes need to be minimized and performance and service life maximized so as to ensure effective use of resources. In many applications the long-life performance increasingly depends on many interfaces in which power and forces are transmitted. Rolling bearings are crucial mechanical part to guide rotating motion whilst transfer of load between machine components with low friction. As a result of downsizing and higher speeds, its operating conditions become increasingly severe. In order to enhance the reliability, extend the durability and reduce the maintenance frequency of rolling bearings, a lot of improvements have been applied in the past decades, for example material and geometry optimization, high performance lubricants and additives, seal design, etc.

Accurate prediction of rolling contact fatigue (RCF) requires knowledge of the stress fields accounting for the influence of anisotropic heterogeneous bearing material with appropriate contact boundary conditions such as elastohydrodynamic lubrication (EHL), mixed lubrication, boundary lubrication and dry contact. Numerical simulations of stress fields have the potential to understand the generation and evolution of cracks and its resulting RCF. Due to the heterogeneous and anisotropic feature of bearing material on a small scale, the computing time of its stress field increases quickly with the number of unknowns for direct methods and commercial software. The objective of this thesis is to develop an efficient multigrid based algorithm, which can allow a dense grid to consider the effect of complex heterogeneous anisotropic microstructure for stress field calculation and fatigue life.

Firstly, a multigrid algorithm has been developed for a 2D/line dry contact problem. The effects of coating and material inclusions on the stress field and contact pressure distribution are studied. Local stress concentrations can be found around the boundaries between coating or inclusions and the surrounding substrate material. The level of local stress variation depends on the difference of elastic moduli. Besides, the contact pressure diverges from the classical Hertzian pressure distribution which is commonly used in fatigue life analyses.

Then, the developed 2D multigrid algorithm is extended to solve a $3 \mathrm{D} /$ point contact problem where the efficiency of the multigrid method is highly needed. Material anisotropy is an intrinsic feature of bearing material, and its stress field analysis requires huge computational efforts for traditional numerical methods. It is proven that the developed multigrid algorithm has the required accuracy and 
high efficiency for polycrystalline anisotropic material and can be applied for relevant industrial applications on small scale computers. Different from isotropic material, the stiffness of grain depends on the load directions, which means its stiffness varies with orientation. Due to the random distribution of orientation angles, the resulting effect of anisotropic grains on the stress fields is like that of soft and hard inclusions. Local stress concentrations are found around grain boundaries that have large orientation differences. Moreover, the variation of stiffness results in contact pressure fluctuations.

In order to advance the understanding of the mutual influences between the EHL pressure and the subsurface stress field and their combined effects on the RCF, a multigrid algorithm is developed for simultaneous solution of a 3D elastic problem with a 2D lubrication problem as the boundary condition. The time cost for solving the 3D stress field and the EHL pressure further proves the high efficiency of the developed multigrid algorithm. The results show a strong effect of local crystal elasticity on the EHL contact pressure and the subsurface stress field. As a consequence, the crystallographic microstructure may have a significant effect on rolling contact fatigue when these variations occur on a scale comparable to the Hertzian contact half width. By analysing cases of granular material with varying orientations and topology, a standard deviation of the value and of the depth of the maximum von Mises stress is observed of about $2.76 \%$ and $3.32 \%$ respectively. This is in line with the life scatter observed in RCF experiments of rolling bearings.

Finally, the effect of material anisotropy on the predicted rolling contact fatigue life is investigated based on the Ioannides-Harris fatigue life model. The effect of contact pressure, shear stress, grain size, and rotation angles on stress fields and fatigue life is analysed. The local stress concentrations of anisotropic heterogeneous material lead to a reduction of predicted life compared to homogeneous isotropic material. The life reduction depends on the average grain diameter and crystal orientations.

This thesis develops efficient multigrid algorithms and studies the effects of heterogeneous anisotropic material variation on the stress field and the fatigue life prediction of bearing material. In order to extend the fatigue life, rolling bearing material should be manufactured with fine grain size and optimized distribution of rotation angles. The developed multigrid algorithms can be applied for material optimization and computational diagnostics using actual data from electron back-scatter diffraction analysis of bearing material in future research.

This thesis is divided into two parts. In the first part (Part I), a short description of the work is given. Full details of the work are given in appended papers in the second part (Part II). 


\section{Samenvatting}

De mensheid staat voor de ongekende taak om onze kwetsbare planeet leefbaar te houden voor toekomstige generaties en haar rijke biodiversiteit te behouden. Essentieel daarvoor is het beperken van de opwarming van de atmosfeer als gevolg van de uitstoot van broeikasgassen zoals $\mathrm{CO}_{2}$. Daarnaast is bescherming tegen de toekomstige gevolgen van de reeds ingezette klimaatverandering noodzakelijk. De ontwikkeling van duurzame technologie met hoge efficiëntie door minimale energieverliezen, optimaal (her)gebruik van grondstoffen, een lange levensduur, een goede onderhoudbaarheid en een minimale negatieve invloed op de omgeving (zoals uitstoot van schadelijke stoffen, maar ook geluid) is de grote uitdaging van de huidige en toekomstige generaties wetenschappers en ingenieurs.

Efficiëntie en levensduur in technische toepassingen hangt direct samen met de nauwkeurige beheersing van alle situaties waarin krachten overgedragen worden tussen bewegende onderdelen. Hierin spelen wentellagers ("kogellagers") variërend in diameter van millimeters tot meters, zoals bij de huidige generaties grote windturbines, een cruciale rol. De hoge eisen t.a.v. functionaliteit, efficiëntie (minimale verliezen door ongewenste wrijving), levensduur en de enorme consequenties van onverwacht falen, vertalen zich in steeds striktere eisen ten aanzien van het functioneren. Minder materiaalgebruik leidt vaak tot extremere condities zoals hogere belastingen en hogere temperaturen en een gereduceerde beschikbaarheid van smeermiddel voor het scheiden van de loopvlakken van de contacten tussen het rollende element en de binnen- en buitenring van het lager. Dit leidt tot dunnere smeerfilms met een grotere gevoeligheid voor de variatie van de operationele condities, de effecten van de ruwheid van de oppervlakken en de effecten van imperfecties in het materiaal, met als gevolg een toename van het risico van ongewenst metallisch contact en slijtage en eerder optreden van vermoeiing in het materiaal. Nauwkeurige voorspelling van de levensduur van lagers betreffende zowel de vermoeiing van het materiaal als de functionaliteit van de smering is essentieel. Het huidige hoge betrouwbaarheidsniveau van het functioneren van wentellagers is te danken aan geavanceerde productieprocessen en zuivere materialen met een minimum aan insluitingen en een zeer hoog niveau van de kennis op het gebied van de ElastoHydrodynamisch gesmeerde (EHL) contacten tussen de rollende elementen en de binnen- en buitenring van het lager. Tot op heden is er ten aanzien van de modellering van het materiaal voor de voorspelling van vermoeiing meestal uitgegaan van homogeen isotroop materiaal. In werkelijkheid is kogellagerstaal op microscopische schaal echter verre van homogeen en isotroop. Met het oog 
op de steeds strengere eisen en extremere condities met dunnere smeerfilms, en ten behoeve van de verdere ontwikkeling en optimalisatie van het gebruikte materiaal is het essentieel om ook de invloed van de variatie van de granulaire microstructuur en de effecten van de oriëntatie van de kristalstructuur (anisotropie) op de spanningen onder het oppervlak en de smering goed te kunnen voorspellen. Het opvullen van deze lacune in kennis is het onderwerp van dit proefschrift.

Voorspelling van de vermoeiingslevensduur (Rolling Contact Fatigue RCF) vereist kennis van de spanningsvelden in het materiaal die alleen verkregen kan worden middels numerieke simulaties. Vanwege de zeer kleine schaal waarop de structuurvariaties zich voordoen is het gebruik van zeer fijne rekenroosters vereist hetgeen met standaard (commerciële) methoden leidt tot extreme rekentijden op grote computers. In dit onderzoek is een efficiënt algoritme ontwikkeld op basis van Multigrid technieken waarmee de vereiste berekeningen mogelijk zijn met de relatief beperkte computercapaciteit beschikbaar in een ontwerpgerichte onderzoeksomgeving. Deze ontwikkeling is gedaan middels een zorgvuldige 'stap voor stap'-aanpak.

Als eerste stap is een Multigrid-algoritme ontwikkeld voor een 2D/lijn droog contactprobleem. Daarmee zijn effecten van coatings en materiaalinsluitingen op de contactdrukverdeling en op het spanningsveld in het materiaal onder de contacten bestudeerd en de resultaten geverifieerd met reeds bekende resultaten uit de literatuur.

Vervolgens is het ontwikkelde algoritme uitgebreid tot volledige 3D simulaties met het contact gemodelleerd als een puntcontactprobleem. Voor deze simulaties is de efficiëntie van de Multigrid technieken cruciaal. Door middel van resultaten voor diverse problemen wordt angetoond dat het ontwikkelde algoritme de vereiste nauwkeurigheid en de hoge efficiëntie heeft voor de simulatie van de invloed van polykristallijn anisotroop materiaal in contactproblemen en kan worden toegepast voor relevante industriële toepassingen op relatief kleinschalige computers. Door de variatie van de oriëntatiehoeken van het materiaal in de korrels ontstaan spanningsconcentraties op korrelgrenzen met grote oriëntatieverschillen. Tevens wijkt de contactdrukverdeling af van de algemeen gebruikte Hertze contactdruk in levensduurberekeningen. Dit heeft directe consequenties voor de voorspelde levensduur.

Tot slot is het algoritme uitgebreid tot de meest complexe realistische situatie, nl. het simultaan oplossen van de spanningen en vervormingen in het $3 \mathrm{D}$ polykristallijn materiaal met de stromingsvergelijkingen die de smeerfilmvorming en drukverdeling in de smeerfilm beschrijven. De resultaten tonen een sterk effect aan van de lokale oriëntatie op de EHL-contactdruk en het spanningsveld in het materiaal. De resultaten laten zien dat de kristallografische microstructuur een significant reducerend effect kan hebben op de iv 
vermoeiingslevensduur van het contact met name wanneer de microstructurele variaties optreden op een schaal die vergelijkbaar is met de afmeting van het Hertze contact. Door gevallen van granulair materiaal met verschillende oriëntaties en topologie te analyseren, blijkt een standaardafwijking van de waarde en de diepte van de maximale von Mises-spanning op te treden van ongeveer 3\%. Dit komt ruwweg overeen met de geobserveerde standaardafwijking in levensduurtesten van wentellagers. De resultaten laten verder zien dat het effect van de microstructuur op de smeerfilmvorming in stationaire condities beperkt is, hetgeen gunstig is voor ontwerp.

Om de effecten van de microstructuur op de levensduur verder te kwantificeren is het ontwikkelde algoritme gebruikt in een studie van het effect van de microstructuur op de voorspelde levensduur van het contact op basis van het Ioannides-Harris levensduur model. Het effect van de contactbelasting, de schuifspanning aan het oppervlak, de korrelgrootte en de rotatiehoeken van het materiaal op de spanningsvelden en de voorspelde vermoeiingslevensduur is onderzocht. De lokale spanningsconcentraties in granulair anisotroop materiaal leiden tot een significante reductie van de voorspelde levensduur in vergelijking met homogeen isotroop materiaal. De voorspelde reductie van de levensduur is afhankelijk van de gemiddelde korreldiameter en van de kristaloriëntaties.

De in het kader van dit onderzoek ontwikkelde algoritmes kunnen niet alleen worden toegepast ten behoeve van nauwkeurigere levensduurvoorspellingen, maar ook voor materiaaloptimalisatie alsmede voor diagnostiek, door gebruik te maken van detailgegevens van materiaal verkregen uit microscopische analyse zoals Electronic Backscatter Diffraction. Tevens kunnen de ontwikkelde algoritmes toegepast worden in andere vakgebieden zoals bijvoorbeeld bij de analyse en voorspelling van het gedrag van composietmaterialen en nieuw ontwikkelde heterogene (meta)materialen.

Dit proefschrift bestaat uit twee delen. In het eerste deel (deel I) wordt in elk hoofdstuk een korte beschrijving van de verschillende aspecten van het werk gegeven. Deel II bestaat uit de gedetailleerde wetenschappelijke publicaties, en appendices. 



\section{Contents}

\section{Part I}

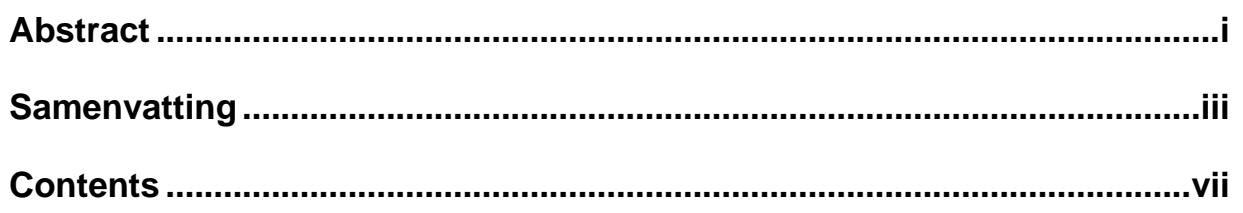

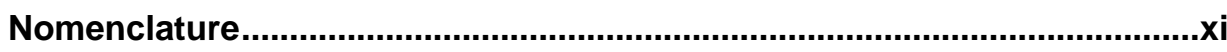

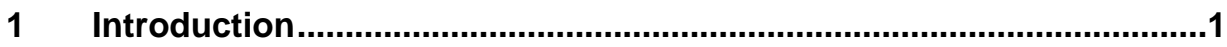

1.1 Tribology and the history of rolling bearings.......................................... 1

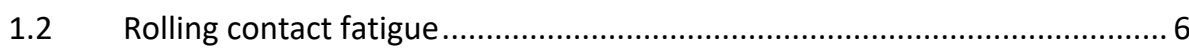

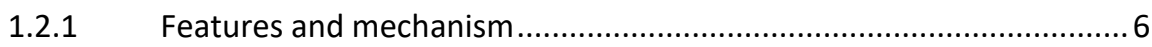

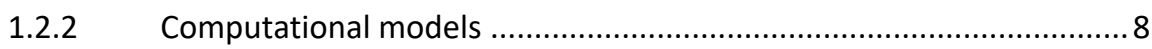

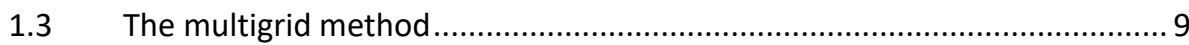

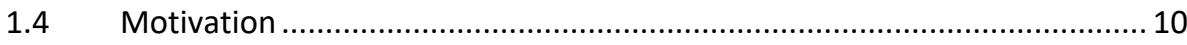

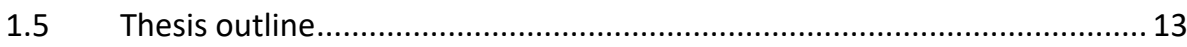

2 Inhomogeneous material in dry contact: 2D line contact ...................15

2.1 Theoretical model..................................................................................... 16

2.2 Algorithm verification and solver performance ..................................... 17

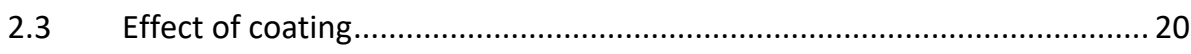

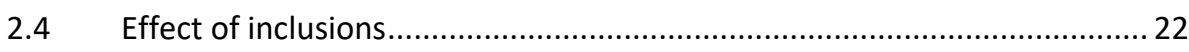

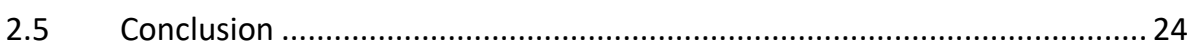

3 Anisotropic material in dry contact: 3D point contact ........................25

$3.1 \quad$ Theoretical model................................................................................... 26

3.2 Algorithm verification and solver performance ........................................ 29

3.3 Homogeneous anisotropic material ........................................................ 32

3.4 Polycrystalline anisotropic material ......................................................... 34

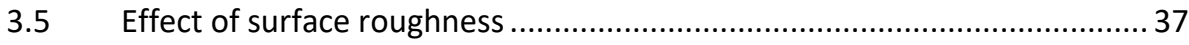


4 Anisotropic material in elasto-hydrodynamic lubrication: 3D point contact .41

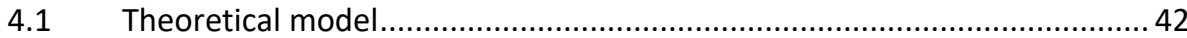

4.2 Algorithm verification and solver performance ................................... 43

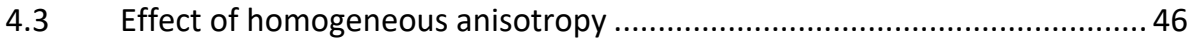

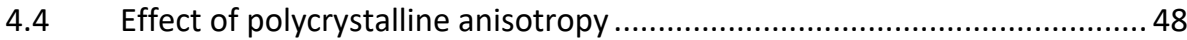

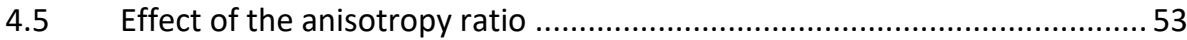

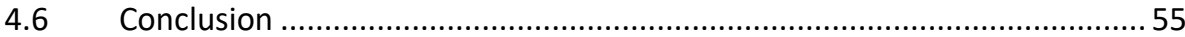

5 Rolling contact fatigue life analysis: material anisotropy effect........57

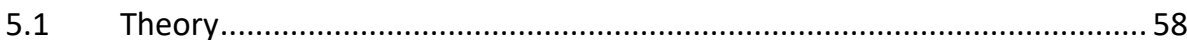

5.2 Comparison of dry contact and lubricated contact ................................... 59

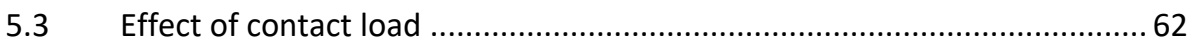

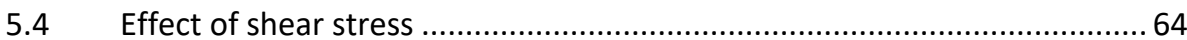

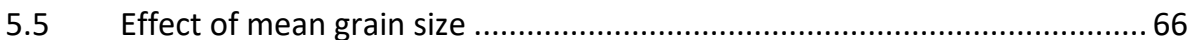

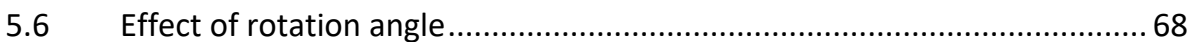

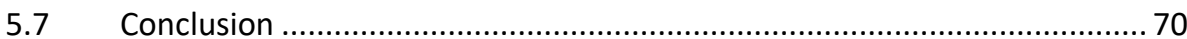

Conclusions and recommendations .........................................................

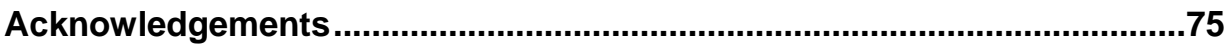

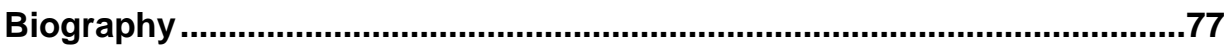

Appendix I: Probabilistic engineering models .........................................79

Appendix II: Deterministic research models .............................................83

Bibliography...........................................................................................85

\section{Part II List of Appended Papers}

Paper A: Zhang B B, Boffy H, Venner C H. Multigrid solution of 2D and 3D stress fields in contact mechanics of anisotropic inhomogeneous materials. Tribology International 2020. https://doi.org/10.1016/j.triboint.2019.02.044.

Paper B: Zhang B B, Liu H C, Quiñonez A F, Venner C H. Effects of 3D anisotropic heterogeneous subsurface topology on film thickness, pressure, 
and subsurface stresses in an elasto-hydrodynamically lubricated point contact. Tribology International 2020. https://doi.org/10.1016/j.triboint.2020.106471.

Paper C: Zhang B B, Quiñonez A F, Venner C H. Effect of material anisotropy on the fatigue life of bearing steel under dry and lubricated point contact conditions: a numerical study. Tribology International 2020. ...155 https://doi.org/10.1016/j.triboint.2020.106584. 



\section{Nomenclature}

$b$

$A_{\mathrm{s}}$

A

$c_{11}, c_{12}, c_{44}$

$e, c, h_{\mathrm{s}}$

$C_{i, j, k, l}$

$\bar{C}_{i j k l}$

E

$E^{\prime}$

$E_{i}$

$f$

$f_{\mathrm{c}}$

F

$h$

$h_{0}$

H

$L, M$

$n$

$N$

$N_{x}, N_{y}, N_{z}$

$p$

$p_{\mathrm{h}}$ half width of Hertzian contact, (m)

probability normalization factor, (-)

anisotropy ratio, $2 c_{44} /\left(c_{11}-c_{12}\right),(-)$

elastic constants for cubic anisotropic material, $(\mathrm{Pa})$

Lundberg-Palmgren exponents, (-)

elastic stiffness matrix, $(\mathrm{Pa})$

dimensionless of elastic stiffness matrix, $C_{i, j, k, l} / p_{\mathrm{h}}$

Young's modulus, $(\mathrm{Pa})$

reduced Young's modulus, $(\mathrm{Pa})$

Young's modulus of inclusions, $(\mathrm{Pa})$

right side function

friction coefficient, (-)

applied load, (N/m, N)

gap distance/film thickness, (m)

rigid normal approach, (m)

dimensionless gap distance, $h / b, h /\left(b^{2} / R\right)$

Moes dimensionless parameters for point contacts,

$L=\alpha^{\prime} E^{\prime}\left(\frac{\eta_{0} u_{\mathrm{m}}}{E^{\prime} R}\right)^{1 / 4}, M=\frac{F}{E^{\prime} R^{2}}\left(\frac{\eta_{0} u_{\mathrm{m}}}{E^{\prime} R}\right)^{-3 / 4}$

the number of nodes in one spatial dimension, (-)

number of contact cycles, (-)

number of grid points in $X, Y$ and $Z$ directions, (-)

pressure, $(\mathrm{Pa})$

maximum Hertzian pressure,

$p_{\mathrm{h}}=\frac{2 F}{\pi b}(2 \mathrm{D}), p_{\mathrm{h}}=\frac{3 F}{2 \pi b^{2}}(3 \mathrm{D}),(\mathrm{Pa})$ 


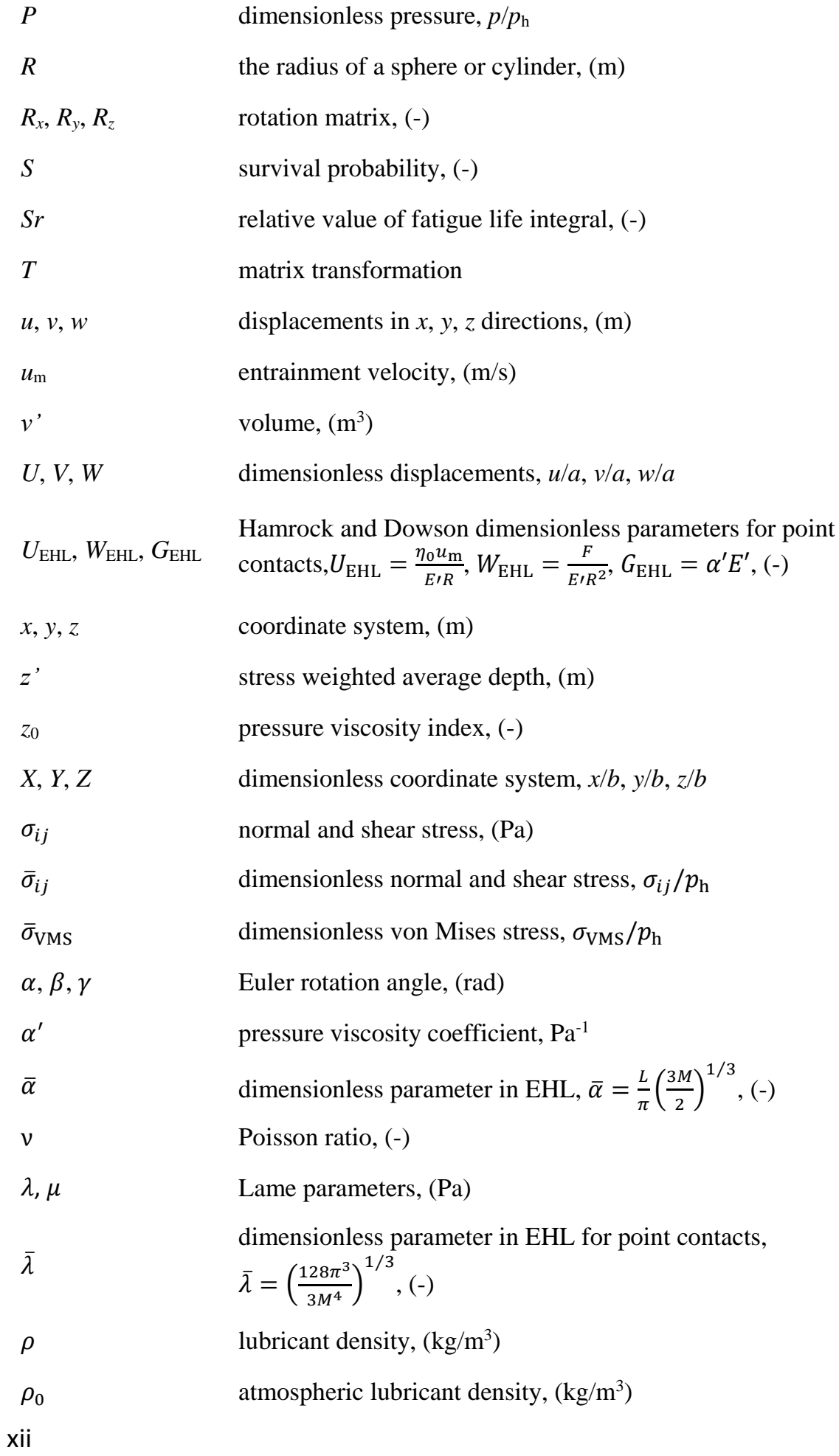


$\eta_{0}$

$\bar{\eta}$

\section{Abbreviation}

EHL

$\mathrm{I}-\mathrm{H}$

L-P

$\mathrm{RCF}$

VMS

\section{Subscript}

Ani

Dry

EHL

Hertz

in

Iso

out

shear dimensionless lubricant density, $\rho / \rho_{0}$

lubricant viscosity, (Pas)

atmospheric lubricant viscosity, (Pas)

dimensionless lubricant viscosity, $\eta / \eta_{0}$

elasto-hydrodynamic lubrication

Ioannides-Harris fatigue life model

Lundberg-Palmgren fatigue life model

rolling contact fatigue

von Mises stress

anisotropic material

dry contact

elasto-hydrodynamic lubrication

Hertzian pressure

inlet of the domain

isotropic material

outlet of the domain

maximum shear stress 



\section{1}

Introduction

\subsection{Tribology and the history of rolling bearings}

Tribology comes from the Greek root "tribos" and the suffix "ology". "Tribo" means "rubbing", and "ology" means "the study of". The literal translation of tribology is "the study of rubbing". In 1966, tribology was first used in a report by Jost [1]. The aim of Jost's study was to investigate the energy losses in UK industry related to friction and wear and the need for lubrication research and education. According to his report, a potential saving about $1 \%$ of the gross national product can be achieved by a better application of tribological principles and practices. Similar studies have also been conducted in other industrialized countries like the US and Germany and suggested that correct use of tribological knowledge would save an enormous amount of energy [2]. As scientific field, tribology was defined as "the science and technology of interacting surfaces in relative motion" in 1967 by a committee of the Organization for Economic Cooperation and Development. It includes the study and application of the principles of friction, lubrication and wear. Tribology is highly interdisciplinary as shown in Fig. 1.1.

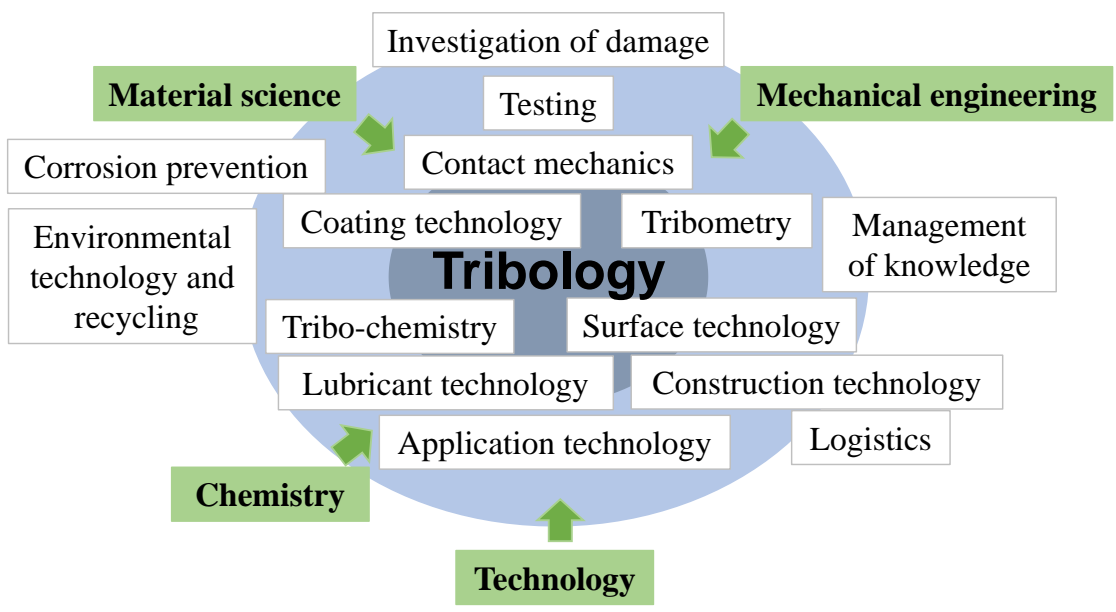

Figure 1.1: Graphic description of Tribology interacting with other science [3] 
The milestone contributions of tribology in the fields of contact and lubrication include the work of Leonardo Da Vinci, the law of viscous flow by Isaac Newton, the friction law by Guillanme Amontons, the experimental studies by Beauchamp Tower, the publication of Reynolds equation, the dry contact theory by Heinrich Hertz, the establishment of elastohydrodynamic lubrication (EHL) theory, the development of efficient numerical algorithms and optical interference technique and so on. Today, the application of tribology is not limited to improve operation and extend the lifecycle of industrial machinery. It also involves many aspects in our daily life ranging from shaving cream and cosmetics to skis and swimsuits.

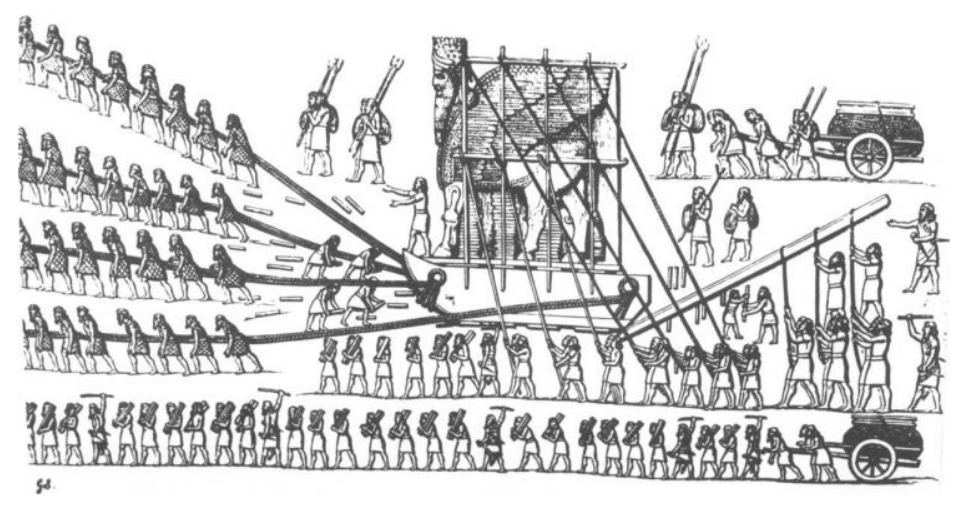

Figure 1.2: Assyrians use rollers to move colossus (about 700 BC) [5]

The invention of wheeled vehicles (dated back to the era 2000-3000 B.C.) and using wooden rollers to move a heavy human-headed lion shown in Fig. 1.2 both employ the same idea that the rolling resistance is lower than sliding resistance. During that time, the wheels were rotating on the stationary axles. The sliding motion between the vehicles and the ground was transformed into the rolling motion by wheels. However, sliding contacts still existed between the wheels and the stationary axles. In order to decrease the friction and wear, wheel hubs need to be lubricated. When the sliding motion between wheels and axles was also transformed into rolling motion, the force applied to move vehicles was further decreased. Different from the previous rolling motion practices, the rolling motion here needs to be constrained in a limited space. The wisdom and practice of using constrained rolling elements for the constrained rolling motion dominated the development of rolling bearings [4]. The function of rolling bearings is to change sliding motion between contact bodies into rolling motion, 
which can significantly reduce the friction and thus the energy required to maintain the relative motion.

The first sign of application of rolling bearings was found from sunken ships which were built between A.D. 44 and 54 and discovered in Lake Nemi. As shown in Fig. 1.3 (b), the bronze balls were restrained from moving freely by the trunnions and iron straps. This contraption is considered a rudimentary form of a rolling bearing.

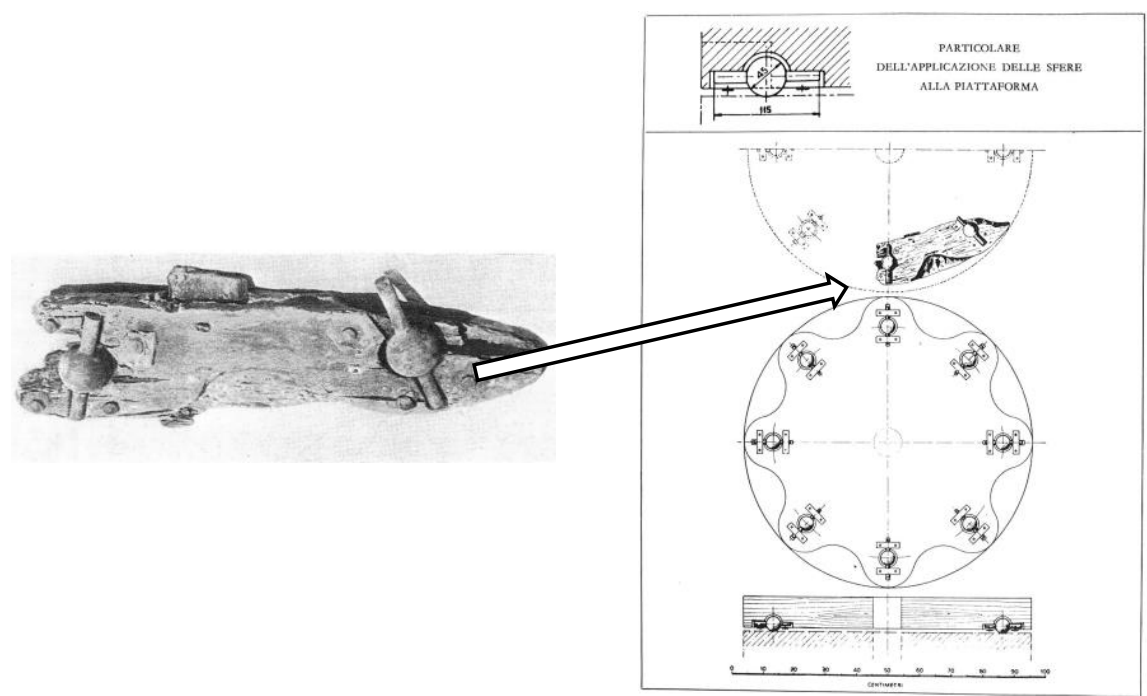

(a) Fragment of a thrust ball bearing [6]

(b) Reconstruction graph [6]

Figure 1.3: Fragment and reconstruction of revolving wooden platform with bronze balls from ships in Lake Nemi

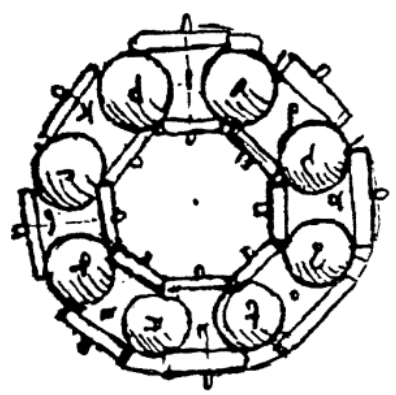

Figure 1.4: An early form of a thrust ball bearing with separators proposed by Leonardo Da Vinci [7] 
The birth of modern rolling bearings came from Leonardo Da Vinci's work Codex Madrid I [6]. Da Vinci realized that if contact existed between adjacent rollers, then the rubbing between rollers affected their motion. This can be avoided when the rollers are separated from each other at a distance. His insight led to the concept of the separator shown in Fig. 1.4 and contributed greatly to the subsequent development of retainers or cages for rolling bearings.

In 1710, the Academy of Sciences in Paris approved Mondran's carriage design, which was probably the earliest reference for the use of roller-disc bearings on vehicles. It was said that under the rolling contact, one horse could easily do the work which could hardly be accomplished by two horses. Later, Jacob Rowe performed lots of experiments on rolling friction and published his results in 1734 in a compendium entitled "All sorts of Wheel Carriage, Improved" [8]. Rowe explained that his "friction-wheel" shown in Fig. 1.5 had great advantages in terms of cost and labour and could be applied to carts, wagons, watermills and horse-operated mills. Rowe was awarded the first patent for rolling bearings by his majesty King George II [6].

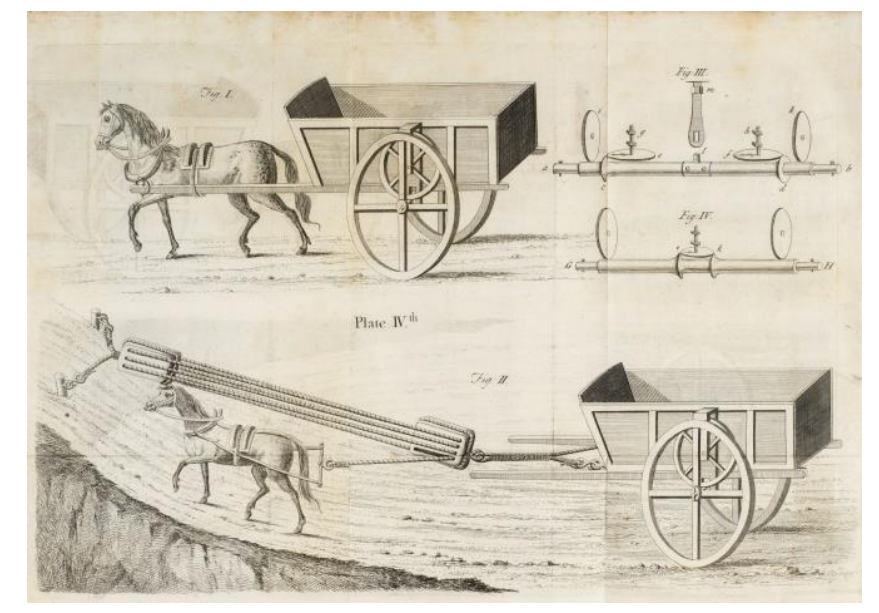

Figure 1.5: Friction-wheel applied to a vehicle by Jacob Rowe [8]

In 1794, the first patent on a ball bearing was given to Philip Vaughan [9], an inventor and ironmaster from Wales (UK). The illustration of Vaughan's patent is given in Fig. 1.6, in which the iron balls were running inside deep grooves and placed between the wheel and the axle of a carriage. His design makes the wheels rotate easily compared to the sliding motion used before. In 1802, the first tapered roller bearing was patented by a French inventor M. Cardinet [10]. In 
1862, the first patent for ball bearings used in bicycles was issued to A. L. Thirion [6]. In 1868, A. C. Cowper made a bicycle with ball bearings [10]. Also, in the same year, a French bicycle builder won a bicycle race from Paris to Rouen with a bicycle equipped with ball bearings. The friction for bicycles with ball bearings was reduced to one-fifth or even one-tenth compared to its former value.

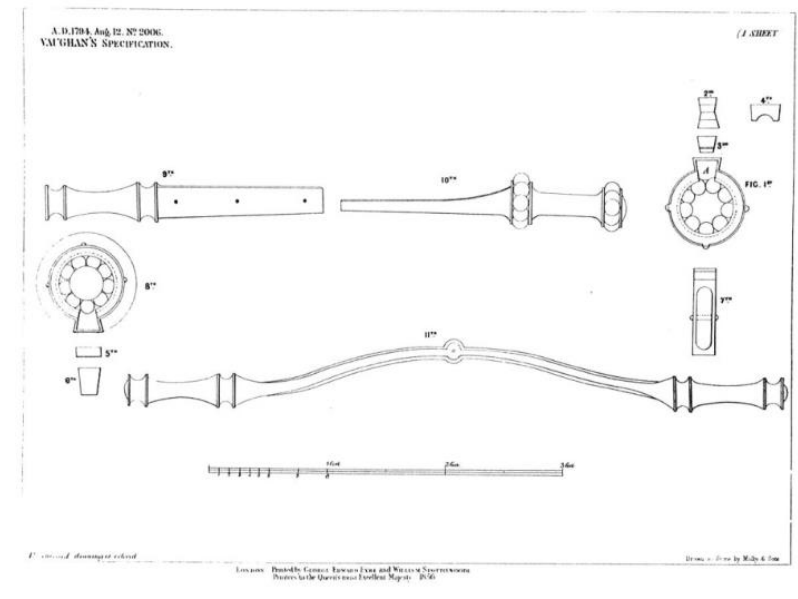

Figure 1.6: Iron ball bearings for carriages by Philip Vaughan [9]

As an important transportation mode during that time, the demand for bicycles with rolling bearings installed provided the ideal commercial conditions which promoted the emergence and development of the bearing industry. Some bearing companies were established during that time. In 1883, the FAG company in Germany, which was established as a bicycle manufacturer, started to manufacture ball bearings. In 1898, the Timken company in USA began to manufacture tapered-roller bearings. In 1907, the SKF company in Sweden began manufacturing double-row, self-aligning ball bearings, which can solve bearing failures due to the misalignment and deflection of line shafting. Some other bearing companies were also established during this time. The role of rolling bearings in machineries is so important that the UK air force regularly bombed German ball bearing factories during world war II in an effort to stop the war machines. As an important mechanical component, rolling bearings were applied to lots of machineries during the industrial revolution. The application also accelerated the developments of rolling bearings. A lot of improvements were made to the quality and performance of bearings, ranging from material to lubrication, roller geometry, seals and so on. Nowadays, rolling bearings are 
applied in many fields with specific demands or with extreme precision requirements such as the main spindle of computer numerical control machines working at a high rotational speed, atomic reactors with high temperatures, gyroscopes requiring a low friction torque, wind turbines with long lifetime and so on.

\subsection{Rolling contact fatigue}

\subsubsection{Features and mechanism}

Rolling contact fatigue (RCF) is defined as the fatigue caused by cyclic loading in rolling-sliding contacts. It occurs in mechanical components, such as wheelrail contacts, gears, cam-followers and rolling bearings. In this thesis, it is restricted to the RCF of rolling bearings. Even when a rolling bearing is properly designed, installed, well lubricated and not overloaded, RCF may happen during service life. RCF differs from classical fatigue because of $[11,12]$ :

(1) The existence of a high hydrostatic pressure which is absent in classical cases such as tension-compression fatigue and bending fatigue.

(2) The contact stress is highly localized.

(3) RCF is a multiaxial fatigue mechanism in non-conformal contacts with a complex stress state.

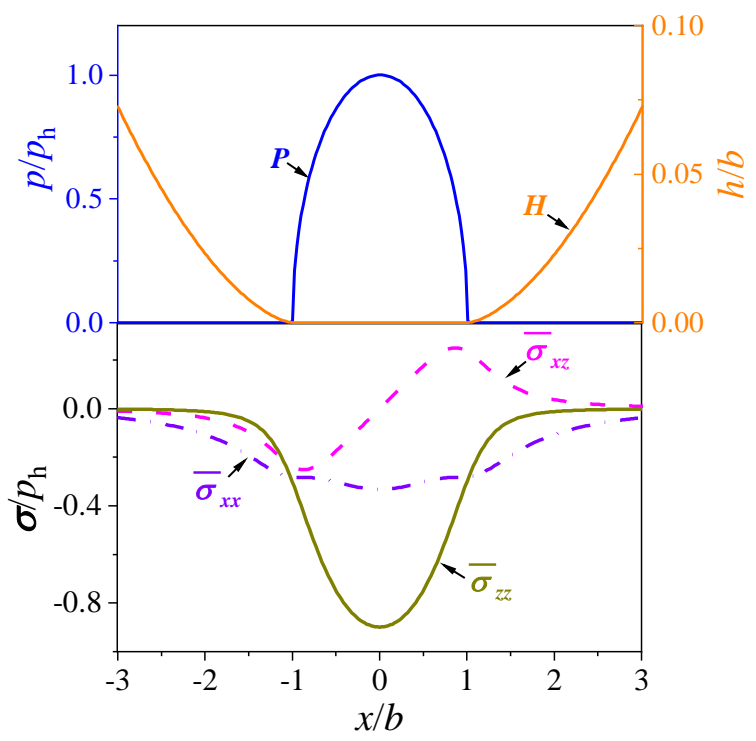

Figure 1.7: Contact pressure, gap distance and subsurface stress distribution (at a depth of $y=0.5 b$ ) in a Hertzian line contact 
(4) The variation of stress components is inconsistent. The stress variation at a depth, where the maximum shear stress $\sigma_{x z}$ is located, is shown in Fig. 1.7. The peaks of normal stresses $\sigma_{x x}$ and $\sigma_{z z}$ do not coincide with the peaks of the shear stress.

(5) The plane of the maximum shear stress is changing in a stress cycle and depends on the load (rollers) position. As a result, it is difficult to predict where the fatigue damage will initialize.

The RCF of rolling bearings can be divided into two phases, namely (1) the initiation phase and (2) the propagation phase $[13,14]$ :

(1) The initiation phase: The intermittent contact between rolling elements (rollers or balls) and raceway generates a cyclic stress condition. With increasing number of contact cycles, crack-like flaws are gradually formed locally around stress concentration points. Generally, it is believed that the duration of this phase is much longer than the propagation phase.

(2) The propagation phase: The flaws grow into small cracks and propagate upwards or downwards at shallow angles relative to the surface. The growing cracks may create a network during this process. When it grows upwards, a part of surface material may finally spall away and, the bearing fails. The material spalling phenomenon is time and cycle dependent.

Subsurface and surface originated spalling are the two main mechanisms of RCF. The first is mostly a result of the material inhomogeneities, such as non-metallic inclusions, voids, anisotropy and other discontinuities. This is the dominant failure mode when the surfaces are very smooth and operate under well lubricated conditions. Surface originated spalling occurs commonly when the surface has defects such as dents and scratches. Rolling contact fatigue has been studied extensively with the aim to understand the details of the physical mechanism causing RCF and to develop accurate prediction methods considering the relevant effects of load, lubrication conditions, material surface and subsurface topology. According to Refs [11,12], the developed models can be classified into three types:

(1) Probabilistic engineering models: These are widely used as engineering tool. The calibration for this kind of model requires extensive experimental life tests which are time consuming and expensive. Besides, 
they do not give detailed insights in the physical mechanisms causing the fatigue. A brief summary of these models is given in Appendix I.

(2) Deterministic research models: These models focus on the failure process and aim to simulate the initiation and propagation of fatigue cracks. However, it is hard to explain the life scatters in observed real experiments. A brief introduction to these models is given in Appendix II.

(3) Computational models: A bridge to connect the above two model types. It is introduced below.

\subsubsection{Computational models}

In computational models, material is modelled consisting of heterogeneous microstructures whose shape, size and elastic modulus are randomly distributed. The scale of the microstructure is close to that of grains in bearing steels. Using continuous mechanics modeling and numerical methods such as FEM, gridless FEM etc., the stress field is solved by computations. The variation of the subsurface topology and the material properties affect the stress field and may help to understand the mechanism of the fatigue life scatter phenomena [12]. Compared to probabilistic engineering models and deterministic research models, computational models have the following advantages:

(1) The effect of material inclusions, anisotropy can be incorporated into the model. The heterogeneous structure is much closer to the morphology of bearing material.

(2) Instead of assuming a Weibull slope, the life scatter, which is affected by heterogeneous material properties, can be an output of many simulations.

(3) The analysis of the stress field on a local scale provides insight in the physical mechanism of the failure process.

In 2008, Raje et al. [15] performed a line contact analysis to study the effect of nonuniform distributed elastic properties and material flaws. Instead of a continuous representation of bearing material, the material is modelled by discretized Voronoi elements. It is hypothesized that the variation of the critical stress (including its depth and value) results in the scatter of bearing life. The results showed a two-parameter Weibull distribution with a limiting Weibull slope close to the value used in the Lundberg-Palmgren model. Later, they extended the model with damage mechanics to consider the effect of gradual material degradation under repeated load cycles [16]. The predicted fatigue life 
was found to follow a three-parameter Weibull distribution. Finally, they developed a statistical life equation for subsurface initiated spalling [17]. Later developments for the computational models include additions of plastic deformation [18], material anisotropy [19] and EHL pressure [20].

\subsection{The multigrid method}

An efficient numerical solution of a complex system of equations is needed in many disciplines. The classical iterative/relaxation methods like Jacobi and Gauss-Seidel produce smooth errors after a few iterations. It means errors with wavelengths that are close to the grid size are reduced quickly. The wavelengths of remaining and unremoved errors are larger compared to the mesh size which results in a slow convergence speed. Due to the local nature of iterative methods, the computing times increase quickly with the number of unknowns. For 3D problems, the time to obtain the numerical solution will be unacceptably large. The solution is to perform the relaxation with another grid whose mesh size is coarser. On a coarser grid, the same equation as for the original problem with a different right-side function is solved using the same relaxation process but for the smooth errors from a fine grid. On a coarse grid, these smooth errors become rough, and low frequencies act like high frequencies. After the high frequency errors on a coarse grid are solved, the results obtained on this coarser grid can be interpolated back to the fine grid to serve as a correction to the original approximation on this fine grid. Then, a few relaxations are needed to remove the high frequency errors introduced from the interpolation of the correction. Using a recursive approach and a series of grids as shown in Fig. 1.8 to solve the same problem, a grid independent convergence speed can be obtained which leads to an efficient algorithm compared to classical single-grid iterative methods. The high efficiency of multigrid methods originates from two aspects: firstly, different frequency errors can be solved on different grid levels which ensures that the convergence speed is not stalling due to the occurrence of smooth error components; secondly, the amount of work per relaxation is small on coarse grids compared to the fine target grid. As most of the relaxations are performed on coarser grids, the overall computational work for the total number of relaxations is still small.

The multigrid method was introduced in 1977 by Brandt originally for scalar elliptic partial differential equations [21]. However, since then it has been developed further to many problems in science and engineering. In addition to 
geometric multigrid, also gridless methods such as algebraic multigrid [22] have been developed. The multigrid method can be applied for complicated and nonlinear partial differential equations, integral equations and eigenvalue problems. The application of the multigrid method in tribology, particularly for rolling bearing (lubricated) contacts, starts from the pioneering work of Lubrecht [23] and Venner [24,25]. With the multigrid method and multilevel multiintegration technique, a wide range of factors such as time-dependent problems, roughness and thermal effects can be considered and solved efficiently on a personal computer even with a fine mesh size. The recent applications of multigrid method in tribology include the solution to a moving heat source problem [26] and the evaluation of stress field distribution of nonhomogeneous material $[27,28,29]$ and composite materials [30].

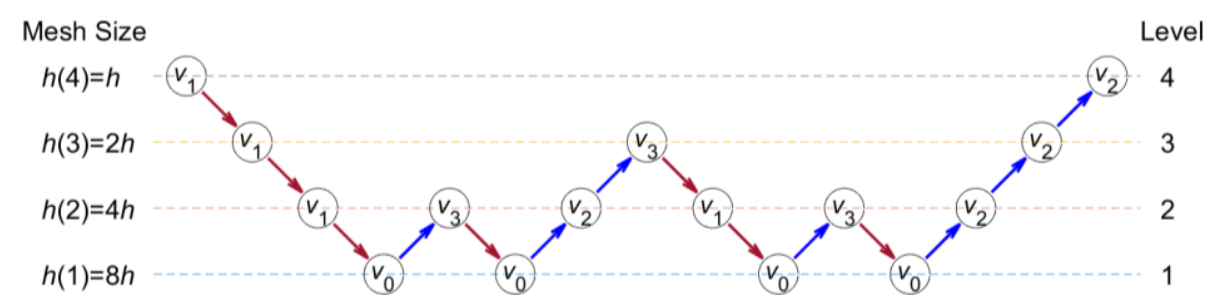

Figure 1.8: Flow diagram of a $\mathrm{W}$ cycle for the case of four levels $\left(v_{0}, v_{1}, v_{2}\right.$ and $v_{3}$ are number of cycles)

\subsection{Motivation}

With increasingly strict performance requirements, rolling bearings operate in severe conditions involving higher contact loads and thinner lubricating film. As a result, the effect of subsurface material topology on RCF becomes more important. From bearing material analyses, it is clear that the bearing material is not homogeneous due to the existence of inclusions, defects and voids. By decreasing the oxygen content of steel and using super clean bearing steel, the non-metallic oxide inclusions can be reduced, and bearing life has been much improved in recent decades. In order to improve the performance and extend the life of bearings, solid coatings have been used. The coating layer may fulfil additional functions such as wear resistance, corrosion prevention, thermal and electrical insulation. The elastic modulus difference between inclusions, coating and substrate material could lead to stress concentration and failure. The effect of inhomogeneous material and the resulting local stress concentrations can be 
decreased gradually by the metallurgical technology. However, in addition to such relatively large-scale property variations, on a very local scale from grain to grain the material properties vary. The anisotropic nature of bearing material exists intrinsically due to grain rotations and different compositions $\left(\mathrm{Fe}_{3} \mathrm{C}\right.$, martensite and austenite). The effects of this feature has attracted researchers' attention recently [19,20,31,32].

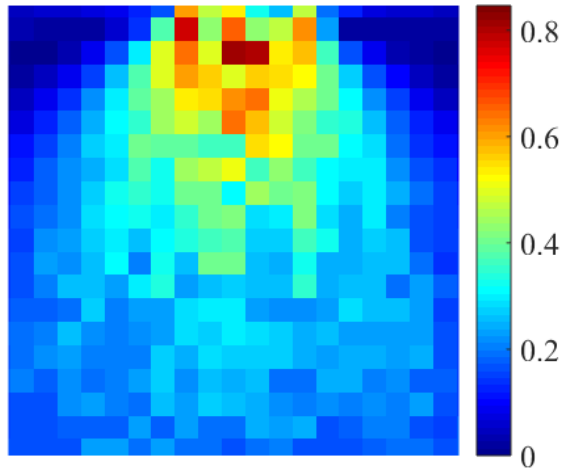

(a) $33 \times 33$

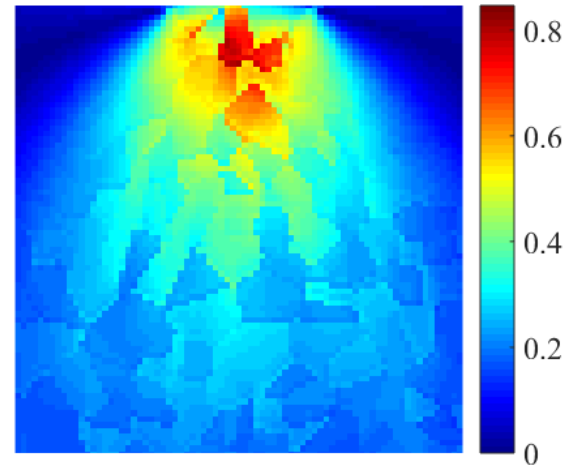

(b) $129 \times 129$

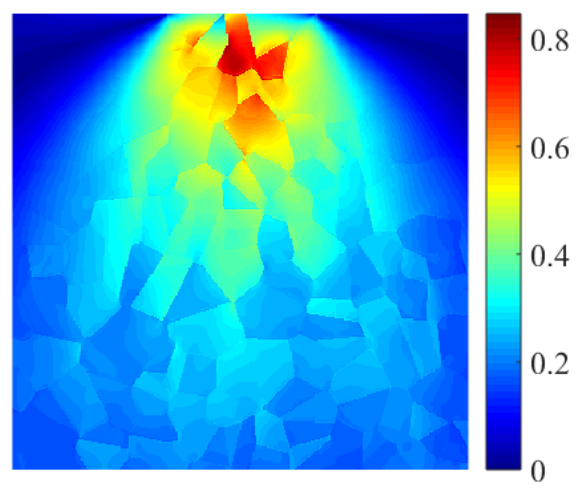

(c) $513 \times 513$

Figure 1.9: Von Mises stress fields of polycrystalline anisotropic material with different mesh sizes

Compared to inhomogeneous material such as inclusions and coatings, the morphology of polycrystalline anisotropic material is more complex due to the rotation of grains. Fig. 1.9 shows the influence of discretization points on the stress field distribution. With the increase of grid points, the local material variation is observed and the solution of stress fields is more accurate. However, 
a dense discretization (grid) for 3D problems leads to systems of equations with many millions of unknowns. This requires an excessive computational effort, and it is time consuming to calculate the stress field of polycrystalline anisotropic material with most numerical methods unless a very efficient algorithm is used.

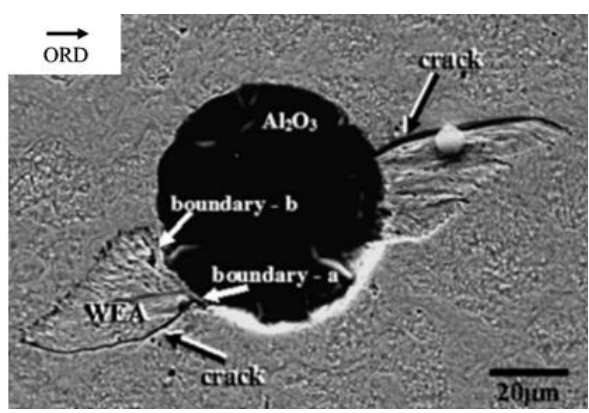

(a) Material inclusion ${ }^{[33]}$

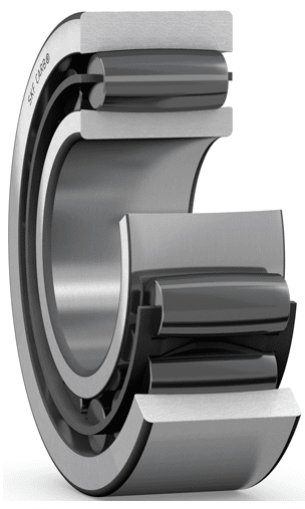

(b) Material coating ${ }^{[34]}$

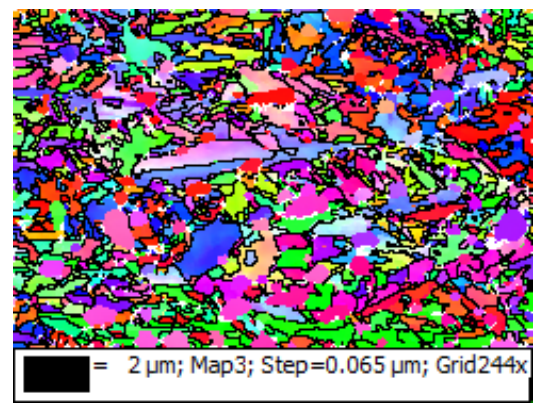

(c) Material anisotropy [SKF ERC]

Figure 1.10: Heterogeneous bearing material

As a result of complex material topology, the published studies considering the effect of material anisotropy have used 2D microstructures or 3D microstructures with very coarse grains. Besides, the pressure is usually assumed to be the Hertzian dry contact pressure rather than a realistic contact pressure considering the effect of subsurface material or the lubrication film. The realization of considering the effect of realistic contact pressure, 3D microstructures and material anisotropy require efficient and robust algorithms to deal with the huge computational efforts. The objective of this thesis is to develop efficient algorithms which can allow dense meshes for describing the small scale of 
variations on a normal computer. Based on the developed efficient algorithms, complex numerical optimizations of bearing material can be achieved which may bring promising prospects to extend the fatigue life of rolling bearings.

\subsection{Thesis outline}

In this thesis, multigrid algorithms are developed for the stress field and contact pressure analyses of anisotropic heterogeneous material.

In chapter 2 and 3,2D and 3D multigrid algorithms are presented for a dry contact problem of anisotropic heterogeneous material. The algorithm for the 2D dry contact problem with inhomogeneous material lays the foundation for the 3D multigrid algorithms for anisotropic heterogeneous material. To obtain full multigrid efficiency, it is crucial to correctly treat the top boundary and side boundaries equations to avoid local errors introduced by boundary conditions [35]. This is also crucial for integration of the solution of the contact problem equation at the surface.

In chapter 4 , the 3D dry contact algorithm developed in chapter 3 is extended to the case of EHL. In this case, the material problem is solved simultaneously with the Reynolds equation describing the pressure generation in the lubricant film. This problem has several specific features that need to be addressed correctly to obtain full multigrid efficiency. In line with Ref. [25], here we need to apply line relaxation for solving the strong coupling problem in the Reynolds equation in the surface plane at higher loads. To account for the coupling with the adjacent region in the interior one needs to develop this line relaxation collectively. From the solution of the displacement equations, the stress fields can be determined a posteriori. This stress field can then be used as input to further analysis (computational diagnostics) and fatigue life prediction. The variation of the simulated von Mises stress (VMS) with different microstructures helps to explain the dispersion of bearing life observed in experiments.

Finally, the effect of material anisotropy on the fatigue life of bearing steel is studied. The effects of contact pressure, shear stress, grain size and rotation angles on the fatigue life are shown. 



\section{2 \\ Inhomogeneous material in dry contact: 2D line contact}

The stress field can be affected due to differences in elastic modulus between e.g. inclusions, coating and the bulk material. Under cyclic stress, inhomogeneous material gives a higher risk to initiate cracks around their boundaries, which is harmful for the service life of bearings. The stress field analysis for inhomogeneous materials can be achieved numerically by Eshelby's equivalent inclusions method [36], the finite element method [37], discrete convolution and Fourier transform method [38]. The Eshelby's equivalent inclusions method cannot consider the influence of inclusions with irregular shapes. Most numerical methods demand a major computational effort (CPU and memory) when the mesh is very fine [27]. The Fourier transform method offers a fast alternative but is not appropriate for material with three-dimensional mechanical properties [27]. The disadvantages of the above methods can be overcome with the multigrid method. Besides, it can be easily coupled with grid mesh refinement strategies allowing one to solve problems with different contact scales. As a first step towards realistic 3D configurations of heterogeneous anisotropic material, a multigrid algorithm was developed for solving a 2D dry contact problem of inhomogeneous (isotropic) material. This chapter is a summarized version of the published paper A in appendix.
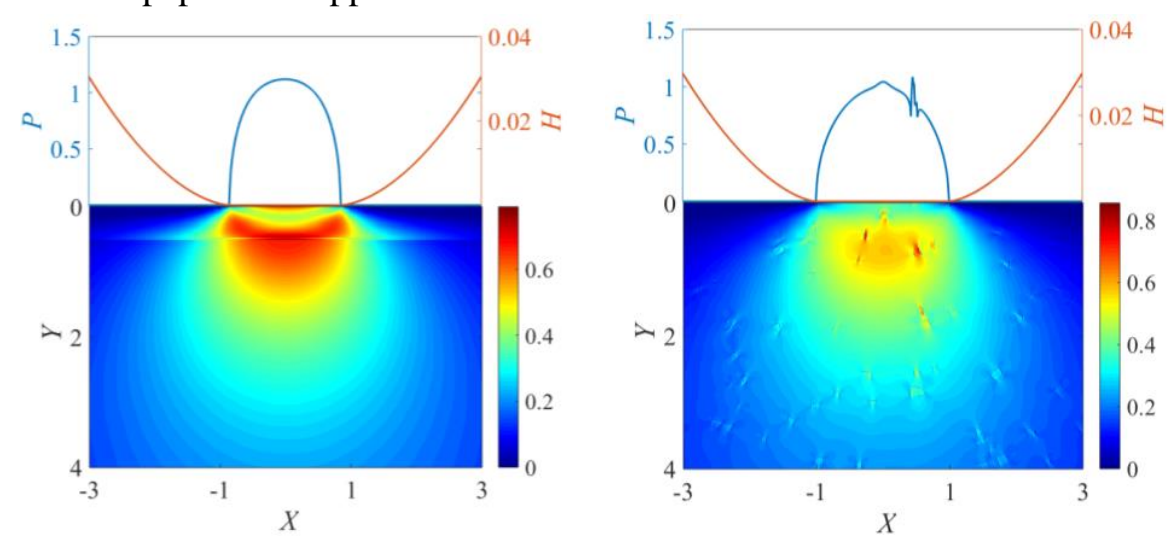

Pressure, gap height and VMS field of coated material (left) and material with inclusions (right) 


\subsection{Theoretical model}

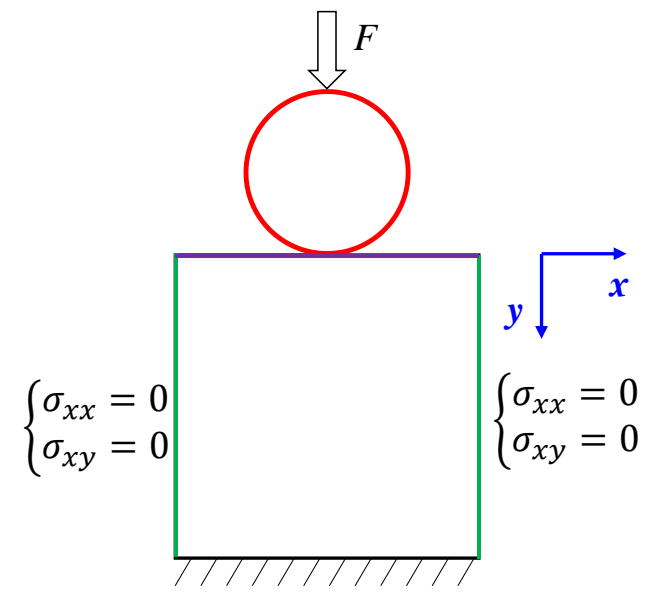

Figure 2.1: Schematic graph of a 2D elastic line contact

Figure 2.1 shows the problem studied: a rigid cylinder in contact with a linear elastic body (plane strain problem). The bottom boundary is fixed (Dirichlet boundary condition), and the two vertical boundaries (the left and right) are stress free (Neumann boundary condition). The contact stresses at the top boundary need to balance the applied force. Assuming a steady state, the interior stress field is governed by the stress equilibrium equation [39]:

$$
\left\{\begin{array}{l}
\frac{\partial \sigma_{x x}}{\partial x}+\frac{\partial \sigma_{x y}}{\partial y}=0 \\
\frac{\partial \sigma_{y y}}{\partial y}+\frac{\partial \sigma_{x y}}{\partial x}=0
\end{array}\right.
$$

with

$$
\left(\begin{array}{c}
\sigma_{x x} \\
\sigma_{y y} \\
\sigma_{x y}
\end{array}\right)=\left(\begin{array}{ccc}
\lambda+2 \mu & \lambda & 0 \\
\lambda & \lambda+2 \mu & 0 \\
0 & 0 & \mu
\end{array}\right)\left(\begin{array}{c}
\partial u / \partial x \\
\partial v / \partial y \\
\partial u / \partial y+\partial v / \partial x
\end{array}\right)
$$

in which $\sigma_{x x}, \sigma_{y y}$ and $\sigma_{x y}$ are the stress components, $\lambda$ and $\mu$ are the Lame parameters, $u$ and $v$ are displacements in $x$ and $y$ directions respectively. Substituting Eq. (2.2) into Eq. (2.1), the first order stress equilibrium equations Eq. (2.1) with three unknowns yields a system of second order equations with displacements $u$ and $v$. After solving the displacements, the stress field can be 
obtained. The stress and contact pressure at the top boundary are solved from the following equation:

$$
\left\{\begin{array}{c}
\sigma_{x y}-f_{c} p=0 \\
\sigma_{y y}+p=0
\end{array}\right.
$$

in which $f_{\mathrm{c}}$ is the coefficient of friction and $p$ is the contact pressure. The HertzSignorini-Moreau contact boundary condition needs to be satisfied [24,29]:

$$
\left\{\begin{array}{lr}
h(x)>0, p(x)=0 & \text { no contact } \\
h(x)=0, p(x)>0 & \text { contact }
\end{array}\right.
$$

where $h(x)$ is the gap between the rigid cylinder and the elastic half-space:

$$
h(x)=h_{0}+\frac{x^{2}}{2 R}-v(x, y=0)
$$

in which $R$ is the radius of the cylinder. The rigid normal approach $h_{0}$ needs to be determined by the global constraint:

$$
\int p(x) \mathrm{d} x=F
$$

where $F$ is the external load (per unit width).

\subsection{Algorithm verification and solver performance}

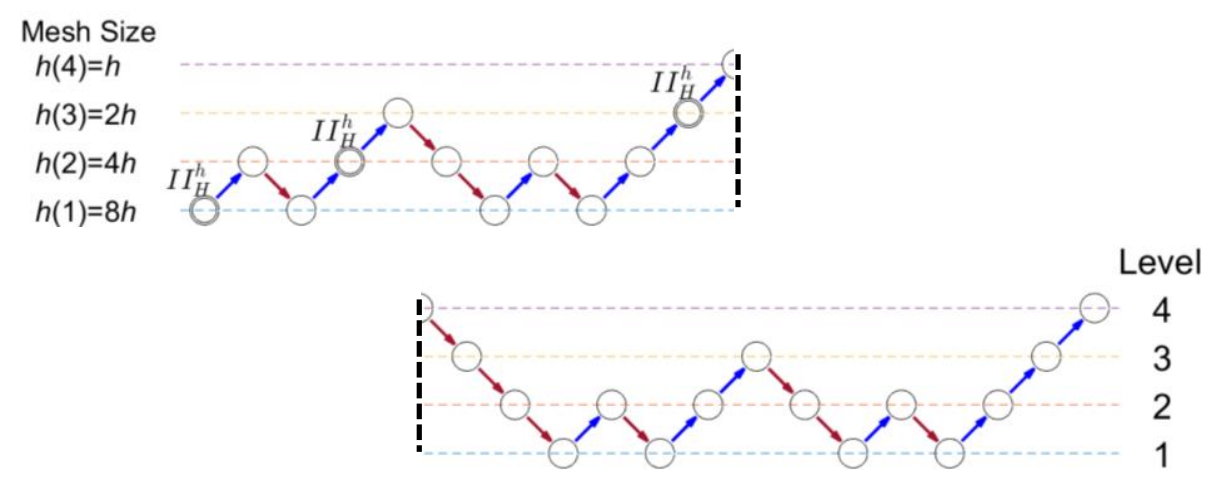

Figure 2.2: Flow diagram of a full multigrid $\mathrm{W}$-cycle for a case of four levels and 1 cycle per grid refinement

The resulting system of partial differential equations in terms of the displacements was discretized on a uniform grid with second order accuracy. 
The discretization and relaxation of equations can be found in the Appendix paper A [40]. The developed multigrid algorithm uses full multigrid (FMG) which is also referred to as the nested iteration with $\mathrm{W}$ coarse grid correction cycles. Its flow diagram is shown in Fig. 2.2. It starts from the coarsest grid level and uses the solution results as an approximation for a high level. The equations are made dimensionless using the following dimensionless parameters:

$$
X=x / b, Y=y / b, U=u / b, V=v / b, P=p / p_{\mathrm{h}}, H=h / b, \bar{\sigma}_{i j}=\sigma_{i j} / p_{\mathrm{h}}
$$

where $p_{\mathrm{h}}$ is the maximum Hertzian contact pressure and $b$ is the half contact width for homogeneous isotropic material. The material and contact parameters used for the verification are given in Tab. 2.1.

Table 2.1 Material and contact parameters

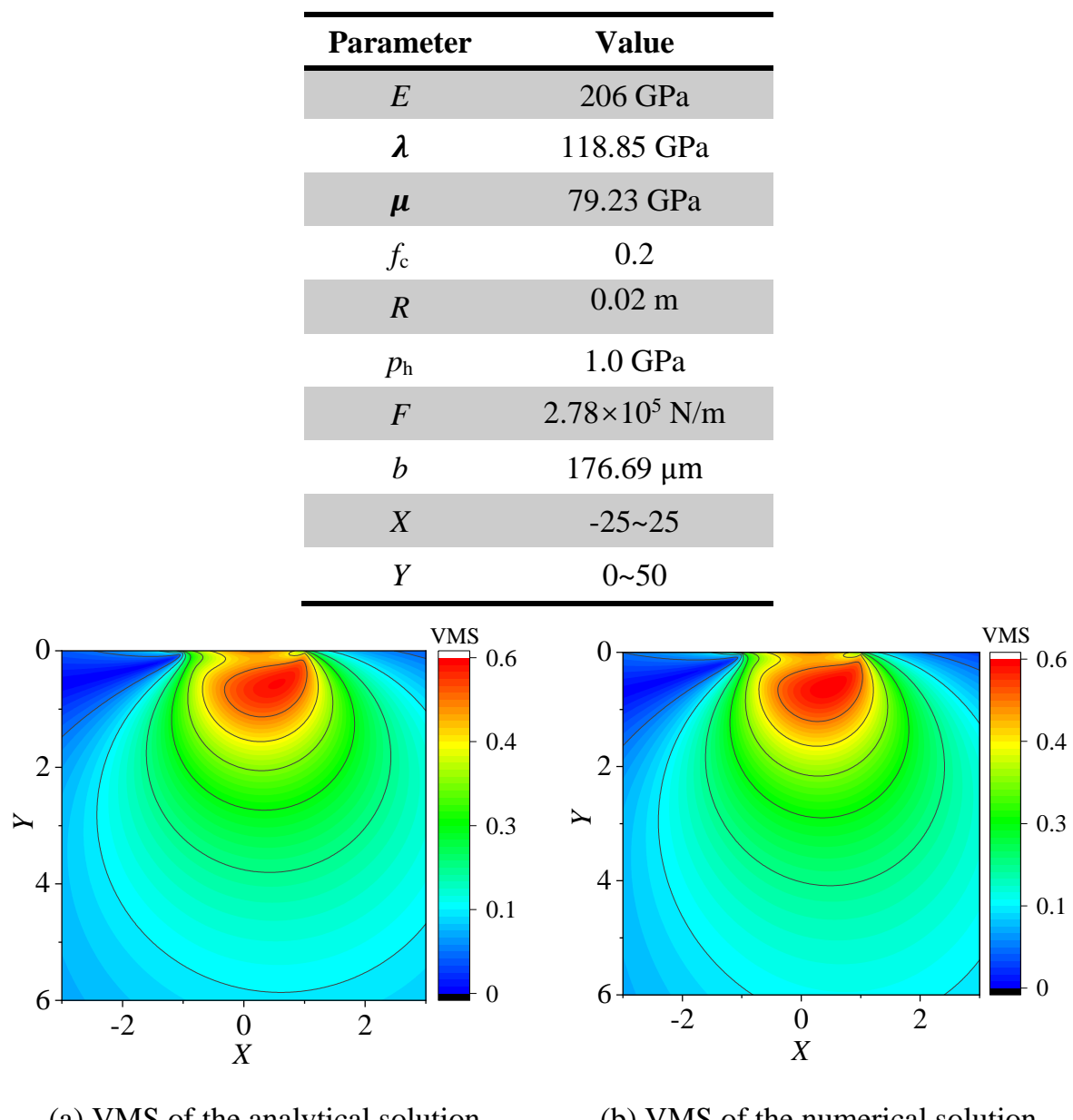

(a) VMS of the analytical solution

(b) VMS of the numerical solution 


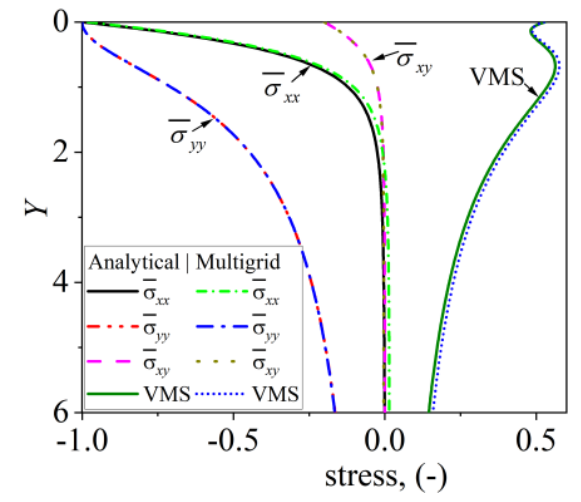

(c) Stress variation along the centerline $X=0$

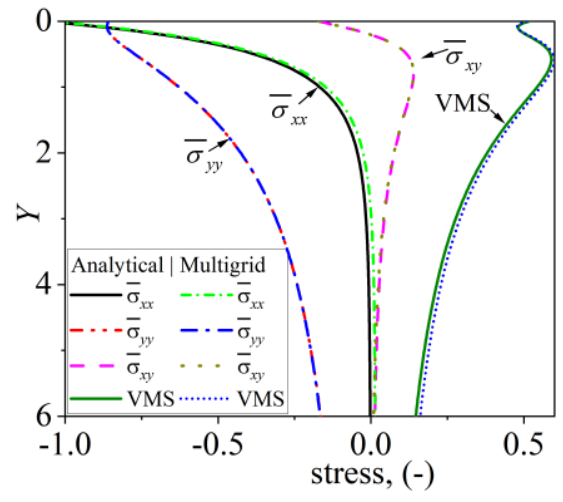

(d) Stress variation along the line $X=0.5005$

Figure 2.3: Stress comparison between the numerical solution $\left(N_{x}=N_{y}=4096\right)$ and the analytical solution [41]

To verify that the developed multigrid algorithm does not affect the accuracy, stress calculations for homogeneous isotropic material have been carried out in Fig. 2.3 and are compared with the analytical solution of Hertz [41]. The von Mises stress (VMS) in 2D for the plane strain problem is defined as:

$$
\mathrm{VMS}=\sqrt{\frac{\left(\sigma_{x x}-\sigma_{y y}\right)^{2}+\left(\sigma_{y y}-\sigma_{z z}\right)^{2}+\left(\sigma_{z z}-\sigma_{x x}\right)^{2}+6 \sigma_{x y}^{2}}{2}}
$$

Fig. 2.3 (a) and (b) give the VMS distribution. The stress field is asymmetric due to the applied shear stress. For a direct comparison, the stress variations at $X=0$ and $X=0.5005$ are plotted in Fig. 2.3 (c) and (d). Results from the analytical solution and the developed algorithm agree well. From these results, it can be concluded that the developed algorithm is able to predict the subsurface stress field accurately. To demonstrate the numerical performance, the convergence of the multigrid algorithm is shown in Fig. 2.4 as a function of the number of Wcycles. The residual as a measure of the error is defined in Eq. (2.9):

$$
\text { Residual }=\sum_{i, j}\left|\frac{f(i, j)-L^{h} u^{h}(i, j)}{N_{x} N_{y}}\right|
$$

in which $f$ is the right-side function, $L^{h}$ is the discrete operator, $N_{x}$ and $N_{y}$ are the number of grid points in $X$ and $Y$ direction respectively, $i$ and $j$ are the grid indices. 
After a few initial cycles, the convergence speed stays almost unchanged with $\mathrm{W}$-cycles. The residual reduces quickly with the increasing number of cycles, which is characteristic for a well-developed multigrid algorithm due to the removal of high and low frequency errors with different mesh sizes.

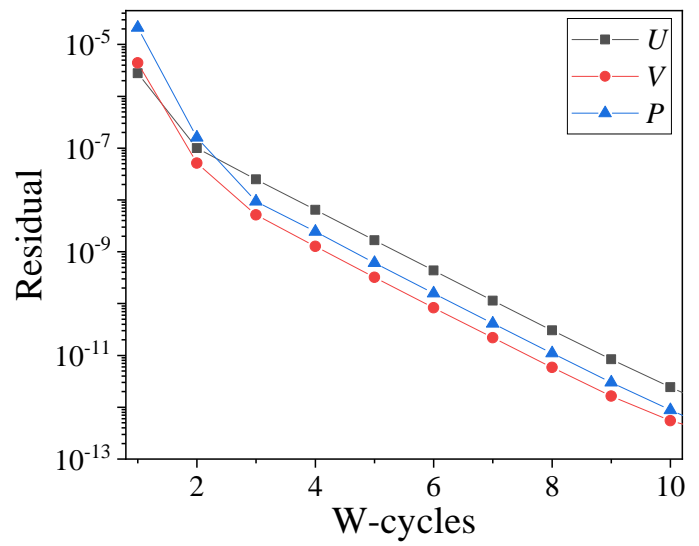

Figure 2.4: Residual as a function of cycle, $4096^{2}$ grid points, 6 multigrid levels

\subsection{Effect of coating}

As a first step, we consider a large-scale inhomogeneity, i.e., a coating on the surface. This problem has been extensively studied before, e.g. see [4] and here, it serves as a validation test problem. Fig. 2.5 shows the effect of a coating on the stress field and the pressure distribution. Only a hard coating is considered here. The coating layer does not affect the shape of the contact pressure too much, i.e. the pressure is still a smooth distribution. In Fig. 2.5 (a), the elastic modulus of coating is two times larger than the base material and keeps constant throughout the thickness which leads to a material property discontinuity at the interface between the coating and the bulk material. The variation of the elastic modulus can also be observed in the stress field, i.e. a clear boundary exists between two different materials. As a result, the location of the maximum VMS is near the interface. Different from the coating in Fig. 2.5 (a), the elastic modulus of coatings in Fig. 2.5 (b) and (c) has a continuous variation in different depths which results in a smooth transition at the interface and reduces the level of stress concentration. This can also be seen in Fig. 2.5 (d). The coating layer also affects the maximum contact pressure and contact radius. For the studied cases, the larger the maximum contact pressure, the smaller the contact radius [29]. If the 
coating is very thick, the maximum Hertzian pressure would increase by a factor of $1.41(\sqrt{2})$, and the Hertzian contact radius reduces by this factor. With the development of the technique, tri-layer material and multilayer material have been used, which introduces more interfaces. The stress field analysis can help engineers design and optimize the mechanical properties with the aim to achieve the longest service life and the best performance.

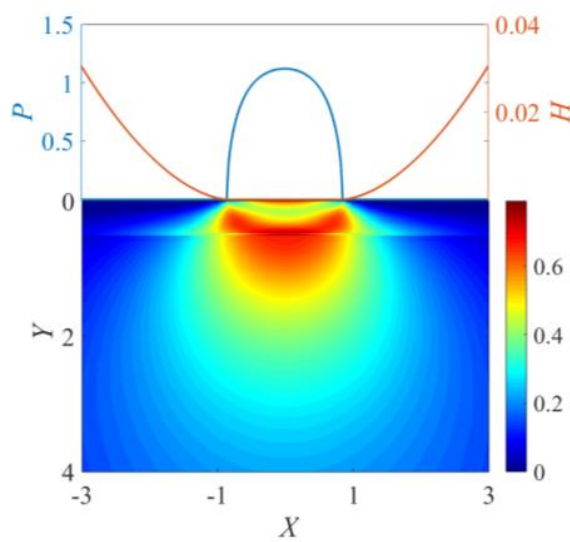

(a) Step variation of elastic modulus $\left(1.12 p_{\mathrm{h}}, 0.84 b\right)$

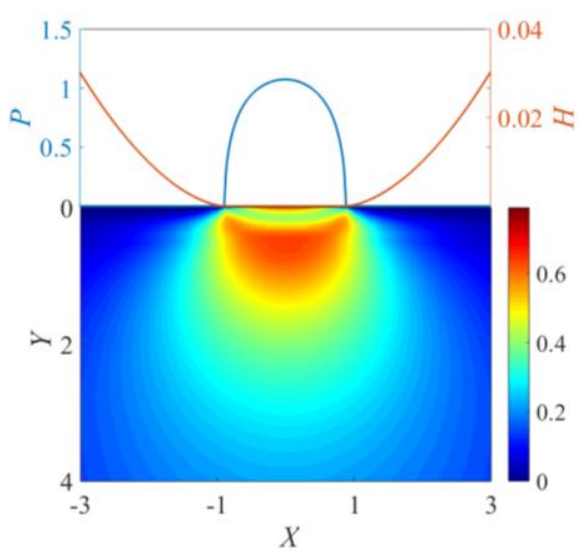

(c) Sinusoidal variation of elastic modulus $\left(1.07 p_{\mathrm{h}}, 0.87 b\right)$

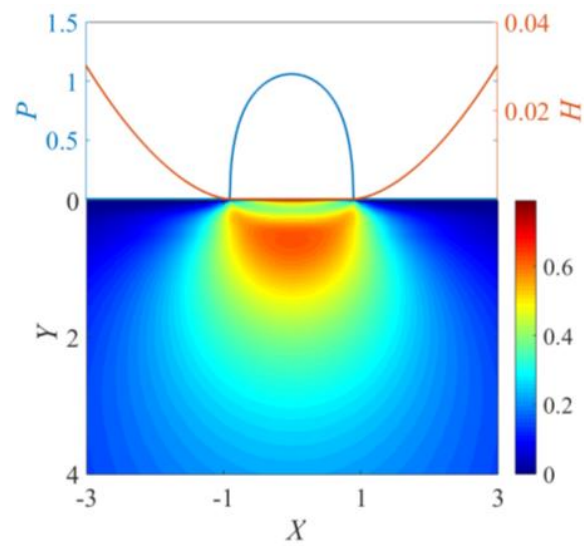

(b) Linear variation of elastic modulus $\left(1.06 p_{\mathrm{h}}, 0.89 b\right)$

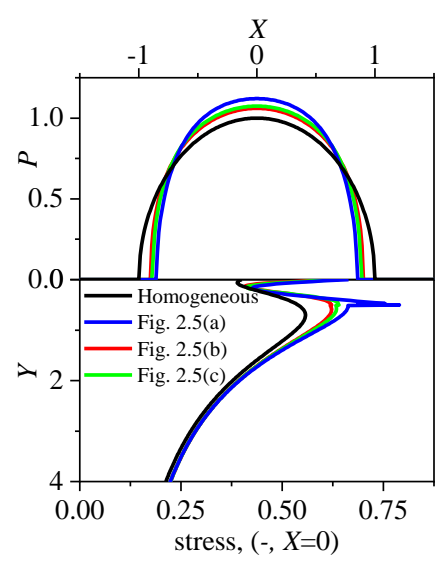

(d) Pressure and stress comparison

Figure 2.5: Dimensionless pressure, gap height and VMS field of coated material 


\subsection{Effect of inclusions}

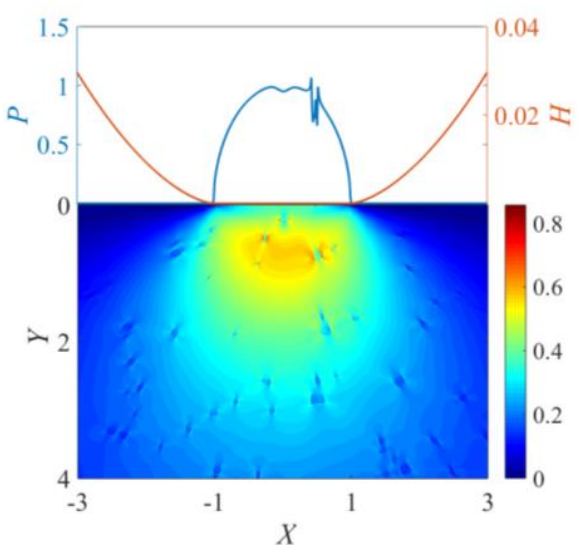

(a) Soft inclusions, $\left(E_{\mathrm{i}}=0.5 E\right)$

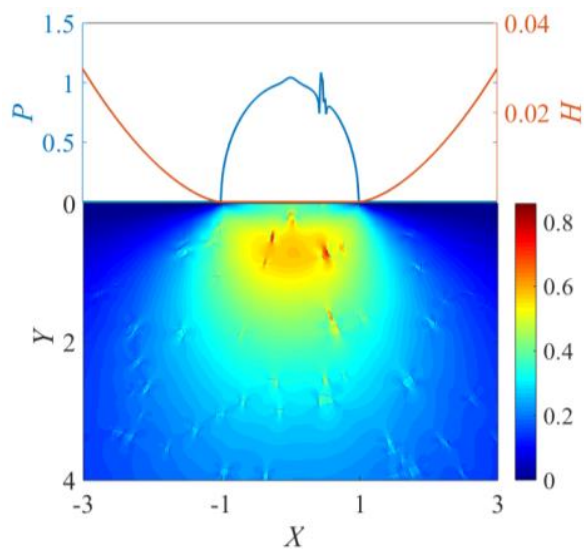

(c) Hard inclusions, $\left(E_{\mathrm{i}}=2 E\right)$

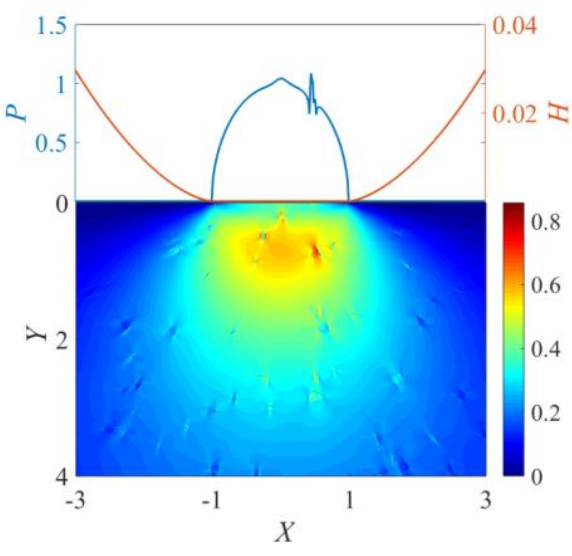

(b) Soft and hard inclusions, $\left(E_{\mathrm{i}}=0.5 E, 2 E\right)$

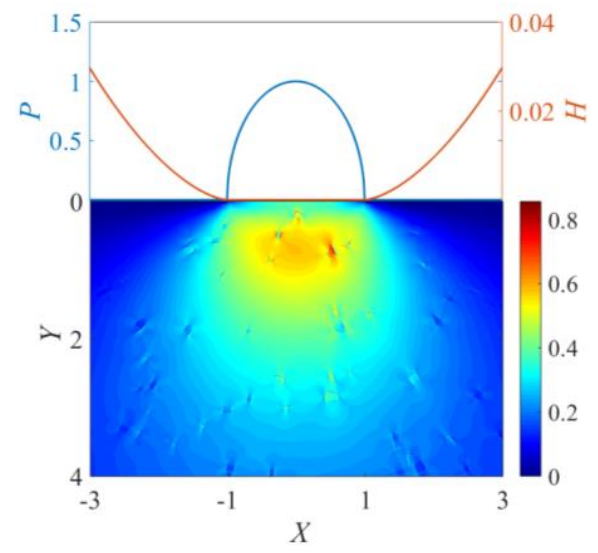

(d) Soft and hard inclusions with Hertzian pressure, $\left(E_{\mathrm{i}}=0.5 E, 2 E\right)$

Figure 2.6: Dimensionless pressure, gap height and VMS stress fields of material with inclusions

Instead of assuming specific inclusion shapes as used in studies [29,42], a Voronoi tessellation is used to generate a distribution of grains. The position and shape of the inclusions are randomly selected from the generated grains, which is thought to be closer to bearing material compared to using specific shapes such as a sphere. The other material and contact parameters are the same as in Tab. 2.1 except for the friction coefficient. In the following analyses, no shear stress 
is considered. The average grain diameter is $15 \mu \mathrm{m}$. The number of inclusions is about $1 \%$ of the total grains. The elastic moduli of hard and soft inclusions are two times larger or smaller than that of the base material. The contact pressure shown in Fig. 2.6 (a) (c) is solved according to the material inhomogeneity. Pressure fluctuations can be found due to the impurity of material. The existence of inclusions results in stress concentrations locally. The stiffness and location of the inclusions affect the level of the stress concentration. The value of the maximum VMS is as follows: $\mathrm{VMS}_{\text {Fig. } 2.6(\mathrm{a})}(0.771)<\mathrm{VMS}_{\text {Fig. } 2.6(\mathrm{~b})}(0.827)<\mathrm{VMS}_{\text {Fig. }}$ $2.6(\mathrm{c})(0.856)$ and all of them are larger than that of homogeneous material which means the existence of inclusions increases the probability of crack initiation. When inclusions are sufficiently close to the contact surface, the classical smooth contact pressure distribution for homogeneous material is affected due to incompatible deformation of subsurface material. Fig. 2.6 (d) gives the result using the Hertzian pressure rather than using the accordingly solved pressure taking the influence of subsurface material into account. Comparing Fig. 2.6 (b) and (d), it may be found that the effect of the different contact pressures on the stress field is not very significant. However, the maximum VMS is different, and this difference may become larger when also considering the influence of surface roughness and lubricant pressure. In order to predict the RCF more accurately, the realistic pressure distribution solved from the contact/lubricated problem may be essential.

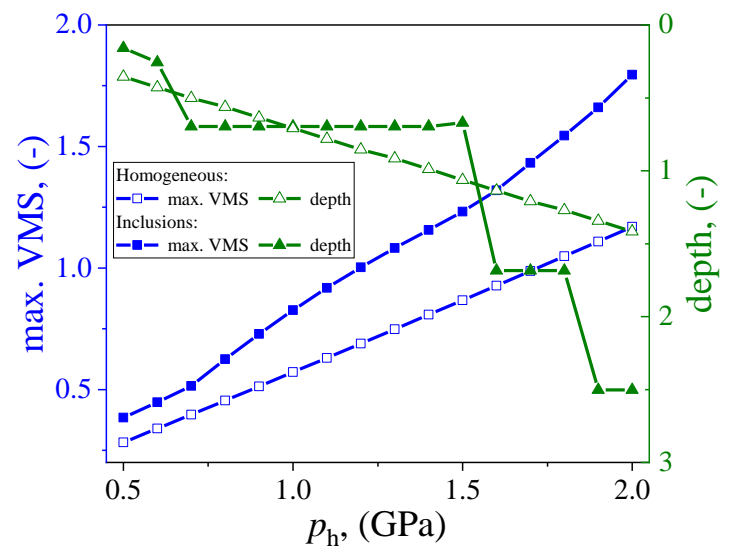

Figure 2.7: Influence of load on the maximum VMS

Figure 2.7 shows the influence of the load on the value and the depth of the maximum VMS for the homogeneous case and for the grain structured case studied in Fig. 2.6 (b). The analytic value of the maximum VMS for 
homogeneous material is $0.557 p_{\mathrm{h}}$ located at $0.703 b$ below the surface [41]. With increasing load, the maximum VMS increases for both cases. The largest value is about four times larger than that of the smallest one. Compared to homogeneous material, the value of the maximum VMS for the inclusion case is about 1.29 1.53 times larger. Under low loads, the location of the maximum VMS is near the surface. The variation of depth with load for the inclusion case is step wise which means it remains at one of the near surface inclusions under low load; while for higher loads, its location moves gradually to a deeper inclusion.

\subsection{Conclusion}

In this chapter, a multigrid algorithm has been developed for 2D dry contact problems of inhomogeneous material. The developed algorithm exhibits a grid independent fast convergence with the number of cycles and allows solving the problems with many millions of unknowns. The results were verified using homogeneous material solutions. The effect of inclusions and coatings on the stress field and the contact pressure distribution is analysed. Different from homogenous material, stress variations can be found around the boundaries between inclusions (or coating) and the bulk material. The level of stress variation depends on the difference of material elastic modulus. The efficiency of the numerical solution method allows the use of many grains which provides excellent prospects for realistic 3D problems to be discussed in the next chapter. 


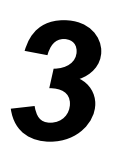

\section{Anisotropic material in dry contact: 3D point contact}

On a macro scale, bearing material is isotropic which means its mechanical property is the same in each direction. On a micro scale, for example just below Hertz contact region, the effect of material anisotropy may be significant particularly in view of the stress fields. Anisotropy is an intrinsic feature of bearing material resulting from the variation of the crystallographic orientations. The measured rotation data by electron back scatter diffraction (EBSD) techniques [43] also confirms the existence of rotation differences between grains. In fact, the macroscopic isotropy results from the accumulative effect of the microscopic anisotropic grains. As the margins between safe and fail are becoming more critical, the validity of the general assumption of isotropic material for RCF predictions has drawn researchers' attention recently $[19,20,31,32]$. Material anisotropy introduces additional terms in the stress-strain relation. This increases the computational complexity, which is further burdened by the need for realistic problems to consider the full 3D problem. To achieve this within acceptable computing time on computational facilities available in an engineering development environment, the efficiency of the multigrid method is essential. In this chapter, a multigrid algorithm was described for a 3D dry contact problem of anisotropic material. This chapter is a summarized version of the published paper A in appendix.

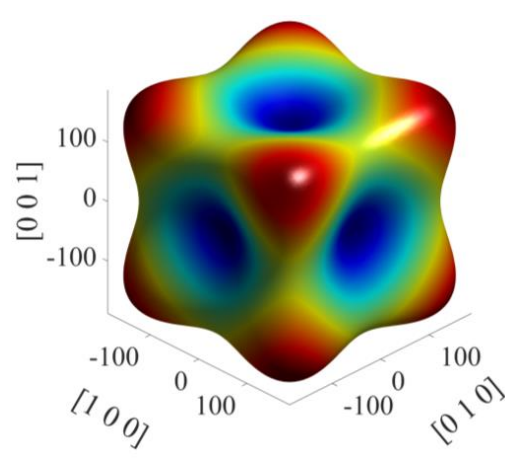

3D elasticity for an anisotropic grain (left) and VMS distribution of heterogeneous anisotropic material (right)

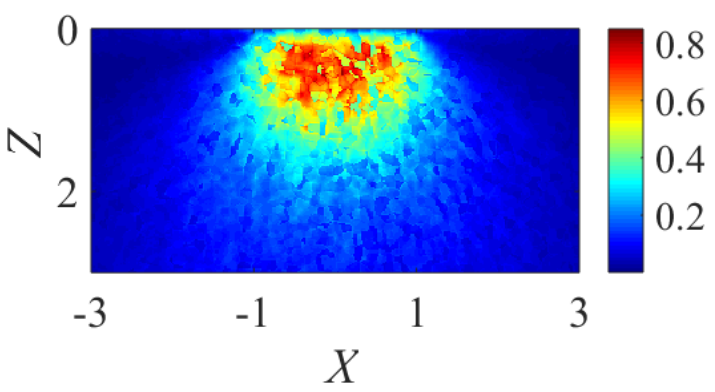




\subsection{Theoretical model}

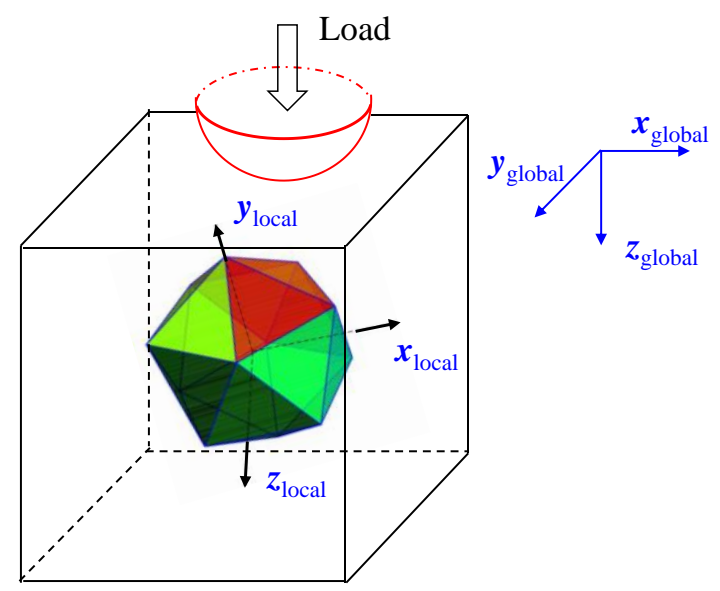

Figure 3.1: Schematic graph of a 3D elastic contact

Figure 3.1 schematically shows the point contact problem studied, i. e., a rigid ball loaded against an elastic body. The boundary conditions for the elastic body are: the bottom plane is fixed and the four vertical planes are stress free. The interior needs to satisfy the steady state stress equilibrium equations [39]:

$$
\left\{\begin{array}{l}
\frac{\partial \sigma_{x x}}{\partial x}+\frac{\partial \sigma_{x y}}{\partial y}+\frac{\partial \sigma_{x z}}{\partial z}=0 \\
\frac{\partial \sigma_{y x}}{\partial x}+\frac{\partial \sigma_{y y}}{\partial y}+\frac{\partial \sigma_{y z}}{\partial z}=0 \\
\frac{\partial \sigma_{z x}}{\partial x}+\frac{\partial \sigma_{z y}}{\partial y}+\frac{\partial \sigma_{z z}}{\partial z}=0
\end{array}\right.
$$

where

$$
\left[\begin{array}{c}
\sigma_{x x} \\
\sigma_{y y} \\
\sigma_{z z} \\
\sigma_{y z} \\
\sigma_{x z} \\
\sigma_{x y}
\end{array}\right]=C\left[\begin{array}{c}
\partial u / \partial x \\
\partial v / \partial y \\
\partial w / \partial z \\
\partial v / \partial z+\partial w / \partial y \\
\partial u / \partial z+\partial w / \partial x \\
\partial u / \partial y+\partial v / \partial x
\end{array}\right]
$$

in which $C$ is the stiffness matrix in the global coordinate system $x, y, z$. Apart from the global coordinate systems shown in Fig. 3.1, an additional local 26 
coordinate system located in the crystal nucleus is used to define the rotation angle of the crystal. The crystal nucleus location and the Euler rotation angles $\alpha$, $\beta, \gamma$ will be given randomly during the generation of a Voronoi tessellation which is used to represent the microscale structure of the material. The elastic stiffness tensor of each grain in the global coordinate system is defined by:

$$
\left(C_{i, j, k, l}\right)_{\text {global }}=R_{x}(\alpha) R_{y}(\beta) R_{z}(\gamma)\left(C_{i, j, k, l}\right)_{\text {local }}\left(R_{x}(\alpha) R_{y}(\beta) R_{z}(\gamma)\right)^{T}
$$

in which $R_{x}, R_{y}$ and $R_{z}$ are three rotation matrices. The elastic stiffness tensor of cubic crystal in the local coordinate system has the following form Ref. [39]:

$$
\left(C_{i, j, k, l}\right)_{\text {local }}=\left[\begin{array}{cccccc}
c_{11} & c_{12} & c_{12} & 0 & 0 & 0 \\
c_{12} & c_{11} & c_{12} & 0 & 0 & 0 \\
c_{12} & c_{12} & c_{11} & 0 & 0 & 0 \\
0 & 0 & 0 & c_{44} & 0 & 0 \\
0 & 0 & 0 & 0 & c_{44} & 0 \\
0 & 0 & 0 & 0 & 0 & c_{44}
\end{array}\right]
$$

in which $c_{11}, c_{12}$ and $c_{44}$ are three material constants. After rotating the stiffness tensor to the global coordinate system, the matrix becomes full for anisotropic grains which introduces additional terms in the stress-strain relation compared to an isotropic grain. The anisotropy ratio $A$ (Zener ratio) provides a convenient measure of anisotropy and is defined as:

$$
A=\frac{2 c_{44}}{c_{11}-c_{12}}
$$

For $A=1$, the material is isotropic and the elastic stiffness matrix is unaffected even when it is rotated. However, when $A \neq 1$, the elastic moduli of anisotropic grains varies in the global coordinate system due to the rotation. The variation of Young's modulus with rotation angle according to Ref. [44] is shown in Fig. 3.2. The material parameters are given in Tab. 3.1. The radius from the body centre to the body face represents the value of Young's modulus. In Fig. 3.2 (a), the representation surface of Young's modulus for cubic anisotropic grains has eight rounded protruding corners and six valleys at the centre of the faces. This means that the elastic modulus varies in different directions. For an anisotropic grain with $A=2.4167$, the Young's modulus varies between $132.27 \mathrm{GPa}$ and 283.34 $\mathrm{GPa}$ in different directions. The elasticity comparison between anisotropic and isotropic material with varying rotation angles is shown in Fig. 3.2 (b). For 
isotropic material, the shape is a circle as the elasticity is same in all directions. With the increase of the Zener ratio, the ratio between the largest and the smallest value of the Young's modulus increases. This means that the directional dependence increases with increasing value of $A$.

Table 3.1 Cubic anisotropic material parameters

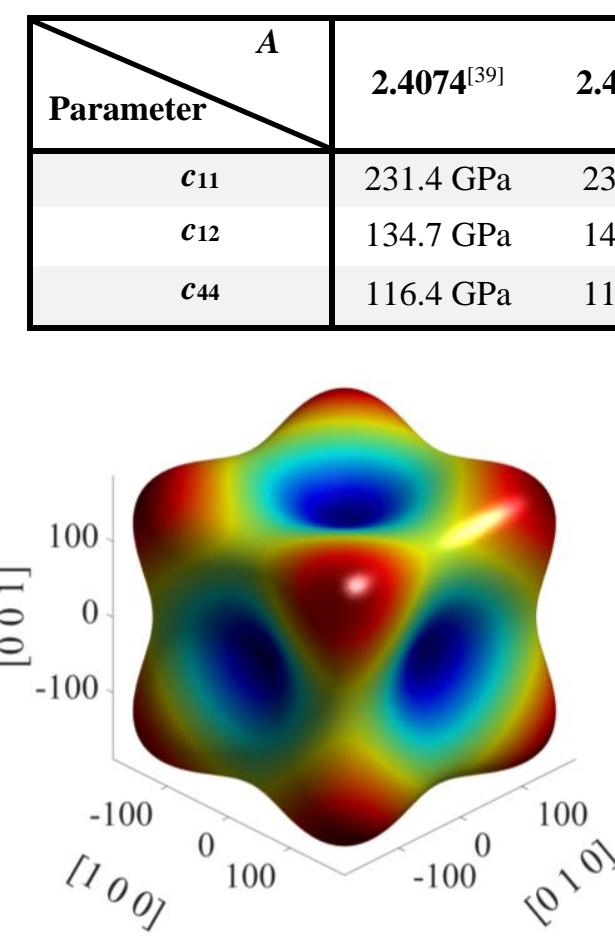

(a) 3D elasticity for an anisotropic grain,

$$
A=2.4167
$$

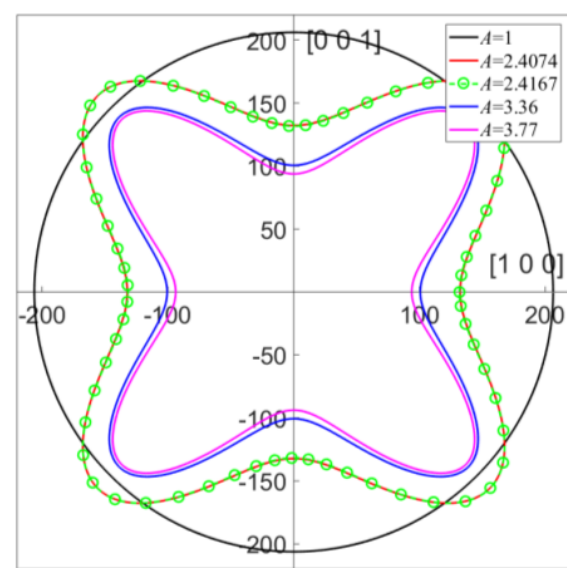

(b) 2D elasticity of $X Z$ plane $(Y=0)$

Figure 3.2: Representation surface of Young's modulus (GPa) for a cubic anisotropic grain

At the top boundary, Eq. (3.6) and (3.7) are used to solve displacements and pressure distribution:

$$
\begin{gathered}
\left\{\begin{array}{c}
\sigma_{x z}-f_{c} p=0 \\
\sigma_{y z}=0 \\
\sigma_{z z}+p=0
\end{array}\right. \\
h(x, y)=h_{0}+\frac{x^{2}}{2 R}+\frac{y^{2}}{2 R}+w(x, y, z=0)
\end{gathered}
$$


Eq. (3.6) and (3.7) need to satisfy the Hertz-Signorini-Moreau condition, Eq. (3.8).

$$
p \geq 0, h \geq 0 \text { and } p h=0
$$

This implies that for the rigid ball in contact with the elastic body $p>0$ and $h=$ 0 . When the gap is open $h>0$, Eq. (3.7) cancels with $p=0$, and Eq. (3.6) is used to calculate the top boundary displacements, i.e. a stress-free boundary condition. Finally, the contact pressure needs to balance the applied load $F$ :

$$
\iint p(x, y) \mathrm{d} x \mathrm{~d} y=F
$$

\subsection{Algorithm verification and solver performance}

The equations are made dimensionless using the following parameters:

$$
\begin{gathered}
X=x / b, Y=y / b, Z=z / b, U=u / b, V=v / b, W=w / b, \\
P=p / p_{\mathrm{h}}, C_{11}=c_{11} / p_{\mathrm{h}}, C_{12}=c_{12} / p_{\mathrm{h}}, C_{44}=c_{44} / p_{\mathrm{h}}, \bar{\sigma}_{i j}=\sigma_{i j} / p_{\mathrm{h}}, H=h / b
\end{gathered}
$$

in which $p_{\mathrm{h}}$ and $b$ are the maximum Hertzian contact pressure and contact radius respectively for homogeneous isotropic material. The details of the development of the multigrid algorithm including the discretization and relaxation of equations and inter-grid operators can be found in the Appendix, paper A [40]. In order to keep optimal multigrid performance of a grid independent convergence, some special measures should be taken in the relaxation of intersecting lines between adjacent boundary planes [45]. From the solution of the displacement equations, the stress fields can be determined a posteriori. The VMS in 3D is defined as:

$$
\mathrm{VMS}=\sqrt{\frac{\left(\sigma_{x x}-\sigma_{y y}\right)^{2}+\left(\sigma_{y y}-\sigma_{z z}\right)^{2}+\left(\sigma_{z z}-\sigma_{x x}\right)^{2}+6\left(\sigma_{x y}^{2}+\sigma_{y z}^{2}+\sigma_{x z}^{2}\right)}{2}}
$$

The material and contact parameters used for the verification are given in Tab. 3.2. The contact problem for the case of homogeneous isotropic material and a normal load with a friction coefficient $\left(f_{c}=0.2\right)$ is used as a test case for the numerical model verification. Fig. 3.3 (a) and (b) show the VMS field from the analytical solution [46] and the developed algorithm. The stress field in the $X Z$ 
$(Y=0)$ plane is asymmetric as a result of the shear stress. The value and the location of the maximum VMS are affected. The distribution of the normal stress, the maximum shear stress and the VMS at $X=0(Y=0)$ and $X=0.5078(Y=0)$ is given in Fig. 3.3 (c) and (d) respectively. The latter two stresses have been widely used as the stress criterion for crack initiation in RCF analyses. The maximum VMS from the analytic solution and the developed multigrid algorithm is 0.6377 and 0.6455 respectively and is located at the same position $X=0.2148, Y=0$, $Z=0.4492$. The maximum VMS deviation of the numerical solution from the analytical solution is $1.23 \%$. The results from the analytical solution and the developed 3D multigrid algorithm agree well.

Table 3.2 Material and contact parameters

\begin{tabular}{cc}
\hline Parameter & Value \\
\hline$E$ & $206 \mathrm{GPa}$ \\
$c_{11}$ & $277.3 \mathrm{GPa}$ \\
$c_{12}$ & $118.8 \mathrm{GPa}$ \\
$c_{44}$ & $79.2 \mathrm{GPa}$ \\
$f_{\mathrm{c}}$ & 0.2 \\
$R$ & $0.02 \mathrm{~m}$ \\
$p_{\mathrm{h}}$ & $1.0 \mathrm{Gpa}$ \\
$F$ & $40.34 \mathrm{~N}$ \\
$b$ & $138.78 \mu \mathrm{m}$ \\
$X, Y$ & $-5 \sim 5$ \\
$Z$ & $0 \sim 10$ \\
\hline
\end{tabular}

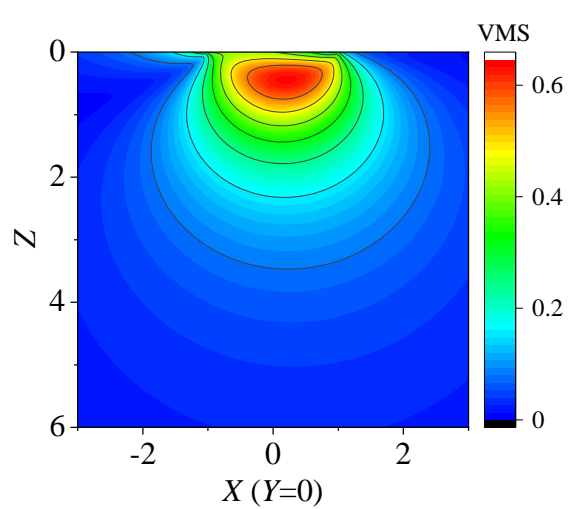

(a) VMS of the analytical solution

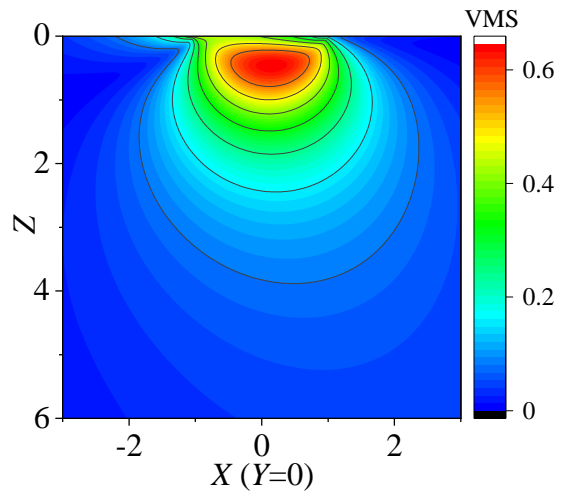

(b) VMS of the numerical solution 


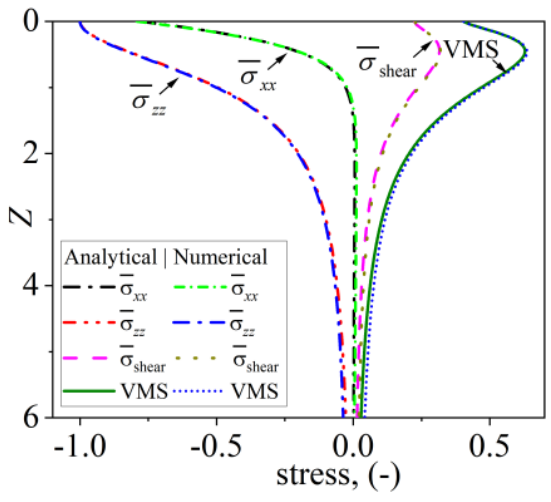

(c) Stress variation along the centerline $X=0(Y=0)$

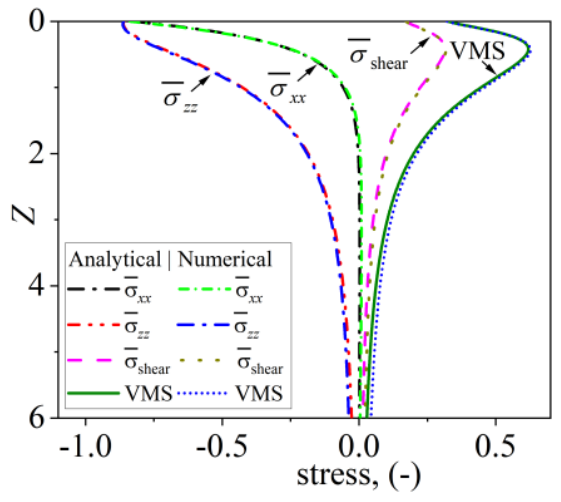

(d) Stress variation along the line $X=0.5078(Y=0)$

Figure 3.3: Stress distribution comparison between the numerical solution $\left(N_{x}=N_{y}=\right.$ $N_{z}=513$ ) and the analytical solution

Figure 3.4 shows the convergence speed and computing time of the developed multigrid algorithm for homogenous isotropic material and for polycrystalline anisotropic material. When not specified, anisotropic material with an anisotropic ratio of 2.4167 is used. In Fig. 3.4 (a), the residuals of the stress equilibrium equations and of the contact condition equation reduce roughly by a factor of 10 per $2 \mathrm{~W}$-cycles for homogenous isotropic material which is almost the same as the result shown in Fig. 3.4 (b) with a finer grid (over 1 billion unknowns). This indicates the developed algorithm gives a grid independent convergence speed. This excellent convergence is essentially maintained for the anisotropic problem shown in Fig. 3.4 (a). In terms of real dimensions for the given conditions, the average grain diameter is about $15 \mu \mathrm{m}$ for the heterogeneous anisotropic material. Note that each equation converges at the same speed with an order of magnitude error reduction per two W-cycles which in general is sufficient to achieve an error below the discretization error that is made anyway.

The computations were done on a computer with an Intel X5650 CPU at 2.66 $\mathrm{GHz}$, using a single core. For homogeneous isotropic material, the time cost for two cycles is about 40 minutes and for 10 cycles about 3.5 hours. For heterogeneous anisotropic material, the time cost increases due to the additional terms in the displacement equations introduced by the rotations. For two cycles, it uses 1 hour and 29 minutes to solve over four hundred million 
$(513 \times 513 \times 512 \times 3)$ unknowns and it is 7 hours for 10 cycles. The average time cost of heterogeneous anisotropic material is about 2.75 3.31 times larger than that of homogenous isotropic material. In general, only one or two W-cycles are needed to solve the problem with an error below discretization error. The results shown in Fig. 3.4 demonstrate that the developed solver is well suited for realistic material topologies. In the sections below, we present representative results. For detailed discussions, see the paper A in appendix.

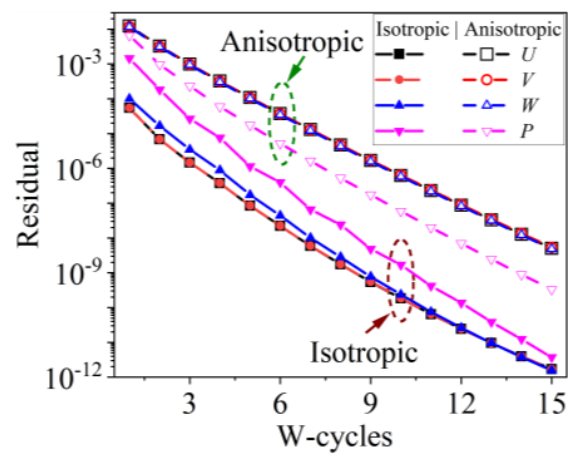

(a) Function residual $\left(513^{3}\right.$ points, 5 levels)

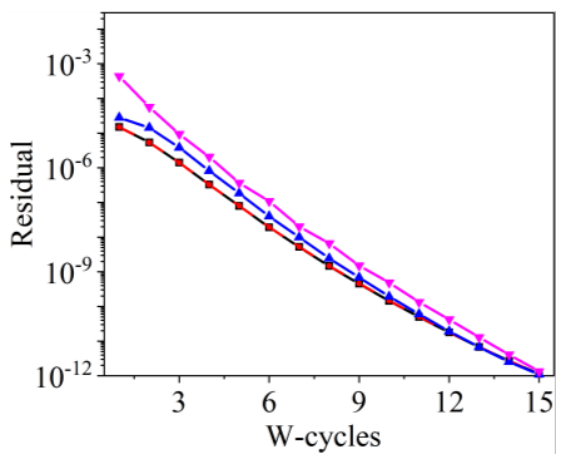

(b) Function residual $\left(1025^{3}\right.$ points, 6 levels)

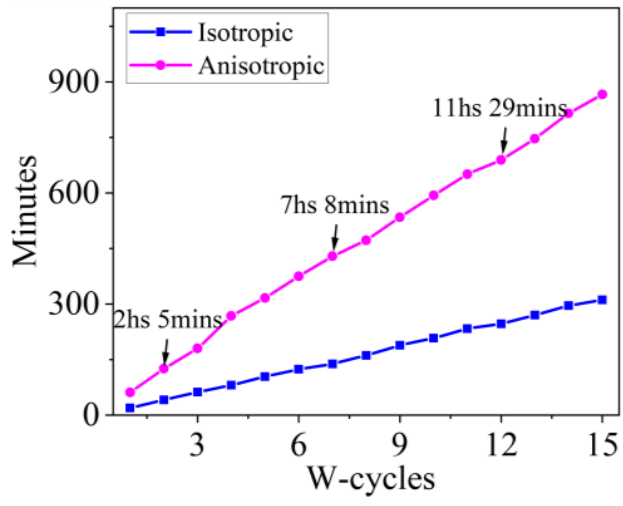

(c) Time cost $\left(513^{3}\right.$ points, 5 levels $)$

Figure 3.4: Residual and time cost as a number of multigrid $\mathrm{W}$-cycles (single processor, Intel X5650 CPU at $2.66 \mathrm{GHz}$ )

\subsection{Homogeneous anisotropic material}

For the following results in section 3.3 and 3.4, no friction is assumed at the top boundary. The anisotropic material parameters and the contact conditions are the 
same as those in Tab. 3.1 and Tab. 3.2. The stress field of homogeneous isotropic material and anisotropic material aligned with the global coordinate system are symmetric. For isotropic material shown in Fig. 3.5 (a), there is a single maximum VMS point located along the $Z$ axis $(X=Y=0)$. The elastic modulus of the anisotropic material depends on the load direction. For homogeneous anisotropic material aligned with the coordinate, the elastic modulus along the $Z$ axis direction is the smallest (Fig. 3.2). As a result, the maximum VMS point is not located along the $Z$ axis $(X=Y=0)$ (Fig. 3.5(b)). It occurs on a circle below the surface near the contact edge and shows in the central $X Z$ plane at two points which are distributed symmetrically about $X=0$. Besides, the value is smaller than that of homogeneous isotropic material.

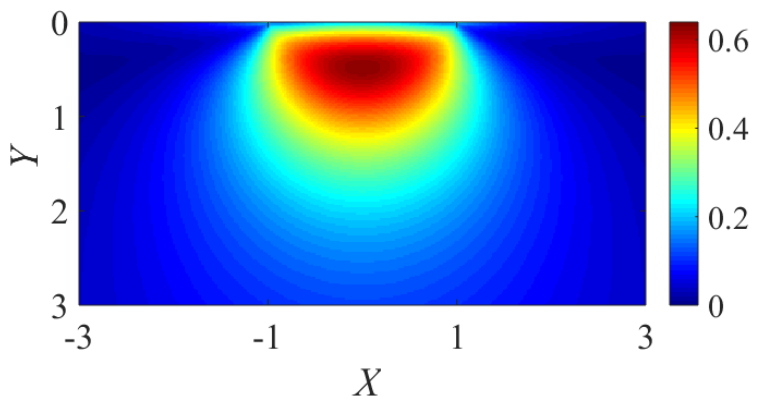

(a) Homogeneous isotropic material

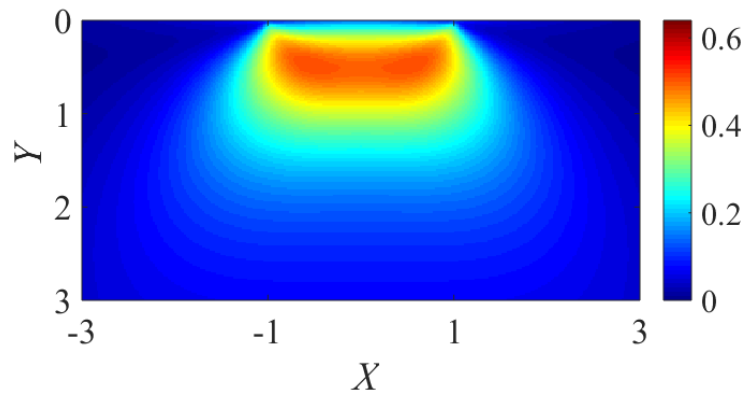

(b) Aligned anisotropic material, $A=2.4167$

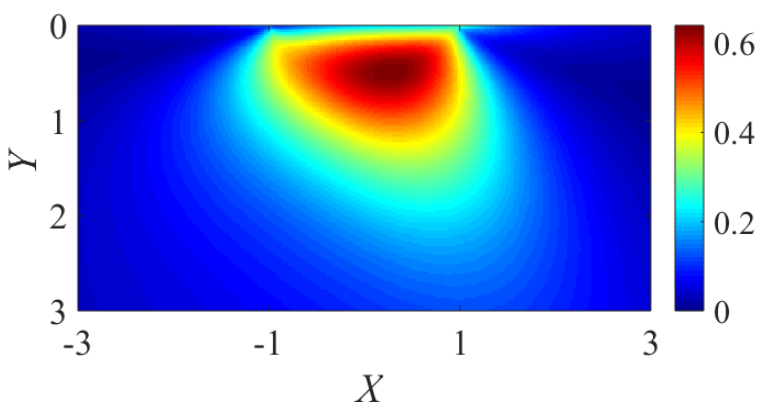

(c) Rotated anisotropic material, $A=2.4167$ 


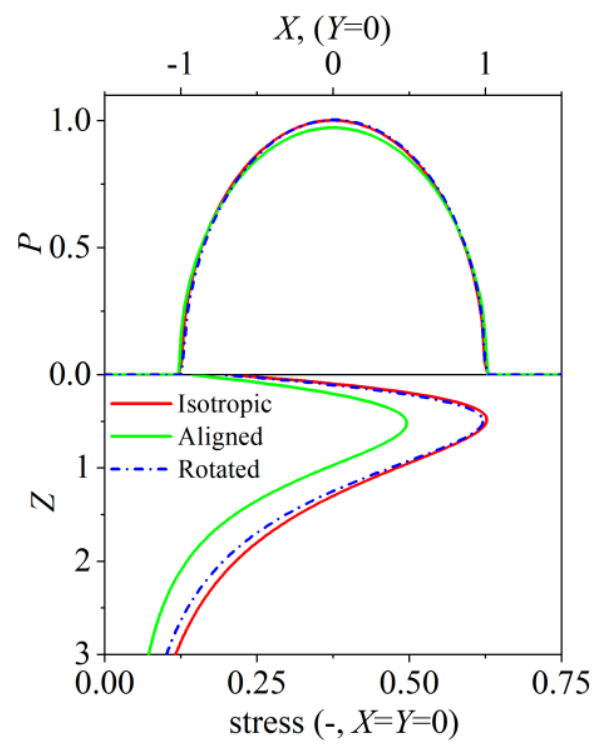

(d) Contact pressure and VMS comparison

Figure 3.5: VMS in the $X Z$ plane $(Y=0)$ and comparison between cases of homogeneous anisotropic and isotropic material on the line $X=Y=0$

Fig. 3.5 (c) shows the stress field of homogeneous anisotropic material with a rotation angle $0.2 \times \pi / 2$ in each direction. The stress field is asymmetric, and the location and value of the maximum VMS are also affected. After rotation, the stiffness of the material becomes larger which can be seen in the pressure distribution in Fig. 3.5 (d). The value of the maximum VMS for the three cases has the following order: $\bar{\sigma}_{3.5(\mathrm{~b})}(0.509)<\bar{\sigma}_{3.5(\mathrm{a})}(0.627)<\bar{\sigma}_{3.5(\mathrm{c})}(0.647)$.

\subsection{Polycrystalline anisotropic material}

The grain shape and distribution in the 3D domain are created by Voronoi tessellation. For the anisotropic material, the parameters and the contact conditions are in Tab. 3.1 and Tab. 3.2. The average grain diameter is $15 \mu \mathrm{m}$. The pressure, gap distance and the VMS distribution in the central $X Z$ and $Y Z$ planes are shown in Fig.3.6 (a) and (b), respectively. Also shown is the Hertzian contact pressure for homogeneous isotropic material. Note that a variation of crystallographic orientation angles between grains implies different stiffness properties in the global coordinate system. As a result, some grains behave as hard inclusions whereas others behave as soft inclusions. Stress concentrations appear near grain boundaries with a large variation of rotation angles. The 
change of the local orientation also induces a significant variation of the pressure relative to the homogeneous isotropic and anisotropic cases which can be seen in Fig. 3.6 (a) (c). The pressure fluctuations appear near the grain boundaries. In order to achieve a smooth transition between grain boundaries in the stress field, the variation of local grain orientation should be reduced. The effect of the contact pressure on the stress distribution is shown in Fig.3.6 (d). This figure clearly shows that the contact pressure for the polycrystalline case differs from the Hertzian pressure for the homogeneous isotropic case. The variation will mainly affect the stress field close to the surface. Besides, it also influences the maximum VMS value and location. For the accurate prediction of stresses, the realistic contact pressure rather than the commonly used Hertzian pressure should be used.

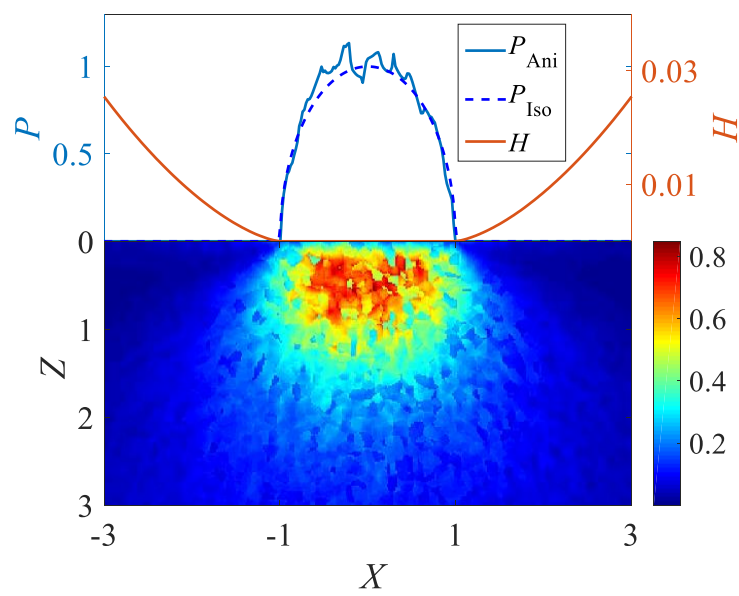

(a) $P, H$ and VMS of $X Z$ plane $(Y=0)$

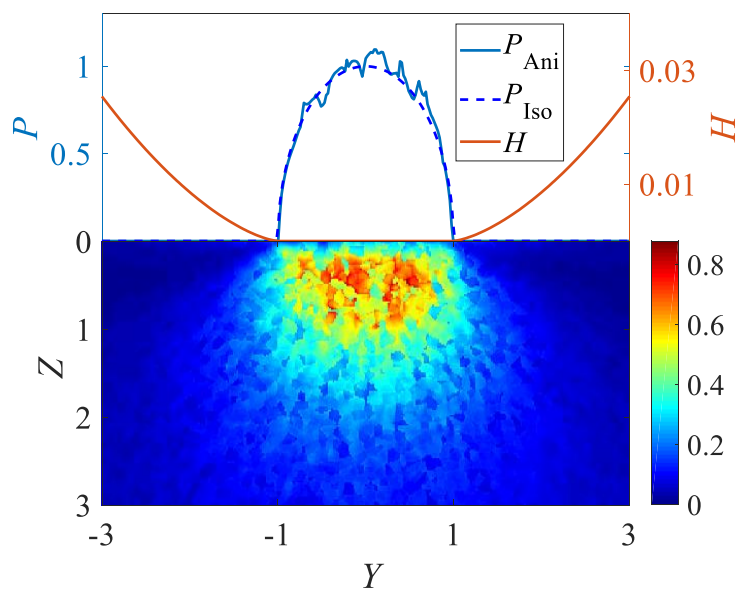

(b) $P, H$ and VMS of $Y Z$ plane $(X=0)$ 


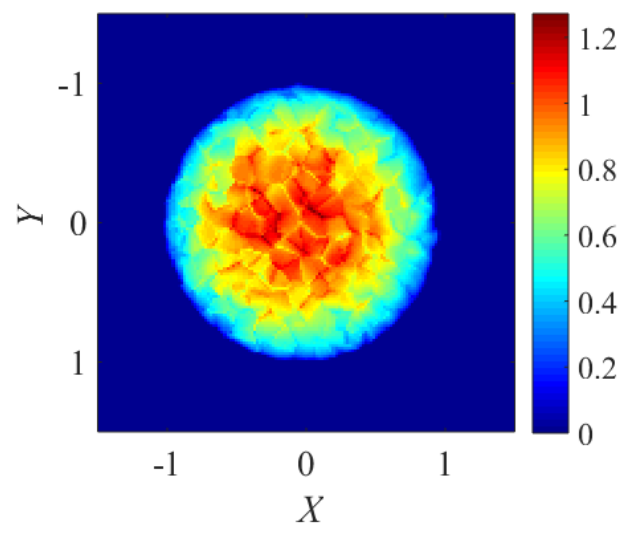

(c) Top boundary pressure distribution

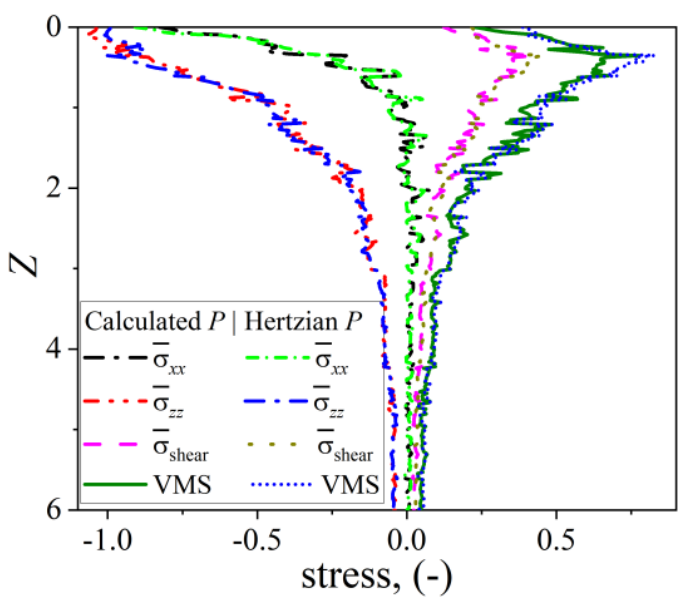

(d) Dimensionless stress of line $(X=Y=0)$

Figure 3.6: Dimensionless pressure, gap distance and VMS distribution

As a next step, the average effect of multiple randomly generated orientation angles and topologies is investigated. The results are shown in Fig. 3.7. In total, 49 cases of contact at different locations relative to the grain topology were solved. Due to the random variation of the crystallographic orientation and the topology, there is a significant variation in the value and depth of the VMS. The average value of the maximum VMS is larger than that predicted for homogeneous isotropic material, while its average depth is very close to that of homogeneous isotropic material. The average of the dry contact pressure distribution of the 49 cases is shown in Fig. 3.7 (c) together with the pressure distribution for homogeneous isotropic material. Different from the pressure distribution shown in Fig. 3.6 (c), the average pressure curve becomes smooth and quite close to the result for isotropic material. 


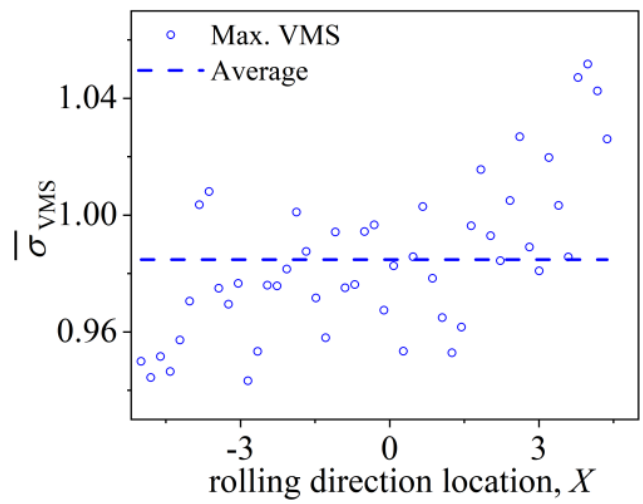

(a) Value of the maximum VMS

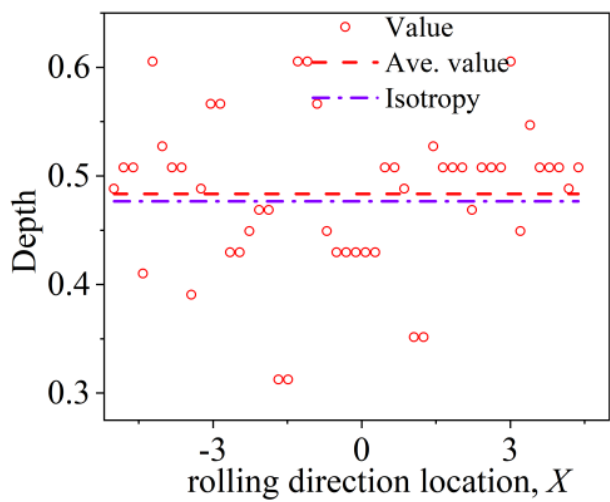

(b) Depth of the maximum VMS

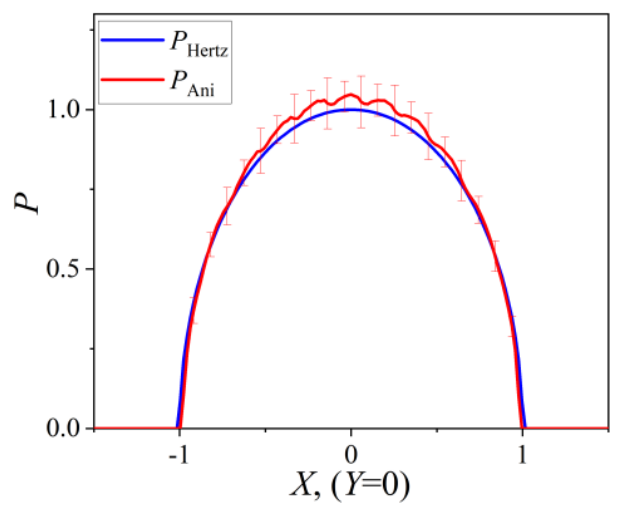

(c) Pressure comparison $(Y=0)$

Figure 3.7: The variation of the maximum VMS and the averaged pressure for 49 microstructure domains

\subsection{Effect of surface roughness}

So far, the surface of the contacting bodies is perfectly smooth in the studied cases. However, in reality also surface roughness will affect the pressure profile 
and the subsurface stress field. To demonstrate that the developed method can also efficiently deal with the combined case of a complex contact problem with local separation due to roughness and material anisotropy, Fig. 3.8 shows the influence of an isotropic harmonic surface waviness (with wavelength $91.32 \mu \mathrm{m}$ $(0.658 b)$ and amplitude $0.139 \mu \mathrm{m}(0.001 b))$ on the contact pressure and the VMS distribution. It can be seen from the contact pressure (Fig. 3.8(a)) that the relatively large amplitude of the waviness leads to multiple isolated contact islands at the waviness peaks. Regarding the behaviour of the VMS, it leads to near surface concentrations, which are detrimental for the contact bodies. To avoid these, the rollers and raceway of rolling bearings should be manufactured with good surface finish. This result demonstrates that the developed algorithm is fully suited for extensive studies of polycrystalline anisotropic material behaviour in contact applications.

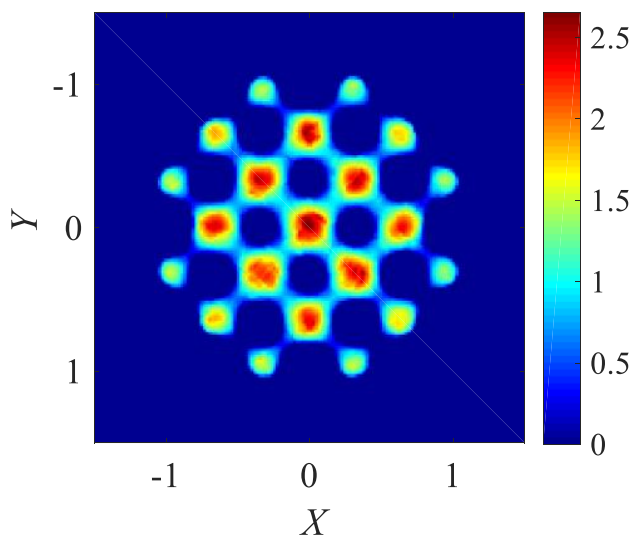

(a) Dimensionless pressure distribution of rough contact

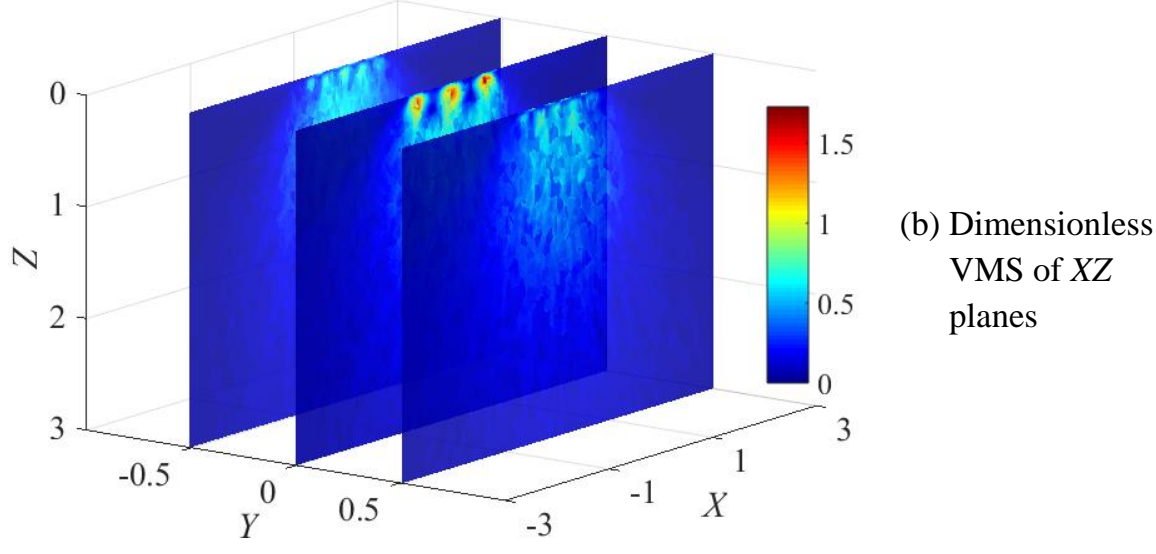

Figure 3.8: Effect of roughness on dimensionless pressure and VMS distribution 


\subsection{Conclusion}

A multigrid algorithm has been developed for the 3D dry contact problem of polycrystalline material. The developed method has excellent performance even when the local grain elasticity is considered. The multigrid algorithm can solve problems with high spatial resolution allowing detailed study of local variations in the material. The variation of grain elasticity and surface roughness significantly affect subsurface stress and contact pressure distribution. In order to extend the RCF of rolling bearings, the local anisotropy variation in bearing material should be minimized as much as possible by modern manufacturing technology. With this excellent result, the next step is to tackle the added complexity of considering lubricated contacts. Finally, in chapter 5, we exploit the method in a study where actual fatigue life integrals are computed to investigate the effect of polycrystalline material topology on the predicted fatigue life. 


hydrodynamic lubrication: 3D point contact

When rolling bearings are well lubricated, the rolling elements and the raceway are separated by a lubricant film. In the past decades, a lot of theoretical and experimental studies related to EHL and its corresponding effects on the RCF [47] have been done. Studying the point EHL problem is more complex compared to the dry contact problem analysed in the previous chapter. Modelling the effect of inhomogeneous material requires simultaneous calculation of the EHL pressure and subsurface stress field. The solution considering the effect of material anisotropy is more complicated and requires much longer calculation times compared to other inhomogeneous effects such as material inclusions. So far in the literature, only the EHL line contact problem considering the influence of material anisotropy has been studied with the finite element method [20]. In this chapter, the developed multigrid algorithm for the 3D dry contact problem is extended to simulate the effects of heterogeneous anisotropic materials on the subsurface stress, the EHL pressure and on the film thickness. This chapter is a summary of the full publication on this topic published by Tribology International and given in appendix paper B.
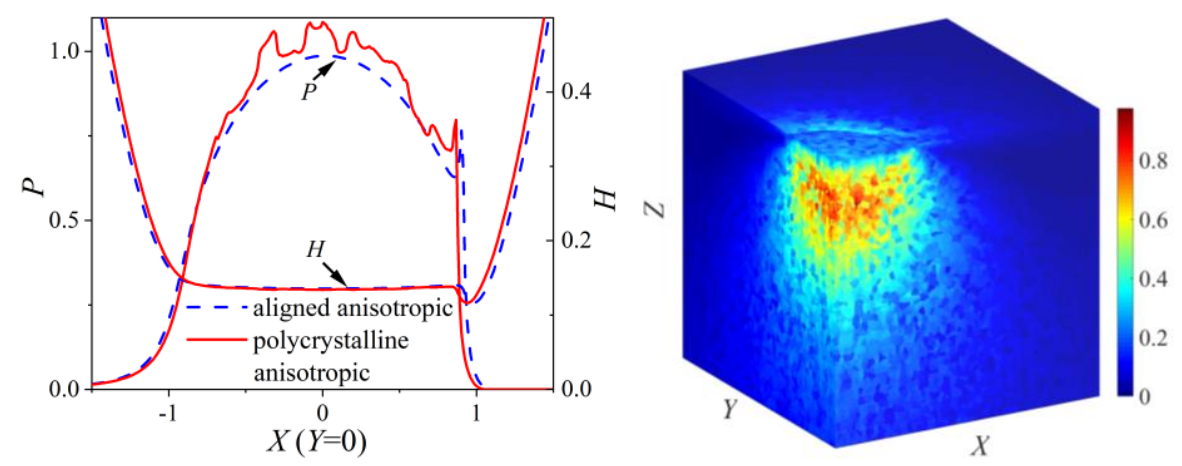

Pressure and film thickness distribution of aligned and polycrystalline anisotropic material (left) and 3D VMS field of polycrystalline anisotropic material (right) 


\subsection{Theoretical model}

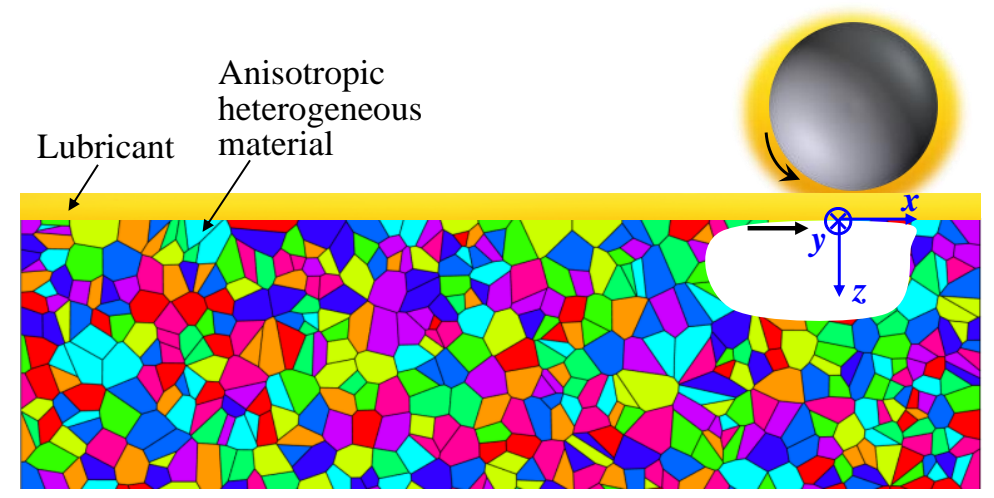

Figure 4.1: Schematic representation of an elasto-hydrodynamically lubricated contact between a sphere and a polycrystalline anisotropic material under pure rolling conditions

Figure 4.1 shows the schematic representation of an EHL lubricated (point) contact problem with anisotropic material, in which the different colours represent different crystalline orientation angles of grains. In this chapter, we restrict ourselves to the steady state problem with constant load and the subsurface topology fixed relative to the reference coordinate system attached to the lubricated contact location. This is the case for a pure sliding contact of a homogeneous body over a heterogeneous body. The extension to the case where the topology relative to the contact varies in time requires solving the time dependent problem. The method presented here can be readily extended in the same way as is done in conventional EHL problems [48]. The difference in model development between this chapter and the dry contact problem in the previous chapter is the top boundary condition. The lubricant is entrapped into the contact region by the entrainment of the contact bodies and the pressure distribution is solved from the lubricant condition, which requires solution of some additional equations when compared to the model used in the previous chapter. The lubricant is assumed to behave Newtonian, and the Reynolds equation for the point contact problem of steady state can be written as [25]:

$$
\frac{\partial}{\partial x}\left(\frac{\rho h^{3}}{12 \eta} \frac{\partial p}{\partial x}\right)+\frac{\partial}{\partial y}\left(\frac{\rho h^{3}}{12 \eta} \frac{\partial p}{\partial y}\right)-u_{\mathrm{m}} \frac{\partial(\rho h)}{\partial x}=0
$$


in which $\rho, \eta$ and $p$ are lubricant density, viscosity and pressure respectively, $u_{\mathrm{m}}$ is entrainment velocity, $h$ is film thickness. The boundary and cavitation conditions for the pressure are:

$$
\left\{\begin{array}{c}
p\left(x_{\mathrm{in}}, y\right)=p\left(x_{\text {out }}, y\right)=p\left(x, y_{\text {out }}\right)=p\left(x,-y_{\text {out }}\right)=0 \\
p(x, y) \geq 0\left(x_{\text {in }}<x<x_{\text {out }}, y_{\text {in }}<y<y_{\text {out }}\right)
\end{array}\right.
$$

where "in" and "out" refer to the inlet and outlet side of the domain. The isothermal problem is considered taking as equations of state for the viscosity and the density, the empirical relations presented by Roelands [49] and Dowson and Higginson [50]:

$$
\eta(p)=\eta_{0} \exp \left\{\left(\ln \eta_{0}+9.67\right)\left[-1+\left(1+5.1 \times 10^{-9} p\right)^{z_{0}}\right]\right\}
$$

and

$$
\rho(p)=\rho_{0}\left(1+\frac{0.6 \times 10^{-9} p}{1+1.7 \times 10^{-9} p}\right)
$$

Besides, the top boundary equations (Eq. (3.6) Eq. (3.7)) and stress field related equations (Eq. (3.1) Eq. (3.4)) introduced in the last chapter are also needed for the solution of the coupled EHL problem. For the sake of simplicity, it is not explained again here.

\subsection{Algorithm verification and solver performance}

The governing equations were non-dimensionalized using:

$$
\begin{gathered}
X=\frac{x}{b}, Y=\frac{y}{b}, Z=\frac{z}{b}, U=\frac{u}{b}, V=\frac{v}{b}, W=\frac{w}{b}, \\
P=\frac{p}{p_{\mathrm{h}}}, \bar{\sigma}_{i j}=\frac{\sigma_{i j}}{p_{\mathrm{h}}}, \bar{C}_{i j k l}=\frac{C_{i j k l}}{p_{\mathrm{h}}}, H=\frac{h}{b^{2} / R}, \bar{\eta}=\frac{\eta}{\eta_{0}}, \bar{\rho}=\frac{\rho}{\rho_{0}}
\end{gathered}
$$

where $b=\sqrt[3]{3 F R /\left(2 E^{\prime}\right)}, p_{\mathrm{h}}=3 F /\left(2 \pi b^{2}\right)$ are the values of the Hertzian contact radius and the maximum Hertzian pressure for the case of dry contact between homogeneous isotropic elastic materials. The discretization and relaxation of the governing equations can be found in the Appendix, paper B. As the Reynolds equation under higher loads exhibits a strong coupling in the $x$ direction, a line relaxation strategy [25] is required for good error smoothing in the top boundary plane and is essential to maintain optimal Multigrid performance. In view of the strong coupling between the boundary equations and 
the interior equations this line relaxation should be done collectively. For the verification of the algorithm, the results obtained with the 3D elastic model are compared with the results obtained using a conventional EHL model [25] for the case of homogeneous isotropic material. In the conventional model, the elastic deformation of the surface is modelled using the Boussinesq integral for an elastic half space. The operating conditions, lubricant parameters, the Hertzian dry contact parameters (isotropic), and values of commonly used dimensionless parameters are given in Tab. 4.1. The values of the Moes dimensionless load parameters for this case are $M=100$ and $L=10$.

Table 4.1 Material parameters, lubricant parameters, operating conditions and values of different sets of dimensionless parameters for the reference case

\begin{tabular}{cc}
\hline Parameters & Value \\
\hline$E^{\prime}$ & $226 \mathrm{GPa}$ \\
$R$ & $0.02 \mathrm{~m}$ \\
$p_{\mathrm{h}}$ & $0.76 \mathrm{GPa}$ \\
$F$ & $73.55 \mathrm{~N}$ \\
$u_{\mathrm{m}}$ & $0.46 \mathrm{~m} / \mathrm{s}$ \\
$\eta_{0}$ & $0.08 \mathrm{Pas}$ \\
$z_{0}$ & 0.6036 \\
$U_{\text {EHL }}$ & $8.18 \times 10^{-12}$ \\
$W_{\text {EHL }}$ & $8.14 \times 10^{-7}$ \\
$G_{\mathrm{EHL}}$ & 4972 \\
$\bar{\alpha}$ & 16.91 \\
$\bar{\lambda}$ & $2.37 \times 10^{-2}$ \\
$X, Y$ & $-3 b \sim 3 b$ \\
$Z$ & $0 \sim 6 b$ \\
\hline
\end{tabular}

In Fig. 4.2 (a) and (b), the centreline pressure and film thickness profiles in the flow direction $(X)$ and in the cross flow direction $(Y)$ are given for both models. Also shown is the contour plot of the dimensionless film thickness, but only for the EHL model with the 3D elasticity solution. The results exhibit all characteristic aspects of a steady EHL solution in the piezo-viscous regime: a nearly Hertzian pressure profile with short entrainment region leading up to it, and a pressure spike at the exit; a nearly uniform film thickness in the direction of flow with a small restriction at the exit and the side-lobes where the minimum 
film thickness occurs. The results of the two models are virtually identical. For more verifications such as the convergence with decreasing mesh size and parameters variation, the reader is referred to the Appendix paper B.

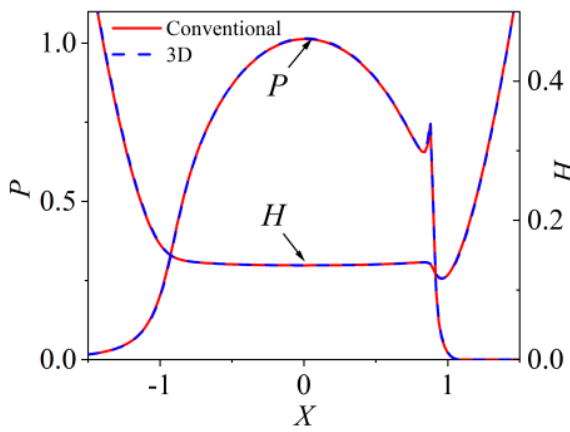

(a) $P(X, Y=0)$ and $H(X, Y=0)$

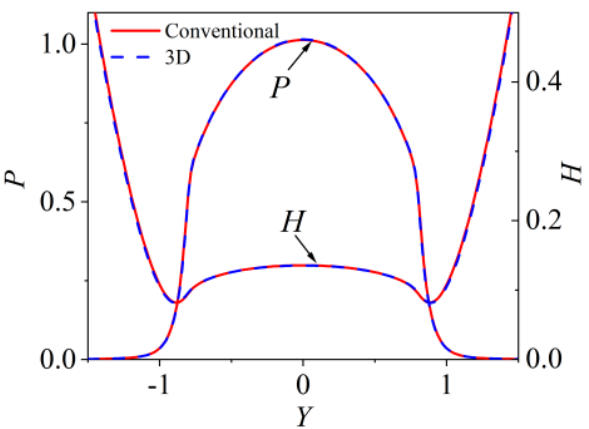

(b) $P(X=0, Y)$ and $H(X=0, Y)$

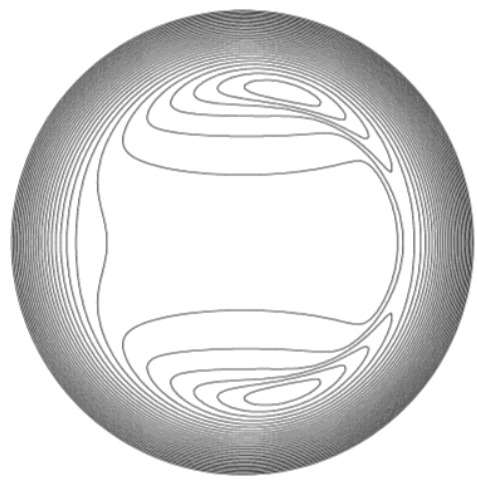

(c) Film thickness contour plot $H(X, Y)$

Figure 4.2: Pressure and film thickness comparison between the 3D elastic coupled EHL solution and the conventional solution

In Tab. 4.2, computing times used on a single processor (Intel X5650 CPU at $2.66 \mathrm{GHz}$ ) are presented as a function of the mesh size on the grid used for several EHL and dry contact models. In all cases, a full multigrid algorithm was used with 2 multigrid $\mathrm{W}(2,1)$ cycles per refinement, which solves the problem to the level of the discretization error. Results are presented for five problems. Firstly, for the conventional EHL point contact problem, solving this problem required 22 seconds on a $513 \times 513$ grid with $33 \times 33$ points on the coarsest grid. The subsequent evaluation of the 6 independent stress components in the subsurface on 513 planes requires about one minute. Secondly, the dry contact 
problem with 3D elastic equation solver for isotropic material. The third problem is of the same complexity but now for the case of anisotropic material. The fourth and the fifth case are for the 3D elastic coupled EHL problem with the isotropic and anisotropic material respectively. Taking the useful data to be the $n^{2}$ ( $n$ is the number of nodes in one spatial dimension) values of surface pressure and gap height, and the $n^{3}$ values of each of the 6 components of the stress tensor, the number of useful data values obtained per second CPU time invested can be computed. This value ranges from $\mathrm{O}\left(10^{5}\right)$ for the $3 \mathrm{D}$ problems to $\mathrm{O}\left(10^{7}\right)$ for the conventional problem illustrating that the $3 \mathrm{D}$ coupled model and algorithm should be used only when really needed.

Table 4.2 Computing time results of an FMG algorithm with 2 cycles per refinement as a function of the number of grids (levels) used

\begin{tabular}{|c|c|c|c|c|c|}
\hline Grid level & $\begin{array}{c}\text { Conventional } \\
\text { EHL } \\
\text { (MG+MLMI) }\end{array}$ & $\begin{array}{c}\text { Dry contact } \\
\text { +Stress field } \\
\text { (MG, Iso) }\end{array}$ & $\begin{array}{l}\text { Dry contact } \\
\text { +Stress field } \\
\text { (MG, Aniso) }\end{array}$ & $\begin{array}{c}\text { EHL } \\
\text { +Stress field } \\
\text { (MG, Iso) }\end{array}$ & $\begin{array}{c}\text { EHL } \\
\text { +Stress field } \\
\text { (MG, Aniso) }\end{array}$ \\
\hline $\begin{array}{c}3 \\
\left(129^{2} / 129^{3}\right)\end{array}$ & $\begin{array}{c}3 \\
+(3) \operatorname{secs}\end{array}$ & 2 mins & 5 mins & 7 mins & 15 mins \\
\hline $\begin{array}{c}4 \\
\left(257^{2} / 257^{3}\right)\end{array}$ & $\begin{array}{c}8 \\
+(8) \text { secs. }\end{array}$ & 7 mins & 16 mins & $21 \mathrm{mins}$ & 39 mins \\
\hline $\begin{array}{c}5 \\
\left(513^{2} / 513^{3}\right)\end{array}$ & $\begin{array}{c}22 \\
+(62) \operatorname{secs}\end{array}$ & 43 mins & $1 \mathrm{~h} 27 \mathrm{mins}$ & $1 \mathrm{~h} 16$ mins & $2 \mathrm{~h} 22$ mins \\
\hline
\end{tabular}

\subsection{Effect of homogeneous anisotropy}

The pressure and stress field of the EHL solution are asymmetric and display the characteristic features, see Fig. 4.3 (a), namely a closely semi-ellipsoidal (Hertzian) pressure profile with a continuous pressure rise and decline in the inlet and outlet region; a local maximum, the so-called pressure spike near the outlet; a nearly uniform film thickness in the center of the contact; the outlet film constriction and side lobes where the minimum film thickness occurs. The pressure spike causes a near surface local maximum in the VMS. Fig. 4.3 (b) shows the results for homogeneous anisotropic material aligned with the global coordinate. Different from the dry contact case (Fig. 3.5 (b)), the stress field is not symmetric due to the EHL pressure distribution. The location of the 
maximum VMS is affected as well. This value depends on the orientation as is shown in Fig. 4.3(c) where the material is rotated over an angle of $0.1 \pi$ in each direction. After rotation, its stiffness in the global coordinate system increases which results in a larger contact pressure and stress values as can be seen in Fig. 4.3(d). However, the EHL film thickness profiles are nearly identical for the three cases. The reason is as follows: in the steady state considered here, the flow in the central region is dominated by the decrease of Poisseulle flow in the inlet region, i.e. the film thickness decreases and the viscosity increases due to the rising pressure. Because the difference in deformation between the isotropic case and the anisotropic case is small in the inlet region, shear flow dominance with constant film starts at roughly the same location and at the same film thickness level.

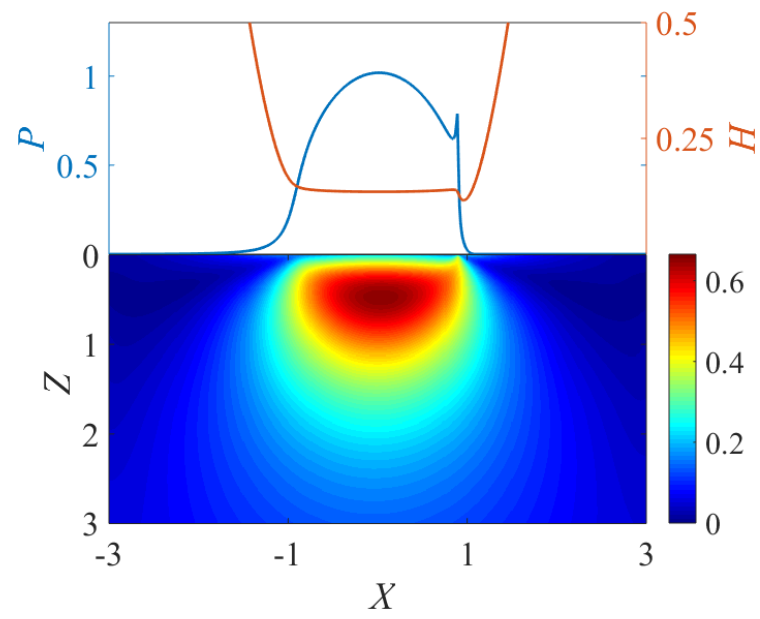

(a) Homogeneous isotropic material

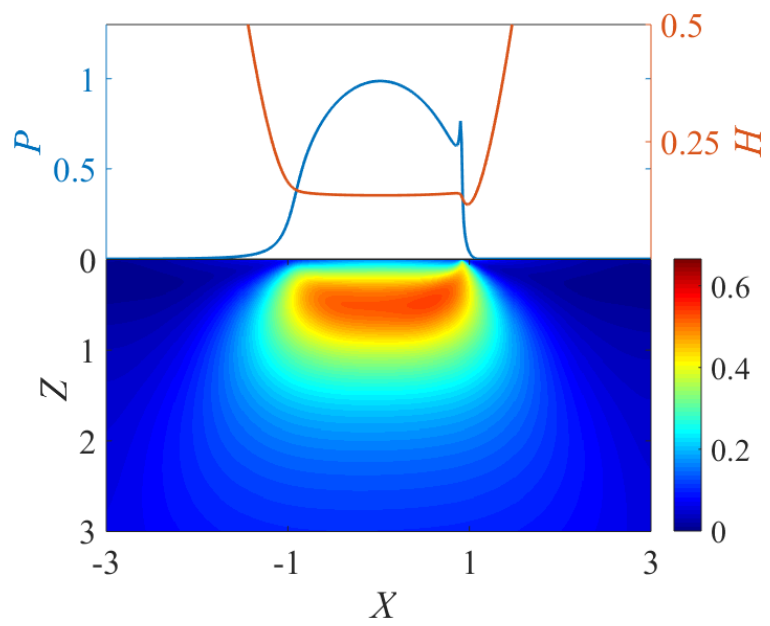

(b) Aligned anisotropic material, $A=2.4167$ 


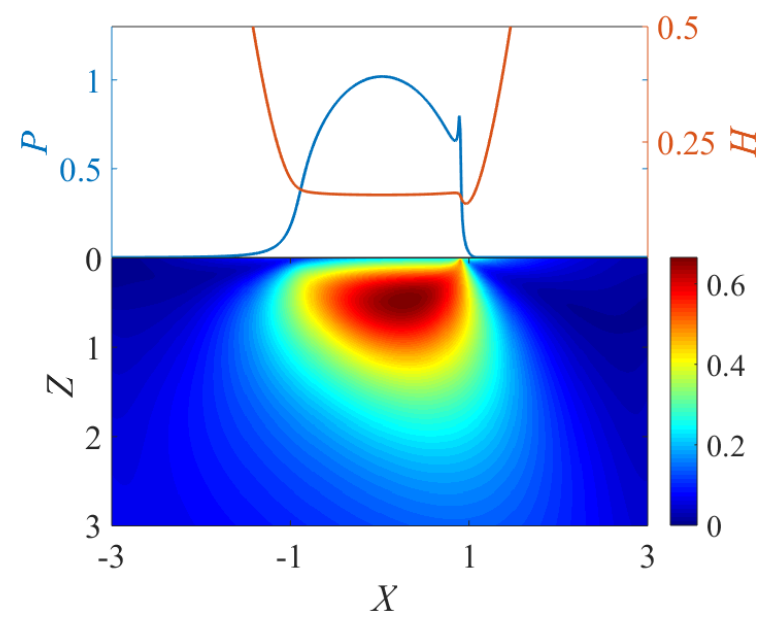

(c) Rotated anisotropic material, $A=2.4167$

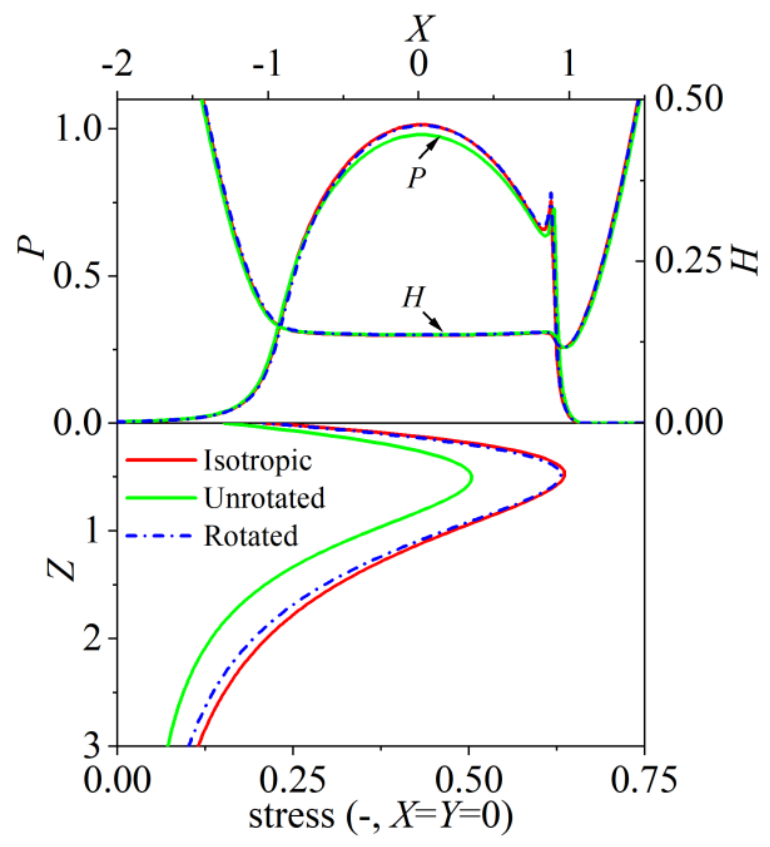

(d) Contact pressure and VMS comparison

Figure 4.3: VMS of $X Z$ plane $(Y=0)$ and contact pressure comparison between homogeneous anisotropic and isotropic material

\subsection{Effect of polycrystalline anisotropy}

In this part, results are presented for an EHL contact with load conditions as considered before but now with polycrystalline anisotropic material. The grains are created by Voronoi tessellation with random varying rotation angles. For the present case, translated to real data, the average grain diameter is $15 \mu \mathrm{m}$. As the 48 
Hertzian contact radius for isotropic material is $0.21 \mathrm{~mm}$, there are about 28 grains in $X$ and $Y$ directions of the Hertzian contact region.

Firstly, for a fixed value of $A=2.4167$, the effect of polycrystalline anisotropic topology on the pressure, film thickness and VMS distribution is investigated. Fig. 4.4 (a) and (b) show the dimensionless pressure and film thickness at the centerlines of the contact for the homogeneous anisotropic case (without rotation) and for the heterogeneous anisotropic case. Fig. 4.4 (c) and (d) show the pressure distribution at the surface and the contour plot of the dimensionless film thickness for the polycrystalline anisotropic case. The variation of the orientation of the grains leads to a locally increased or decreased stiffness of the material relative to the isotropic material. Depending on the orientation, the grain acts as a hard or soft inclusion which causes pressure fluctuations, as was also seen in the dry contact [40]. However, the film thickness profile is not significantly affected, for the same reason as explained in the previous section. This behavior is also reported in Ref. [20] for an EHL line contact. The film thickness contour plot is shown in Fig. 4.4 (d). Only small local film variations can be seen which result from the variation of the deformation of the rotated grains.

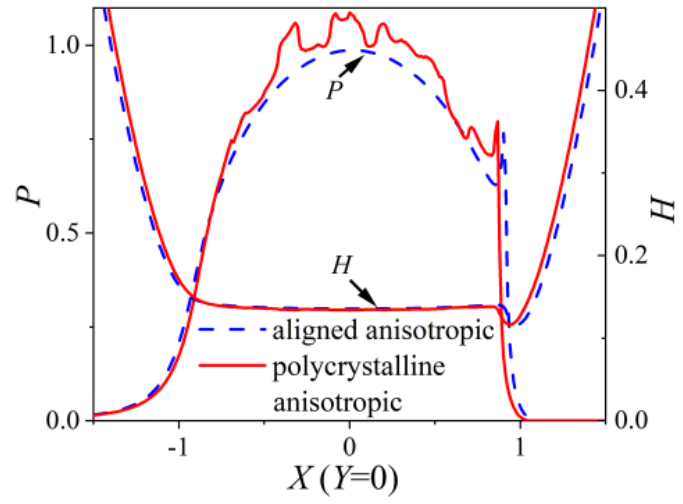

(a) $P(X, Y=0)$ and $H(X, Y=0)$

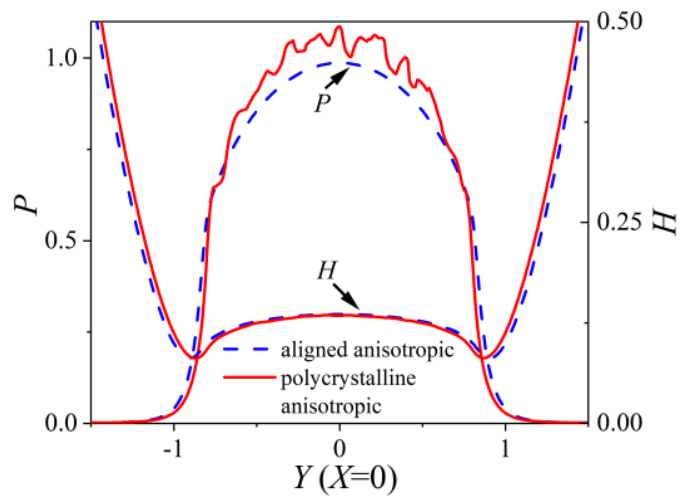

(b) $P(X=0, Y)$ and $H(X=0, Y)$ 


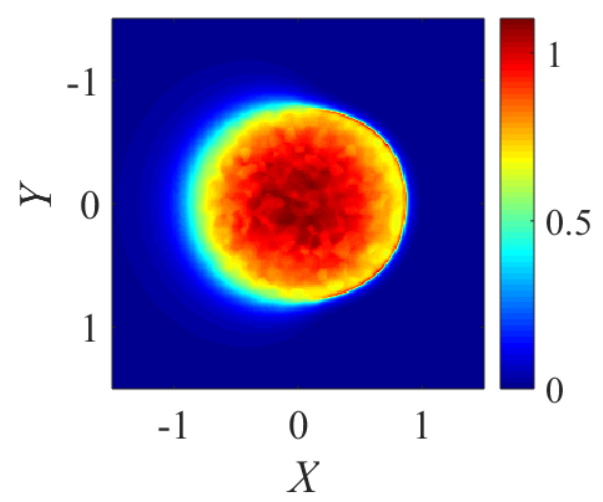

(c) Pressure distribution $P(X, Y)$

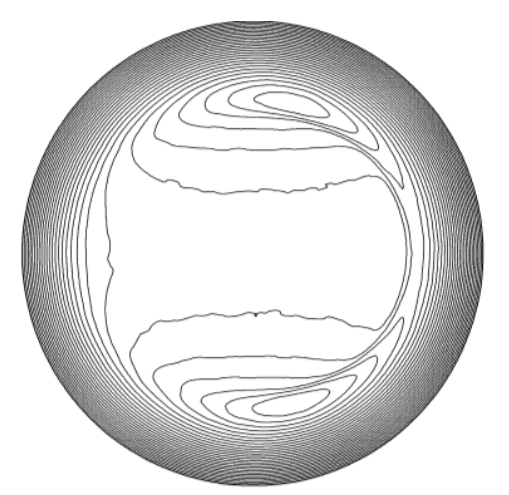

(d) Film thickness contour plot $H(X, Y)$

Figure 4.4: Pressure and film thickness distribution $(M=100, L=10)$

Figure 4.5 (a) shows the VMS in the part of the elastic volume $X>0, Y>0$ and $Z>0$. Each grain can be clearly identified. The main variations in the VMS occur quite close to the surface which indicates that material anisotropy may lead to a reduction of RCF life relative to the isotropic material case. The biggest difference is expected to occur when neighboring grains have large variation in orientation on the scale of the Hertzian contact radius. In such cases, predictions of RCF based on isotropic homogeneous material may be unrealistically optimistic. The distributions of different stresses along the centreline $(X=Y=0)$ as a function of $Z$ for the isotropic and the heterogeneous anisotropic material are shown in Fig. 4.5 (b). The largest deviations from the isotropic results appear around the location of the maximum VMS, which depends on the variation of the rotation difference and the strain in that region. For isotropic material, the maximum VMS and the largest strain occur at a depth of $Z=0.4688$ for the coupled EHL solution, whereas for the present case the depth of the maximum VMS is close to but not equal to the depth of $Z=0.4688$ (for this case, $Z=0.4453$ ). 
Note that the specific details will depend on the local grain orientation. Away from the region of the maximum stresses $(0.25<Z<1.0)$, the differences owing to the variation of the orientation decrease.

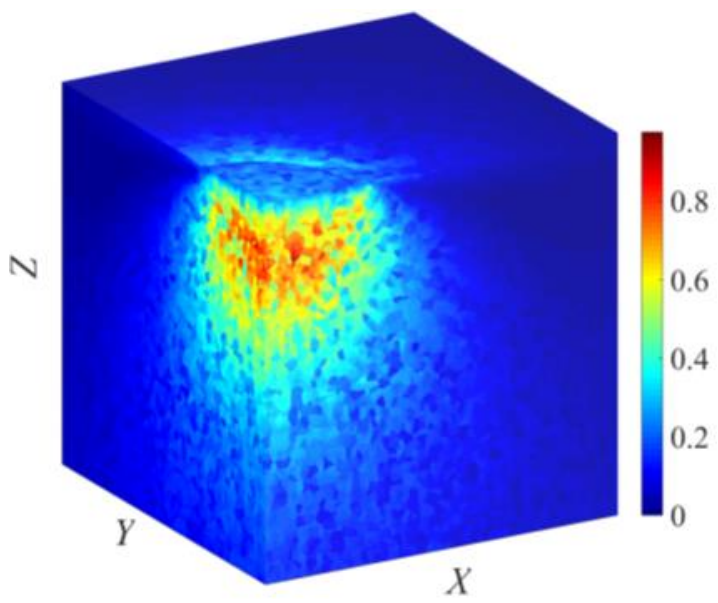

(a) 3D VMS distribution

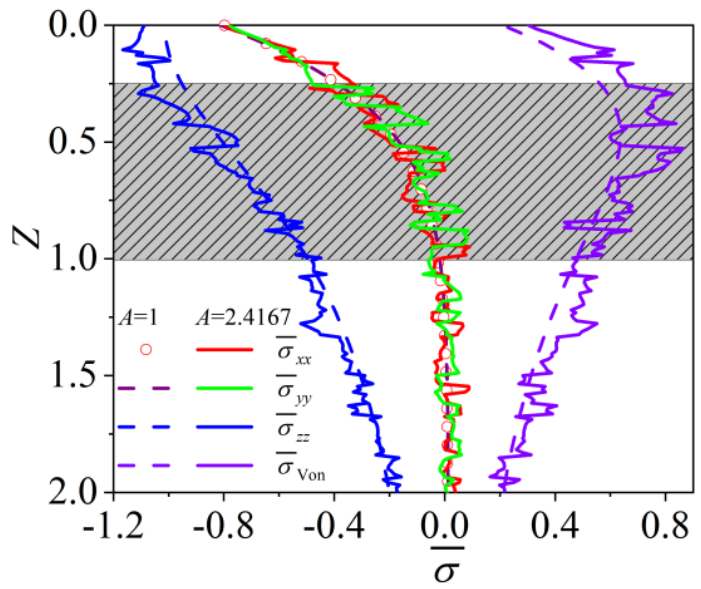

(b) Stresses distribution of the centreline $(X=Y=0)$

Figure 4.5: 3D VMS distribution and the comparison of stresses along the centreline $(M=100, L=10)$

The average effect of multiple randomly generated orientation angles and topologies is investigated with the anisotropy ratio $A$ being equal to 2.4167 . In total, 49 cases of different contact locations in rolling direction were solved. The value and location of the maximum VMS for each case are given in Fig. 4.6. The random nature in the orientation and topology is reflected in both the value and the depth of the maximum VMS, which shows significant variations from case 
to case. The overall average value of the maximum VMS is 0.9693 , which is significantly higher than the value predicted for isotropic material (0.6366). The average depth of the maximum VMS is 0.4437 , which is close to the value predicted for isotropic material (0.4688). The minimum depth is 0.375 , when the corresponding value of the maximum VMS exceeds the threshold of fatigue limit as well, these cases have higher potential to initiate cracks close to the surface. The standard deviation of the value and the depth of the maximum VMS is $2.76 \%$ and $3.32 \%$ respectively. The average of the EHL pressure distribution of the 49 cases is shown in Fig. 4.6 (c) together with the pressure distribution for isotropic material. It can be seen that the average pressure curve is smooth and quite close to the result for isotropic material. Compared to the result of dry contact (Fig. 3.7 (c)), the average pressure distribution of EHL cases is smoother.

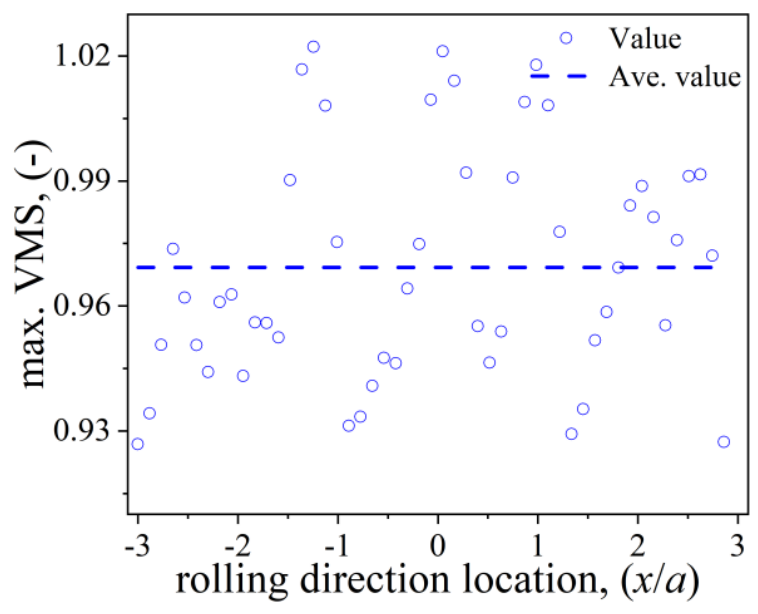

(a) Value of the maximum VMS

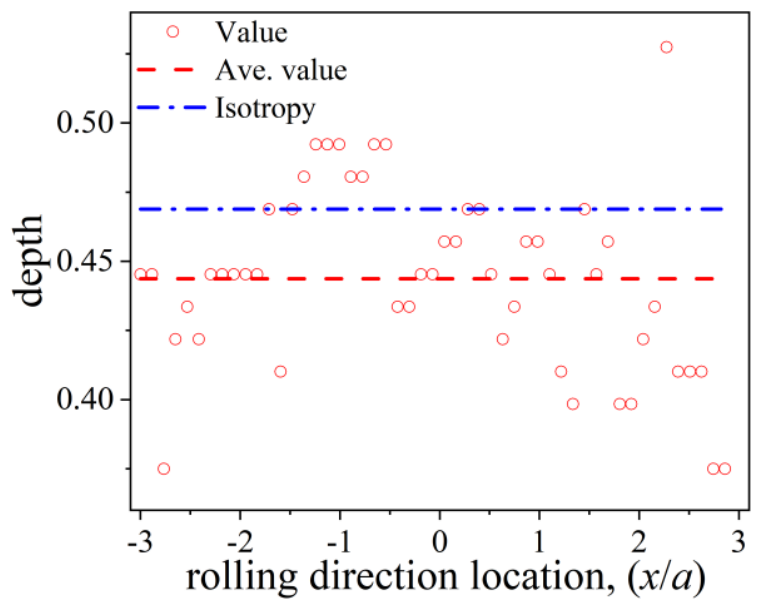

(b) Depth of the maximum VMS 


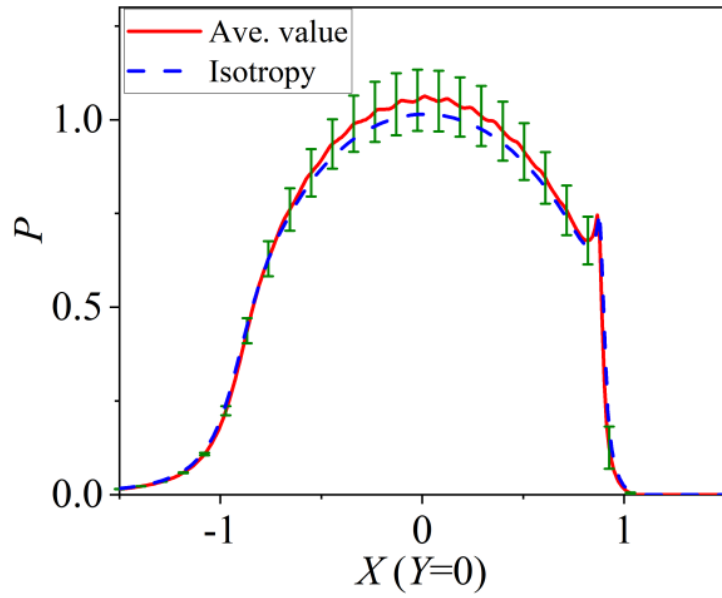

(c) Pressure comparison $(Y=0)$

Figure 4.6: The value and the depth of the maximum VMS and the averaged pressure for 49 microstructure domains

\subsection{Effect of the anisotropy ratio}

With exactly the same topology and orientation distribution, the effects of the anisotropy ratio on the pressure, the film thickness and the stress field distribution are shown. Three values of the anisotropic ratio $(A=2.4167, A=3.36$, and $A=3.77)$ are used. The results are shown in Fig. 4.7. The topology and rotation angles of grains are kept the same for the three cases. When comparing the stress distribution from Fig.4.7 (a) to Fig.4.7 (c), the local stress concentration increases in magnitude with the increase of the anisotropy ratio. The values of the maximum VMS for these three cases are 0.993, 1.086 and 1.141, respectively. However, again as in the previous cases, the effect on the EHL film thickness distribution is minor. The lubricant pressure distribution for the three cases is compared in Fig. 4.7 (d). Pressure fluctuations are caused by the variation of the rotation angles in grains and are influenced by the anisotropy ratio. The pressure peaks and valleys are marked with up- and down- arrows respectively. In the present case, the pressure profile exhibits 5 local maxima indicated in the figure with $\mathrm{p}$ (peak) and local minima indicated with $\mathrm{v}$ (valley). Tab. 4.3 compares the amplitude of each of the maxima-minima in relation to the anisotropy ratio. From the table, it is observed that with the increase of anisotropy ratio, the local pressure variation increases. 


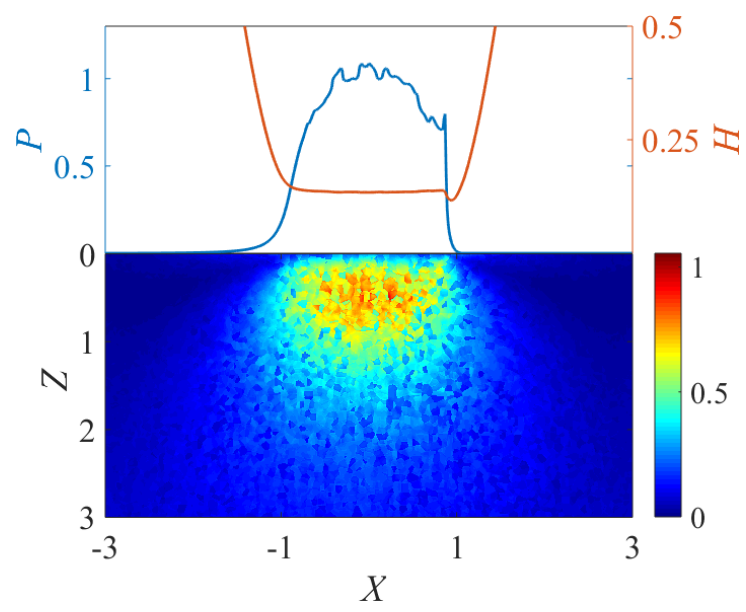

(a) $A=2.4167$

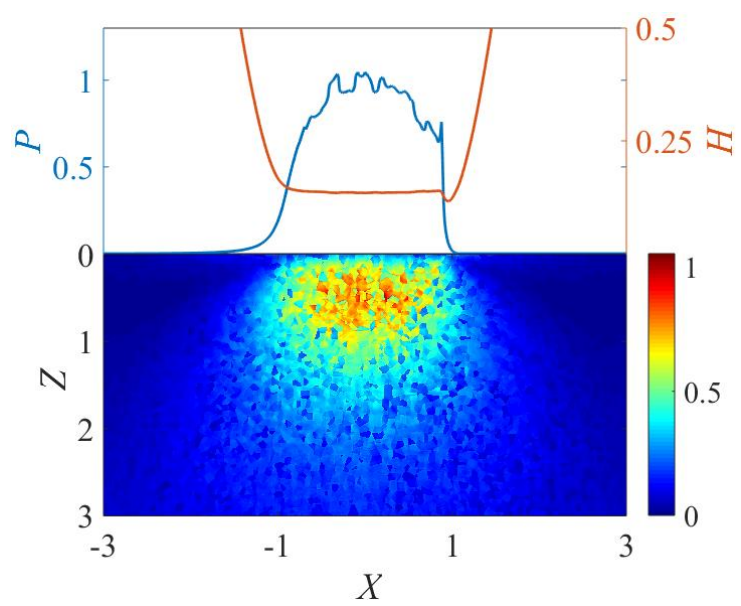

(b) $A=3.36$

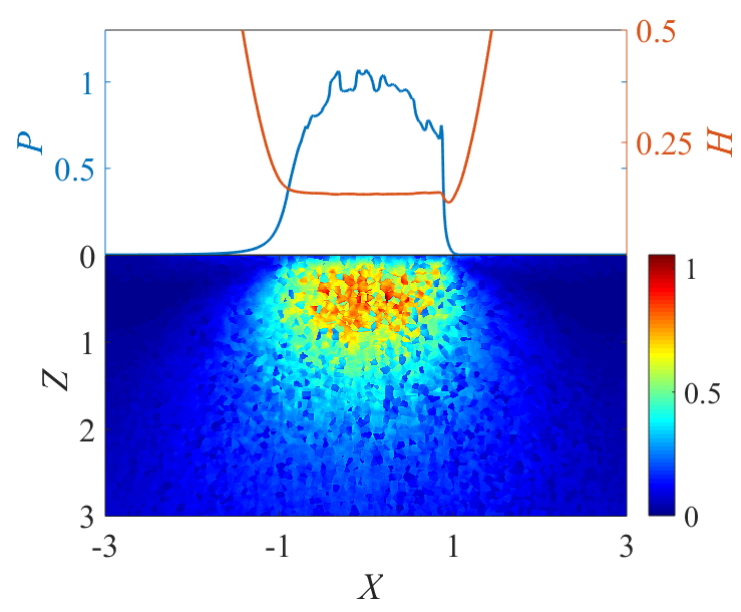

(c) $A=3.77$ 


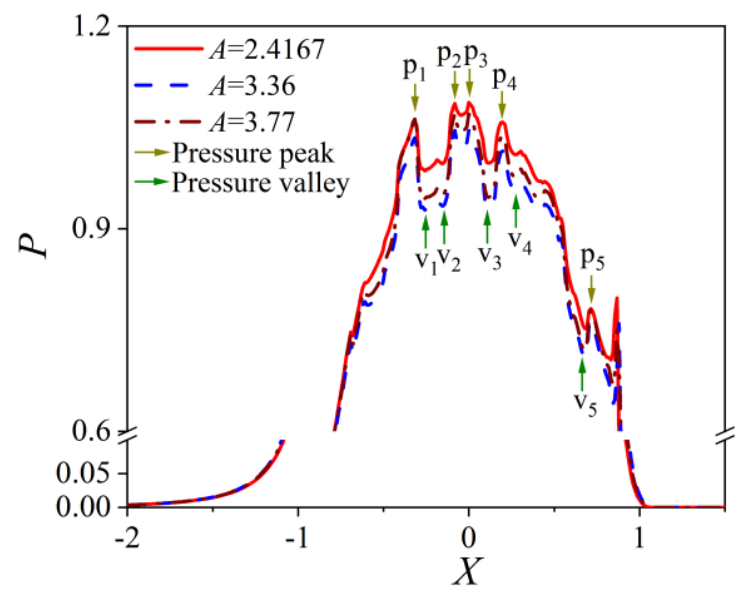

(d) Pressure comparison

Figure 4.7: Effect of the anisotropy ratio on surface pressure, film thickness profile and the VMS distribution on the $X Z$ plane $(Y=0)$

Table 4.3 Height of local EHL pressure variations (c.f. to Fig. 4.7(d))

\begin{tabular}{|c|ccc|}
\hline No. & $\boldsymbol{A = 2 . 4 1 6 7}$ & $\boldsymbol{A}=\mathbf{3 . 3 6}$ & $\boldsymbol{A}=\mathbf{3 . 7 7}$ \\
\hline 1 & 0.0744 & 0.10743 & 0.11762 \\
2 & 0.08913 & 0.11205 & 0.11982 \\
3 & 0.09009 & 0.11492 & 0.12297 \\
4 & 0.04795 & 0.05683 & 0.06037 \\
5 & 0.02974 & 0.05345 & 0.0599 \\
\hline
\end{tabular}

\subsection{Conclusion}

Multigrid techniques are shown to be very well suited for the numerical simulation of the pressure and film thickness distribution as well as the 3D stress distribution also for an EHL contact with heterogeneous anisotropic material. First, the result of the developed solver was validated using a conventional EHL solver and considering homogeneous isotropic material. Next the effects of anisotropy were considered for homogeneous material and finally the target case and ultimate goal of 3D grain structured material with variation of the crystallographic angle over the domain and from grain to grain. The presented results are the first reported EHL solutions for point contacts with full 3D grain subsurface topology which is also anisotropic. The developed method is fast efficient and accurate. It sets a new standard for EHL contact analysis and research into crystallographic structure initiated failure. The actual application 
to determine the effect on predicted rolling contact fatigue will be described in the next chapter. 


\section{5 \\ Rolling contact fatigue life analysis: material anisotropy effect}

Rolling bearings have to operate reliably and efficiently under increasingly severe conditions. Previously ignored effects of material inhomogeneity with varying crystallographic orientation may significantly affect rolling contact fatigue life. However, this problem tends to be computationally expensive. In the previous chapters, the developed multigrid algorithms have been proven to be very efficient allowing dense grids to represent heterogeneous structures in great detail. This chapter shows how the maximum VMS and a predictive fatigue life integral over the stress field vary as a function of load, friction, mean grain size and crystallographic orientation distribution. The results are compared with those of a homogeneous isotropic material. This chapter is a summarized version of the paper $\mathrm{C}$ in appendix, and it was published by Tribology International.

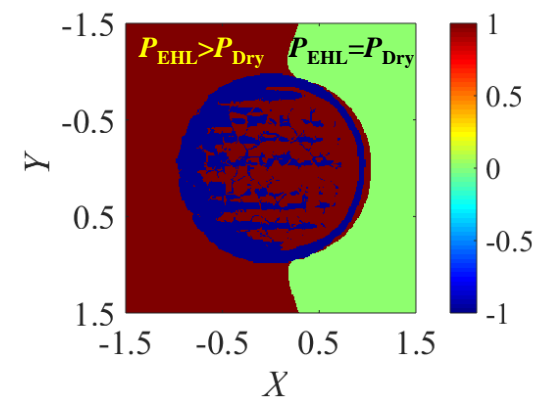

Pressure (top) and

VMS (bottom) comparison between lubricated and dry contacts for heterogeneous anisotropic material

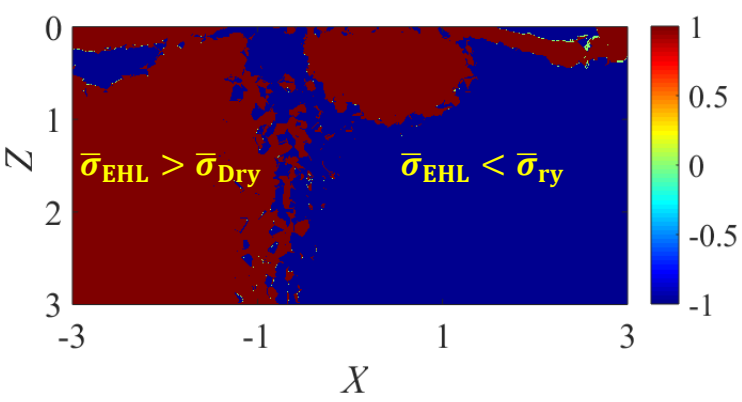




\subsection{Theory}

In chapter 3 and 4, multigrid algorithms have been developed for the solution of the displacement and stress field under dry and lubricated contacts to investigate the effect of grain topology and crystallographic orientation on the stress field and the contact pressure distribution. In this chapter, we analyse the effect of material isotropy on the fatigue life, a stress integral in the whole calculation domain is taken according to the Ioannides-Harris fatigue life equation with the fatigue limit being zero. The VMS is chosen as the stress criterion [51]. The integral measure is:

$$
\ln \frac{1}{S}=A_{\mathrm{s}} N^{e} \int \frac{\sigma^{c}}{z^{\prime h_{\mathrm{s}}}} \mathrm{d} v^{\prime}
$$

where $S$ is the probability of survival of $N$ load cycles with $e=10 / 9, c=31 / 3$, $h_{\mathrm{s}}=7 / 3$ [52]. The integral can be normalized using a reference case. This is taken as the same contact problem with a particular load for homogeneous isotropic material with the associated reference maximum Hertzian pressure:

$$
S r=\frac{A_{\mathrm{s}} N^{e} \int \frac{\sigma^{c}}{Z^{\prime h_{\mathrm{s}}}} \mathrm{d} v^{\prime}}{A_{\mathrm{S}} N^{e} \int \frac{\sigma^{c}}{Z^{\prime h_{\mathrm{s}}}} \mathrm{d} v^{\prime}} \quad \begin{aligned}
& p_{\mathrm{h}}=1 \mathrm{GPa}, \mu=0, \text { isotropic material } \\
& \text { vang } p_{\mathrm{h}}, \mu \text { or material property }
\end{aligned}
$$

The variation of $S r$ with the material parameters and topology, e.g. grain topology, crystallographic details such as variation of anisotropy orientation angle over the grains, is studied by means of numerical calculations. All equations are made dimensionless with Hertzian contact parameters:

$$
\begin{gathered}
X=\frac{x}{b}, Y=\frac{y}{b}, Z=\frac{z}{b}, U=\frac{u}{b}, V=\frac{v}{b}, W=\frac{w}{b}, \\
P=\frac{p}{p_{\mathrm{h}}}, \bar{\sigma}_{i j}=\frac{\sigma_{i j}}{p_{\mathrm{h}}}, \bar{C}_{i j k l}=\frac{C_{i j k l}}{p_{\mathrm{h}}}, H=\frac{h}{b}
\end{gathered}
$$

where $b=\sqrt[3]{\frac{3 F R\left(1-v^{2}\right)}{4 E}}, p_{\mathrm{h}}=\frac{3 F}{2 \pi a^{2}}$ are the Hertzian contact radius and the maximum contact pressure for the reference condition of a load which gives a maximum Hertzian pressure of $1 \mathrm{GPa}$ for homogeneous isotropic material. For contact and material (isotropic) parameters, see Table 5.1. When not specified, the following conditions are used: (1) average grain diameter is $15 \mu \mathrm{m}$ for polycrystalline anisotropic material; (2) anisotropic material with anisotropic 
ratio $A\left(2 c_{44} /\left(c_{11}-c_{12}\right)\right)=2.4167$ [31]; (3) the load for homogeneous isotropic material gives the maximum Hertzian contact pressure $p_{\mathrm{h}}=1 \mathrm{GPa}$ (except for the section 5.3).

Table 5.1 Contact and material parameters

\begin{tabular}{cc}
\hline Parameter & Value \\
\hline$F$ & $40.34 \mathrm{~N}$ \\
$R$ & $0.02 \mathrm{~m}$ \\
$p_{\mathrm{h}}$ & $1.0 \mathrm{GPa}$ \\
$E$ & $206 \mathrm{GPa}$ \\
$\alpha, \beta, \gamma$ & $0 \sim \pi / 2$ \\
$X, Y$ & $-3 \sim 3$ \\
$Z$ & $0 \sim 6$ \\
$v$ & 0.3 \\
\hline
\end{tabular}

\subsection{Comparison of dry contact and lubricated contact}

First for the same 3D material topology, the stress field under dry contact and under lubricated contact are compared for the reference load condition. The additional parameters for the lubricated point contact are an entrainment velocity $u_{\mathrm{m}}=0.5 \mathrm{~m} / \mathrm{s}, \eta_{0}=0.08 \mathrm{~Pa} \cdot \mathrm{s}, \alpha_{\text {oil }}=22 \mathrm{GPa}^{-1}$. In terms of the Moes dimensionless load and material parameters for point contacts $M=211.7, L=9.51$. The Dowson-Higginson density-pressure equation [50] and the Roelands viscosity-pressure equation [49] are used as equations of state for the density and viscosity as a function of pressure.

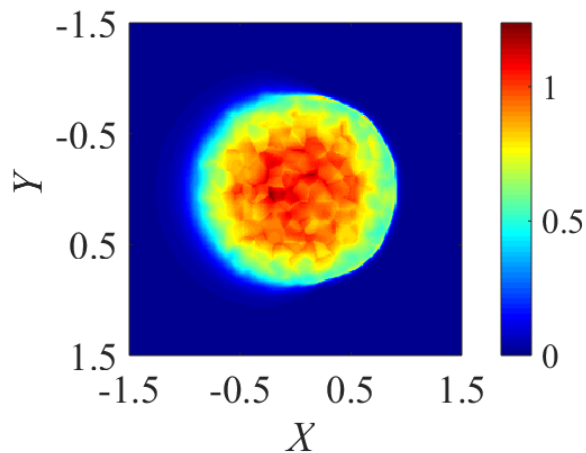

(a) EHL pressure

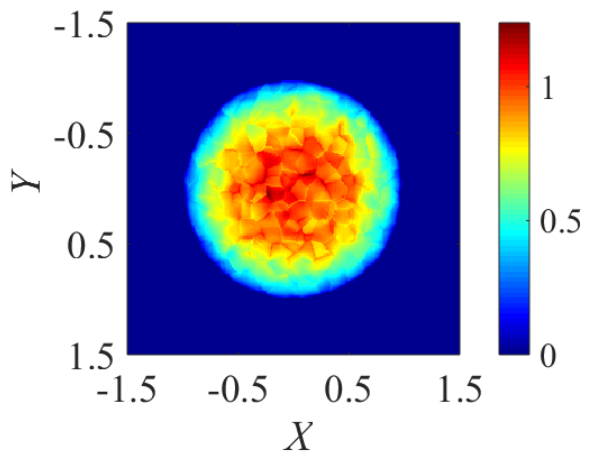

(b) Dry contact pressure 


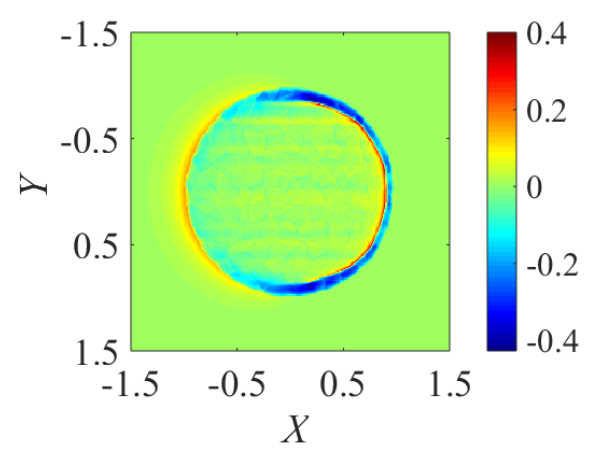

(c) $P_{\text {EHL }}-P_{\text {Dry }}$

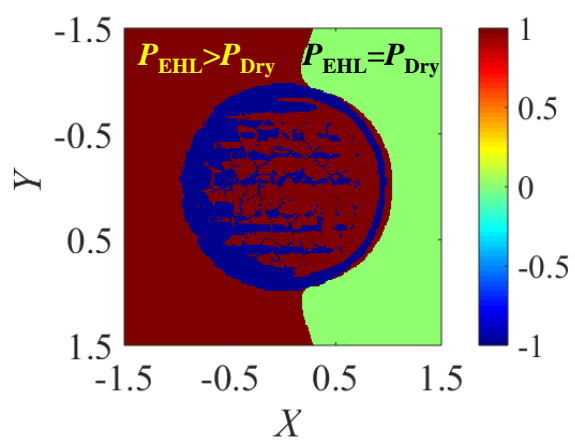

(d) Sign distribution of $P_{\text {EHL }}-P_{\text {Dry }}$

Figure 5.1: Pressure comparison between (a) lubricated and (b) dry contacts for heterogeneous anisotropic material

Figure 5.1 shows the pressure distribution at the top surface under lubricated (Fig. 5.1(a)) and dry contact (Fig. 5.1(b)) conditions. Relative to the well-known smooth (near) Hertzian semi-elliptic pressure distribution for homogeneous isotropic material, pressure fluctuations are clearly observed. These result from the effect of the heterogeneous anisotropic crystallography of the material, see also Ref. [20]. For the dry contact condition, the grain boundaries are much clearer, which means the variation of pressure between grain boundaries is less smooth compared to the lubricated case in Fig. 5.1 (a). Figure 5.1 (c) shows the difference between the (dimensionless) EHL pressure and the (dimensionless) dry contact pressure. The differences are localized around the edge of the Hertzian contact region and inside the contact region near the grain boundaries. Figure 5.1 (d) further emphasizes the pressure difference by the sign function:

$$
P_{\mathrm{EHL}}-P_{\text {Dry }}= \begin{cases}1.0 & P_{\mathrm{EHL}}>P_{\text {Dry }} \\ 0 & P_{\mathrm{EHL}}=P_{\text {Dry }} \\ -1.0 & P_{\mathrm{EHL}}<P_{\text {Dry }}\end{cases}
$$

The overall view is that in the entire inlet region the EHL pressure exceeds the dry contact pressure whereas in the outlet region it is lower. Inside the contact, the EHL pressure can either be smaller or larger. This is in line with the fact that both solutions have to satisfy the same overall load condition. Generally, the transition points do not exactly coincide with the grain boundary as in the dry contact case, as the grain boundaries cannot be clearly observed in Fig. 5.1 (d). 
For both cases, the VMS has been computed in the 3D volume below the surface. Figure 5.2 shows the result in the central plane $Y=0$.

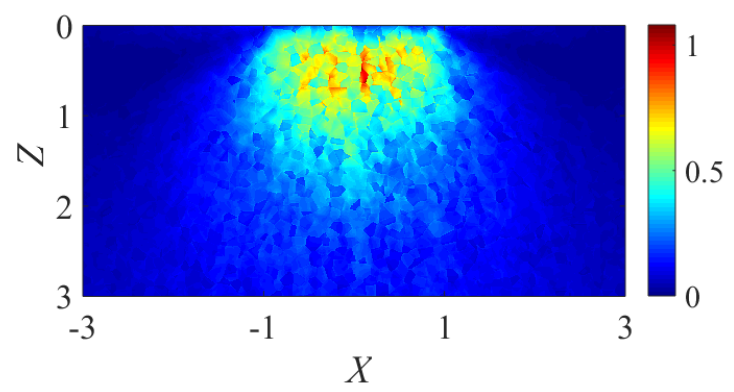

(a) Stress field of lubricated condition

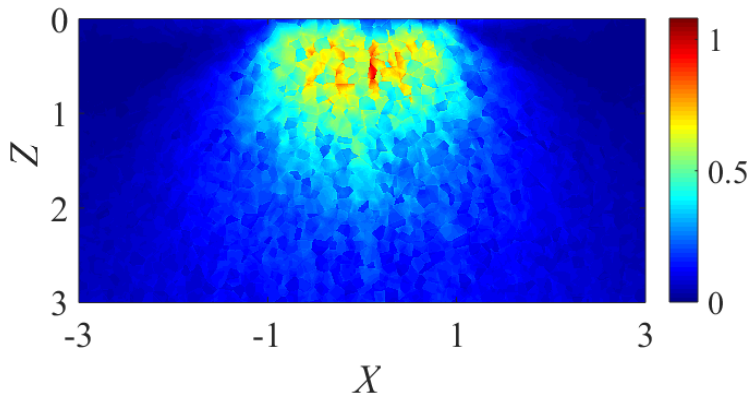

(b) Stress field of dry contact

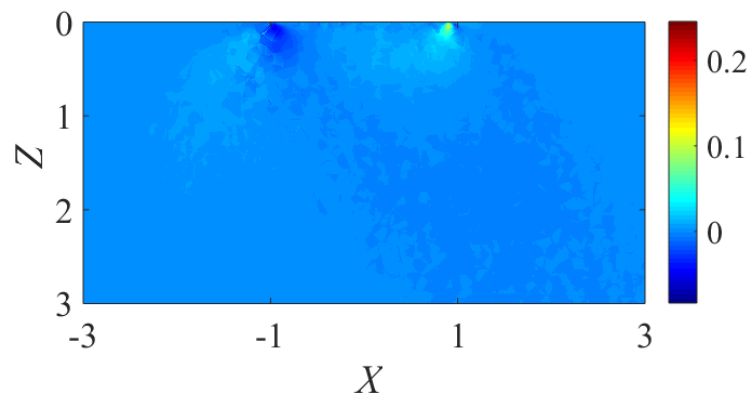

(c) $\bar{\sigma}_{\mathrm{EHL}}-\bar{\sigma}_{\text {Dry }}$

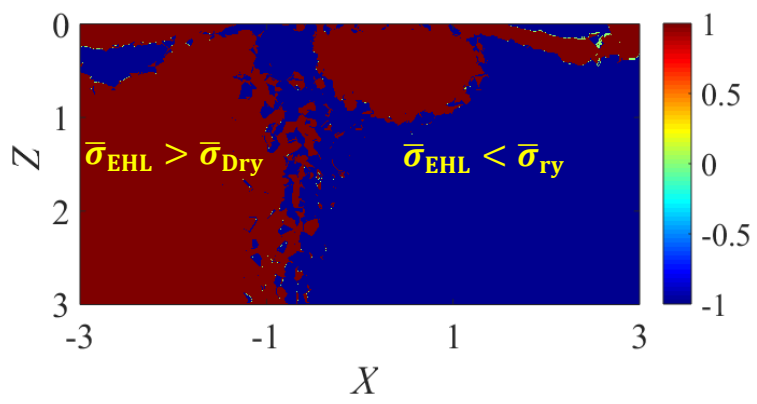

(d) Sign distribution of $\bar{\sigma}_{\mathrm{EHL}}-\bar{\sigma}_{\text {Dry }}$

Figure 5.2: VMS of $X Z$ plane comparison between dry contact and lubricated conditions for heterogeneous anisotropic material $(Y=0)$ 
The VMS stress fields (Fig. 5.2 (a) and (b)) for the lubricated and dry contact are almost identical. Figure 5.2 (c) and (d) aim to emphasize the differences. As can be seen in Fig. 5.2 (c), these differences are concentrated near the edge of the contact region close to the surface. This is in accordance with the pressure differences, see Fig. 5.1(c). In Fig. 5.2 (d), the sign of the difference between the stress fields is shown using Eq. (5.4) by replacing $P$ by $\bar{\sigma}$. In the inlet region and in the contact region near the top surface, the VMS of the lubricated case is in general larger than that of the dry contact.

The relative stress integral values according to Eq. (5.2) for the lubricated and the dry contact are 3.918 and 3.556 respectively for the studied cases. As this is the reference load case, the value for the dry contact with isotropic material is unity so the heterogeneity and anisotropy at the grain size/scale significantly reduces the predicted fatigue life. The relative stress integral value for the lubricated condition is about $10 \%$ larger than the value for the dry contact condition. The major differences originate from the regions near the outlet pressure spike(s) where also the largest difference between the dry and lubricated pressure profile is observed Based on these results and taking also into account current industry trends involving increasingly severe operating conditions, such as higher load, higher degree of starvation, higher temperature, lubricant films tend to be thinner and pressures higher and closer to that of dry contact, then it is justified to perform the following analyses assuming dry contact conditions.

\subsection{Effect of contact load}

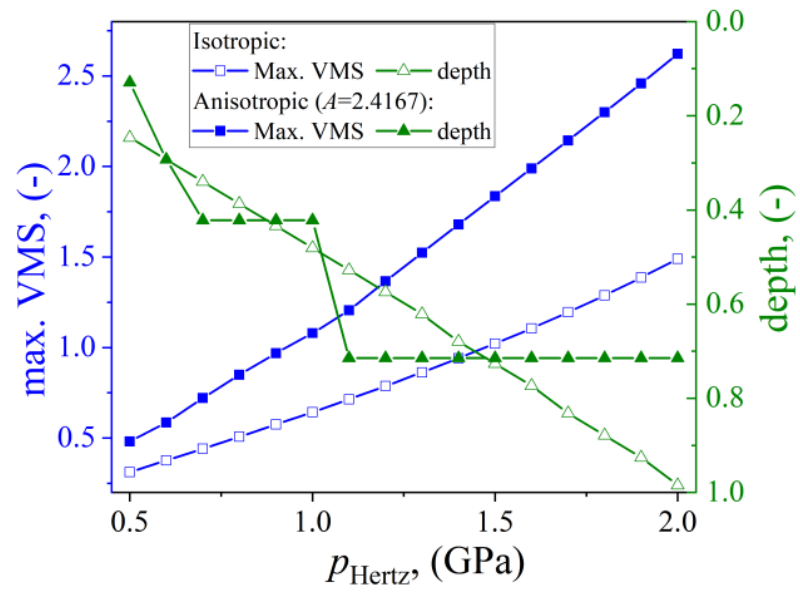

(a) Maximum VMS value and its depth 


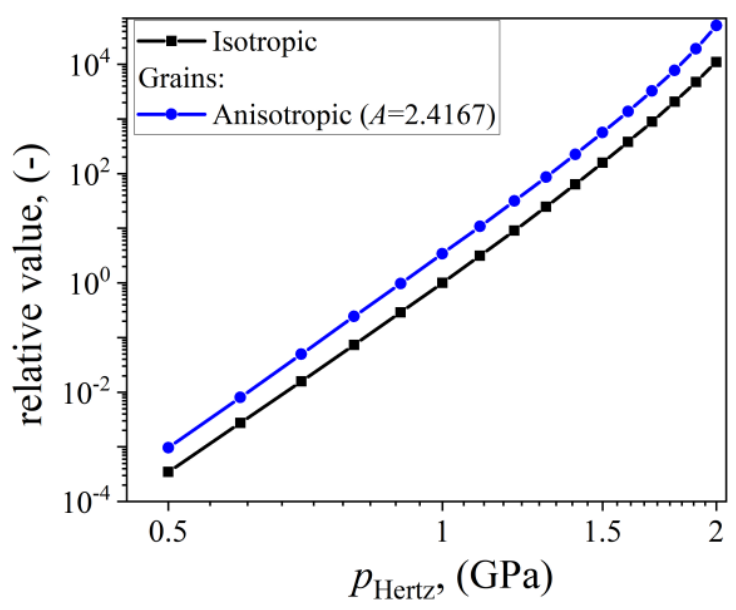

(b) Relative stress integral value

Figure 5.3: Effect of contact pressure on the maximum VMS and the relative stress integral $\mathrm{Sr}$ for heterogeneous anisotropic and isotropic material

Figure 5.3 (a) shows the influence of the contact load on the maximum VMS and the depth at which it occurs. Figure 5.3 (b) shows the relative fatigue life integral value with the variation of contact load. The results for the homogeneous isotropic case match the theoretical values where the maximum VMS is $0.62 p_{\mathrm{h}}$ at a dimensionless depth $0.47 b$, where $p_{\mathrm{h}}$ and $b$ are the actual values of the Hertzian contact pressure and radius. As in the present case the results are scaled on the $1 \mathrm{GPa}$ Hertzian pressure case, one should see a linear increase of the maximum VMS value with slope 0.62 and a linear dependence of the depth at which it occurs with slope 0.47 for the homogeneous isotropic case. However, with the increase of load, the contact radius becomes larger and the side boundaries affect the stress field and thereby the stress integral value. As a result, the linear variation of the maximum VMS and its depth is affected. In Fig. 5.3 (a) it can also be seen that with increasing load, the deviation of the maximum VMS from the value for the homogeneous isotropic case increases. The change of its depth with load is a stepwise function owing to the fact that with increasing load, the stressed region increases involving deeper laying grains. When a deeper grain whose strain and corresponding global stiffness can generate a larger stress is involved, this will become the location of the maximum VMS. With the increase of load, the relative integral value increases almost linearly on a log-log scale, see Fig. 5.3 (b). For the grain structured material, the slope (on the log-log scale) is identical to the slope for the isotropic homogeneous material. However, due to the local stress concentrations around grain boundaries, the value of the 
relative stress integral is larger. The ratio varies between 2.76 and 4.65. Interpreting the observed results in terms of rolling contact design, it is obvious that crystallographic structure and orientation may considerably affect fatigue life calculations of rolling bearings and thus should be studied and understood in detail.

\subsection{Effect of shear stress}

Figure 5.4 shows the effect of the shear stress due to friction on the VMS field for the case of the heterogeneous grain structured material with stochastically distributed crystallographic orientation as considered above. The figure shows the difference between the VMS field with and without friction in the central $X Z$ and the central $Y Z$ plane for the same case of heterogeneous anisotropic material. In Fig. 5.4 (a) and (b), the difference in the VMS field for the frictionless case and for $\mu=0.1$ is shown. It can be seen that the main change is a strong asymmetry in the $X Z$ plane due to the friction with the maximum VMS moving closer to the surface on the inlet side. This trend adversely affects the RCF. Near surface stress concentrations of sufficient magnitude may induce surface cracks and pits close to the contact surface referred to as surface initiated RCF [53].

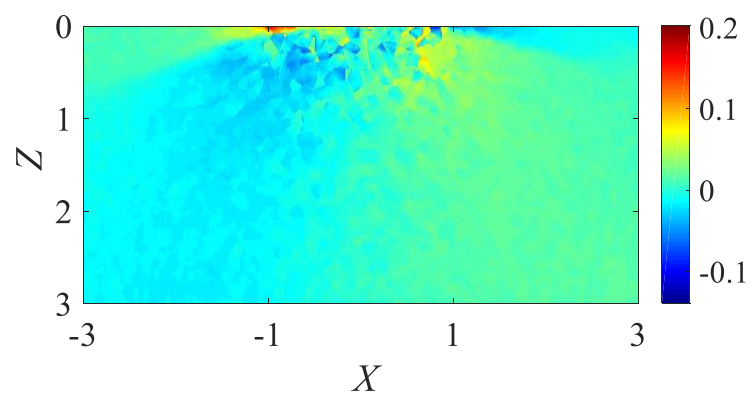

(a) $X Z$ plane of $\bar{\sigma}_{\mathrm{VMS}}(\mu=$ $0.1)-\bar{\sigma}_{\mathrm{VMS}}(\mu=0)$

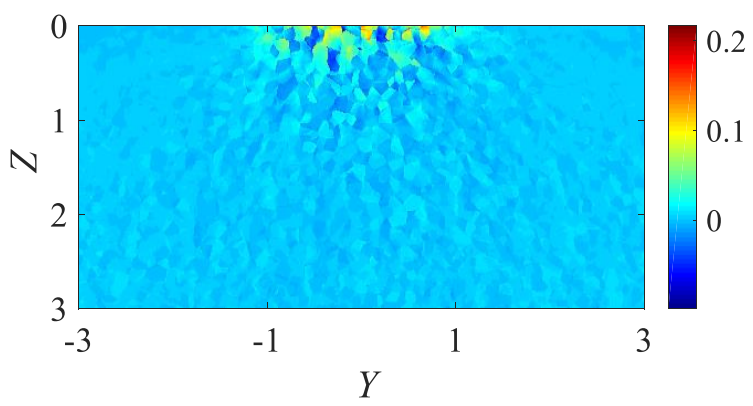

(b) $Y Z$ plane of $\bar{\sigma}_{\mathrm{VMS}}(\mu=$ $0.1)-\bar{\sigma}_{\mathrm{VMS}}(\mu=0)$

Figure 5.4: Effect of shear stress on the stress field of heterogeneous anisotropic material 

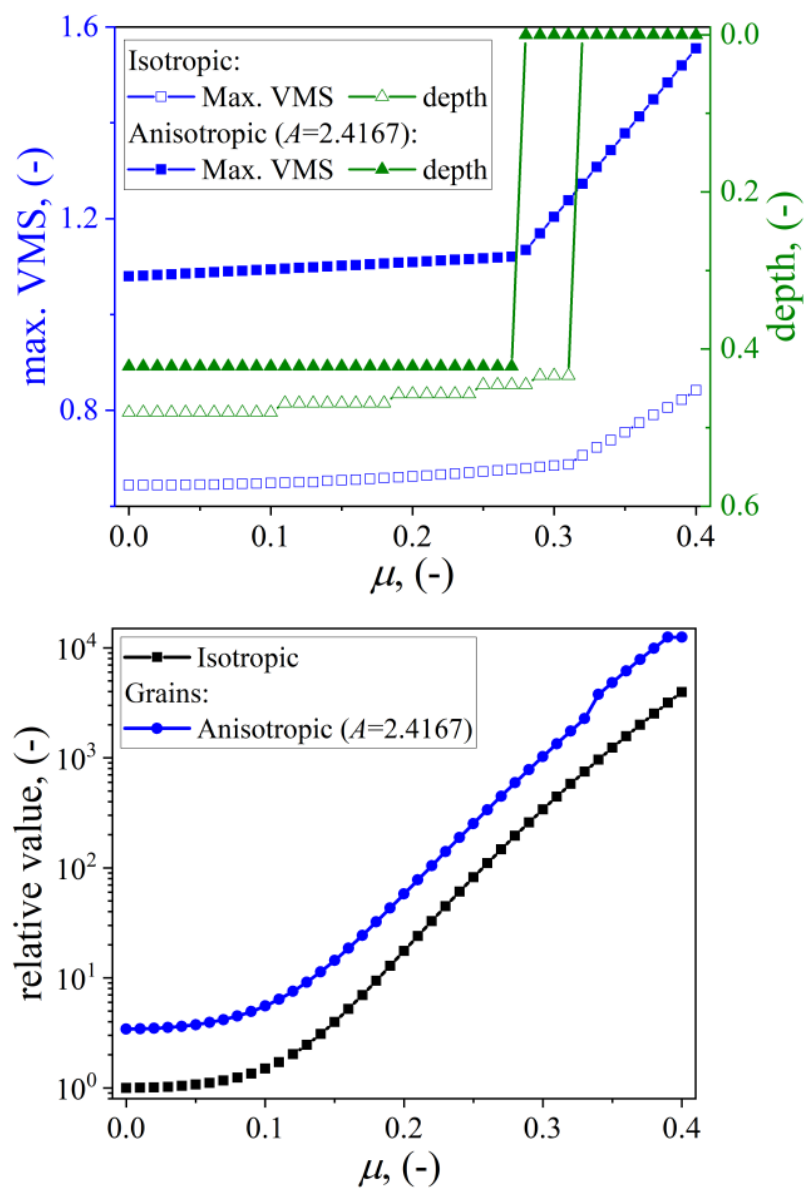

(a) Maximum VMS value and its depth (b) Relative stress integral value

Figure 5.5: Effect of shear stress on the maximum VMS and relative stress integral $\mathrm{Sr}$ of heterogeneous anisotropic and isotropic material

The variation of the maximum VMS and the depth at which it occurs with the coefficient of friction is shown in Fig. 5.5 (a). The value of $S r$ is shown in Fig. 5.5 (b). For homogeneous isotropic material the depth of the maximum VMS depends on the normal load (stress) and the coefficient of friction. For the grain topology with varying orientation, the variation of the crystallographic orientation affects the grain stiffness and thereby the location of the maximum VMS. The overall trend of the dependence on the coefficient of friction is the same for both cases: the larger shear stress increases the value of the maximum VMS and moves its location from the inner material to the contact surface. The difference between the two cases is in the small shear stress region. As for the heterogeneous anisotropic material, the location is unaffected until at a 
sufficiently high coefficient of friction to change it to the contact surface. The reason is that although the combined influence of normal stress and shear stress is the strongest, the variation of the stiffness from grain to grain (in the global coordinate system) still does not lead to a different overall maximum VMS value. Once occurring at the surface, the value of the maximum VMS strongly increases with friction. The ratio of the maximum VMS value between the two case is 1.66 1.85 (on average 1.71 \pm 0.065 ). In Fig. 5.5 (b) the effect of the coefficient of friction on the stress integral value is shown. Similar to the effect of load, the stress integral value for the case of grain topology case with varying crystallographic orientation is larger than that of homogeneous isotropic material. The ratio between the two cases is 3.02 3.95 (on average 3.44 \pm 0.309 ).

\subsection{Effect of mean grain size}

The material properties such as strength, stiffness, hardness, as well as the morphology of generated cracks in RCF are closely related to the crystallographic topology. For different values of the mean grain size in the Voronoi tessellation, two hundred microstructures were generated with randomly varying distribution of the orientation over the grains. For each case, the contact problem was solved and the stress field evaluated.

In Fig. 5.6 (a), the variation of the contact area relative to the value for homogeneous isotropic material (Eq. (5.5)) is shown with the variation of the mean grain size. The spread of the value in the batch of two hundred generated cases for each grain size is also indicated. With the decrease of grain size, the variation of the relative contact area in the batch decreases. From about $30 \mu \mathrm{m}$ downwards, the decreasing average grain size seems to reduce the contact area a little which means that the apparent stiffness of the base material increases and agrees with the Hall-Petch's Law [55].

$$
=\frac{\sum \sum P(>0),(\text { varying grain size and crystallographic topology })}{\sum \sum P(>0),\left(p_{\mathrm{h} \_ \text {reference }}, \mu=0, \text { isotropic material }\right)}
$$

In Fig. 5.6 (b), it can be seen that the value of the relative fatigue life value decreases with finer mean grain size from $30 \mu \mathrm{m}$. Also, the spread among the two hundred randomly generated cases reduces. This seems to align with the experimental findings [54] showing that a fine grain size is beneficial to fatigue 
life and its dispersion would be smaller. The larger fatigue life calculated with finer grains can be explained as follows: The decrease of grain size introduces more grain boundaries and makes the stress field more continuous. The incidence of local stress concentration can be lowered. As a result, the integral value of stress field decreases (Fig. 5.6 (b)) and the survival probability increases.

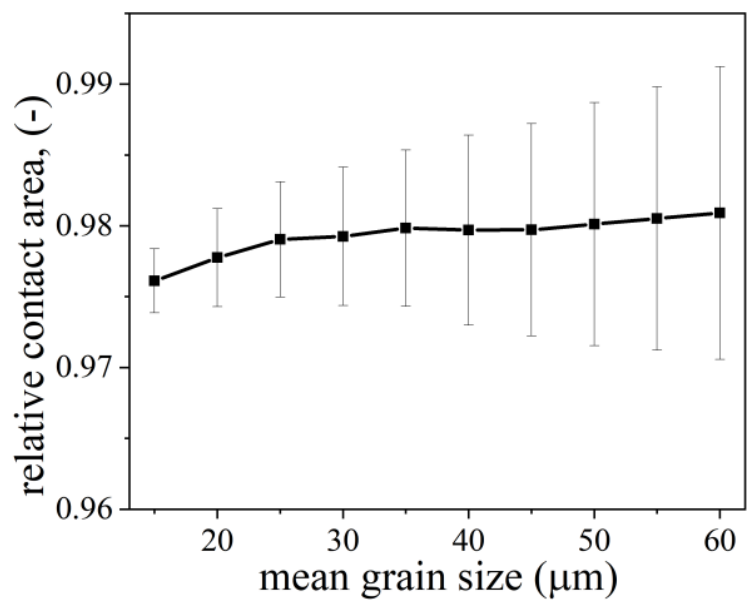

(a) Relative contact area

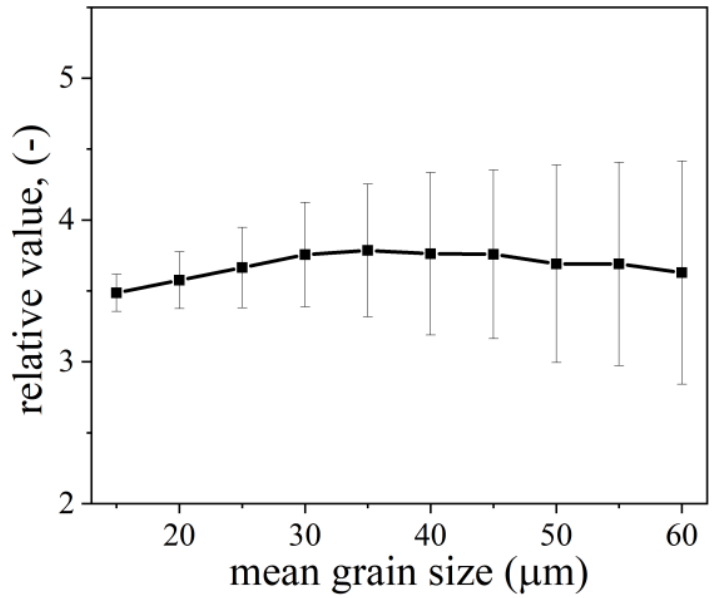

(b) Relative stress integral value

Figure 5.6: Effect of grain size on the relative contact area and stress integral $\mathrm{Sr}$ for heterogeneous anisotropic material

Figure 5.7 gives the influence of mean grain size on the maximum VMS and the depth at which it occurs. For the studied case, the deviation of depth in Fig. 5.7 (b) is larger compared to the maximum VMS value in Fig. 5.7 (a). The tendency found in Fig. 5.6 does not apply to the variation of the maximum VMS. It can be explained as follows: compared to isotropic and homogeneous anisotropic 
material, the value and location of the maximum VMS for heterogeneous anisotropic material depends both on the microstructure and on the rotation angles. Even with the same microstructure, the stress field can be different when the rotation angles are different. This implies that the fatigue life integrals only based on a local maximum stress as the fatigue criterium may not be accurate when the effect of grains with varying crystallographic orientation needs to be predicted.

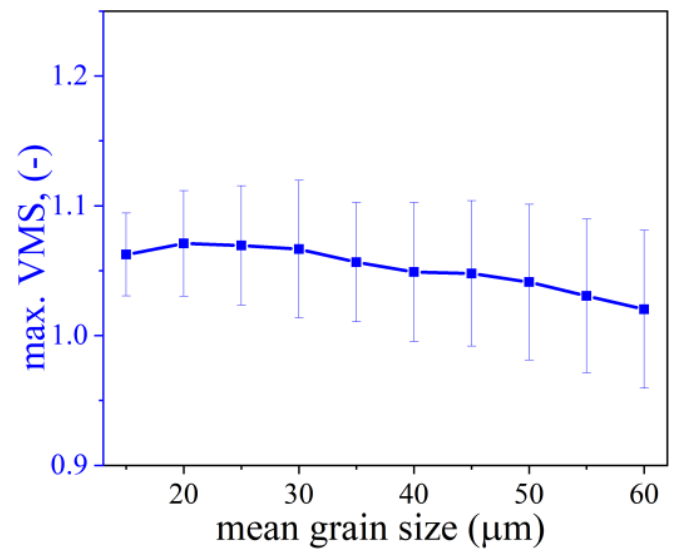

(a) Value of the maximum VMS

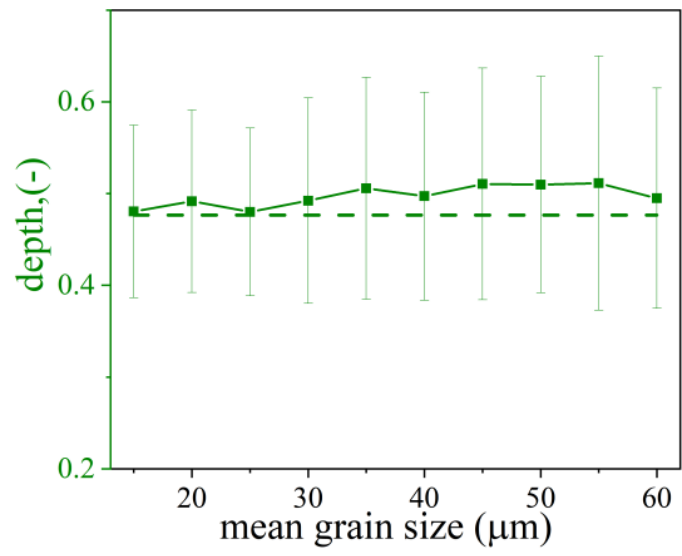

(b) Depth of the maximum VMS

Figure 5.7: Effect of average grain size on the VMS for heterogeneous anisotropic material

\subsection{Effect of rotation angle}

For the results shown before, the range of variation of the rotation angles $\alpha, \beta, \gamma$ is taken from 0 to $\pi / 2$. In this part, the effect of restricting this range is investigated. It should be pointed out that the rotation angle is uniformly 
distributed at each rotation range. Fig. 5.8 shows the influence of the rotation range on the relative contact area and the relative stress integral value. For each case, twenty randomly generated microstructures are employed to check the influence of range of rotation angles. With the increase of range, the relative contact area decreases at first and then increases. It means the stiffness of the 3D body increases at first and then decreases. For the relative stress integral value, its trend is inverse. This implies that the fatigue life of bearing material can be optimized by control of the crystallography variations. At around $0.7 \times \pi / 2$, the relative contact area and stress integral value reach the minimum and maximum value respectively. Different to the effect of the mean grain size shown in section 5.5, the stiffness and stress integral value show an opposite trend with the variation of range of rotation angle.

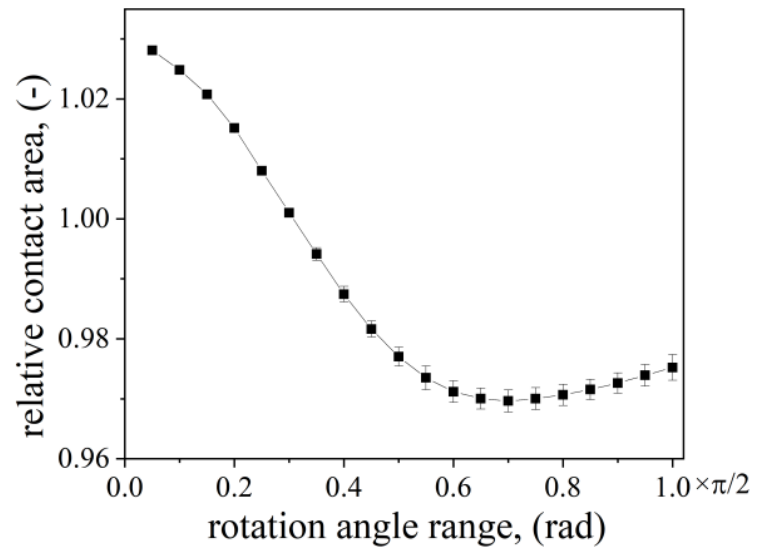

(a) Relative contact area

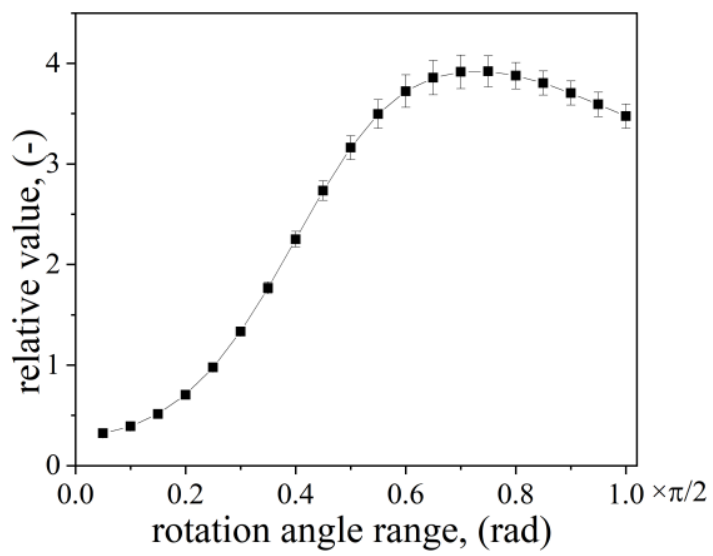

(b) Relative stress integral value

Figure 5.8: Effect of rotation angle range on the relative contact area and the stress integral $\mathrm{Sr}$ for heterogeneous anisotropic material 


\subsection{Conclusion}

In this paper, a multigrid method developed for the numerical simulation of dry and lubricated contacts for the case of 3D elastic heterogeneous material with varying crystallographic orientation was used to analyse the effects of various parameters on the predicted fatigue life using an Ioannides-Harris model-based analysis. The effect of contact load (pressure), friction coefficient, mean grain size and effects of distribution of rotation angles on the stress field and the fatigue life stress integral value were investigated. The results show that the developed method has excellent prospect to help assess criticality of heterogeneous material topology and crystallographic orientation variations down to a grain size that is about 10 times smaller than the Hertzian contact radius. The developed method can be a very useful tool to aid microstructural criticality assessment, to perform computational diagnostics, and to help optimize EHL contact and bearing performance. 


\section{Conclusions and recommendations}

In view of trends in bearing applications towards increasingly severe operating conditions, the effect of grain topology and variation in crystallographic orientation on the rolling contact fatigue life of the material becomes more important. To generate predictive and diagnostic knowledge and to evaluate criticality of particular crystallographic structures, efficient computational methods which allow a dense discretization grid are essential. In this thesis, multigrid based algorithms have been developed for the stress field and fatigue life analysis of anisotropic heterogeneous material. It has been shown that the solvers are efficient and allow the dense grids needed to represent grain structured material topology with varying crystallographic orientations.

Firstly, multigrid algorithms were developed for 2D line and 3D point dry contacts. The effect of inhomogeneous material is studied in the $2 \mathrm{D}$ problem. The existence of inclusions and coating not only affects the stress field but also changes the distribution of the contact pressure. In order to avoid stress concentrations, the number of inhomogeneous grains should be reduced and the thickness and elastic modulus of a coating layer could be optimized. The 3D point contact problem considering the local grain elasticity proves the efficiency of the developed multigrid algorithm. This is a case where the efficiency of multigrid method is really needed. Using the developed multigrid method, the stress field with many millions of unknowns can be obtained efficiently. Different from isotropic material, rotation angles change the stiffness of grains and then affects the stress fields. Compared to isotropic material, stress concentrations appear around grain boundaries and this results in a larger VMS. The randomness of grain shapes and rotation angles causes a scattered distribution of the VMS in both value and depth, which is in line with the experimentally observed life dispersion of rolling bearings.

The 3D multigrid algorithm is extended to Elasto-Hydrodynamically lubricated contacts. This is the first report of full 3D grain structure with varying crystallographic orientations in EHL. The variation of grain stiffness results in pressure fluctuations which are not observed in the classical EHL studies 
assuming homogeneous isotropic material. However, the influence of crystallographic microstructure on the film thickness distribution under the considered steady state conditions is very small. The location and value of the maximum VMS depends on material topology and anisotropy which is similar to the dry contact results. The average EHL pressure of anisotropic material is close to the pressure predicted by homogenous isotropic material and it is smoother compared to the result of dry contact. With an increase in anisotropy ratio, the value of the maximum VMS and the height of local EHL pressure variation increases.

Finally, the developed 3D multigrid algorithms were applied for rolling contact fatigue life analysis. The difference between dry and lubricated pressures does not affect the stress integral value too much with the used I-H fatigue life model. By studying the effect of contact pressure, shear stress, grain size and rotation angle, it can be concluded that the fatigue life predicted with polycrystalline anisotropic material is smaller than that of homogenous isotropic material. By refining the grain size and control the rotation angles, the fatigue life can be improved.

In this work, a major step is made towards the objective of optimizing the 3D topology and structural heterogeneity of materials for the maximum life in contact mechanics and lubrication. The present work can be extended in several ways. Some of the possible future research directions are given below.

In this thesis, the grain topology is generated by Voronoi tessellation, and rotation angles of grains are randomly distributed. The application of electron back scatter diffraction (EBSD) technique for the material analysis makes the acquisition of grain orientations and shapes possible which would allow researchers to use actual bearing material data for analysis and predict fatigue life more accurately.

The fatigue life of rolling bearings is affected by many factors such as grain topology, rotation angles and top boundary condition. Localized grain optimizations based on the developed algorithms may pave the way to obtain optimum performances of bearing material which can meet the increasingly severe working conditions and higher reliability requirements of rolling bearings.

In the coupled EHL study in chapter 5, pure rolling with Newtonian fluid model is used. However, rolling and small sliding co-exist in rolling bearings. This not only introduces shear stress on the top contact boundary but also affects lubricant 
property. Non-Newtonian fluid models with different slide to roll ratio can be considered for the coupled EHL modeling of anisotropic material.

The current available probabilistic engineering models do not consider the influence of material anisotropy. By summarizing the results in chapter 6 , a penalty parameter depending on anisotropy ratio and rotation angles can be proposed for these models to take the material anisotropy into account. 



\section{Acknowledgements}

This research project was supported by the China Scholarship Council (CSC) and by SKF Research and Technology Development (RTD) in Houten, the Netherlands. I would like to thank the former and the present managing director of SKF RTD Mr. Stefan Lammens and Mr. Bernie van Leeuwen for their permission to publish the results and their support of the long-term collaboration with the University of Twente of which this research has been a part. I would also like to thank Mr. Mark Verbakel (Head of Tribology \& Prognostics Department) and Mr. Jeroen Bongaerts (Competence Team Leader tribology \& life) for their support, their kind hospitality, and for embedding my project in the portfolio of their department and team to maximize the potential use of my results in the future for actual applications. Thank Duncan Dowson award from Journal Lubricants for offering travel supports for attending the 46th Leeds-Lyon Symposium on Tribology.

I would like to express my enormous gratitude to my supervisor Kees Venner for his continuous guidance, support and patience throughout my entire $\mathrm{PhD}$ study. Your supervision and encouragement helped me to avoid potential trouble and arrive at the destination of this project gradually. You are a mentor in scientific research and a friend in life which has affected me a lot in the past four years.

Furthermore, I would like to thank Hugo Boffy from SKF Germany, Armando Félix Quiñonez and Guillermo Morales-Espejel from SKF RTD the Netherlands for their supports and their constructive advice. Thanks also to Boris Minov from SKF RTD for providing the EBSD images and data analysis suggestions.

Many thanks to my committee members: Prof. A. A. Lubrecht of the LaMCoS department of Insa Lyon, Prof. Gerhard Poll of the IMKT of Leibniz Universität Hannover, Prof. Ton van den Boogaard of the group Nonlinear Solid Mechanics of the faculty of ET of University of Twente, Prof. Luding of the group Multiscale Mechanics of the faculty of ET of University of Twente. Thank you all for your time and effort. 
Many thanks also to the staff of EFD and TFE at the University of Twente for providing a good working atmosphere: in particular, thanks to Walter Lette and Wouter Den Breeijen for their help with computer and cluster related issues, and thanks to the group secretaries Susan, Brenda, Sylvia and Sally for their kind help in many aspects.

I would like to thank my girlfriend Min Lin, my family members (张文芳，明 玉叶，张真真，张丽丽) and my friends (in particular, Haichao Liu, Yan Zhao). Their support has given me the confidence to bravely face difficulties in study and in life.

Finally, I would like to thank all people who have contributed to this work, your support has helped me get through difficulties and complete this thesis.

Binbin Zhang

张涁涁

August 2020 


\section{Biography}

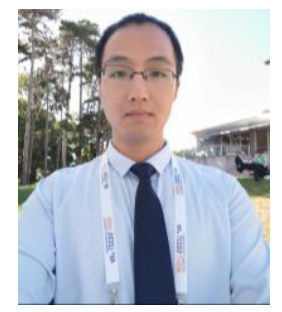

Binbin Zhang was born on 29 November 1988 in ShanDong Province, China. He obtained his BSc degree (2019) and MSc degree (2016) of Engineering in Qingdao University of Technology. From October 2016, he started as a $\mathrm{PhD}$ candidate at the Faculty of Engineering Technology, University of Twente. His research is focused on developing high efficiency algorithms for the stress field and fatigue life analysis of anisotropic heterogeneous material.

\section{List of Publications:}

[1] Zhang B B, Boffy H, Venner C H. Multigrid solution of 2D and 3D stress fields in contact mechanics of anisotropic inhomogeneous materials. Tribology International 2020; 149. https://doi.org/10.1016/j.triboint.2019.02.044.

[2] Zhang B B, Liu H C, Quiñonez A F, Venner C H. Effects of 3D anisotropic heterogeneous subsurface topology on film thickness, pressure, and subsurface stresses in an elasto-hydrodynamically lubricated point contact. Tribology International 2020; 151. https://doi.org/10.1016/j.triboint.2020.106471.

[3] Zhang B B, Venner C H, Quiñonez A F. Effect of material anisotropy on the fatigue life of bearing steel under dry and lubricated point contact conditions: a numerical study. Tribology $\quad$ International 2020. https://doi.org/10.1016/j.triboint.2020.106584.

[4] Liu H C, Zhang B B, Bader N, Guo F, Poll G, \& Yang P. Crucial role of solid body temperature on elastohydrodynamic film thickness and traction. Tribology international 2019; 131: 386-397. https://doi.org/10.1016/j.triboint.2018.11.006.

[5] Liu H C, Zhang B B, Bader N, Poll G, \& Venner, C. H. Influences of solid and lubricant thermal conductivity on traction in an EHL circular contact. Tribology International 2020; 146: 106059. https://doi.org/10.1016/j.triboint.2019.106059.

[6] Liu H C, Zhang B B, Bader N, Venner C H, \& Poll G. Simplified traction prediction for highly loaded rolling/sliding EHL contacts. Tribology International 2020; 106335. https://doi.org/10.1016/j.triboint.2020.106335.

[7] Liu H C, Zhang B B, Bader N, Venner C H, \& Poll G. Scale and contact geometry effects on friction in thermal EHL: twin-disc versus ball-on-disc. Submitted to Tribology International. 


\section{Conferences Proceedings:}

[1] Zhang B B, Boffy H, Venner C H. Multigrid solution of 2D and 3D stress fields in contact mechanics of anisotropic inhomogeneous materials. Leeds Lyon Symposium on Tribology 2018. [oral presentation]

[2] Zhang B B, Venner C H, Quiñonez A F. Stress fields in inhomogeneous and anisotropic material. 3rd Young Tribological Researcher Symposium 2019. [oral presentation]

[3] Zhang B B, Venner C H, Quiñonez A F. Thin layer flow: Elasto-hydrodynamic lubrication and heterogeneous anisotropic material topology. Burgers Symposium 2019. [oral presentation]

[4] Zhang B B, Liu H C, Quiñonez A F, Venner C H. EHL modeling of heterogeneous anisotropic material for point contacts. Leeds Lyon Symposium on Tribology 2019. [oral presentation]

[5] Zhang B B, Venner C H. Modeling in subsurface including grains. University Day of SKF 2019. [oral presentation]

[6] Liu H C, Zhang B B, Bader N, Terwey T, Poll G. Traction in rolling/sliding EHL contacts. Young Tribological Researcher Symposium 2019. [poster]

[7] Bader N, Liu H C, Zhang B B, Poll G. Film thickness measurements in EHLcontacts using capacitance measurements. Leeds Lyon Symposium on Tribology 2019. [poster]

\section{Awards:}

[1] Zhang B B. Duncan Dowson Travel Awards for attending the $46^{\text {th }}$ Leeds Lyon Symposium on Tribology in Lyon. 


\section{Appendix I: Probabilistic engineering models}

In the early application period of rolling bearings, engineers focused on their reliability and durability. It seemed that bearing fatigue tests were the only way to predict the average and minimum life. Experiments with full-scale bearings (Ref. [57] and [58]) were performed at first and experience was summarized from the fatigue data to recommend the optimal load and speed for rolling bearings. A significant step forward was the publication of the bearing life prediction theory by Palmgren in 1924 [59]. An empirical equation was proposed based on the $L_{10}$ life concept (number of millions of revolutions that $90 \%$ of a group of bearings will equal or exceed before the first sign of RCF). Later, Palmgren matched his predictions using the test data [60]. The weakness of his formula is that it lacks a theoretical foundation. In 1939, Weibull published his statistics probability theory, namely Weibull distribution, which gave the probability density distribution and was the theoretical basis for the analysis of reliability [61]. Weibull stated that the probability of survival for rolling bearings could be expressed according to the following relation [62]:

$$
\ln \frac{1}{S} \sim \tau^{c} N^{e} V
$$

in which $S$ is the survival probability, $\tau$ the critical shear stress, $N$ millions of stress cycles, $V$ stressed volume of material, $c$ critical shear stress component and $e$ the Weibull exponent. The combination of the Weibull theory and Palmgren's previous formula generates the Lundberg-Palmgren (L-P) model [63]:

$$
\ln \frac{1}{S} \sim \frac{\tau_{0}^{c} N^{e} V}{z_{0}^{h}}
$$

where $\tau_{0}$ is the maximum orthogonal shear stress, $z_{0}$ the depth at which the critical shear stress occurs, $h$ the depth exponent. This equation gives the probability of survival $S$ as a function of the number of repeated concentrated stress cycles $N$, and it applies to subsurface originated fatigue. The model assumes that a fatigue crack initiates at a weak point whose orthogonal shear stress is over its threshold, and these weak points are assumed to be stochastically 
distributed in the material. The limitations of the L-P model are as follows: (1) The influence of an irregular contact surface, such as roughness and scratches, is not considered explicitly; (2) The contact condition is assumed to be purely normal with no surface shear traction.

In 1971, Chiu and Tallian proposed a new statistical fatigue life model considering the influence of both subsurface and surface originated fatigue [6466]:

$$
\ln \frac{1}{S}=\phi_{0}^{*} \phi_{1}^{*} \phi_{2}^{*} \phi_{3}^{*} \phi_{4}^{*} N^{\alpha \mu^{*} / \zeta}
$$

in which $\phi_{0}^{*}$ to $\phi_{4}^{*}$ are modifying factors accounting for physical effects such as surface imperfection, asperity interactions, lubrications, inhomogeneous material and so on. The dispersion parameter of this equation is $\alpha \mu^{*} / \zeta$ in which $\alpha$ is a numerical constant, $\mu^{*}$ is a defect dispersion parameter and $\zeta$ is the Manson-Coffin fatigue ductility exponent.

In order to overcome the limitations of L-P model, Ioannides and Harris (I-H) extended the L-P model into a discrete-stressed-volume approach $[52,67]$ :

$$
\ln \frac{1}{S}=A N^{e} \int_{v} H\left(\sigma-\sigma_{u}\right) \frac{\left(\sigma-\sigma_{u}\right)^{c}}{z^{h}} \mathrm{~d} v
$$

where $A$ is an empirical constant, $H$ is the Heaviside step function, $\sigma$ is a stress quantity at a average depth $z$, and $\sigma_{u}$ is the stress threshold. There are three innovative points in this model. Firstly, the failure risk is the summation of each individual stressed volume, i.e. the final failure probability is composed of the risk of every small material unit. Secondly, the concept of stress limit has been introduced, and the volume element with stress below this limit doesn't contribute to the risk function. Thirdly, the stress criterion is not limited to the orthogonal shear stress.

In 1992, Tallian proposed a fatigue life model given in Eq. (AII.5) with the assumptions that cracks initiate only from the surface defects, and the time of crack initiation and material exfoliation is negligible when compared to the time of crack propagation $[68,69]$.

$$
\ln \frac{1}{S}=\phi_{0} \phi_{2}\left[\frac{p_{\max }^{\zeta}}{n_{0} z_{0}}\right]^{\beta} N^{\beta} V
$$


where $\phi_{0}$ is a fatigue susceptibility parameter, $\phi_{2}$ is a defect parameter, $n_{0}$ is a dimensionless crack growth integral growth parameter, $z_{0}$ is the depth of the maximum shear stress, $\beta$ is the dispersion coefficient, $\zeta$ is the Paris-law exponent.

After a search of published literature, Zaretsky found that the critical shear stress exponent does not depend on bearing life scatter or dispersion. Hence, Zaretsky rewrote the Weibull equation to reflect his observation in 1994 [70]:

$$
\ln \frac{1}{S} \sim \tau^{c e} N^{e} V
$$

The modifications are as follows: (1) The dependence of critical shear stress $c$ on Weibull slope $e$ is eliminated. With $e=1$, Eq. (AII.1) and Eq. (AII.6) reflect the same power relation. (2) It does not recognize the effect of stress depth $z_{0}$ which is employed in the L-P model, Eq. (AII.2). (3) The critical shear stress used in this equation is the maximum shear stress rather than the orthogonal shear stress.

Cheng et al. [71] found that the spalling started from the subsurface crack initiation and was not controlled by the surface crack initiation from the fatigue life test of a needle-roller bearing. And that most of the fatigue life was spent on the crack initiation. Based on their test results, a fatigue life which is similar to the I-H model was proposed:

$$
\ln \frac{1}{S} \sim \frac{N^{e}\left(\sigma-\sigma_{u}\right)^{c} V}{b^{h}}
$$

Compared to the I-H model, this equation avoids complicated subsurface surface stress calculations, and the fatigue life can be easily obtained after knowing the Hertzian contact pressure and contact width under pure rolling condition. Besides, the influence factors such as surface roughness, material hardness and film thickness are considered in this model.

In 2001, Yu and Harris [72] introduced a stress-based fatigue life model in which the fatigue life is related to the magnitude of stress, stress cycles and stress volume. The new model reads:

$$
\ln \frac{1}{S} \sim N^{e}\left(\int \tau^{c} \mathrm{~d} v\right)^{e}
$$


in which the fatigue initiating stress $\tau$ is a multiaxial fatigue criterion including the average stress and the alternating stress. 


\section{Appendix II: Deterministic research models}

These models focus on either the fatigue crack initiation or the fatigue crack propagation. Few models combine the two parts together. The first deterministic research model is the crack propagation model of rolling/sliding Hertzian contacts from Keer and Bryant [73]:

$$
N \approx N_{p}=\frac{b^{1-m / 2}}{\beta_{0} p_{\max }^{m}}
$$

in which $N_{p}$ is crack propagation cycles, $\beta_{0}$ and $m$ are numerical constants governing the crack growth rate. The predicted lives with Hertzian pressure are shorter than that predicted by probabilistic engineering models. Later, Hanson and Keer [74] updated the model with a modified Paris power law for a discontinuity crack growth rate. The modifications make the predicted fatigue life closer to engineering models.

By analysing the subsurface stress distribution with the micro-macro contact model, Zhou et al. [75] presented a life model which considers both the crack initiation and the crack propagation:

$$
N=N_{i}+N_{p}=\frac{A W_{c}}{\left(\Delta \sigma-2 \sigma_{k}\right)^{2} D}+\int_{a_{i}}^{a_{f}} \frac{1}{C}(\Delta K)^{-n} \mathrm{~d} a
$$

where $A, C$ and $n$ are material constants, $W_{\mathrm{c}}$ the specific fracture energy for a unit area, $\Delta \sigma$ the range of local shear stress, $\sigma_{k}$ the frictional shear stress, $D$ the damage accumulation factor, $\Delta K$ the stress intensity factor range at the crack tip, $a_{i}$ the initial length of microcrack, $a_{f}$ the final length of crack to failure.

Vincent proposed a model which assumes that the dislocations occurred because of the presence of high modulus inclusions [76]. With this model, the shape and size of white etching areas formed around the inclusions can be calculated together with the number of cycles $N$ to initiate cracks following:

$$
\frac{\mu}{\pi(1-v)}\left(\gamma_{\mathrm{pl}}+2 f N \gamma_{\mathrm{pc}}\right) \frac{d}{2 \lambda} \ln \left[\frac{1}{8}\left(\left(\gamma_{\mathrm{pl}}+2 f N \gamma_{\mathrm{pc}}\right) \frac{d}{b^{\prime}}\right)^{2}\right]-\frac{\sigma_{x}+\sigma_{y}}{2}=\frac{\mu}{\alpha}
$$


in which $\mu$ and $v$ are the shear moduli and Poisson's ratio of the material, $\gamma_{\mathrm{pl}}$ is the effective plastic strain after the first loading cycle, $\gamma_{\mathrm{pc}}$ is the effective plastic cyclic strain, $f$ is a damage efficiency accumulation factor, $d$ is the inclusion diameter, $\lambda$ is the length of dislocation domain, $b^{\prime}$ is the modulus of Burgers vector, $\sigma_{x}$ and $\sigma_{y}$ are stress components, $\alpha$ is the theoretical strength factor. Later, Lormand et al. [77] extended the model to take the crack propagation into account.

Jiang et al. [78] used a multiaxial stress-strain plasticity model in the calculation of stress fields and developed a combined ratchetting-multiaxial fatigue model. The total damage $D$ consists of two parts: the fatigue damage $D_{\mathrm{f}}$ and the ratchetting damage $D_{\mathrm{r}}$, i.e.,

$$
D=D_{\mathrm{f}}+D_{\mathrm{r}}=\sum_{1}^{N}\left(\frac{\left(\mathrm{FP}-\mathrm{FP}_{0}\right)^{m}}{C}+\frac{\left|\mathrm{d} \gamma_{\mathrm{r}} / \mathrm{d} N\right|}{\gamma_{\mathrm{cri}}}\right)
$$

in which $N$ is number of cycles, FP multiaxial fatigue parameter, $m, C, \mathrm{FP}_{0}$ and $\gamma_{\text {cri }}$ material constant, $\gamma_{\mathrm{r}}$ shear ratchetting strain. 


\section{Bibliography}

[1] Jost H P. Lubrication (Tribology)-A report on the present position and industry's needs. London: HM Stationary Office; 1966.

[2] Holmberg K, Erdemir A. Influence of tribology on global energy consumption, costs and emissions. Friction 2017; 5(3): 263-284. https://doi.org/10.1007/s40544-017-0183-5.

[3] Dašić P, Franek F, Assenova E, Radovanović M. International standardization and organizations in the field of tribology. Industrial Lubrication and Tribology 2003; 55(6): 287-291. https://doi.org/10.1108/00368790310496437.

[4] Wang, J. Interfacial mechanics: theories and methods for contact and lubrication. United States: CRC Press; 2019.

[5] Layard A H. Discoveries in the ruins of Nineveh and Babylon: with travels in Armenia, Kurdistan and the desert. London: John Murray; 1853.

[6] Dowson D, Hamrock B J. History of ball bearings. NASA Technical Memorandum 1981; NASA-TM-81689.

[7] Frêne J. La tribologie de l'antiquité à nos jours. Revue Francaise De Mecanique 2001; 263-282.

[8] Rowe J. All sorts of wheel-carriage, improved. London: Alexander Lyon; 1734.

[9] Vaughan P. Iron ball bearings for carriage wheel-axles. UK Patent, 1794.

[10] Zaretsky E V. A. Palmgren revisited: A basis for bearing life prediction. STLE Annual Meeting 1997: NASA-TM-107440.

[11] Sadeghi F, Jalalahmadi B, Slack T S, Raje N, Arakere N K. A review of rolling contact fatigue. Journal of Tribology 2009; 131(4): 041403. https://doi.org/10.1115/1.3209132.

[12] Paulson N R. Finite element modeling of elastohydrodynamic lubricated rolling contact fatigue. PhD Thesis, Purdue University; 2017.

[13] Chiu Y, Tallian T, Mccool J. An engineering model of spalling fatigue failure in rolling contact: I. The subsurface model. Wear 1971; 17(5-6): 433-446. https://doi.org/10.1016/0043-1648(71)90049-4.

[14] Ioannides E, Harris T A. A new fatigue life model for rolling bearings. Journal of Tribology 1985; 107(3): 367-377. https://doi.org/10.1115/1.3261081. 
[15] Raje N, Sadeghi F, Rateick R G, Hoeprich M R. A numerical model for life scatter in rolling element bearings. Journal of Tribology 2008; 130(1): 011011. https://doi.org/10.1115/1.2806163.

[16] Raje N, Sadeghi F, Rateick R G. A statistical damage mechanics model for subsurface initiated spalling in rolling contacts. Journal of Tribology 2008; 130(4): 042201. https://doi.org/10.1115/1.2959109.

[17] Raje N, Sadeghi F. Statistical numerical modelling of sub-surface initiated spalling in bearing contacts. Proceedings of the Institution of Mechanical Engineers, Part J: Journal of Engineering Tribology 2009; 223(6): 849-858. https://doi.org/10.1243/13506501JET481.

[18] Bomidi J A, Weinzapfel N, Sadeghi F, Liebel A, Weber J. An improved approach for 3D rolling contact fatigue simulations with microstructure topology. $\begin{array}{llll}\text { Tribology } & \text { Transactions } & \text { 2013; } & \text { 385-399. }\end{array}$ https://doi.org/10.1080/10402004.2012.754072.

[19] Paulson N R, Bomidi J A, Sadeghi F, Evans R D. Effects of crystal elasticity on rolling contact fatigue. International Journal of Fatigue 2014; 61: 67-75. https://doi.org/10.1016/j.ijfatigue.2013.12.005.

[20] Paulson N R, Sadeghi F. EHL modeling of nonhomogeneous materials: the effects of polycrystalline anisotropy on RCF. Tribology International 2017; 112: 137-146. https://doi.org/10.1016/j.triboint.2017.04.007.

[21] Brandt A. Multi-level adaptive solutions to boundary-value problems. Mathematics of computation 1997; 31(138): 333-390. https://doi.org/10.1090/S0025-5718-1977-0431719-X.

[22] Stüben, K. Algebraic multigrid (AMG): experiences and comparisons. Applied mathematics and computation 1983; 13(3-4): 419-451. https://doi.org/10.1016/0096-3003(83)90023-1.

[23] Lubrecht A. Numerical solution of the EHL line and point contact problem using multigrid techniques. PhD Thesis, University of Twente; 1987.

[24] Venner, C. H. Multilevel solution of the EHL line and point-contact problems. PhD Thesis, University of Twente; 1992.

[25] Venner C H, Lubrecht A A. Multi-level methods in lubrication. Amsterdam: Elsevier; 2000.

[26] Boffy H, Baietto M-C, Sainsot P, Lubrecht A. Detailed modelling of a moving heat source using multigrid methods. Tribology International 2012; 46(1): 279287. https://doi.org/10.1016/j.triboint.2011.06.011.

[27] Boffy H, Baietto M-C, Sainsot P, Lubrecht A A. An efficient 3d model of heterogeneous materials for elastic contact applications using multigrid methods. Journal of Tribology 2012; 134(2): 021401. https://doi.org/10.1115/1.4006296. 
[28] Boffy H, Venner C H. Multigrid solution of the 3D stress field in strongly heterogeneous materials. Tribology International 2014; 74: 121-129. https://doi.org/10.1016/j.triboint.2014.02.019.

[29] Boffy H, Venner C H. Multigrid numerical simulation of contact mechanics of elastic materials with 3D heterogeneous subsurface topology. Tribology International 2015; 92: 233-245. https://doi.org/10.1016/j.triboint.2015.06.015.

[30] Gu H, Réthore J, Baietto M-C, Sainsot P, Lecomte-Grosbras P, Venner C H, Lubrecht A A. An efficient MultiGrid solver for the 3D simulation of composite materials. Computational Materials Science 2016; 112: 230-237. https://doi.org/10.1016/j.commatsci.2015.10.025.

[31] Noyel J-P, Ville F, Jacquet P, Gravouil A, Changenet C. Development of a granular cohesive model for rolling contact fatigue analysis: crystal anisotropy modeling. Tribology Transactions 2016; 59(3): 469-479. https://doi.org/10.1080/10402004.2015.1087076.

[32] Zeghadi A, N'guyen F, Forest S, Gourgues A-F, Bouaziz O. Ensemble averaging stress-strain fields in polycrystalline aggregates with a constrained surface microstructure-Part 1: Anisotropic elastic behaviour. Philosophical Magazine 2007; 87(8-9): 1401-1424. https://doi.org/10.1080/14786430601009509.

[33] Grabulov A, Ziese U, Zandbergen H. TEM/SEM investigation of microstructural changes within the white etching area under rolling contact fatigue and 3-D crack reconstruction by focused ion beam. Scripta Materialia 2007; 57(7): 635-638. https://doi.org/10.1016/j.scriptamat.2007.06.024.

[34] No wear coated bearings, https://www.skf.com/uk/products/rollingbearings/engineered-products/nowear-coated-bearings; 2020 [accessed 13 April 2020].

[35] Watremetz B, Baietto-Dubourg M C, Lubrecht A A. 2D thermo-mechanical contact simulations in a functionally graded material: A multigrid-based

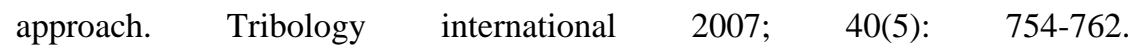
https://doi.org/10.1016/j.triboint.2006.07.001.

[36] Dong Q, Zhou K, Wei R, Luo J, Srikanth N. Analysis of fluid pressure, interface stresses and stress intensity factors for layered materials with cracks and inhomogeneities under elastohydrodynamics lubrication contact. International Journal of Mechanical Sciences 2015; 93: 48-58. https://doi.org/10.1016/j.ijmecsci.2015.01.007.

[37] Sun Y, Bloyce A, Bell T. Finite element analysis of plastic deformation of various TiN coating/substrate systems under normal contact with a rigid sphere. Thin Solid Films 1995; 271(1-2): 122-131. https://doi.org/10.1016/00406090(95)06942-9. 
[38] Yu C, Wang Z, Liu G, Keer L M, Jane Wang Q. Maximum von mises stress and its location in trilayer materials in contact. Journal of Tribology 2016; 138(4): 041402. https://doi.org/10.1115/1.4032888.

[39] Bower A F. Applied mechanics of solids. United States: CRC press; 2009.

[40] Zhang B B, Boffy H, Venner C H. Multigrid solution of 2D and 3D stress fields in contact mechanics of anisotropic inhomogeneous materials. Tribology International 2019. https://doi.org/10.1016/j.triboint.2019.02.044.

[41] Mcewan E. Stresses in elastic cylinders in contact along a generatix. $\begin{array}{llll}\text { Philosophical } \quad \text { Magazine } & \text { 454-460. }\end{array}$ https://doi.org/10.1080/14786444908521733.

[42] Guan J, Wang L, Zhang C, Ma X. Effects of non-metallic inclusions on the crack propagation in bearing steel. Tribology International 2017; 106: 123-131. https://doi.org/10.1016/j.triboint.2016.10.030.

[43] Daniel G. Fast simultaneous EBSD and EDS measurements for complete analysis of multiphase materials. Bruker Nano GmbH 2015.

[44] Zhang J M, Zhang Y, Xu K W, Ji V. Young's modulus surface and Poisson's ratio curve for cubic metals. Journal of Physics and Chemistry of Solids 2007; 68(4): 503-510. https://doi.org/10.1016/j.jpcs.2007.01.025.

[45] Pérez-Ruiz, J. A., Luzón, F., García-Jerez, A. Simulation of an irregular free surface with a displacement finite-difference scheme. Bulletin of the Seismological Society of America 2005; 95(6): 2216-2231. https://doi.org/10.1785/0120050014.

[46] Hamilton G M, Goodman L. The stress field created by a circular sliding contact. Journal of Applied Mechanics 1966; 33(2): 371-376. https://doi.org/10.1115/1.3625051.

[47] Houpert L, Ioannides E, Kuypers J, Tripp J. The effect of the EHD pressure spike on rolling bearing fatigue. Journal of Tribology 1987; 109(3): 444-450. https://doi.org/10.1115/1.3261468.

[48] Venner C H, Lubrecht A. Numerical simulation of a transverse ridge in a circular EHL contact under rolling/sliding. Journal of Tribology 1994; 116(4): 751-761. https://doi.org/10.1115/1.2927329.

[49] Roelands C A. Correlational aspects of the viscosity temperature pressure relationship of lubricating oils. PhD Thesis, Technical University Delft; 1966.

[50] Dowson D, Higginson G R. Elastohydrodynamic lubrication, the fundamentals of roller and gear lubrication. Great Britain: Pergamon Press; 1966.

[51] Zaretsky E V, Poplawski J V, Peters S M. Comparison of life theories for rollingelement bearings. Tribology transactions 1996; 39(2): 237-248. https://doi.org/10.1080/10402009608983525. 
[52] Ioannides E, Harris T A. A new fatigue life model for rolling bearings. Journal of Tribology, 1985; 107(3): 367-377. https://doi.org/10.1115/1.3261081.

[53] Soda N, Yamamoto T. Effect of tangential traction and roughness on crack initiation/propagation during rolling contact. ASLE Transactions 1982; 25(2): 198-206. https://doi.org/10.1080/05698198208983081.

[54] Ooki C. Improving rolling contact fatigue life of bearing steels through grain refinement. SAE Technical Paper 2004; 2004-01-0634. https://doi.org/10.4271/2004-01-0634.

[55] Petch N J. The cleavage strength of polycrystals. Journal of the Iron and Steel Institute 1953; 174: 25-28.

[56] Daniel H H. Grain size and its influence on materials properties. Industrial heating 2005.

[57] Stribeck R. Reports from the central laboratory for scientific investigation. ASME Transaction 1907; 29: 420-466 (Translation by Hess H).

[58] Goodman J. Roller and ball bearings. Minutes of the Proceedings of the Institution of Civil Engineers 1912; 189 (3): 82-127.

[59] Palmgren A. The service life of ball bearings. Zeitschrift des Vereines Deutscher Ingenieure 1924; 68(14): 339-341.

[60] Zaretsky E V. Rolling bearing life prediction, theory, and application. NASA/TP 2016; 2013-215305/REV1.

[61] Weibull W. A statistical theory of the strength of materials. Stockholm: Generalstabens litografiska anstalts förlag; 1939.

[62] Weibull W. The phenomenon of rupture in solids. Stockholm: Generalstabens litografiska anstalts förlag; 1939.

[63] Lundberg G, Arvid P. Dynamic capacity of rolling bearings. Stockholm: Generalstabens litografiska anstalts förlag; 1947.

[64] Chiu Y P, Tallian T E, McCool J I. An engineering model of spalling fatigue failure in rolling contact: I. The subsurface model. Wear 1971; 17(5-6): 433-446. https://doi.org/10.1016/0043-1648(71)90049-4.

[65] Tallian T E, McCool J I. An engineering model of spalling fatigue failure in rolling contact: II. The surface model. Wear 1971; 17(5-6): 447-461. https://doi.org/10.1016/0043-1648(71)90050-0.

[66] Tallian T E. An engineering model of spalling fatigue failure in rolling contact: III. Engineering discussion and illustrative examples. Wear 1971; 17(5-6): 463480. https://doi.org/10.1016/0043-1648(71)90051-2. 
[67] Ioannides E, Jacobson B, Tripp J H. Prediction of rolling bearing life under practical operating conditions. Tribology Series 1989; 14: 181-187. https://doi.org/10.1016/S0167-8922(08)70193-7.

[68] Tallian T E. Simplified contact fatigue life prediction model-Part I: Review of published models. Journal of Tribology 1992; 114(2): 207-213. https://doi.org/10.1115/1.2920875.

[69] Tallian T E. Simplified contact fatigue life prediction model-Part II: New model. Journal of Tribology 1992; 114(2):214-220. https://doi.org/10.1115/1.2920876.

[70] Zaretsky E V. Design for life, plan for death. Machine Design 1994; 66(15):5759.

[71] Cheng W, Cheng H S. Semi-analytical modeling of crack initiation dominant contact fatigue life for roller bearings. Journal of Tribology 1997; 119(2): 233240. https://doi.org/10.1115/1.2833163.

[72] Yu W K, Harris T A. A new stress-based fatigue life model for ball bearings. Tribology Transactions 2001; 44(1):11-18. https://doi.org/10.1080/10402000108982420.

[73] Keer L M, Bryant M D. A pitting model for rolling contact fatigue. Journal of Tribology 1983; 105(2): 198-205. https://doi.org/10.1115/1.3254565.

[74] Hanson M, Keer L M. An analytical life prediction model for the crack propagation occurring in contact fatigue failure. Tribology Transactions 1992; 35(3): 451-461. https://doi.org/10.1080/10402009208982143.

[75] Zhou R, Cheng H, Mura T. Micropitting in rolling and sliding contact under mixed lubrication. Journal of Tribology 1989; 111(4): 605-613. https://doi.org/10.1115/1.3261984.

[76] Vincent A, Lormand G, Lamagnere P, Gosset L, Girodin D, Dudragne G, Fougeres R. From white etching areas formed around inclusions to crack nucleation in bearing steels under rolling contact fatigue. ASTM International 1998; 109-123. https://doi.org/10.1520/STP12123S.

[77] Lormand G, Meynaud P, Vincent A, Baudry G, Girodin D, Dudragne G. (1998). From cleanliness to rolling fatigue life of bearings-a new approach. ASTM International 1998; 55-69. https://doi.org/10.1520/STP12120S.

[78] Jiang Y, Sehitoglu H. A model for rolling contact failure. Wear 1999; 224(1): 38-49. https://doi.org/10.1016/S0043-1648(98)00311-1. 
Appendix: Paper A 
Multigrid solution of 2D and 3D stress fields in contact mechanics of anisotropic inhomogeneous materials

\author{
Binbin Zhang ${ }^{1}$, Hugo Boffy ${ }^{2}$, Cornelis H. Venner ${ }^{1}$ \\ 1 Faculty of Engineering Technology, University of Twente, P.O. Box 217, 7500AE \\ Enschede, The Netherlands \\ 2 Research and Technology Development, SKF, Kelvinbaan 16, 3439MT Nieuwegein, \\ The Netherlands
}

\begin{abstract}
Increasing demands on performance of machines lead to more sever operating conditions of rolling bearings, i.e. higher loads, less lubricant, thinner lubricant films. Under these conditions, the effects of inhomogeneity and anisotropy on the fatigue life become more important. Accurate prediction of such effects requires detailed surface pressure and subsurface stress calculations. For practically relevant 3D cases with realistic grain sizes, this can only be done with very efficient numerical solution methods. In this paper, multigrid techniques are demonstrated to yield the required performance. The influence of inclusions, crystal orientation and roughness on the Von Mises stress distribution is investigated. The algorithm is suited for subsurface material analysis and optimization as well as for computational diagnostics using image analysis.
\end{abstract}

\title{
Keywords
}

Multigrid method, Contact mechanics, Inhomogeneous material, Polycrystalline material

\section{Introduction}

Increasingly critical design implies higher operational requirements for rolling bearings in many applications. As a result, further improvement of bearing life is a key target for rolling bearing analysis, design and development. Bearing damage can be caused by external working conditions (e.g. load, speed, temperature, lubrication condition, corrosion) and by intrinsic bearing properties (e.g. surface finish, coating, non-metallic inclusions, material anisotropy, residual stress). Even when a rolling bearing is properly installed and well lubricated, rolling contact fatigue (RCF) may occur initiated at the surface or in the subsurface after millions of load cycles. 
Fatigue of rolling bearings can be classified into two types: subsurfaceinitiated fatigue and surface-initiated fatigue. For the subsurface-initiated fatigue, the Lundberg-Palmgren fatigue theory [1] presumes that the large orthogonal shear stress and a weak point in the material result in the initiation of fatigue crack. Later, Ioannides and Harris [2] extended the fatigue theory by introducing an additional material parameter. Recently, the surface-originated damage was explicitly formulated into the basic fatigue equations of rolling contact by Morales-Espejel et al. [3]. Performance factors were introduced into the new model, which makes it possible to target specific bearing features and operating conditions. Surface-initiated fatigue can be decreased by using better lubricants, surface heat treatment and better surface finish. Subsurface-initiated fatigue is much harder to control as it involves the local subsurface material composition and behaviour. To model fatigue life well, analysis of the subsurface stress field in the bearing material induced by the contact pressure is needed. In the tribology literature, many publications have investigated the influence of surface defect/roughness, coating, inclusions, and anisotropy on subsurface stresses in bearing material. Relatively recent examples are the Voronoi finite element model was used for damage mechanics by Warhadpande and Sadeghi [4] who observed that surface defects have a significant effect on RCF life in heavily loaded lubricated conditions. Considering surface coating, subsurface inclusions and surface roughness, Dong et al [5] developed an approach for computing the stress field distribution. In their study, both inclusions and coating were homogenized using the Eshelby's equivalent inclusion method. Moghaddam et al. [6] studied the influence of non-metallic inclusions on butterfly wing initiation and crack formation. Their results showed that the stiffness and location of an inclusion have a significant effect on RCF. Slack et al. [7] investigated the influence of inclusions on an elastohydrodynamically lubricated (EHL) line contact. They found that the subsurface inclusions changed the EHL pressure and film thickness profiles. Morales-Espejel et al. [8] used a rapid micro-EHL methodology combined with a multigrid method for stress calculation and surface deformation [9] to study surface fatigue with heterogeneous material under rough lubricated rolling-sliding contact. The inhomogeneities near the contact surface affect the pressure and the subsurface stress distribution. Minimizing the distribution of inhomogeneous material in bearing material can be achieved through advanced manufacturing processes. However, the anisotropy is an intrinsic property of the bearing material. It should 
be noted that the anisotropy of bearing material is scale dependent. On a macro scale, RCF is less sensitive to grain size and orientation. On a micro scale, its effect cannot be ignored. Noyel et al. [10] developed a granular cohesive model for RCF analysis. They found that RCF was influenced by anisotropic elasticity. Paulson and Sadeghi [11] developed a fully coupled line contact EHL model to investigate the effects of polycrystalline anisotropy on rolling contact fatigue. It was found that the anisotropy leads to stress components variation and then life scatter.

To model the stress concentration areas in anisotropic and inhomogeneous material under load in a theoretical/numerical study requires very detailed grids to be able to describe the small-scale variations and obtain accurate results. To achieve this in acceptable computational times requires a highly efficient method. In Ref. [12, 13], Boffy et al. applied the multigrid method to the 3D stress field solution in heterogeneous and strong heterogeneous material with given contact pressure distribution. It is proven that the developed multigrid algorithm possesses high accuracy and efficiency. Later, it was extended to 3D contact mechanics with heterogeneous material [14]. In this paper, the multigrid method is demonstrated to be very well suited to solve the computationally even more demanding problem of contact mechanics and subsurface stress field for bearing material with heterogeneous properties on the very local scale of grains including anisotropy.

\section{Methods}

\subsection{Theoretical model}

The problem considered is the contact of a rigid indenter and an elastic body with anisotropic inhomogeneous material. A rectangular (2D) and cubic (3D) domains are considered.

\subsubsection{Interior equations}

The computational task can be described as the solution of the unknown displacements in a 2D or 3D domain from the stress equilibrium equations:

$$
\left\{\begin{array}{l}
\frac{\partial \sigma_{x x}}{\partial x}+\frac{\partial \sigma_{x y}}{\partial y}=0 \\
\frac{\partial \sigma_{x y}}{\partial x}+\frac{\partial \sigma_{y y}}{\partial y}=0
\end{array}\right.
$$




$$
\text { or }\left\{\begin{array}{l}
\frac{\partial \sigma_{x x}}{\partial x}+\frac{\partial \sigma_{x y}}{\partial y}+\frac{\partial \sigma_{x z}}{\partial z}=0 \\
\frac{\partial \sigma_{x y}}{\partial x}+\frac{\partial \sigma_{y y}}{\partial y}+\frac{\partial \sigma_{y z}}{\partial z}=0 \\
\frac{\partial \sigma_{x z}}{\partial x}+\frac{\partial \sigma_{y z}}{\partial y}+\frac{\partial \sigma_{z z}}{\partial z}=0
\end{array}\right.
$$

where $\sigma_{i j}=C_{i j k l} \varepsilon_{k l}$. Details of the stress-strain tensor are given in appendix A. The stress-strain tensor in a local coordinate system (single grain) is still a relatively sparse matrix. However, in the global coordinate system needed to describe the complete problem and equations the tensor becomes full. This implies additional terms in the equations to be solved, the nature and spatial variation of which may adversely affect convergence behavior of an iterative numerical solution algorithm.

\subsubsection{Top boundary equations}

The unknown displacements and contact pressure of top boundary can be solved with Eqs. (2)-(4) [14]. For 2D:

$$
\begin{gathered}
\sigma_{x y}=0 \\
h(x)=h_{0}+g(x)-v(x, y=0)=0 \\
\sigma_{y y}+p=0
\end{gathered}
$$

For 3D:

$$
\begin{gathered}
\sigma_{x z}=0 \quad \sigma_{y z}=0 \\
h(x, y)=h_{0}+g(x, y)-w(x, y, z=0)=0 \\
\sigma_{z z}+p=0
\end{gathered}
$$

In Eqs. (3), $g(x)$ and $g(x, y)$ represent the shape of the indenters. Eqs. (2)(4) are used to solve the top boundary displacements and pressure distribution for the contact problem satisfying the Hertz-Signorini-Moreau condition, Eq. (5).

$$
p \geq 0 \quad h \geq 0 \quad p h=0
$$

This implies that for the indenter in contact with the elastic body $p>0$ and $h=$ 0 . When the gap is open $h>0$, Eqs. (3) cancels with $p=0$, and Eqs. (2) and (4) are used to calculate the top boundary displacements, i.e. stress free boundary 
condition.

Finally, the applied load $F$ should be balanced by the contact pressure:

$$
\int p(x)=F \text { or } \quad \iint p(x, y)=F
$$

This equation determines the value of $h_{0}$.

2.1.3 Vertical and bottom boundary equations

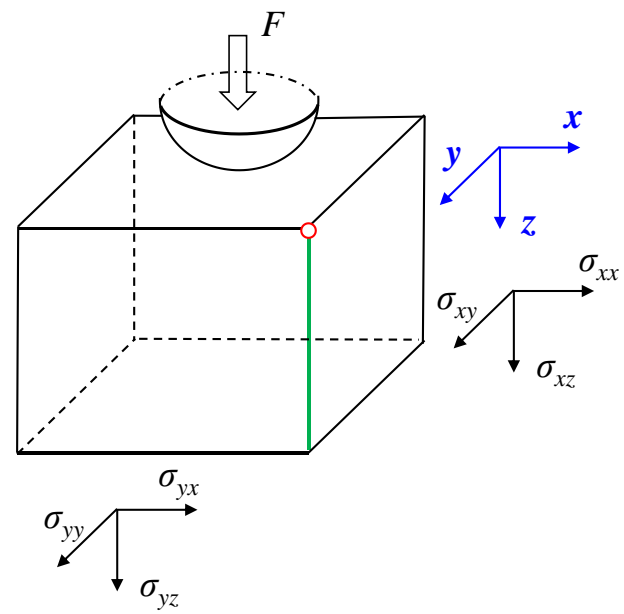

Figure 1 Schematic graph of 3D elastic contact

The bottom boundary is specified as zero displacement (Dirichlet) and the vertical boundaries are assumed to be stress free (Neumann). Special attention should be paid to the intersections. Here, the problem is detailed for the 3D case, see Fig. 1. Normal and shear stresses are used to determine the displacements $u$, $v, w$ of the boundaries. At the intersection of the boundary planes (e.g. green line in Fig. 1), the conditions of the both planes should be satisfied. At the corner points (e.g. red point in Fig. 1), the sum of the stresses is imposed to be zero [15].

\subsection{Numerical technique}

The equations are discretized on a uniform grid using a finite difference approach, see Appendix A. The discrete equations are solved using multigrid techniques [9, 14]. An iterative process is designed using a Gauss-Seidel (consecutive) relaxation scheme for the displacement equations with special treatment for the boundary equations to ensure a good error smoothing which is 
essential for a multigrid solver. For the top boundary, the complementarity equation for the contact pressure is solved simultaneously with the prescribed (zero) shear stress conditions in a pointwise collective boundary relaxation.

Figure 2 gives the flow chart for the relaxation including the boundary treatment. The relaxation method is detailed in Appendix B. The key idea of the multigrid method is to overcome the slow grid dependent convergence of the relaxation process by using a coarser grid to solve smooth error components. Applied recursively using multiple coarser grids so that each error component is solved on a grid at which this can be done most efficiently, a high grid independent convergence rate is achieved, allowing the solution of problems with dense grids very efficiently. Multigrid techniques enable solving much larger problems with the available computational power. Further details are given in Ref. [9, 14].

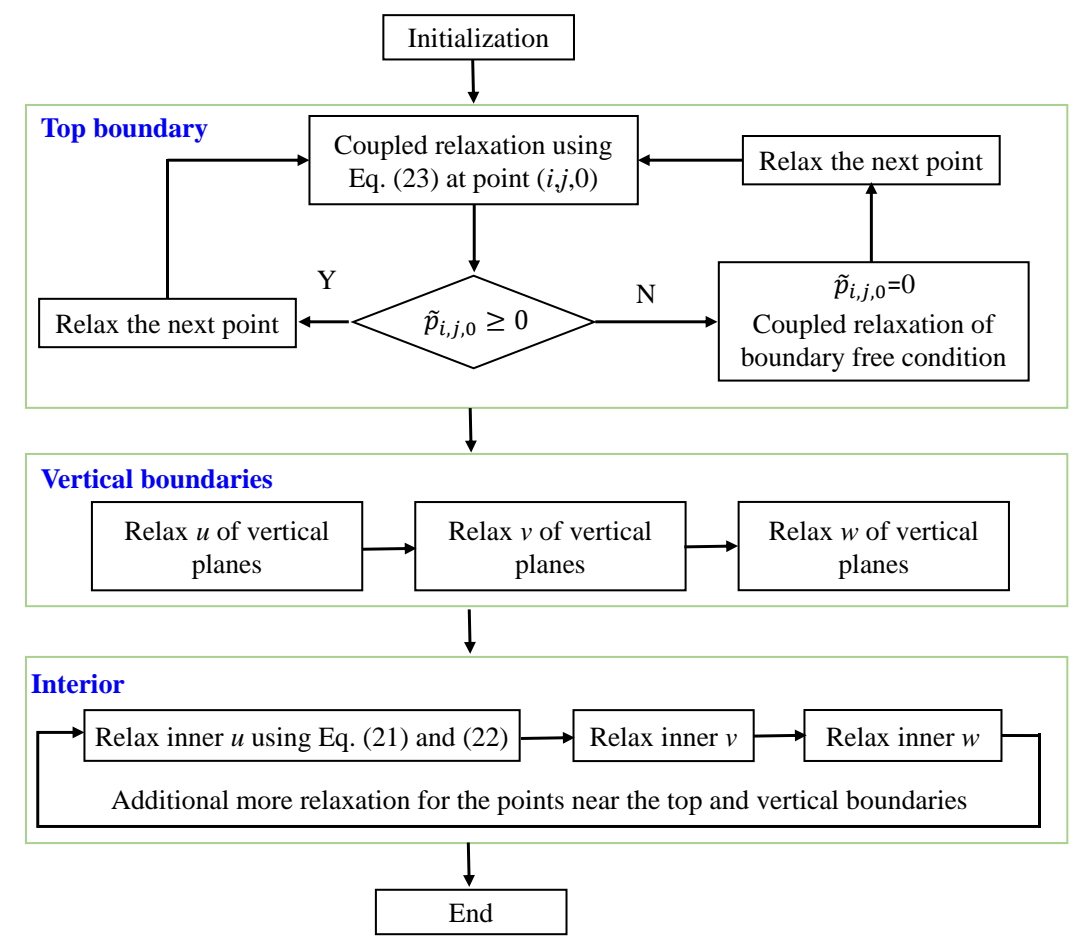

Figure 2 Flow chart of relaxation on one grid level

\subsection{Solver performance}

The computational performance for the 3D problem is shown in this section. 
In the first example, homogeneous anisotropic ferrite is considered. The elastic constants are given in Table 1. The anisotropy ratio A (see definition in Appendix A) for ferrite is 2.4. The elastic stiffness matrix of the single grain is rotated based on Eq. (7) [16].

$$
C_{\text {global }}=R(\alpha) R(\beta) R(\gamma) C_{\text {local }}(R(\alpha) R(\beta) R(\gamma))^{T}
$$

where $\alpha, \beta, \gamma$ are the three Euler angles. A grid with $513^{3}$ points is used, and 5 grid levels in the multigrid algorithm. The material and contact parameters are given in Table 2. The problem is solved using a computational domain [-3a:3a, $-3 a: 3 a, 0: 6 a]$, with a the Hertzian dry contact radius for uniform isotropic material.

Table 1 Stiffness matrix components of Ferrite

\begin{tabular}{cc}
\hline Elastic constant & Value (GPa) \\
\hline$c_{11}$ & 237 \\
$c_{12}$ & 141 \\
$c_{44}$ & 116 \\
\hline
\end{tabular}

Table 2 Material and contact parameters

\begin{tabular}{cc}
\hline Parameter & Value \\
\hline$E$ & $206 \mathrm{GPa}$ \\
$V$ & 0.3 \\
$R$ & $0.01 \mathrm{~m}$ \\
$p_{\mathrm{Hz}}$ & $1 \mathrm{Gpa}$ \\
$b(2 \mathrm{D})$ & $69.4 \mu \mathrm{m}$ \\
$b(3 \mathrm{D})$ & $88.7 \mu \mathrm{m}$ \\
\hline
\end{tabular}

The residual for each of the discretized equations is defined by:

$$
\text { res }=\sum_{i, j, k}\left|\frac{f(i, j, k)-L^{h} u^{h}(i, j, k)}{N_{x} N_{y} N_{z}}\right|
$$

The convergence of the solver is monitored by the reduction of the L1 norm of the residual as a function of the number of multigrid W-cycles, see Fig. 3. The figure shows that the developed multigrid algorithm exhibits uniform fast convergence for each of the three displacements equations and the contact 
condition.

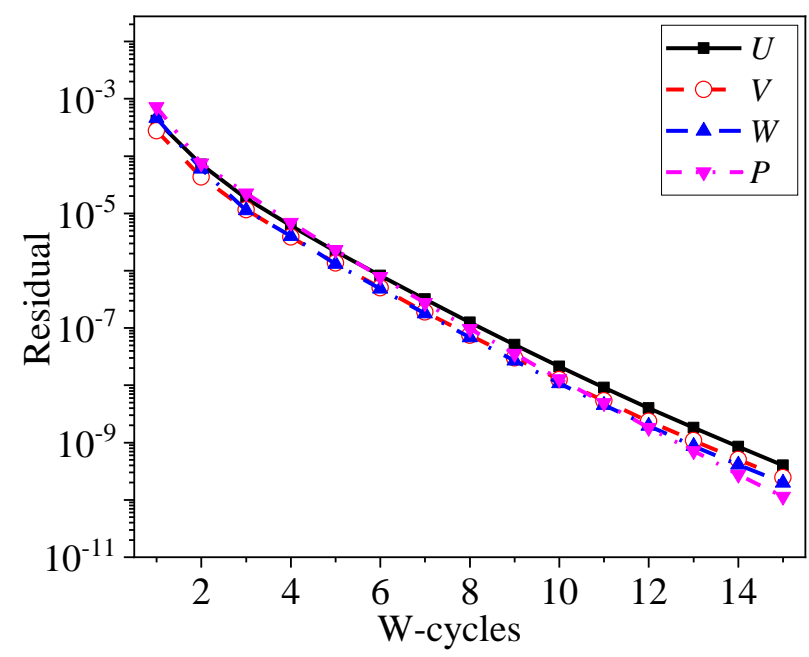

Figure 3 Residual as a function of cycles (homogeneous ferrite), $513^{3}$ grid points, 5 multigrid levels

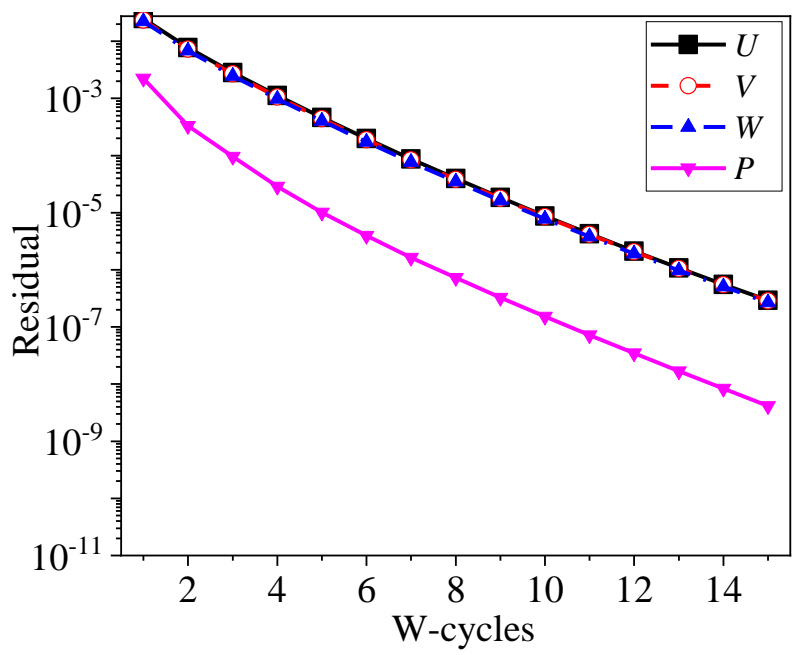

Figure 4 Function residual as a function of cycles (about 4500 grains)

This excellent convergence behavior is essentially maintained for the anisotropic problem. This is illustrated in Fig. 4 for the case of ferrite with some 4500 grains having randomly varying Euler angles $\alpha, \beta, \gamma$, ranging from 0 to $\pi / 2$. In terms of real dimensions for the given conditions, the average grain diameter is about $25 \mu \mathrm{m}$ [10]. In Fig. 4, the black, red and blue lines represent the residuals 
for the displacement variables $u, v$ and $w$ respectively. The pink line represents the residual of the force balance condition. Note that each equation converges at the same speed with an order of magnitude error reduction per two W-cycles which in general is sufficient to achieve an error below the discretization error that is made anyway. The computations were done on a computer with an Intel $\mathrm{X} 5650 \mathrm{CPU}$ at $2.66 \mathrm{GHz}$, using a single core. The wall clock time for two cycles is about 89 minutes and for 10 cycles about 7 hours. In general, only one or two $\mathrm{W}$-cycles are needed to solve the problem with an error below discretization error. The results shown in Fig. 4. demonstrate that the developed solver is well suited for realistic material topologies. Detailed results for some 2D and 3D cases in terms of computed surface pressure and subsurface stresses will be shown in the next section.

\section{Results}

In this section, the influence of inclusions (heterogeneous material), anisotropy and surface roughness on the Von Mises stress distribution is illustrated. The average size of the Voronoi cells is $25 \mu \mathrm{m}$. First, as a reference a case of an isotropic material case in 2D is studied with some of the cells having smaller or larger elastic modulus. Material properties and contact pressure are given in Table 2.

The results are presented in dimensionless form taking the Hertz contact parameters as a reference (see nomenclature), i.e. the coordinates $x, y, z$, displacements $u, v, w$ and gap distance $h$ are dimensionalized by Hertzian half contact width $b$. The pressure, elastic stiffness matrix and stress are scaled by maximum Hertzian contact pressure. The dimensionless computational domain used is $[-3: 3,0: 6]$ for $2 \mathrm{D}$ and $[-3: 3,-3: 3,0: 6]$ for $3 \mathrm{D}$.

Figure 5(a) shows a 2D Voronoi tessellation in which the black and green regions represent randomly selected inclusions. Fig. 5 (b) (d) show the top pressure distribution, gap distance and subsurface Von Mises stress respectively. Fig. 5(b) and (c) give results when the black and green regions in Fig. 5(a) represent inclusions four times softer or harder than the bulk material. Fig. 5(d) shows the result when the black regions are treated as hard inclusions and the green regions as soft. The Von Mises stress shows that both soft and hard inclusions act as local stress raisers. Hard inclusions result in larger local stress concentration, which increases $21 \%$ compared to the result of soft inclusions. 
When inclusions are sufficiently close to the surface, they affect the contact pressure distribution [17]. The local stress concentration is detrimental for the fatigue life of bearing material. Compared to homogeneous material, cracks are likely to initiated at/near the inclusions [6].

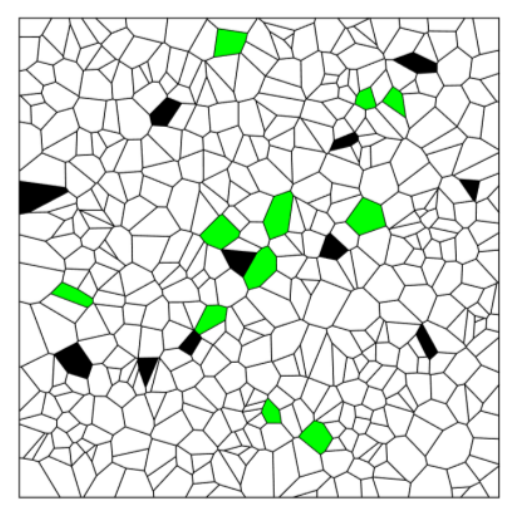

(a) 2D Voronoi tessellation

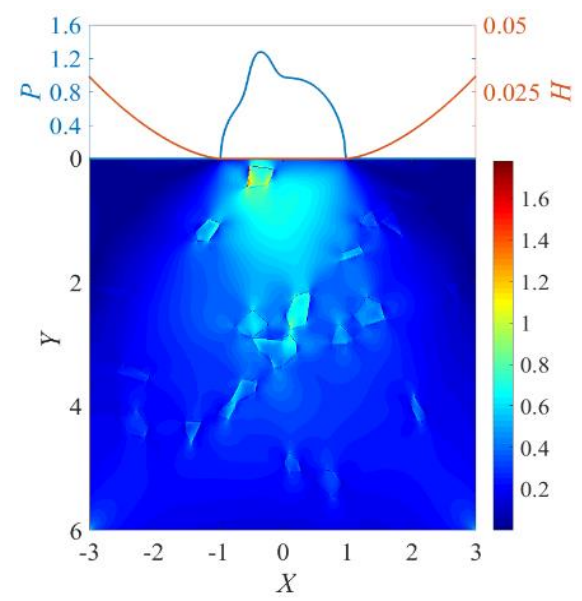

(c) $E_{\mathrm{i}}=4 E$

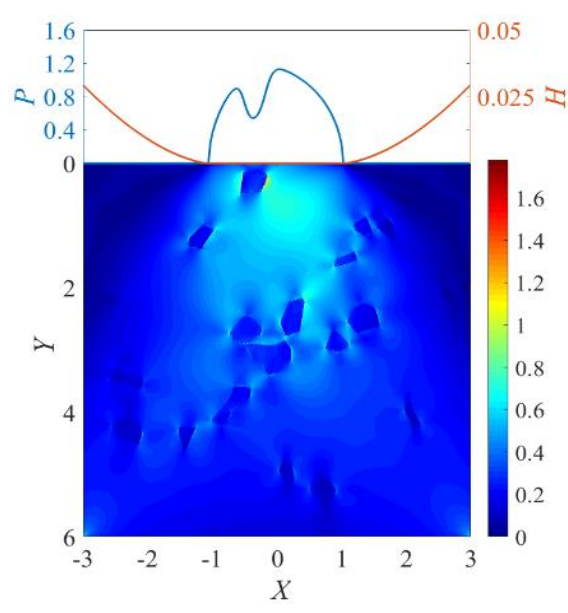

(b) $E_{\mathrm{i}}=0.25 E$

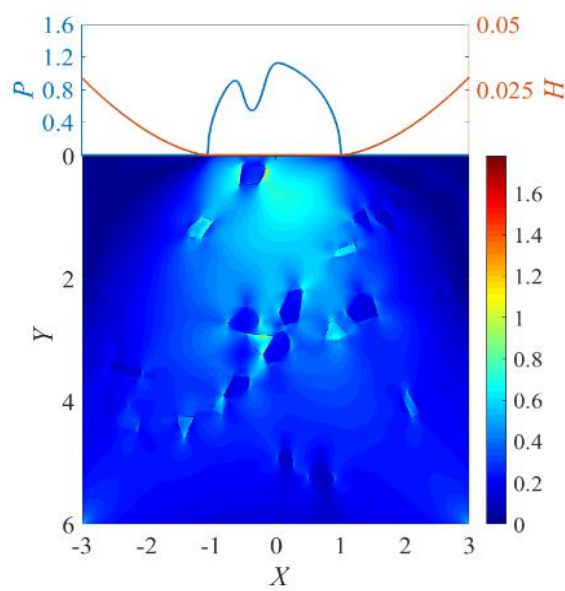

(d) $\left(E_{\mathrm{i}}\right)_{\text {green }}=0.25 E$ and $\left(E_{\mathrm{i}}\right)_{\text {black }}=4 E$

Figure 5 Voronoi tessellation and top boundary pressure, gap distance and Von Mises stress distribution

Figure 6 shows the influence of the load (relative to the homogeneous case) 
on the maximum Von Mises stress value and its location for the case studied in Fig.5 (d). For low loads (below 1.0), the maximum Von Mises stress increases with load and its location remains at one of the near surface inclusions. For higher loads (larger than 1.0), the location of the maximum Von Mises stress changes to deeper inclusions. With the increase of the load, the variation of maximum Von Mises stress becomes steeper. In the end, the value of maximum Von Mises stress is around eight times that of the lowest load case. Thus, the potential possibility of crack formation is much higher with a heavy load in the presence of inclusions.

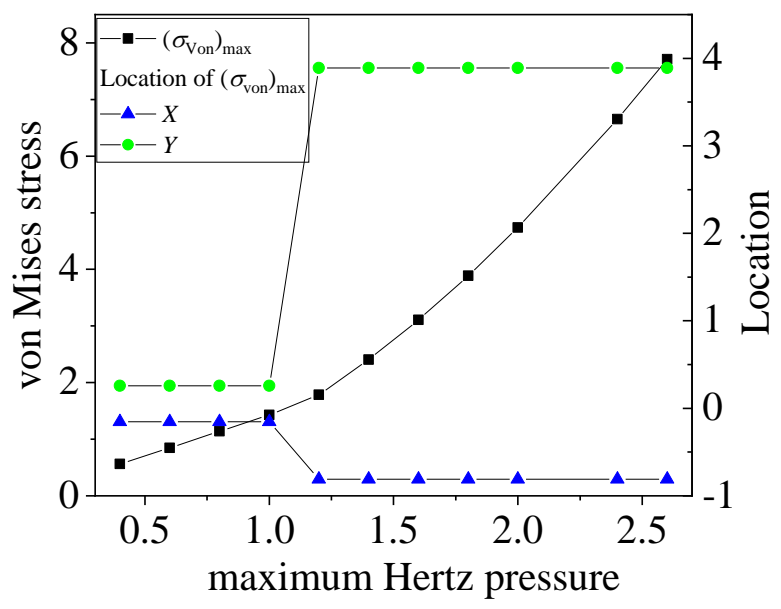

Figure 6 The influence of load on the maximum Von Mises stress

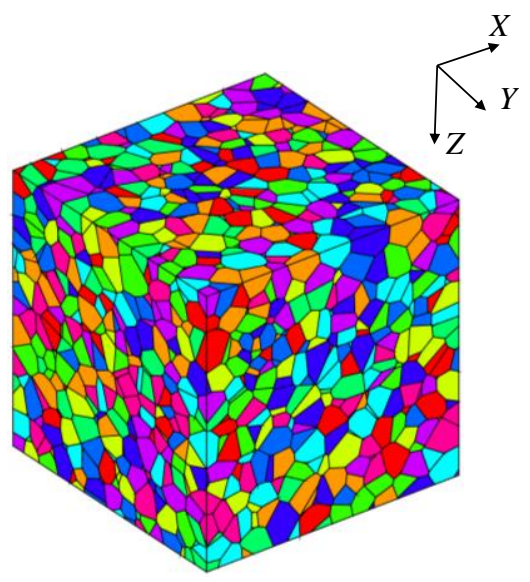

(a) 3D Voronoi tessellation 


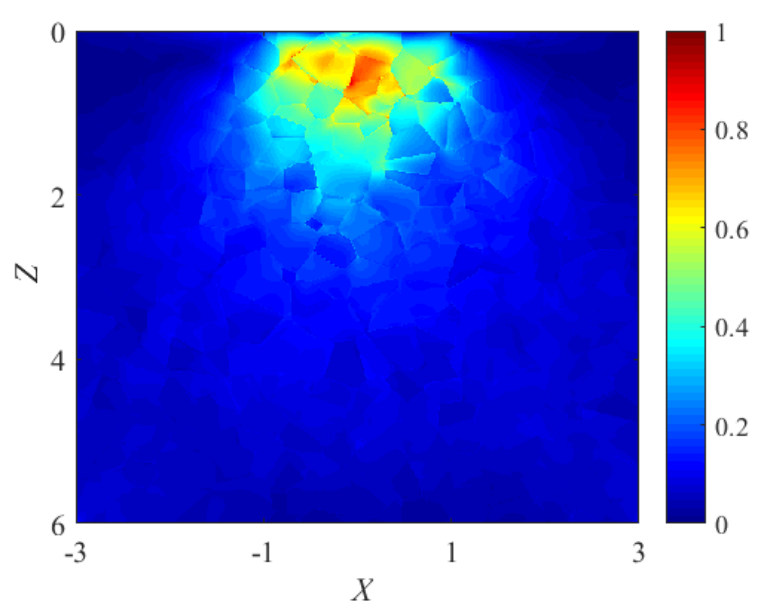

(b) $X Z$ plane $(Y=0)$
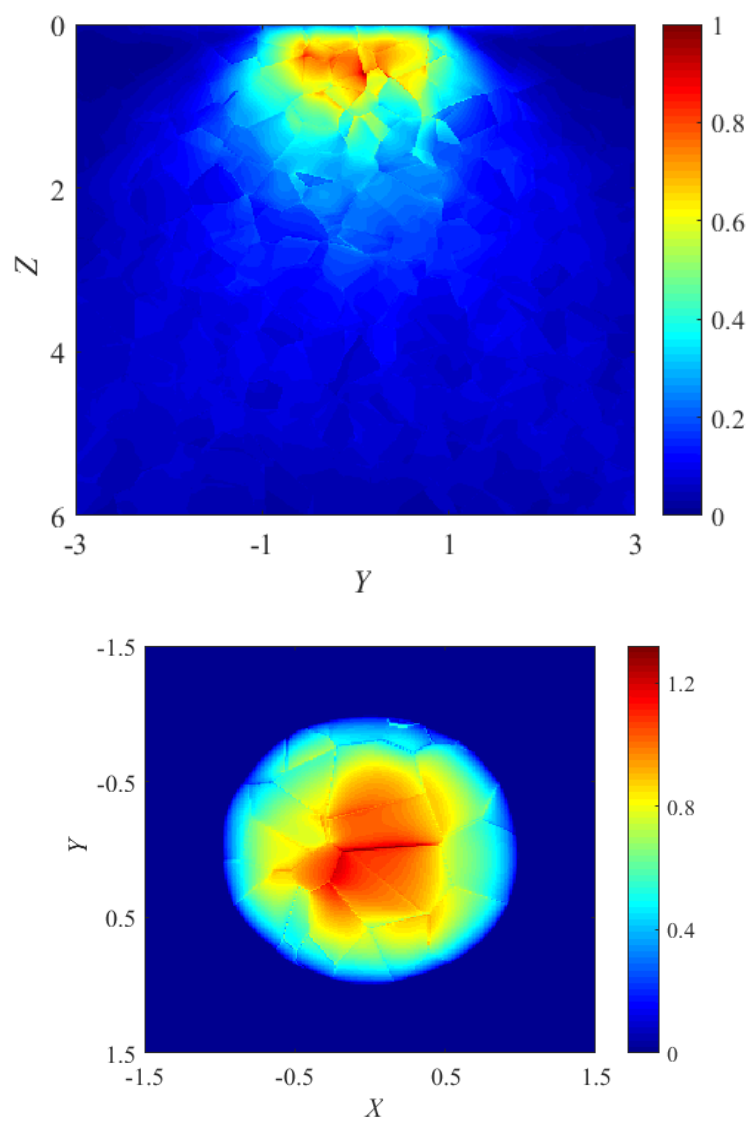

(c) $Y Z$ plane $(X=0)$

(d) Top surface pressure distribution

Figure 7 Voronoi tessellation and Von Mises stress, contact pressure distribution 
Next, a more challenging 3D problem is considered for which the solver was developed, i.e. anisotropic material and where the efficiency of multigrid method is really needed. Fig.7 (a) shows the 3D Voronoi tessellation [18]. The parameters of grain elastic stiffness matrix in local coordinate system are given in Table 1. Material and contact parameters are as given in Table 2. Each grain is assigned three random Euler angles $\alpha, \beta, \gamma$, ranging from 0 to $\pi / 2$. From local coordinate system to global coordinate system, the rotation of the elastic stiffness matrix is based on Eq. (7).

The Von Mises stress in the central $X Z$ and $Y Z$ planes is shown in Fig.7 (b) and (c) respectively. Note that a difference of rotation angles between grains in the anisotropic material represents different stiffness properties in the global coordinate system. As a result, some grains behave as hard inclusions whereas others behave as soft inclusions. Stress concentrations appear around grain boundaries with large rotation angle variation. Figure 7 (d) shows the top surface pressure distribution. The change of local grain orientation induces significant variation of the pressure relative to the homogeneous anisotropic case. Pressure fluctuations appear near the grain boundaries. In order to achieve a smooth transition between grain boundaries for stress field and extend the fatigue life of rolling bearings, the variation of local grain orientation should be reduced.

Finally, it is demonstrated that the developed algorithm can efficiently deal with the combined case of a complex contact problem with local separation due to roughness and material anisotropy. Figure 8 shows the influence of an isotropic harmonic surface waviness (with wavelength $45.68 \mu \mathrm{m}$ and amplitude $0.069 \mu \mathrm{m}$ ) on the contact pressure and the Von Mises stress distribution. It can be seen from the contact pressure (Fig. 8(a)) that the relatively large amplitude of the waviness leads to multiple isolated contact islands at the peaks. Regarding the behavior of the Von-Mises stress, it leads to shallow concentrations, which are detrimental for the contact bodies. To avoid these, the rollers and raceway of rolling bearings should be manufactured with good surface finish. This result demonstrates that the developed algorithm is fully suited for extensive studies of anisotropic material behavior in contact applications. 


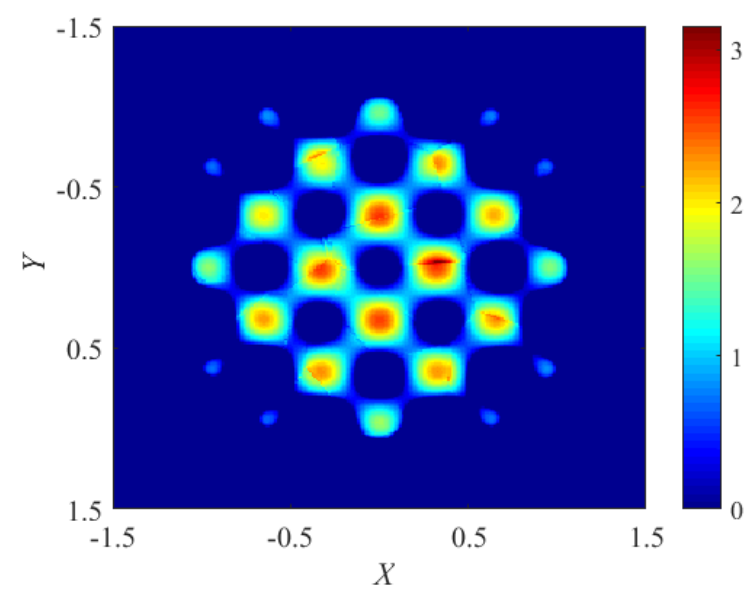

(a) Pressure distribution of rough contact

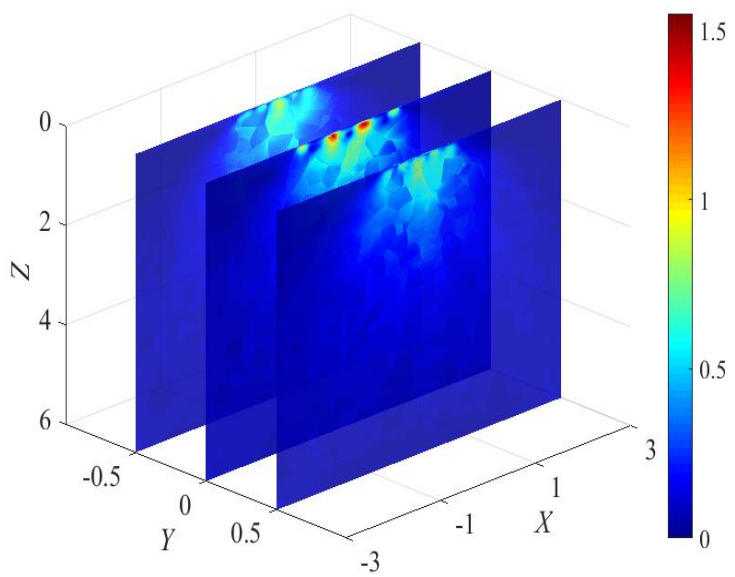

(b) Von Mises stress of $X Z$ planes

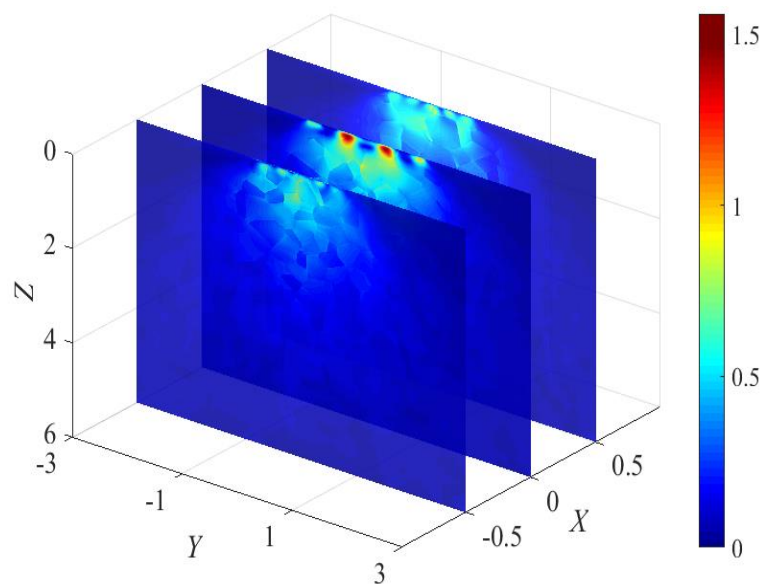

(c) Von Mises stress of $Y Z$ planes

Figure 8 Effect of roughness on pressure and Von Mises stress distribution 


\section{Discussion}

Both soft and hard inclusions affect the subsurface stress distribution (Fig. 5 (b)-(d)). The local stress variation is unbeneficial for fatigue life of rolling bearings. After millions of load cycles, cracks may be easier to occur around these inclusions. And the cracks will gradually grow in the horizontal and vertical directions and result in material spalling eventually. The influence of anisotropy on the subsurface stress field is not obvious as that is shown in the inclusions case. With the decrease of grain size and local anisotropy variation, its effect will become tinier.

Material inclusions and anisotropy also affect contact pressure distribution. When contact bodies are lubricated, the EHL pressure distribution can be affected by material inclusions and anisotropy as well [7,11]. Thus, in order to extend the fatigue life of rolling bearings, the size and number of inclusions and local anisotropy variation in bearing material should be minimized as much as possible by modern manufacturing technology.

\section{Conclusions and future research}

A multigrid solver has been developed for the numerical solution of the contact problem and subsurface stress field calculation in inhomogeneous and anisotropic materials. Excellent performance has been demonstrated for a 2D problem with inclusions and a 3D problem with grain elasticity (anisotropy) and surface roughness. The developed method can solve problems with high spatial resolution allowing detailed study of local variations in the material. From the results presented, it is concluded that:

1. Material inclusions and anisotropy significantly affect subsurface stress and contact pressure distribution, where these effects significantly increase with increasing load.

2. Surface roughness brings stress concentration point near the contact surface, possibly augmenting material anisotropic effects and are therefore detrimental for rolling bearing fatigue life.

The high efficiency and accuracy of the developed algorithm allows detailed simulations even on relatively standard personal computers. The algorithm can be exploited for many other studies such as: material optimization on a local scale with the aim to extend the fatigue life of rolling bearings. The 
determination of criticality criteria for local material variations/inclusions, and computational diagnostics based on tomographic images. Finally, the developed method can relatively easily be coupled with EHL and study the mutual influence between anisotropic inhomogeneous material and EHL pressure $[8,11]$.

\section{Acknowledgements}

The authors would like to thank Dr. Stefan Lammens, Director of SKF Research and Technology Development, for his kind permission to publish this article. The authors would also like to thank Professor A.A. Lubrecht of INSALyon, France, for the helpful discussions. Mr. Binbin Zhang would like to acknowledge the China Scholarship Council (CSC) for providing the $\mathrm{PhD}$ scholarship.

\section{Nomenclature}

$\begin{array}{ll}A & \text { anisotropy material ratio, (-) } \\ b & \text { half width of Hertzian contact (m) } \\ c_{11}, c_{12}, c_{44} & \text { elastic constants for cubic material, }(\mathrm{Pa}) \\ C, C_{\text {global }}, C_{\text {local }} & \text { elastic stiffness matrix, (Pa) } \\ E & \text { Young's modulus, (Pa) } \\ E_{\mathrm{i}} & \text { Young's modulus of inlusion, (Pa) } \\ F & \text { applied load, (N) for 3D problem, (N/m) for 2D problem } \\ g(x), g(x, y) & \text { shape of cylinder and sphere, (m) } \\ h & \text { gap between rigid indenter and top surface, (m) } \\ h_{x}, h_{y}, h_{z} & \text { mesh space in } x, y, z \text { directions, }(\mathrm{m}) \\ H & \text { dimensionless gap height, } h / b \\ h_{0} & \text { height of rigid indenter, (m) } \\ p & \text { contact pressure, (Pa) } \\ P & \text { dimensionless contact pressure, } p / p_{\mathrm{Hz}}\end{array}$




$\begin{array}{ll}R & \text { radius of rigid indenter, (m) } \\ p_{\mathrm{Hz}} & \begin{array}{l}\text { maximum Hertzian pressure for rigid indenter contacts with } \\ \text { elastic body, (Pa) }\end{array} \\ u, v, w & \text { displacements in } x, y, z \text { directions, (m) } \\ U, V, W & \text { dimensionless displacements, } u / b, v / b, w / b \\ x, y, z & \text { coordinate system, (m) } \\ X, Y, Z & \text { dimensionless coordinate system, } x / b, y / b, z / b \\ \sigma_{x x}, \sigma_{y y}, \sigma_{z z} & \text { normal stress, (Pa) } \\ \sigma_{x y}, \sigma_{x z}, \sigma_{y z} & \text { shear stress, (Pa) } \\ \bar{\sigma}_{\mathrm{von}} & \text { dimensionless Von Mises stress, } \sigma_{\mathrm{von}} / p_{\mathrm{Hz}} \\ \alpha, \beta, \gamma & \text { Euler rotation angle, (rad) } \\ \varepsilon & \text { Strain, (-) } \\ v & \text { Poisson's ratio, (-) } \\ \mu & \text { Lame modulus, (Pa) } \\ & \end{array}$

\section{References}

[1] Lundberg, G., \& Arvid P. (1947). Dynamic capacity of rolling bearings. Stockholm: Generalstabens litografiska anstalts förlag, (pp.1-52).

[2] Ioannides, E., \& Harris, T. A. (1985). A new fatigue life model for rolling bearings. Journal of Tribology, 107(3), 367-377. https://doi.org/10.1115/1.3261081.

[3] Morales-Espejel, G. E., Gabelli, A., \& De Vries, A. J. (2015). A model for rolling bearing life with surface and subsurface survival - tribological effects. Tribology Transaction, 58(5), 894-906. https://doi.org/10.1080/10402004.2015.1025932.

[4] Warhadpande, A., \& Sadeghi, F. (2010). Effects of surface defects on rolling contact fatigue of heavily loaded lubricated contacts. Proceedings of the Institution of Mechanical Engineers, Part J: Journal of Engineering Tribology, 224(10), 10611077. https://doi.org/10.1243/13506501JET785.

[5] Dong, Q., Yang, J., Wang, X., Keer, M., \& Zhou, K. (2016). Heterogeneous structures with inhomogeneous inclusions under elastohydrodynamic lubrication contact with consideration of surface roughness. Proceedings of the Institution of 
Mechanical Engineers, Part J: Journal of Engineering Tribology, 230(5), 571-582. https://doi.org/10.1177/1350650115606944.

[6] Moghaddam, S. M., Sadeghi F., Paulson, K., Weinzapfel, N., Correns, M., Bakolas, V., \& Dinkel, M. (2015). Effect of non-metallic inclusions on butterfly wing initiation, crack formation, and spall geometry in bearing steels. International Journal of Fatigue, 80, 203-215. https://doi.org/10.1016/j.ijfatigue.2015.05.010.

[7] Slack, T. S., Raje, N., Sadeghi, F., Doll, G., \& Hoeprich, M. R. (2007). EHL modeling for nonhomogeneous materials: the effect of material inclusions, Journal of Tribology, 129(2), 256-273. https://doi.org/10.1115/1.2540234.

[8] Morales-Espejel, G. E., Boffy, H., \& Venner, C. H. (2017). Effects of material heterogeneity on surface fatigue for rough lubricated rolling-sliding contacts. Proceedings of the Institution of Mechanical Engineers, Part J: Journal of Engineering Tribology, 231(2), 274-290. https://doi.org/10.1177/1350650116650126.

[9] Venner, C. H., \& Lubrecht, A. A. (2000). Multi-level methods in lubrication. Amsterdam: Elsevier.

[10] Noyel, J. P., Ville, F., Jacquet, P., Gravouil, A., \& Changenet, C. (2016). Development of a granular cohesive model for rolling contact fatigue analysis: crystal anisotropy modelling. Tribology Transactions, 59(3), 469-479. https://doi.org/10.1080/10402004.2015.1087076.

[11] Paulson, N. R., \& Sadeghi, F. (2017). EHL modeling of nonhomogeneous materials: The effects of polycrystalline anisotropy on RCF. Tribology International, 112, 137-146. https://doi.org/10.1016/j.triboint.2017.04.007.

[12] Boffy, H., Baietto, M. C., Sainsot, P., \& Lubrecht, A. A. (2012). An efficient 3D model of heterogeneous materials for elastic contact applications using multigrid methods. Journal of tribology, 134(2), 021401. https://doi.org/10.1115/1.4006296.

[13] Boffy, H., \& Venner, C. H. (2014). Multigrid solution of the 3D stress field in strongly heterogeneous materials. Tribology international, 74, 121-129. https://doi.org/10.1016/j.triboint.2014.02.019.

[14] Boffy, H., \& Venner, C. H. (2015). Multigrid numerical simulation of contact mechanics of elastic materials with 3D heterogeneous subsurface topology. Tribology international, 233-245. https://doi.org/10.1016/j.triboint.2015.06.015.

[15] Pérez-Ruiz, J. A., Luzón, F., \& García-Jerez, A. (2005). Simulation of an irregular free surface with a displacement finite-difference scheme, Bulletin of the Seismological Society of America, 95(6), 2216-2231. https://doi.org/10.1785/0120050014.

[16] Bower, A. F. (2009). Applied mechanics of solids. United States: CRC press.

[17] Zhang, M., Zhao, N., Wang, Z., \& Wang, Q. (2018). Efficient numerical method with a dual-grid scheme for contact of inhomogeneous materials and its applications. Computational Mechanics, 1-17. https://doi.org/10.1007/s00466-0181543-3. 
[18] Herceg, M., Kvasnica, M., Jones, C. N., \& Morari, M. (2013). Multi-parametric toolbox 3.0. In European Control Conference (ECC), 502-510. https://doi.org/10.23919/ECC.2013.6669862.

\section{Appendix A. Discrete equations}

The Voigt stress-strain relation is given in Eq. (9)

$$
\left[\begin{array}{l}
\sigma_{x x} \\
\sigma_{y y} \\
\sigma_{z z} \\
\sigma_{y z} \\
\sigma_{x z} \\
\sigma_{x y}
\end{array}\right]=C\left[\begin{array}{c}
\varepsilon_{x x} \\
\varepsilon_{y y} \\
\varepsilon_{z z} \\
2 \varepsilon_{y z} \\
2 \varepsilon_{x z} \\
2 \varepsilon_{x y}
\end{array}\right]
$$

where $C$ is the elastic stiffness matrix, for isotropic material, it has the form as Eq. (10)

$$
C=\left[\begin{array}{cccccc}
\lambda+2 \mu & \lambda & \lambda & 0 & 0 & 0 \\
\lambda & \lambda+2 \mu & \lambda & 0 & 0 & 0 \\
\lambda & \lambda & \lambda+2 \mu & 0 & 0 & 0 \\
0 & 0 & 0 & \mu & 0 & 0 \\
0 & 0 & 0 & 0 & \mu & 0 \\
0 & 0 & 0 & 0 & 0 & \mu
\end{array}\right]
$$

where $\lambda=\frac{v E}{(1+v)(1-2 v)}, \mu=\frac{E}{2(1+v)}$. For anisotropic material (cubic), it is given in Eq. (11).

$$
\begin{gathered}
C=\left[\begin{array}{cccccc}
c_{11} & c_{12} & c_{12} & 0 & 0 & 0 \\
c_{12} & c_{11} & c_{12} & 0 & 0 & 0 \\
c_{12} & c_{12} & c_{11} & 0 & 0 & 0 \\
0 & 0 & 0 & c_{44} & 0 & 0 \\
0 & 0 & 0 & 0 & c_{44} & 0 \\
0 & 0 & 0 & 0 & 0 & c_{44}
\end{array}\right] \\
C=\left[\begin{array}{lllllll}
c_{1111} & c_{1122} & c_{1133} & c_{1123} & c_{1113} & c_{1112} \\
c_{2211} & c_{2222} & c_{2233} & c_{2223} & c_{2213} & c_{2212} \\
c_{3311} & c_{3322} & c_{3333} & c_{3323} & c_{3313} & c_{3312} \\
c_{2311} & c_{2322} & c_{2333} & c_{2323} & c_{2313} & c_{2312} \\
c_{1311} & c_{1322} & c_{1333} & c_{1323} & c_{1313} & c_{1312} \\
c_{1211} & c_{1222} & c_{1233} & c_{1223} & c_{1213} & c_{1212}
\end{array}\right]
\end{gathered}
$$

The difference of the two matrices is the value of $c_{44}$, which determines the anisotropy ratio $A=2 c_{44} /\left(c_{11}-c_{12}\right)$ to be different from 1 . Note that due to 
this difference, the matrix $C$ in global coordinates is a full matrix. Below, the detailed equations and discretization are given for the 3D anisotropic case.

\section{A.1 Interior equations}

According to the above description, the detailed 3D stress equilibrium equation in $x$ direction can be written as:

$$
\begin{gathered}
\frac{\partial}{\partial x}\left(\begin{array}{c}
c_{1111} \frac{\partial u}{\partial x}+c_{1122} \frac{\partial v}{\partial y}+c_{1133} \frac{\partial w}{\partial z}+ \\
c_{1123}\left(\frac{\partial v}{\partial z}+\frac{\partial w}{\partial y}\right)+c_{1113}\left(\frac{\partial u}{\partial z}+\frac{\partial w}{\partial x}\right)+c_{1112}\left(\frac{\partial u}{\partial y}+\frac{\partial v}{\partial x}\right)
\end{array}\right)+ \\
\frac{\partial}{\partial y}\left(\begin{array}{c}
c_{1211} \frac{\partial u}{\partial x}+c_{1222} \frac{\partial v}{\partial y}+c_{1233} \frac{\partial w}{\partial z}+ \\
c_{1223}\left(\frac{\partial v}{\partial z}+\frac{\partial w}{\partial y}\right)+c_{1213}\left(\frac{\partial u}{\partial z}+\frac{\partial w}{\partial x}\right)+c_{1212}\left(\frac{\partial u}{\partial y}+\frac{\partial v}{\partial x}\right)
\end{array}\right)+ \\
\frac{\partial}{\partial z}\left(\begin{array}{c}
c_{1311} \frac{\partial u}{\partial x}+c_{1322} \frac{\partial v}{\partial y}+c_{1333} \frac{\partial w}{\partial z}+ \\
c_{1323}\left(\frac{\partial v}{\partial z}+\frac{\partial w}{\partial y}\right)+c_{1313}\left(\frac{\partial u}{\partial z}+\frac{\partial w}{\partial x}\right)+c_{1312}\left(\frac{\partial u}{\partial y}+\frac{\partial v}{\partial x}\right) \\
=0
\end{array}\right)
\end{gathered}
$$

The bold terms with blue colour in Eq. (13) directly follow from Eq. (10) and (11). The other terms result from the matrix rotation from the local coordinate system to the global coordinate system. Obviously when the material is homogeneous anisotropic and the global coordinate system aligns with the direction of anisotropy, these terms will disappear.

The equations are discretized using finite differences. The indices $i, j, k$ are used for $x, y, z$ direction respectively. The mesh size for each dimension is $h_{x}, h_{y}, h_{z}$. For the results shown above, a uniform mesh space is used. The discretization of the first term $\frac{\partial}{\partial x}()$ in Eq. (13) at grid point $(i, j, k)$ is given in Eq. (14). The discretization of the $\frac{\partial}{\partial y}()$ and the $\frac{\partial}{\partial z}()$ in Eq. (13) as well as the discretization of the equations for $y$ and $z$ directions in Eq. (1) can be done in the same way. 


$$
\begin{gathered}
\frac{\left(c_{1111}\right)_{i+\frac{1}{2}, j, k} u_{i+1, j, k}-\left(\left(c_{1111}\right)_{i+\frac{1}{2}, j, k}+\left(c_{1111}\right)_{i-\frac{1}{2}, j, k}\right) u_{i, j, k}+\left(c_{1111}\right)_{i-\frac{1}{2}, j, k} u_{i-1, j, k}}{h_{x}^{2}}+ \\
\frac{\left(c_{1122}\right)_{i+1, j, k}\left(v_{i+1, j+1, k}-v_{i+1, j-1, k}\right)-\left(c_{1122}\right)_{i-1, j, k}\left(v_{i-1, j+1, k}-v_{i-1, j-1, k}\right)}{4 h_{x} h_{y}}+ \\
\frac{\left(c_{1133}\right)_{i+1, j, k}\left(w_{i+1, j, k+1}-w_{i+1, j, k-1}\right)-\left(c_{1133}\right)_{i-1, j, k}\left(w_{i-1, j, k+1}-w_{i-1, j, k-1}\right)}{4 h_{x} h_{z}}+ \\
\frac{\left(c_{1123}\right)_{i+1, j, k}\left(v_{i+1, j, k+1}-v_{i+1, j, k-1}\right)-\left(c_{1123}\right)_{i-1, j, k}\left(v_{i-1, j, k+1}-v_{i-1, j, k-1}\right)}{4 h_{x} h_{z}}+ \\
\frac{\left(c_{1123}\right)_{i+1, j, k}\left(w_{i+1, j+1, k}-w_{i+1, j-1, k}\right)-\left(c_{1123}\right)_{i-1, j, k}\left(w_{i-1, j+1, k}-w_{i-1, j-1, k}\right)}{4 h_{x} h_{y}}+ \\
\frac{\left(c_{1113}\right)_{i+1, j, k}\left(u_{i+1, j, k+1}-u_{i+1, j, k-1}\right)-\left(c_{1113}\right)_{i-1, j, k}\left(u_{i-1, j, k+1}-u_{i-1, j, k-1}\right)}{4 h_{x} h_{z}}+ \\
\frac{\left(c_{1113}\right)_{i+\frac{1}{2}, j, k} w_{i+1, j, k}-\left(\left(c_{1113}\right)_{i+\frac{1}{2}, j, k}+\left(c_{1113}\right)_{i-\frac{1}{2}, j, k}\right) w_{i, j, k}+\left(c_{1113}\right)_{i-\frac{1}{2}, j, k} w_{i-1, j, k}}{h_{x}^{2}}+ \\
\frac{\left(c_{1112}\right)_{i+1, j, k}\left(u_{i+1, j+1, k}-u_{i+1, j-1, k}\right)-\left(c_{1112}\right)_{i-1, j, k}\left(u_{i-1, j+1, k}-u_{i-1, j-1, k}\right)}{4 h_{x} h_{y}}+ \\
h_{x}^{2} v_{i+1, j, k}-\left(\left(c_{1112}\right)_{i+\frac{1}{2}, j, k}+\left(c_{1112}\right)_{i-\frac{1}{2}, j, k}\right) v_{i, j, k}+\left(c_{1112}\right)_{i-\frac{1}{2}, j, k} v_{i-1, j, k} \\
\hline
\end{gathered}
$$

\section{A.2 Boundary equations}

For the top boundary, without considering friction in $x$ and $y$ directions, when the indenter contacts the elastic body, the following equations are used:

$$
\begin{gathered}
c_{1311} \frac{\partial u}{\partial x}+c_{1322} \frac{\partial v}{\partial y}+c_{1333} \frac{\partial w}{\partial z}+ \\
c_{1323}\left(\frac{\partial v}{\partial z}+\frac{\partial w}{\partial y}\right)+c_{1313}\left(\frac{\partial u}{\partial z}+\frac{\partial w}{\partial x}\right)+c_{1312}\left(\frac{\partial u}{\partial y}+\frac{\partial v}{\partial x}\right)=0 \\
c_{2311} \frac{\partial u}{\partial x}+c_{2322} \frac{\partial v}{\partial y}+c_{2333} \frac{\partial w}{\partial z}+ \\
c_{2323}\left(\frac{\partial v}{\partial z}+\frac{\partial w}{\partial y}\right)+c_{2313}\left(\frac{\partial u}{\partial z}+\frac{\partial w}{\partial x}\right)+c_{2312}\left(\frac{\partial u}{\partial y}+\frac{\partial v}{\partial x}\right)=0 \\
h_{0}+g(x, y)-w(x, y, z=0)=0
\end{gathered}
$$




$$
\begin{gathered}
c_{3311} \frac{\partial u}{\partial x}+c_{3322} \frac{\partial v}{\partial y}+c_{3333} \frac{\partial w}{\partial z}+c_{3323}\left(\frac{\partial v}{\partial z}+\frac{\partial w}{\partial y}\right) \\
+c_{3313}\left(\frac{\partial u}{\partial z}+\frac{\partial w}{\partial x}\right)+c_{3312}\left(\frac{\partial u}{\partial y}+\frac{\partial v}{\partial x}\right)+p=0
\end{gathered}
$$

The above four equations are solved to determine the displacements $u, v, w$ and the pressure $p$. When the indenter does not contact with the elastic body, i.e. the value of the third equation is larger than zero, the displacement $w$ is solved by the fourth equation with $p=0$. The discretization form for $\sigma_{x z}$ at grid point $(i, j$, 0 ) is given in Eq. (19). The rules for this discretization are as follow: 1. the item with $u$ that exists before rotation uses second order forward discretization; 2 . the items with $u$ that are introduced after rotation use second order central discretization; 3 . the items with $v$ and $w$ use second order central discretization in $x$ and $y$ directions and use first order discretization in $z$ direction. Eqs. 15, 16 and 18 can be discretized according to this rule. Note that for Eq. (16), $u$ in rule 1 and 2 is replace by $v$, and $v, w$ in rule 3 are replace by $u, w$. For Eq. (18), $u$ in rule 1 and 2 is replace by $w$, and $v, w$ in rule 3 are replace by $u, v$. The vertical boundaries are similar to the top boundary when the indenter does not contact the elastic body. And its discretization can be finished according to the top boundary.

$$
\begin{aligned}
& c_{1311} \frac{u_{i+1, j, 0}-u_{i-1, j, 0}}{2 h_{x}}+c_{1322} \frac{v_{i, j+1,0}-v_{i, j-1,0}}{2 h_{y}}+c_{1333} \frac{w_{i, j, 0}-w_{i, j, 1}}{h_{z}}+ \\
& c_{1323}\left(\frac{v_{i, j, 0}-v_{i, j, 1}}{h_{z}}+\frac{w_{i, j+1,0}-w_{i, j-1,0}}{2 h_{y}}\right)+ \\
& c_{1313}\left(\frac{1.5 u_{i, j, 0}-2.0 u_{i, j, 1}+0.5 u_{i, j, 2}}{h_{z}}+\frac{w_{i+1, j, 0}-w_{i-1, j, 0}}{2 h_{x}}\right)+ \\
& c_{1312}\left(\frac{u_{i, j+1,0}-u_{i, j-1,0}}{2 h_{y}}+\frac{v_{i+1, j, 0}-v_{i-1, j, 0}}{2 h_{x}}\right)=0
\end{aligned}
$$

The discrete force balance equation reads:

$$
h_{x} h_{y} \sum_{i} \sum_{j} p_{i, j}=F
$$




\section{Appendix B. Relaxation}

The following analysis is for 3D case and applies to 2D problem as well.

\section{B.1 Interior equations}

The coupling of interior equations in the $x, y$ and $z$ directions is weak here. Thus, the equations in the $x, y$ and $z$ directions can be used for solving unknown displacement $u, v, w$ correspondingly. The three equations are relaxed consecutively. For Eq. (13), a new approximation to $\bar{u}_{i, j, k}$ is:

$$
\begin{gathered}
\tilde{u}_{i, j, k}=\bar{u}_{i, j, k}+r_{i, j, k} /\left(\frac{\partial L_{i, j, k}}{\partial u_{i, j, k}}\right) \\
\frac{\partial L_{i, j, k}}{\partial u_{i, j, k}}=-\frac{\left(c_{1111}\right)_{i+\frac{1}{2}, j, k}+\left(c_{1111}\right)_{i-\frac{1}{2}, j, k}}{h_{x}^{2}}-\frac{\left(c_{1212}\right)_{i, j+\frac{1}{2}, k}+\left(c_{1212}\right)_{i, j-\frac{1}{2}, k}}{h_{y}^{2}} \\
-\frac{\left(c_{1313}\right)_{i, j, k+\frac{1}{2}}+\left(c_{1313}\right)_{i, j, k-\frac{1}{2}}}{h_{z}^{2}}
\end{gathered}
$$

where $r_{i, j, k}$ is the current function residual, $\tilde{u}_{i, j, k}$ is the displacement after relaxations. Gauss-Seidel relaxation is used and the grid points are scanned in a prescribed order. After a whole calculation domain scan, equations in $y$ and $z$ directions are relaxed sequentially. To reach optimum multigrid performance, more relaxations are performed for the points that are close to the top and vertical boundaries.

\section{B.2 Top boundary equations}

$$
\left[\begin{array}{cccc}
\frac{1.5 c_{1313}}{h_{z}} & \frac{c_{1323}}{h_{z}} & \frac{c_{1333}}{h_{z}} & 0 \\
\frac{c_{2313}}{h_{z}} & \frac{1.5 c_{2323}}{h_{z}} & \frac{c_{2333}}{h_{z}} & 0 \\
0 & 0 & -1 & 0 \\
\frac{c_{3313}}{h_{z}} & \frac{c_{3323}}{h_{z}} & \frac{1.5 c_{3333}}{h_{z}} & 1
\end{array}\right]\left[\begin{array}{l}
\delta u \\
\delta v \\
\delta w \\
\delta p
\end{array}\right]=\left[\begin{array}{l}
r_{u} \\
r_{v} \\
r_{w} \\
r_{p}
\end{array}\right]
$$

Different from the interior equations, the top boundary equations have a strong coupling. Here, the coupled or collective relaxation is used [14]. It means that the unknown values $u, v, w, p$ are solved simultaneously at each point. When the indenter contacts with the elastic body, its coupled relaxation is given in Eq. (23). In which, $r_{u}, r_{v}, r_{w}, r_{p}$ are the function residual of Eq. (2-4), $\delta u, \delta v, \delta w$, 
$\delta p$ are variables that make the function residual become zero when it is added to the current approximation. When the indenter does not contact with the elastic body, the third equation is removed with $p=0$, which results in $3 \times 3$ system for a stress free boundary condition. After Eq. (23) is solved, a relaxation parameter is used to apply changes to the current approximation. The adjustment of $h_{0}$ is performed on the lowest grid level every few cycles by the load balance equation,

$$
\tilde{h}_{0}=\bar{h}_{0}+\omega\left(F-h_{x} h_{y} \sum_{i} \sum_{j} p_{i, j}\right)
$$

where $\omega$ is a relaxation parameter.

B.3 Vertical boundary equations

The relaxation of vertical boundaries is similar as the interior equations. The relaxation of $u$ uses the equations associated to it. After the relaxation of $u$ on vertical planes, relaxations for $v$ and $w$ are performed sequentially. Special attention should be paid to the lines and points of intersections, as it uses two or three stresses together to relax. 

Appendix: Paper B 
Effects of 3D anisotropic heterogeneous subsurface topology on film thickness, pressure, and subsurface stresses in an elasto-hydrodynamically lubricated point contact

\author{
Binbin Zhanga*, Haichao Liu ${ }^{\mathrm{b}}$, Armando Félix Quiñonez ${ }^{\mathrm{c}}$, Cornelis H. Venner ${ }^{\mathrm{a}}$ \\ a Faculty of Engineering Technology, University of Twente, 7500AE Enschede, The \\ Netherlands \\ ${ }^{\mathrm{b}}$ Institute of Machine Design and Tribology, University of Hannover, 30167 Hannover, \\ Germany \\ c SKF Research and Technology Development, Meidoornkade 14, 3992AE Houten, The \\ Netherlands
}

\begin{abstract}
Bearing steel on a sufficiently small scale is strongly heterogeneous and anisotropic. To enable evaluation of the criticality of particular aspects of the microstructure, in this paper an EHL model is solved by the developed multigrid algorithm for a full 3D elastic domain containing varying anisotropic heterogeneous material. Pressure fluctuations and local stress concentrations occur mostly near the boundaries of grains that have large orientation differences. As a consequence, the crystallographic microstructure may have a significant effect on rolling contact fatigue life unless grains are very small relative to the Hertzian contact. However, to the contrary, the influence of crystallographic microstructure on the film thickness distribution under the considered steady state conditions is very small.
\end{abstract}

\title{
Keywords
}

Coupled EHL, Anisotropic material, Contact stress, Multigrid method

\section{Introduction}

The increasing awareness of the adverse consequences of climate change for life and its (bio)diversity on our planet is an increasingly strong urge towards greener and more sustainable technology development ranging from energy production to product development in industry. Reduced use of resources, i.e. material usage, reduced emissions and optimization of efficiency including minimization of frictional losses in processes and machine elements are key for current and future technology. Scientists and engineers face major challenges in every field. In engineering applications, these trends show in the development of lighter structures with stronger materials (such as new types of steel with higher 
strength, improved formability, achieving mass reduction without sacrificing toughness and strength [1 4]), in the development of new materials such as composite materials, and in continuous advances in additive manufacturing technologies facilitating local property optimization of (meta) materials for specific purposes, e.g. see Ref. [5].

As materials become more complex and product design, use and maintenance become more critical, there is a great need for accurate prediction of the effects of local variations in structure, properties, material topology (e.g. grain morphology, composite material fiber orientation and distribution) on the stresses and their consequences for service life. Numerical simulations have the potential to play a significant role, in particular as modern material analysis techniques such as electron back-scatter diffraction (EBSD) allow to obtain detailed information about the local material microstructure such as anisotropy variations, phase distribution, etc. Numerical simulations can directly use such microstructural information for computer diagnostics, or to derive macroscopic behavior from the local information using representative volume elements (RVE). In should be noted however that to translate the acquired 2D information in EBSD to actual 3D representative RVE's is not trivial, see Ref. [6]. In the past years, the number of publications dealing with such methods is increasing, e.g. Refs. $[2,4,7,8]$ and many others in various fields.

The above trend also applies to the analysis and performance prediction of tribological contacts such as the elastohydrodynamically lubricated (EHL) contacts between rollers and raceways in rolling bearings. Increasingly severe operating conditions as a result of downsizing and higher speeds lead to higher temperatures, lower viscosity, thinner films in starved contacts and mixed lubrication with increased effect of roughness. As a result of decades of research aided by efficient numerical simulation methods [9] and accurate experimental techniques, e.g. optical interferometry on single ball on disc contacts $[10,11]$, many of these (transient) effects have been analyzed and can nowadays be predicted quite accurately. Recent work demonstrating this even involves lubrication by droplet supply, e.g. Ref. [12].

Most EHL contact studies so far have assumed homogeneous isotropic material. However, as mentioned above the bearing materials are significantly more complex. Firstly, non-metallic inclusions such as sulfides and oxides can be formed during the metallurgical process [13], carbides are also common. 
Studies into the effects of non-homogeneous materials on stresses date back to the 1960's, e.g. single and multiple layers [14]. Later, numerical methods were developed for contact problems with single or multiple layers in two and three dimensions using various numerical methods, and even including surface roughness [15 20]. Also since the pioneering work of Eshelby [21, 22], many studies have considered the effect of single or multiple inclusions on the stress field in the dry contact problem, e.g. Leroux et al. [23], Zhou et al. [24]. For computational efficiency Leroux et al. [23] applied an FFT based method. Zhou et al. [24] used a semi-analytical model for the subsurface. Boffy and Venner [25] developed a multigrid based algorithm which allows detailed 3D crystallographic microstructures to be analyzed.

Studying the EHL problem rather than the dry contact problem is more complex. Modelling the effect of inclusions requires simultaneous calculation of EHL pressure and subsurface stress field. Slack et al. [26] solved the coupled EHL problem with subsurface inclusions for line contact using the discrete element method. They found that the effect of soft and hard inclusions on the pressure and the film thickness distribution is similar to the effect of surface dents and bumps respectively. With the increase of the inclusions' depth, their influence gradually decreases. Wang et al. [27], Zhang et al. [28] and Dong et al. [29] applied the equivalent inclusion method to study EHL point contact problems with inhomogeneous materials. Their results showed that the EHL pressure and film thickness are disturbed due to the existence of subsurface inclusions. Besides, stress concentration appears around the inclusion. MoralesEspejel et al. [30] investigated EHL point contact problems considering surface roughness and material inhomogeneity. A rapid micro-EHL methodology and multigrid method are used to calculate the pressure and the stress distribution respectively. The developed method is of high efficiency, which is suitable for the analysis of realistic engineering problems. Félix Quiñonez and MoralesEspejel [31] studied the transient effects of a single subsurface inclusion passing through the EHL contact region under rolling and rolling sliding conditions for line contact problem. It was found that the two-wave film thickness variation mechanism observed in transient solutions for surface features also applies to the effects of inclusions on the film thickness.

As for dry contact also for EHL, isotropic material was assumed in most cases. However, the isotropy is the large scale behaviour resulting from many grains, and the anisotropic feature exists intrinsically due to grain orientation. In 
reality, bearing steel is far from isotropic on a microscopic scale. On the scale of the EHL contact region, the effect of the crystallographic microstructure on the stress distribution may be important, which has drawn comparatively less attention. Paulson et al. [32] and Noyel et al. [33] investigated its influence for a dry contact problem. Their results showed that the stress field was quite different from that of the isotropic material. Paulson et al. [34] studied anisotropic effect for the EHL line contact problem by finite element method. It was found that there are significant pressure and stress variations due to the inhomogeneous stiffness with its discontinuous behaviour at the grain boundaries.

With the margins between safe and fail becoming more critical, the effect of heterogeneity and varying anisotropy of the different grains on rolling contact fatigue (RCF) life, and thus the limitations of the validity of the common isotropic material assumption for RCF life predictions need to be predicted much more accurately in 3D configurations. Further development of numerical methods may contribute to increase the understanding of the effects of local grain orientation variations on stress concentrations, the accumulation of plastic deformation, and the processes by which this eventually leads to RCF. A key aspect for the contribution of numerical methods in material microstructural simulations is computational efficiency to deal with the dense grids needed to describe the small scale of the variations. For example, in Ref. [8], this is achieved by using multigrid methods and massive parallelization.

To the knowledge of the authors, the problem of an EHL point contact accounting for a 3D heterogeneous anisotropic material with many grains in varying orientation has not been studied yet. Most of the studies concerning heterogeneous materials with grains and an EHL lubricant film only consider 2D or line contact configurations, as a full 3D configuration is too computationally demanding. As a first step towards this capability, the authors have shown that simulations of 3D configurations for heterogeneous anisotropic materials using many grains are feasible for dry contact in Ref. [35] using multigrid based methods [9]. In this paper, we demonstrate that this also applies to the problem of EHL by presenting a multigrid based method for the simulation of the effects of heterogeneous anisotropic materials on the surface pressure, the EHL film thickness, and the subsurface stress field in 3D configurations. 


\section{Theoretical model}

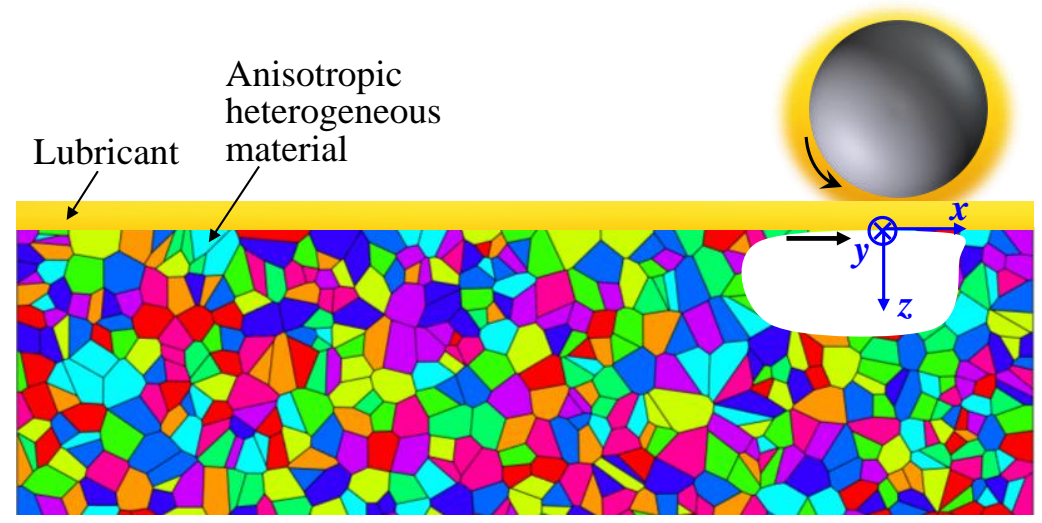

Figure 1 Schematic representation of an Elastohydrodynamically Lubricated contact between a sphere and a polycrystalline anisotropic material under pure rolling conditions. The coordinate system is attached to the contact. The colors indicate different grain orientations.

Figure 1 shows the schematic representation of the problem considered in this study. The colors represent grains with different crystal orientation angles. The grains are created by Voronoi tessellation. The contact is represented as that between a cubic volume of polycrystalline anisotropic material and a homogeneous rigid sphere, also depicted in Fig. 1. In this paper, we restrict ourselves to the steady state problem with constant load and the subsurface topology fixed relative to the reference coordinate system attached to the lubricated contact location. This is the case for a pure sliding contact of a homogeneous body over a heterogeneous body, or for a contact under pure rolling of the bodies with the same topology. The extension to the case where the topology relative to the contact varies in time requires solving the time dependent problem. The method presented here can be readily extended in the same way as is done in conventional EHL problems [36]. For any points inside the polycrystalline solid volume, the stress equilibrium equation is:

$$
\left\{\begin{array}{l}
\frac{\partial \sigma_{x x}}{\partial x}+\frac{\partial \sigma_{y x}}{\partial y}+\frac{\partial \sigma_{z x}}{\partial z}=0 \\
\frac{\partial \sigma_{x y}}{\partial x}+\frac{\partial \sigma_{y y}}{\partial y}+\frac{\partial \sigma_{z y}}{\partial z}=0 \\
\frac{\partial \sigma_{x z}}{\partial x}+\frac{\partial \sigma_{y z}}{\partial y}+\frac{\partial \sigma_{z z}}{\partial z}=0
\end{array}\right.
$$


where

$$
\left[\begin{array}{c}
\sigma_{x x} \\
\sigma_{y y} \\
\sigma_{z z} \\
\sigma_{y z} \\
\sigma_{x z} \\
\sigma_{x y}
\end{array}\right]=C\left[\begin{array}{c}
\partial u / \partial x \\
\partial v / \partial y \\
\partial w / \partial z \\
\partial v / \partial z+\partial w / \partial y \\
\partial u / \partial z+\partial w / \partial x \\
\partial u / \partial y+\partial v / \partial x
\end{array}\right]
$$

with $C$ the stiffness matrix in the global coordinate system $x, y, z$. It can be obtained from the stiffness matrix in the local grain coordinate system by:

$$
\left(C_{i, j, k, l}\right)_{\text {global }}=R_{x}(\alpha) R_{y}(\beta) R_{z}(\gamma)\left(C_{i, j, k, l}\right)_{\text {local }}\left(R_{x}(\alpha) R_{y}(\beta) R_{z}(\gamma)\right)^{T}
$$

$\alpha, \beta$ and $\gamma$ are the three Euler rotation angles, $R$ the rotation matrix, and $C_{i, j, k, l}$ is the elastic stiffness matrix. For the element Fe, the local grain stiffness matrix exhibits cubic symmetry and can be expressed in the following form [37]:

$$
\left(C_{i, j, k, l}\right)_{\text {local }}=\left[\begin{array}{cccccc}
c_{11} & c_{12} & c_{12} & 0 & 0 & 0 \\
c_{12} & c_{11} & c_{12} & 0 & 0 & 0 \\
c_{12} & c_{12} & c_{11} & 0 & 0 & 0 \\
0 & 0 & 0 & c_{44} & 0 & 0 \\
0 & 0 & 0 & 0 & c_{44} & 0 \\
0 & 0 & 0 & 0 & 0 & c_{44}
\end{array}\right]
$$

The ratio

$$
A=\frac{2 c_{44}}{c_{11}-c_{12}}
$$

is defined as the anisotropy ratio, also referred to as the Zener ratio [37]. For isotropic materials $(A=1)$, the stiffness matrix keeps its original sparsity under rotation. For anisotropic materials, the stiffness matrix in the global coordinate system may become a full matrix. Substitution of Eq. (2) (with Eq. (3) and Eq. (4)) in Eq. (1) gives the Navier-Cauchy equations in terms of the displacements $u, v$ and $w$, see Ref. [35]. From the solution of displacements, the associated stresses can be computed from Eq. (2). Note that for the case of heterogeneous anisotropic material, these equations contain a significant number of extra terms compared to the equations for homogeneous isotropic material [35]. 
The boundary conditions on the vertical faces of the material cube are stress free. At the bottom surface, a zero displacement condition is imposed. The boundary condition at the top surface is:

$$
\left\{\begin{array}{c}
\sigma_{z x}=0 \\
\sigma_{z y}=0 \\
\sigma_{z z}+p=0
\end{array}\right.
$$

where $p(x, y)$ is the pressure distribution at the surface. These may be imposed, or may be solved from the dry contact problem, see Ref. [35]. In this paper, we consider the lubricated contact where the pressure is determined by the Reynolds equation:

$$
\frac{\partial}{\partial x}\left(\frac{\rho h^{3}}{12 \eta} \frac{\partial p}{\partial x}\right)+\frac{\partial}{\partial y}\left(\frac{\rho h^{3}}{12 \eta} \frac{\partial p}{\partial y}\right)-u_{\mathrm{m}} \frac{\partial(\rho h)}{\partial x}=0
$$

The boundary and cavitation conditions for the pressure are:

$$
\left\{\begin{array}{c}
p\left(x_{\text {in }}, y\right)=p\left(x_{\text {out }}, y\right)=p\left(x, y_{\text {out }}\right)=p\left(x,-y_{\text {out }}\right)=0 \\
p(x, y) \geq 0\left(x_{\text {in }}<x<x_{\text {out }}, y_{\text {in }}<y<y_{\text {out }}\right)
\end{array}\right.
$$

where "in" and "out" refer to the inlet and outlet side of the domain.

The isothermal problem is considered taking as equations of state for the viscosity and the density, the empirical relations presented by Roelands [38] and Dowson and Higginson [39]:

$$
\eta(p)=\eta_{0} \exp \left\{\left(\ln \eta_{0}+9.67\right)\left[-1+\left(1+5.1 \times 10^{-9} p\right)^{z_{0}}\right]\right\}
$$

and

$$
\rho(p)=\rho_{0}\left(1+\frac{0.6 \times 10^{-9} p}{1+1.7 \times 10^{-9} p}\right)
$$

The "correct" equations of state to be used has been a topic of much discussion [40]. However, regarding compressibility the importance is not so large as a correction on, e.g. the central film thickness, can always be done a posteriori [41]. Regarding the pressure viscosity equation, the real importance is for the case of sliding when the aim is to predict friction, as otherwise unrealistically high values are obtained. However, here we focus on film thickness only, so the shear 
stress that would result from the lubrication solution is not taken as boundary condition in Eq. (6). Alternative, supposedly better equations, e.g Ref. [42], can be implemented quite easily.

The film thickness, or gap height, equation can be expressed as

$$
h(x, y)=h_{0}+\frac{x^{2}}{2 R_{x}}+\frac{y^{2}}{2 R_{y}}+w^{\text {volume }}(x, y, z=0)
$$

where $w^{\text {volume }}(x, y, z=0)$ is the vertical surface displacement of the contacting elements at the surface. For the 3D anisotropic heterogeneous material, $w(x, y, z=0)$ is a part of the solution of the 3D elastic body problem with boundary condition Eq. (6) in which $p$ is determined by the solution of the Reynolds equation (Eq. (7)).

Finally, the equation of motion for the contact reduces to the force balance condition stating that the integral over the surface pressure distribution equals the applied load:

$$
\iint p(x, y) \mathrm{d} x \mathrm{~d} y=F
$$

This global constraint determines the value of the $h_{0}$ in Eq. (11).

\section{Numerical solution}

By solving the steady state problem, the objective is to obtain the contact operating conditions and the subsurface stress distribution. It requires solving simultaneously the Navier-Cauchy equations for the elastic displacement fields $u, v, w$ in the cubic domain following from Eq. (1)-Eq. (4) with the stress-free boundary condition at the sides and with Eq. (6) for the top surface. The lubricant pressure $p$ and film thickness $h$ are determined by Eq. (7), Eq. (11) and Eq. (12) with Eq. (8) as boundary condition and Eq. (9) and Eq. (10) for viscosity and density. The governing equations were non-dimensionalized using:

$$
\begin{gathered}
X=\frac{x}{a}, Y=\frac{y}{a}, Z=\frac{z}{a}, U=\frac{u}{a}, V=\frac{v}{a}, W=\frac{w}{a}, \\
P=\frac{p}{p_{\mathrm{h}}}, \bar{\sigma}_{i j}=\frac{\sigma_{i j}}{p_{\mathrm{h}}}, \bar{C}_{i j k l}=\frac{C_{i j k l}}{p_{\mathrm{h}}}, H=\frac{h}{a^{2} / R_{x}}, \bar{\eta}=\frac{\eta}{\eta_{0}}, \bar{\rho}=\frac{\rho}{\rho_{0}}
\end{gathered}
$$

where $a=\sqrt[3]{3 F R_{x} /\left(2 E^{\prime}\right)}, p_{\mathrm{h}}=3 F /\left(2 \pi a^{2}\right)$ are the values of the Hertzian 
contact radius and maximum Hertzian pressure for the case of dry contact between homogeneous isotropic elastic materials. The following results are all made dimensionless using the above two parameters.

The Navier-Cauchy equations for the interior of the 3D domain and the stress free boundary equations were discretized with a second order finite difference on a uniform grid with equal mesh size in each direction. The discrete equations are given in Ref. [35]. The Reynolds equation on the surface plane was discretized using a central second order accurate discretization for the pressure terms, and an upstream second order discretization for the wedge term [9]. The discrete equations for the surface plane are given in appendix A.

\subsection{Multigrid techniques}

To be able to consider large numbers of grains, a dense grid with a sufficiently large number of nodes is required which leads to a large number of unknowns in 3D. Moreover, as there are three equations with associated unknowns, the number of unknowns easily exceeds many millions. For this purpose, multigrid techniques were used [9, 43]. Exploiting the efficiency of standard iterative schemes to reduce high frequency error components in a recursive cycle using a series of coarser grids, an iterative process (coarse grid correction cycle) can be obtained with a grid independent convergence rate in which each error component is reduced at a grid at which this is done efficiently by the relaxation. Combined with full multigrid, using the coarser grids also generates an accurate first approximation on the target grid. A problem can be solved to the level of the discretization error in only a few coarse grid correction cycles. The amount of work of a cycle is the equivalent of the work of only a few iterations and is proportional to the number of unknowns. The resulting high efficiency allows using dense grids on small scale computers. This has been proven for many problems in science and engineering already. For the conventional dry contact and EHL problems see Ref. [9]. In those cases, to achieve optimal efficiency, the elastic deformation integrals are treated with a separate technique: multilevel multi-Integration (MLMI) [44]. In Ref. [25], the application to contact mechanics with 3D isotropic heterogeneous material elastic problem is explained. The dry contact problem with 3D anisotropic heterogeneous elastic material is discussed in Ref. [35]. Below, the extension to the lubricated contact is discussed, i.e. replacing the dry contact boundary equation by the Reynolds equation (Eq. (7)). 


\subsection{Relaxation}

For the discretized equations in the interior volume, Gauss-Seidel relaxation in lexicographic order, either sequential (one equation after the other) or collective (solving changes for $u, v$ and $w$ simultaneously at each grid point), provides good error smoothing when the material parameters are such that it is sufficiently away from the incompressible limit [35]. Compared to the algorithm discussed in Ref. [35], the relaxation of the top boundary now involves solving the displacements $u, v, w$ and the pressure $p$ simultaneously from the stress boundary conditions and the Reynolds equation. Alternatively, one can use the 3D elastic equation solver as a "black-box" inside an existing conventional EHL solver, i.e. simply replacing the evaluation of the elastic deformation integrals by the $3 \mathrm{D}$ elastic solver $[7,8]$ which is convenient from an application point of view. However, each iteration step involves only moderate changes and solving the entire 3D elastic problem accurately following each relaxation iteration is a waste of effort because the surface pressure itself still has limited accuracy. The most efficient approach is to treat all equations simultaneously with the EHL problem as a boundary condition in the $3 \mathrm{D}$ elastic problem. In that case, one relaxation involves one pass over all equations. In the multigrid coarse grid correction, all equations (interior and boundary equations) are coarsened simultaneously as is done for dry contact in Ref. [35]. For the interior and the side boundaries, one point Gauss-Seidel relaxation is used in lexicographic order with treating the three equations sequentially. For the top boundary at any point, there are four equations: Reynolds, and three discretized stress conditions for four variables (the displacements $u, v$ and $w$ and the pressure $p$ ) when the pressure is positive. On this plane, a collective relaxation scheme is used. At each grid point, a system of four equations is solved for changes to these four variables so as to solve the equations. However, when $p<0$ follows, the cavitation condition is imposed by setting $p=0$, and changes to $u, v$ and $w$ are solved from the system formed by the three discretized stress boundary equations. A crucial point is that this approach applied point by point in e.g. lexicographic order will be stable but will not give grid independent multigrid performance as the Reynolds equation under higher loads exhibits a strong coupling in the $x$ direction [9]. High frequency error components in the $y$ direction are not reduced, hence the error is not smooth and cannot be well resolved on a coarser grid. The remedy is to carry out the line relaxation, simultaneously solving all equations for one line. For more details and the application to the conventional problem 
see Ref. [9]. For the problem considered here, the system of equations to be solved for each line is given in appendix B. Solving can be done in an amount of work proportional to the number of points $n$ of the line, so it does not alter the optimum computational complexity. Summarizing, the relaxation process for the 3D coupled problem consists of:

1) Gauss-Seidel relaxation of interior $u, v$ and $w$ equations in lexicographic order;

2) Relax stress free vertical boundary planes;

3) Collective Gauss-Seidel line relaxation of the stress boundary equations on the top boundary and the Reynolds equation accounting also for the cavitation condition, in order to obtain the surface displacements and the lubricant pressure.

This relaxation process is embedded in a multigrid coarse grid correction cycle. Finally, the treatment of the force balance condition as global constraint is done by changing the value of $h_{0}$ on the coarsest grid in the cycle as explained in Refs. $[9,25,35]$. The resulting cycle provides grid independent convergence at the same rate as for the dry contact problem shown in Ref. [35], and combined with full multigrid, it solves the equations to the level of the discretization error in optimal computational complexity $\mathrm{O}\left(n^{3}\right)$ with $n$ the number of nodes in each dimension.

\subsection{Computational cost comparison}

For the conventional EHL problem, the complexity achieved was the nearly optimal $O(N \log (N))$ [9], where $N$ is the total number of unknowns using standard multigrid techniques for the solution or the Reynolds equation and by applying a separate MLMI algorithm for the fast evaluation of the elastic deformation integrals. For this problem $N=O\left(n^{2}\right)$, where $n$ is the number of nodes in one spatial dimension. The computation of the components of the subsurface stresses on a grid in any plane below the surface can be carried out a posteriori using (discrete) integral transform evaluations using the pressure distribution solved at the surface as input [45]. Using MLMI, this requires an additional $6 \times O(N \log (N))=O\left(6 n^{2} \log (n)\right)$ operations per plane in the subsurface. For a uniform 3D grid with $n$ plane, the total time will be $O\left(n^{3}\right)$ where it should be noted that the evaluations for each plane can be done in parallel. Solution of the coupled 3D problem with $N=O\left(n^{3}\right)$ operations yields the same amount of information (pressure at surface, gap height, and stresses below the surface), but 
here three equations with three variables are solved, where each of the equations contains quite a large number of terms, so the proportionality constant is larger as well as the computational overhead. Hence, unless the problem really requires a 3D approach, it is computationally more efficient to solve the conventional problem. In Tab. 1, computing times used on a single processor (Intel X5650 $\mathrm{CPU}$ at $2.66 \mathrm{GHz}$ ) are presented as a function of the mesh size on the grid used for several EHL and dry contact models. In all cases, a full multigrid algorithm was used with 2 multigrid $\mathrm{W}(2,1)$ cycles per refinement, which solves the problem to the level of the discretization error. Results are presented for five problems. Firstly, for the conventional EHL point contact problem [9], solving this problem required 22 seconds on a $513 \times 513$ grid with $33 \times 33$ points on the coarsest grid. The subsequent evaluation of the 6 independent stress components in the subsurface on 513 planes requires about one minute. Secondly, the dry contact problem with 3D elastic equation solver for isotropic material [35]. The third problem is of the same complexity but now for the case of anisotropic material [35]. The fourth and the fifth case are for the 3D elastic coupled EHL problem with the isotropic and anisotropic material respectively. Taking the useful data to be the $n^{2}$ values of surface pressure and gap height, and the $n^{3}$ values of each of the 6 components of the stress tensor, the number of useful data values obtained per second CPU time invested can be computed. This value ranges from $O\left(10^{5}\right)$ for the $3 \mathrm{D}$ problems to $O\left(10^{7}\right)$ for the conventional problem illustrating the point made above that the 3D coupled model and algorithm should be used only when really needed. Note that the absolute values of the numbers and computing times are not so important. It is the ratios that matters. Comparing the computing times for different grids shows the low complexity of the solver(s). The asymptotic increase of CPU time with halving the mesh size in each dimension should be a factor $2^{3}$. This asymptotic behavior is not yet fully seen owing to the use of $\mathrm{W}$ cycles and the relatively large contribution of coarse grid work. However, in many homogeneous material problems, the coarsest grid can be chosen coarser.

Table 1 Computing time results of an FMG algorithm with 2 cycles per refinement as a function of the number of grids (levels) used. Results for 5 cases: conventional EHL solving $P$ and $H$ [9] (time cost for subsurface stress evaluation is given in the following bracket), dry contact 3D isotropic material [35], dry contact 3D anisotropic material [35], 3D elastic coupled EHL for isotropic material and 3D elastic coupled EHL for anisotropic material, single processor (Intel X5650 CPU at $2.66 \mathrm{GHz}$ ) 


\begin{tabular}{|c|c|c|c|c|c|}
\hline Grid level & $\begin{array}{c}\text { Conventional } \\
\text { EHL } \\
\text { (MG+MLMI) }\end{array}$ & $\begin{array}{c}\text { Dry contact } \\
\text { +Stress field } \\
\text { (MG, Iso) }\end{array}$ & $\begin{array}{l}\text { Dry contact } \\
+ \text { Stress field } \\
\text { (MG, Aniso) }\end{array}$ & $\begin{array}{c}\text { EHL+ } \\
\text { Stress field } \\
\text { (MG, Iso) }\end{array}$ & $\begin{array}{c}\text { EHL+ } \\
\text { Stress field } \\
\text { (MG, Aniso) }\end{array}$ \\
\hline $\begin{array}{c}3 \\
\left(129^{2} / 129^{3}\right)\end{array}$ & $3+(3) \operatorname{secs}$ & 2 mins & 5 mins & 7 mins & 15 mins \\
\hline $\begin{array}{c}4 \\
\left(257^{2} / 257^{3}\right)\end{array}$ & $8+(8)$ secs. & 7 mins & 16 mins & $21 \mathrm{mins}$ & 39 mins \\
\hline $\begin{array}{c}5 \\
\left(513^{2} / 513^{3}\right)\end{array}$ & $22+(62) \operatorname{secs}$ & 43 mins & $1 \mathrm{~h} 27$ mins & $1 \mathrm{~h} 16$ mins & $2 \mathrm{~h} 22$ mins \\
\hline
\end{tabular}

\section{Verification}

Firstly, the results obtained with the 3D elastic model are compared with the results obtained using a conventional EHL model for the case of homogeneous isotropic material. The operating conditions, lubricant parameters, the Hertzian dry contact parameters, and values of commonly used dimensionless parameters are given in Tab. 2. The values of the Moes dimensionless load parameters for this case are $M=100$ and $L=10$.

Table 2 Material parameters, lubricant parameters, operating conditions and values of different sets of dimensionless parameters for reference case

\begin{tabular}{cc}
\hline Parameters & Value \\
\hline$F$ & $73.55 \mathrm{~N}$ \\
$R_{x}, R_{y}$ & $0.02 \mathrm{~m}$ \\
$p_{\mathrm{h}}$ & $0.76 \mathrm{GPa}$ \\
$E^{\prime}$ & $226 \mathrm{GPa}$ \\
$u_{\mathrm{m}}$ & $0.46 \mathrm{~m} / \mathrm{s}$ \\
$\eta_{0}$ & $0.08 \mathrm{Pas}^{-1}$ \\
$\alpha$ & $22 \mathrm{GPa}^{-1}$ \\
$z_{0}$ & 0.6036 \\
$U$ & $8.18 \times 10^{-12}$ \\
$W$ & $8.14 \times 10^{-7}$ \\
$G$ & 4972 \\
$\bar{\alpha}$ & 16.91 \\
$\bar{\lambda}$ & $2.37 \times 10^{-2}$ \\
\hline
\end{tabular}


In Fig. 2 (a) and (b), the centerline pressure and film thickness profiles in the flow direction $(X)$ and in the cross flow direction $(Y)$ are given for both models. Also shown is the contour plot of the dimensionless film thickness, but only for the EHL model with the 3D elasticity solution. The results exhibit all characteristic aspects of a steady EHL solution in the piezo-viscous regime: a nearly Hertzian pressure profile with short entrainment region leading up to it and a pressure spike at the exit; a nearly uniform film thickness in the direction of flow with a small restriction at the exit and the side-lobes where the minimum film thickness occurs. The results of the two models are virtually identical.

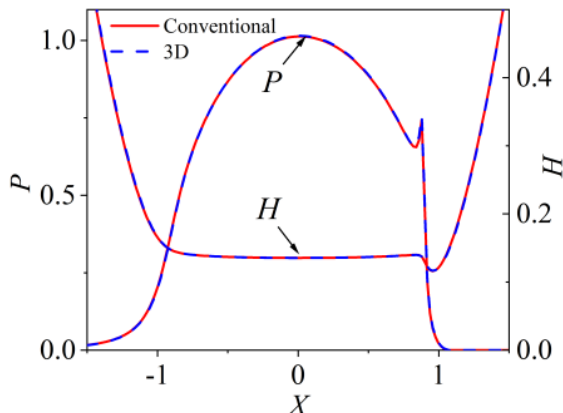

(a) $P(X, Y=0)$ and $H(X, Y=0)$

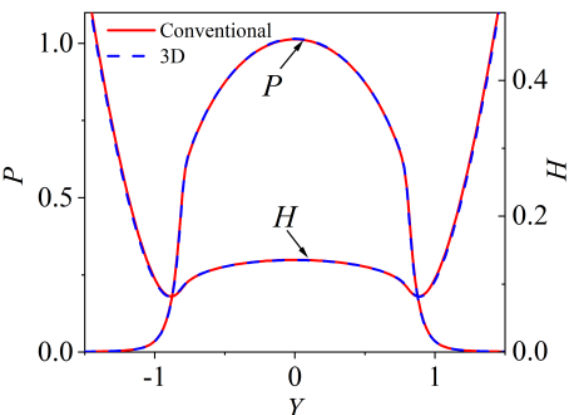

(b) $P(X=0, Y)$ and $H(X=0, Y)$

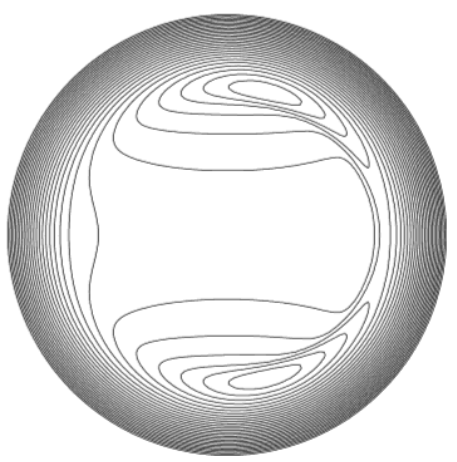

(c) Film thickness contour plot $H(X, Y)$

Figure 2 Centerline dimensionless pressure profile $P(X, 0)$ and dimensionless film profile $H(X, 0)$ (a), and $P(0, Y) H(0, Y)$ (b), for the conventional EHL solution and for the 3D Elastic coupled EHL solution. Film thickness contour plot of the 3D elastic coupled EHL solution (c). Homogeneous isotropic material. Conditions given in

Tab. 2. $(M=100, L=10)$.

In Tab. 3, the numerical values of the central film thickness and minimum 
film thickness obtained for both models are given. Also shown is the effect of the mesh size. The "level" in the first column indicates the finest grid used in the multigrid algorithm. The coarsest grid was set at $33 \times 33(\times 33)$ points. The second column gives the number of nodes in each of the dimensions of the problem. Each reduction of the mesh size by a factor of 2 yields a change in value that decreases roughly by a factor of 4 . This trend is more clearly visible in the central film than in the minimum film results. Because the minimum film thickness may still vary in location by one or a few grid points upon refinement, the asymptotic convergence behavior of its value usually settles in on somewhat finer grids. However, for sufficiently fine grids the trend is also clear in the minimum film thickness results. This behavior is consistent with the second order of the discretization used.

Table 3 Computed values of the central and minimum film thickness with the conventional model and with the 3D elastic EHL model as a function of the mesh size (in one dimension). Homogeneous isotropic material. Conditions as specified in Tab. 2.

\begin{tabular}{|c|c|c|c|c|c|c|c|}
\hline \multirow{2}{*}{ Level } & \multirow{2}{*}{$\begin{array}{c}\text { Grid } \\
\text { points }\end{array}$} & \multicolumn{6}{|c|}{$M=100, L=10$} \\
\hline & & $\boldsymbol{H}_{\text {central }}$ & $\boldsymbol{H}_{\mathrm{con}}, \boldsymbol{H}_{3 \mathrm{D}}$ & Dev. & $\boldsymbol{H}_{\text {minimum }}$ & $\boldsymbol{H}_{\mathrm{con}}, \boldsymbol{H}_{3 \mathrm{D}}$ & Dev. \\
\hline \multirow{3}{*}{3} & \multirow{3}{*}{129} & $\boldsymbol{H}_{\mathrm{con}}$ & 0.122943 & \multirow{3}{*}{$0.2269 \%$} & $\boldsymbol{H}_{\text {con }}$ & 0.064935 & \multirow{3}{*}{$1.3182 \%$} \\
\hline & & & & & & & \\
\hline & & $\boldsymbol{H}_{3 \mathrm{D}}$ & 0.123222 & & $\boldsymbol{H}_{3 \mathrm{D}}$ & 0.065791 & \\
\hline \multirow{3}{*}{4} & \multirow{3}{*}{257} & $\boldsymbol{H}_{\mathrm{con}}$ & 0.132885 & \multirow{3}{*}{$0.0632 \%$} & $\boldsymbol{H}_{\mathrm{con}}$ & 0.071336 & \multirow{3}{*}{$0.9757 \%$} \\
\hline & & & & & & & \\
\hline & & $\boldsymbol{H}_{3 \mathrm{D}}$ & 0.132969 & & $\boldsymbol{H}_{3 \mathrm{D}}$ & 0.072032 & \\
\hline \multirow{3}{*}{5} & \multirow{3}{*}{513} & $\boldsymbol{H}_{\text {con }}$ & 0.135468 & \multirow{3}{*}{$0.0185 \%$} & $\boldsymbol{H}_{\text {con }}$ & 0.072741 & \multirow{3}{*}{$0.3396 \%$} \\
\hline & & & & & & & \\
\hline & & $\boldsymbol{H}_{3 \mathrm{D}}$ & 0.135443 & & $\boldsymbol{H}_{3 \mathrm{D}}$ & 0.072988 & \\
\hline \multirow{3}{*}{6} & \multirow{3}{*}{1025} & $\boldsymbol{H}_{\mathrm{con}}$ & 0.136119 & \multirow{3}{*}{$0.0096 \%$} & $\boldsymbol{H}_{\text {con }}$ & 0.073081 & \multirow{3}{*}{$0.1013 \%$} \\
\hline & & & & & & & \\
\hline & & $\boldsymbol{H}_{3 \mathrm{D}}$ & 0.136106 & & $\boldsymbol{H}_{3 \mathrm{D}}$ & 0.073155 & \\
\hline
\end{tabular}

The difference between the converged results of the two models is less than $1.5 \%$. This difference is mainly determined by the extent to which the 3D domain is sufficiently large for the solution to approximate the behavior of the solution for a semi-elastic half-space in width and depth. For the present case this is quite accurate. It can be seen from the ratio of central to minimum film thickness for 132 
example, and the ratio is closely the same (1.86) for both models. This indicates that in the 3D model the Dirichlet condition at the lower surface is not actually felt in the solution. More details on the influence of the domain size are given below.

The small differences between the results of the models and the convergence behavior observed generalize to the other load conditions. In Tab. 4 , the minimum film values as a function the mesh size is given for a lower $(M=50)$ and higher value $(M=200)$ of the load number $M$ with $L=10$, and also for $L=2.5$. For all cases, the difference between the values of the two models is well below $1 \%$. It should be noted that for sufficiently fine grids this difference converges second order with decreasing mesh size. This is most clearly seen in central film thickness data. In the minimum film thickness it is sometimes obscured and only seen on very fine grids as for cases where the side lobes are small, going from one grid to a finer grid, not only its value but also its location may still change. Nevertheless, for the case $M=50, L=10$, it is already seen in the present results.

Table 4 Computed minimum film thickness values as a function of the grid mesh size in circular contact for 4 load cases. For each case the value obtained using a conventional EHL solver (2D) and the developed 3D elastic coupled EHL algorithm are given. Homogeneous isotropic material.

\begin{tabular}{|c|c|c|c|c|c|c|c|c|c|}
\hline \multirow{2}{*}{$\begin{array}{l}\text { Grid } \\
\text { (L.) }\end{array}$} & \multirow{2}{*}{ M. } & \multicolumn{2}{|c|}{$M=50, L=2.5$} & \multicolumn{2}{|c|}{$M=50, L=10$} & \multicolumn{2}{|c|}{$M=200, L=2.5$} & \multicolumn{2}{|c|}{$M=200, L=10$} \\
\hline & & $\boldsymbol{H}_{\text {minimum }}$ & Dev. & $\boldsymbol{H}_{\text {minimum }}$ & Dev. & $\boldsymbol{H}_{\text {minimum }}$ & Dev. & $\boldsymbol{H}_{\text {minimum }}$ & Dev. \\
\hline 129 & 2D & 0.06968 & \multirow{2}{*}{$\begin{array}{c}0.648 \\
\%\end{array}$} & 0.12899 & \multirow{2}{*}{$\begin{array}{c}0.871 \\
\%\end{array}$} & 0.01637 & \multirow{2}{*}{$\begin{array}{c}0.312 \\
\%\end{array}$} & 0.02987 & \multirow{2}{*}{$\begin{array}{c}0.249 \\
\%\end{array}$} \\
\hline (3) & 3D & 0.06923 & & 0.13011 & & 0.01642 & & 0.02979 & \\
\hline 257 & 2D & 0.07238 & \multirow{2}{*}{$\begin{array}{c}0.038 \\
\%\end{array}$} & 0.13382 & \multirow{2}{*}{$\begin{array}{c}0.676 \\
\%\end{array}$} & 0.01887 & \multirow{2}{*}{$\begin{array}{c}0.012 \\
\%\end{array}$} & 0.03663 & \multirow{2}{*}{$\begin{array}{c}0.979 \\
\%\end{array}$} \\
\hline (4) & 3D & 0.07236 & & 0.13472 & & 0.01886 & & 0.03699 & \\
\hline 513 & 2D & 0.07313 & \multirow{2}{*}{$\begin{array}{c}0.095 \\
\%\end{array}$} & 0.13473 & \multirow{2}{*}{$\begin{array}{c}0.149 \\
\%\end{array}$} & 0.0200 & \multirow{2}{*}{$\begin{array}{c}0.413 \\
\%\end{array}$} & 0.03835 & \multirow{2}{*}{$\begin{array}{c}0.663 \\
\%\end{array}$} \\
\hline (5) & 3D & 0.07306 & & 0.13493 & & 0.0201 & & 0.03860 & \\
\hline
\end{tabular}

Finally, the influence of size of the calculational domain on the central and minimum film thickness is shown in Tab. 5 for the case $M=50, L=10$, using 5 levels with 513 grid points in each direction on the finest grid. The difference 
between the conventional solution and the present 3D solution decreases with increasing domain size and thus decreasing influence of the side and lower boundary condition.

Table 5 Effect of domain size on the calculated value of the central and minimum film thickness for the conventional model and for the model with 3D elastic solver. Homogeneous isotropic material, $M=50, L=10$. Mesh size used $513 \times 513 \times 513$ grid points.

\begin{tabular}{cccccccc}
\hline \multicolumn{2}{c}{ Calculation domain } & \multicolumn{3}{c}{ Central film thickness } & \multicolumn{3}{c}{ Minimum film thickness } \\
\hline $\boldsymbol{X}, \boldsymbol{Y}$ & $\boldsymbol{Z}$ & $\boldsymbol{H}_{\text {con }}$ & $\boldsymbol{H}_{3 \mathrm{D}}$ & Dev. & $\boldsymbol{H}_{\text {con }}$ & $\boldsymbol{H}_{3 \mathrm{D}}$ & $\mathrm{Dev}$ \\
\hline$-1.5 \sim 1.5$ & $0 \sim 3$ & 0.18207 & 0.18498 & $1.597 \%$ & 0.11973 & 0.11861 & $0.933 \%$ \\
$-2 \sim 2$ & $0 \sim 4$ & 0.21119 & 0.21075 & $0.209 \%$ & 0.12936 & 0.12843 & $0.715 \%$ \\
$-3 \sim 3$ & $0 \sim 6$ & 0.22248 & 0.22206 & $0.189 \%$ & 0.13361 & 0.13333 & $0.213 \%$ \\
$-4 \sim 4$ & $0 \sim 8$ & 0.22442 & 0.22424 & $0.083 \%$ & 0.13454 & 0.13449 & $0.032 \%$ \\
$-5 \sim 5$ & $0 \sim 10$ & 0.22485 & 0.22477 & $0.039 \%$ & 0.13495 & 0.13496 & $0.003 \%$ \\
\hline
\end{tabular}

Table 6 Effect of domain size on the maximum VMS for the model with 3D elastic solver. Homogeneous isotropic material, $M=50, L=10$. Mesh size used $513 \times 513 \times 513$ grid points for the first three cases and $1025 \times 1025 \times 1025$ grid points for the last three cases.

\begin{tabular}{cccccc}
\hline \multirow{2}{*}{ Case } & \multicolumn{2}{c}{ Calculation domain } & \multicolumn{2}{c}{ VMS } & VMS value difference \\
\cline { 2 - 6 } & $\boldsymbol{X}, \boldsymbol{Y}$ & $\boldsymbol{Z}$ & depth & value & $\frac{\text { VMS }_{\text {case i }}-\text { VMS }_{\text {case } \mathrm{i}-1}}{\mathbf{V M S}_{\text {case } \mathrm{i}-1}}$ \\
\hline 1 & $-1.5 \sim 1.5$ & $0 \sim 3$ & 0.48633 & 0.75037 & - \\
2 & $-3 \sim 3$ & $0 \sim 6$ & 0.45703 & 0.65893 & $12.18 \%$ \\
3 & $-5 \sim 5$ & $0 \sim 10$ & 0.45898 & 0.64185 & $2.59 \%$ \\
4 & $-10 \sim 10$ & $0 \sim 20$ & 0.44922 & 0.63248 & $1.46 \%$ \\
5 & $-15 \sim 15$ & $0 \sim 30$ & 0.46875 & 0.63154 & $0.15 \%$ \\
6 & $-20 \sim 20$ & $0 \sim 40$ & 0.46875 & 0.63111 & $0.07 \%$ \\
\hline
\end{tabular}

The influence of size of the calculational domain on the maximum von Mises stress (VMS) is shown in Tab. 6. With an increase in calculation domain, the 
difference between the maximum VMS value decreases which means the effect of side boundaries decreases. The differences of the value and depth of the maximum VMS between the second case (-3 3) and the last case (-20 20) are $4.22 \%$ and $2.56 \%$ respectively which can be considered acceptable. Thus, for all cases considered in the following section the calculation domain was [-3 3] in $X$ and $Y$ directions and [0 6] in $Z$ direction with $513 \times 513 \times 513$ points on the target grid. At this point it should be noted that in realistic cases investigating the (relative) effect of the variation of the local crystallographic topology below and near the contact one can easily be done using a smaller volume with a granular structure of the size used here, several times the Hertzian region, embedded in a larger volume with uniform structure. This can be achieved very naturally with multigrid techniques using local grid refinements.

\section{Results}

Table 7 Values of the cubic anisotropic material parameters used in the model

\begin{tabular}{cccc}
\hline Parameter & $\boldsymbol{A}=\mathbf{2 . 4 0 7 4}^{[37]}$ & $\boldsymbol{A}^{3 \mathbf{3 . 3 6}}{ }^{[37]}$ & $\boldsymbol{A = 3 . 7 7 ^ { [ 3 4 ] }}$ \\
\hline$c_{11}$ & $231.4 \mathrm{GPa}$ & $197.5 \mathrm{GPa}$ & $204.6 \mathrm{GPa}$ \\
$c_{12}$ & $134.7 \mathrm{GPa}$ & $125 \mathrm{GPa}$ & $137.7 \mathrm{GPa}$ \\
$c_{44}$ & $116.4 \mathrm{GPa}$ & $122 \mathrm{GPa}$ & $126.2 \mathrm{GPa}$ \\
\hline
\end{tabular}

Table 8 Comparison of Hertzian contact parameters as a function of the Zener (anisotropy) ratio with orientation aligned with the global coordinate system

\begin{tabular}{ccc}
\hline Cases & $\boldsymbol{P}_{\max }$ & $\boldsymbol{a}_{\text {Hertz }}$ \\
\hline $\boldsymbol{A}=\mathbf{1}$ & 1.00416 & 0.99609 \\
$\boldsymbol{A}=\mathbf{2 . 4 0 7 4}$ & 0.96951 & 1.00781 \\
$\boldsymbol{A}=\mathbf{3 . 3 6}$ & 0.89229 & 1.05469 \\
$\boldsymbol{A}=\mathbf{3 . 7 7}$ & 0.89316 & 1.05469 \\
\hline
\end{tabular}

Following verification of the results against a conventional solver, in this section the capability of the developed model and the multigrid solution algorithm are demonstrated by problems for which the computational efficiency is increasingly important due to the amount of detail required in the representation. In section 5.1, results are presented for dry contact and EHL contact, comparing homogeneous isotropic and homogeneous anisotropic material. In section 5.2, heterogeneous anisotropic material is considered. The material parameters of cubic anisotropic material used are given in Tab. 7. Three 
cases of the Zener ratio $A$ (see Eq. (5)) [37] are considered. The other input parameters are as listed in Tab. 2. The actual contact radius and maximum pressure depend on the value of $A$ and the orientation. For the case of homogeneous material aligned with the global coordinate system, the contact radius and the maximum pressure relative to the homogeneous isotropic values are listed in Tab. 8.

\subsection{Homogeneous anisotropic material}

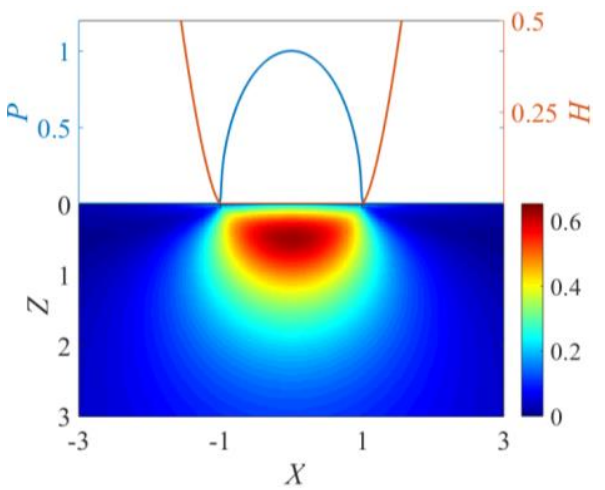

(a) Dry contact, isotropic material

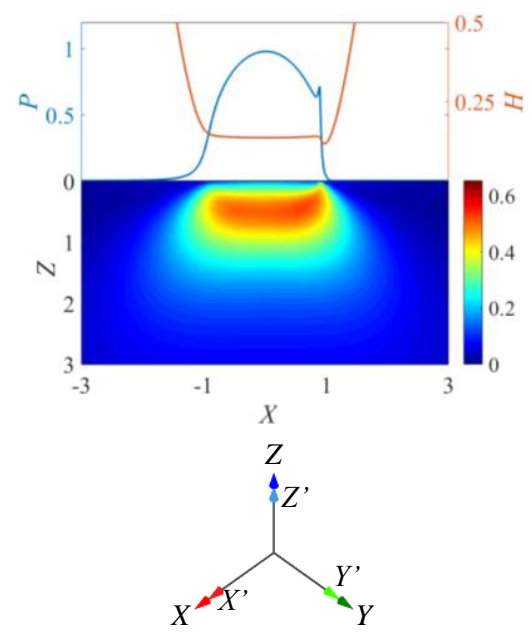

(c) EHL, aligned anisotropic material

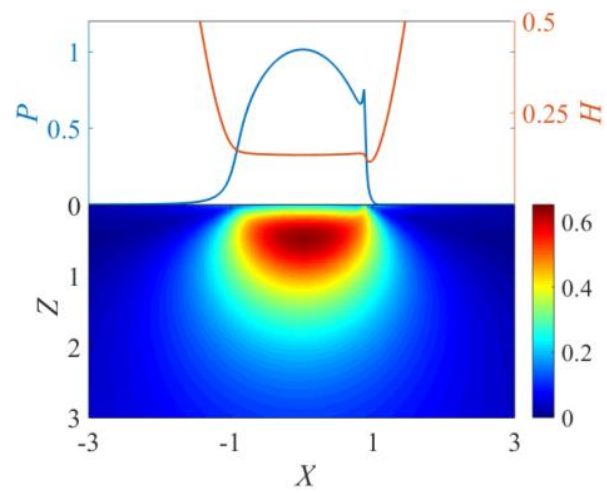

(b) EHL, isotropic material

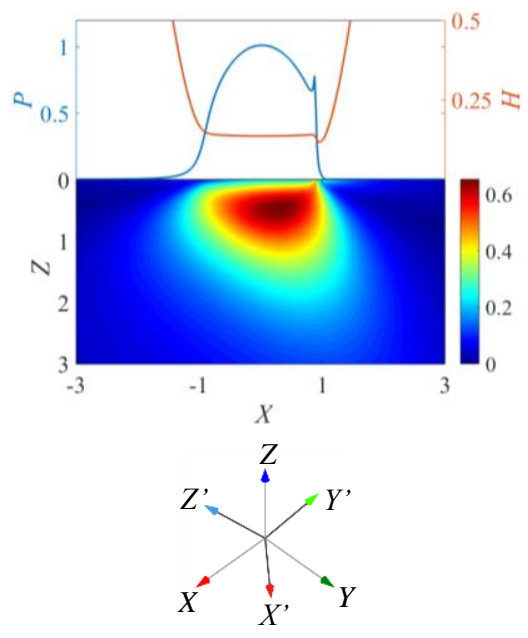

(d) EHL, unaligned anisotropic material (one grain)

Figure 3 Dimensionless pressure, film thickness, and VMS distribution in the plane $Y=0$ for homogeneous material (a) Dry contact, isotropic, $A=1$, (b) EHL, isotropic, $A=1$, (c) EHL anisotropic coordinates aligned, $A=2.4074$, (d) EHL anisotropic, rotation angle $0.1 \pi$ material, $A=2.4074$. 
Figure 3 shows the pressure profile at the surface, the gap height, and the VMS distribution in the subsurface in the central plane $Y=0$ for dry contact (a) and EHL contact (b) with isotropic material, for homogeneous anisotropic material $(A=2.4074)$ aligned with the global coordinate system (c) and at a rotation angle $0.1 \pi$ in each direction relative to the global coordinate system (d). In Tab. 9, the value and the location of the (dimensionless) maximum VMS for each case are given.

For isotropic material in dry contact, the pressure and stress distributions are symmetric with respect to the central planes, see Fig.3 (a). The analytic value of the dimensionless maximum VMS is 0.620 and occurs at a dimensionless distance 0.480 below the contact surface [46][47]. The numerical results obtained with the presented model are very close to these values and the difference can be attributed to the domain size. The EHL solution is not symmetric and displays the characteristic features, see Fig. 3 (b), namely a closely semi-ellipsoidal (Hertzian) pressure profile with continuous pressure rise and decline in the inlet and outlet region; a local maximum, the so-called pressure spike near the outlet; a nearly uniform film thickness in the center of the contact; the outlet film constriction and side lobes where the minimum film thickness occurs. The computed value of the dimensionless central and minimum film thickness are given in Tab. 3. The pressure spike causes a near surface local maximum in the VMS. The overall maximum VMS is $2 \%$ larger than for the dry contact case and occurs slightly off center on the outlet side closer to the surface.

Fig. 3(c) shows the results for homogeneous anisotropic material aligned with the global coordinate with $A=2.4074$. The maximum dry contact pressure for this case is about $5 \%$ lower than the value for the isotropic case, and the contact radius becomes slightly larger, see Tab. 8. The EHL film thickness profile is nearly identical as can be seen from comparing the contour plot in Fig. 2 (c) with Fig. 4 (a). The computed value of the dimensionless central film thickness of 0.136131 and the dimensionless minimum film of 0.072595 are only marginally different from the isotropic case. In the steady state considered here, the flow in the central region is dominated by shear flow which dictates the central film thickness in the $X$ direction to be nearly constant. The central film thickness level is determined by the decrease of Poisseulle flow in the inlet region, i.e. the film thickness decreasing and the viscosity increasing due to the rising pressure. Because the difference in deformation between isotropic and 
anisotropic is small in the inlet region, shear flow dominance with constant film starts at roughly the same location and at the same film thickness level. However, the stress field is quite different. The value of the maximum VMS is $20 \%$ lower, and quite strikingly its location is no longer in the central $X-Z$ plane but occurs at $X=0.3, Y=0.5$, see Tab. 9. These changes are a result of the change of the elastic stiffness of the material in the direction of the load. This stiffness depends on the orientation as is shown in the last case Fig. 3(d) where the material is rotated over an angle of $0.1 \pi$ in each direction. For the same reason as given above, the pressure and film thickness do not change significantly. The computed dimensionless central film and minimum film are 0.136226 and 0.071955 respectively and the film thickness contour plot is nearly identical, see Fig. 4 (b).

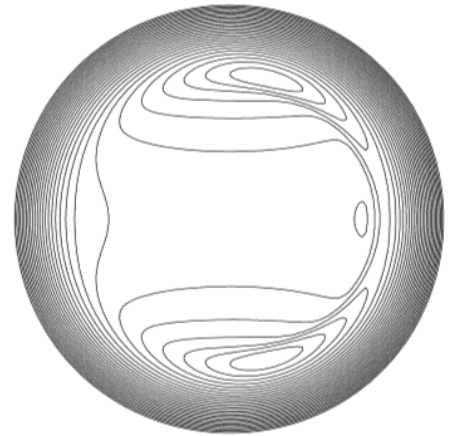

(a) aligned anisotropic material

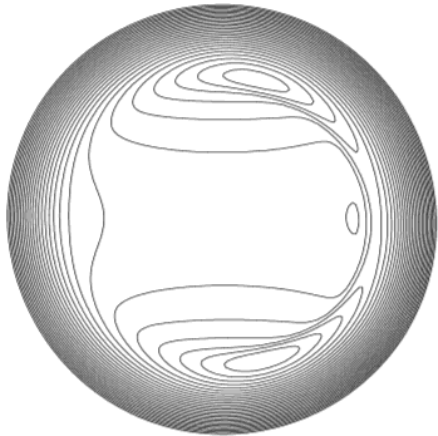

(b) unaligned anisotropic material (one grain)

Figure 4 Contour plots of the dimensionless film thickness: EHL with homogenous anisotropic material aligned with global coordinate (a) and EHL with homogeneous anisotropic material at rotation angle $0.1 \pi$ in each direction (b), $A=2.4074$

Table 9 Location and value of the (dimensionless) maximum VMS for the computed solutions displayed in Fig. 3

\begin{tabular}{ccccc}
\hline Cases & VMS & $\boldsymbol{X}$ & $\boldsymbol{Y}$ & $\boldsymbol{Z}$ \\
\hline $\begin{array}{c}\text { (a) Dry contact, isotropic material } \\
\text { (b) EHL,isotropic material }\end{array}$ & 0.6280 & 0 & 0 & 0.4883 \\
$\begin{array}{c}\text { (c) EHL, homogeneous } \\
\text { aligned anisotropic material }\end{array}$ & 0.5277 & 0.2929 & 0.5078 & 0.4297 \\
$\begin{array}{c}\text { (d) EHL, homogeneous } \\
\text { rotated anisotropic material }\end{array}$ & 0.6609 & 0.2539 & -0.1953 & 0.4492 \\
\hline
\end{tabular}


However, the maximum VMS is $6 \%$ higher than the dry contact case and again occurs at a location not central to the contact, see Tab. 9. These results show that material anisotropy may result in significant changes in the magnitude and the location of the maximum VMS, which might in turn affect the fatigue life of the contact, even though the EHL pressure and film thickness distribution are virtually identical.

\subsection{Polycrystalline anisotropic material}

In this section, results are presented for an EHL contact with load conditions as considered before with polycrystalline anisotropic material. We consider the case of a distribution of grains with random varying rotation angles. For the present case, translated to real data, the average grain diameter is $25 \mu \mathrm{m}$. As the Hertzian contact radius for isotropic material is $0.21 \mathrm{~mm}$, there are about 17 grains in $X$ and $Y$ directions of Hertzian contact region.

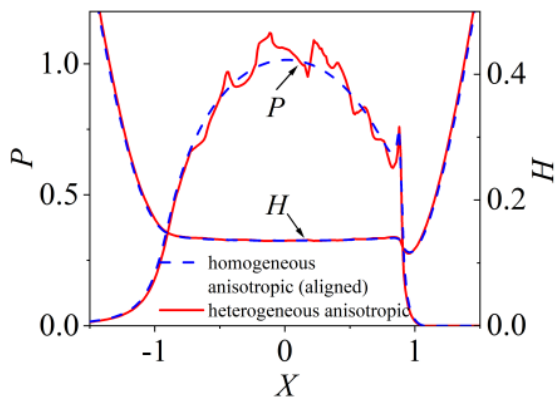

(a) $P(X, Y=0)$ and $H(X, Y=0)$

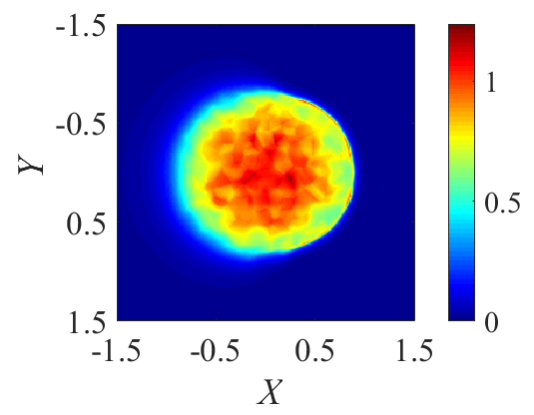

(c) Pressure distribution $P(X, Y)$

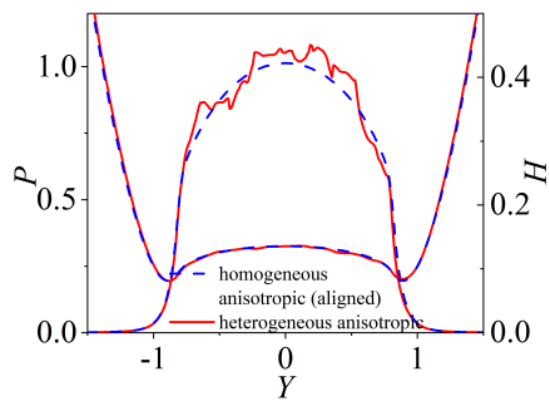

(b) $P(X=0, Y)$ and $H(X=0, Y)$

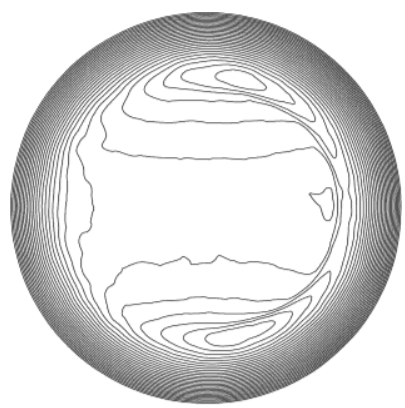

(d) Film thickness contour plot $H(X, Y)$

Figure 5 (a) Dimensionless pressure $P(X, Y=0)$ and film thickness $H(X, Y=0)$, (b) Dimensionless pressure $P(X, Y=0)$ and film thickness $H(X, Y=0)$, (c) Dimensionless pressure distribution $P(X, Y)$ at the surface, (d) Dimensionless film thickness contour plot $H(X, Y),(M=100, L=10)$ 
Firstly, for a fixed value of $A=2.4074$, the effect of polycrystalline anisotropic topology on the pressure, film thickness and VMS distribution is investigated. Fig. 5 (a) and (b) show the dimensionless pressure and film thickness at the centerlines of the contact for the homogeneous anisotropic case (without rotation) and for the heterogeneous anisotropic case. Fig. 5 (c) and (d) show the pressure distribution at the surface and the contour plot of the dimensionless film thickness for polycrystalline anisotropic case.

The variation of the orientation of the grains leads to a locally increased or decreased stiffness of the material relative to the isotropic material. Depending on the orientation, the grain acts as a hard or soft inclusion which causes pressure fluctuations, as was also seen in the dry contact [35]. However, the film thickness profile is not significantly affected, for the same reason as explained in the previous section. This behavior is also reported in Ref. [34] for an EHL line contact. The film thickness contour plot is shown in Fig. 5 (d). Only small local film variations can be seen which result from the variation of the deformation of the rotated grains.

Figure 6 shows the VMS in the part of the elastic volume $X>0, Y>0$ and $Z>0$. Each grain can be clearly identified. The main variations in the VMS occur quite close to the surface which indicates that material anisotropy may lead to a reduction of RCF life relative to the isotropic material case. The biggest difference is expected to occur when neighboring grains have large variation in orientation on the scale of the Hertzian contact radius. In such cases, predictions of RCF based on standard models may be unrealistically optimistic.

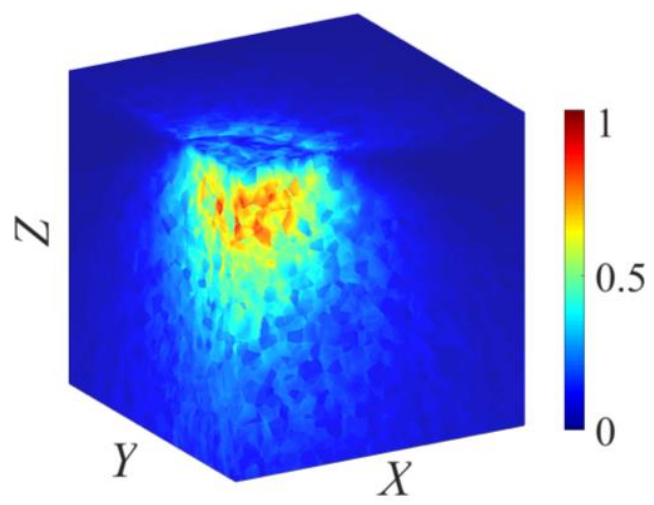

Figure $63 \mathrm{D}$ VMS distribution in the elastic body of polycrystalline anisotropic material (EHL contact, $M=100, L=10$ ) 
The distributions of different stresses along the centreline $(X=Y=0)$ as a function of $Z$ for the isotropic and the heterogeneous anisotropic material are shown in Fig. 7. The largest deviations from the isotropic results appear around the location of the maximum VMS, which depends on the variation of the rotation difference and the strain in that region. For isotropic material, the maximum VMS and the largest strain occur at a depth of $Z=0.4688$ for the coupled EHL solution (Tab. 9, Case b), whereas for the present case the depth of the maximum VMS is close to but not equal to the depth of $Z=0.4688$ (for this case, $Z=0.5163)$. Note that the specific details will depend on the local grain orientation. Away from the region of maximum stresses $(0.25<Z<1.0)$, the differences due to the variation of the orientation decrease.

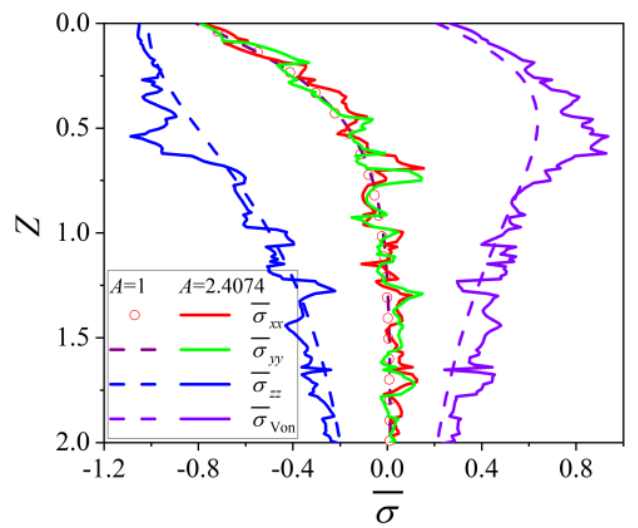

Figure 7 The comparison of stresses between isotropic and anisotropic materials along the centerline $(X=Y=0)$

Next, for exactly the same topology and orientation distribution, the effect of the anisotropy ratio on pressure, film thickness and stress field distribution is shown. Three values of the Zener ratio ( $A=2.4074, A=3.36$, and $A=3.77)$ [34][37] are used and the results are shown in Fig. 8. The topology and rotation angles of grains are kept the same for the three cases. When comparing the stress distribution from Fig.8 (a) to (c), the local stress concentration increases in magnitude with the increase of the anisotropy ratio. The values of maximum VMS for these three cases are 1.0381, 1.217 and 1.299, respectively. However, again as in the previous cases, the effect on the EHL film thickness distribution is minor. The pressure distribution in the lubricant for the three cases is compared in Fig. 8 (d). Pressure fluctuations are caused by the variation of the rotation angle in grains and are influenced by the anisotropy ratio. The pressure peaks 
and valleys are marked with down- and up- arrows respectively. In the present case, the pressure profile exhibits 6 local maxima indicated in the figure with $p$ (peak) and local minima indicated with $\mathrm{v}$ (valley). Tab. 10 compares the amplitude of each of the maxima-minima in relation to the anisotropy ratio, i.e. $P_{\mathrm{p} 1}-P_{\mathrm{v} 1}, P_{\mathrm{p} 2}-P_{\mathrm{v} 2}$ and so on. From the table, it is observed that with the increase of anisotropy ratio, the local pressure variation increases.

Table 10 Height of local EHL pressure variations

\begin{tabular}{cccc}
\hline No. & $\boldsymbol{A = \mathbf { 2 . 4 0 7 4 }}$ & $\boldsymbol{A}=\mathbf{3 . 3 6}$ & $\boldsymbol{A}=\mathbf{3 . 7 7}$ \\
\hline 1 & 0.05683 & 0.08941 & 0.09803 \\
2 & 0.16794 & 0.21690 & 0.23288 \\
3 & 0.10555 & 0.12434 & 0.13876 \\
4 & 0.19655 & 0.21911 & 0.23339 \\
5 & 0.12348 & 0.12602 & 0.12815 \\
6 & 0.10915 & 0.12544 & 0.13122 \\
\hline
\end{tabular}

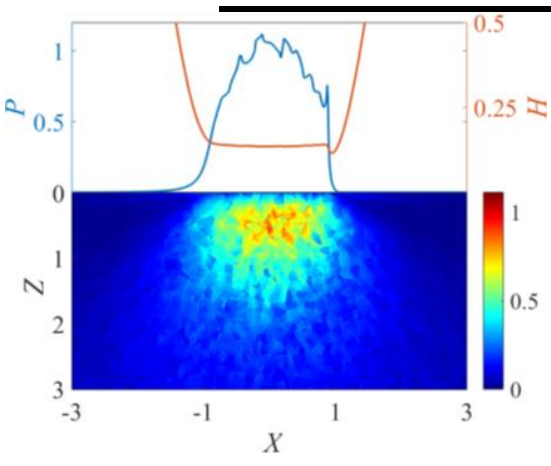

(a) $A=2.4074$

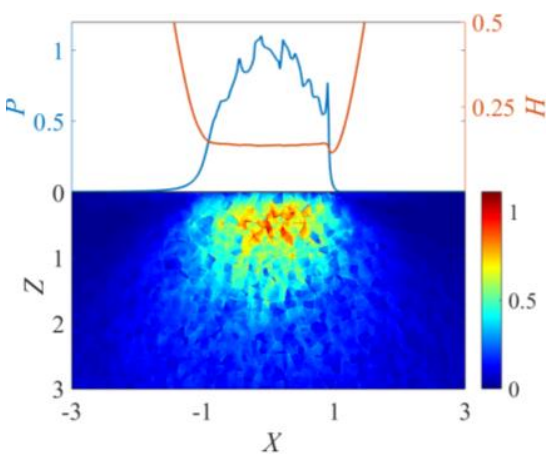

(c) $A=3.77$

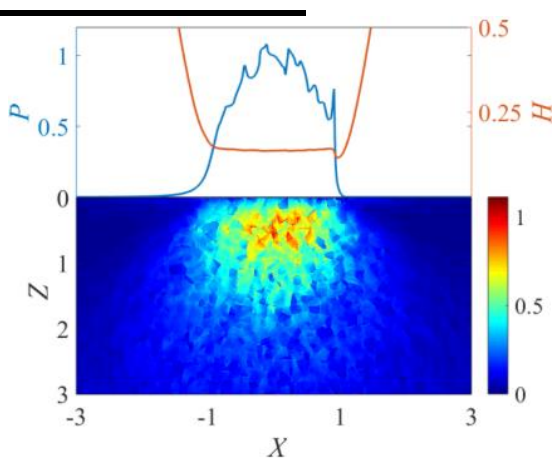

(b) $A=3.36$

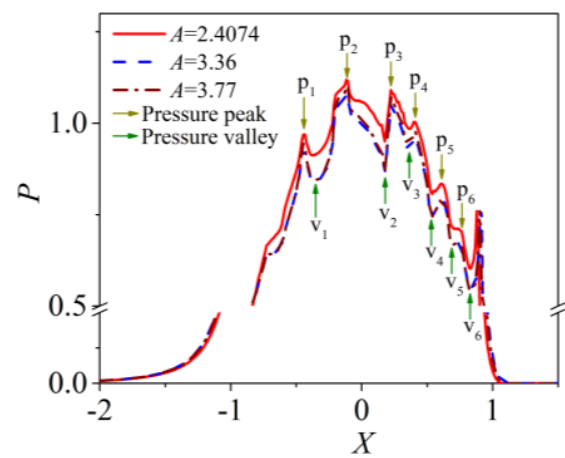

(d) Pressure comparison

Figure 8 Effect of the Zener anisotropy ratio on (dimensionless) surface pressure and film thickness profile, and on the VMS distribution in the plane $(Y=0)$ 


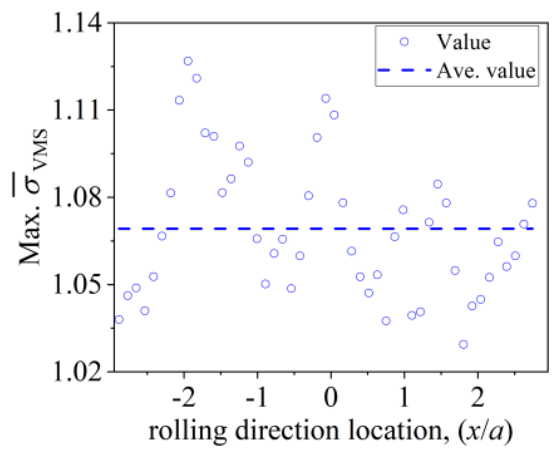

(a) Value of the maximum VMS

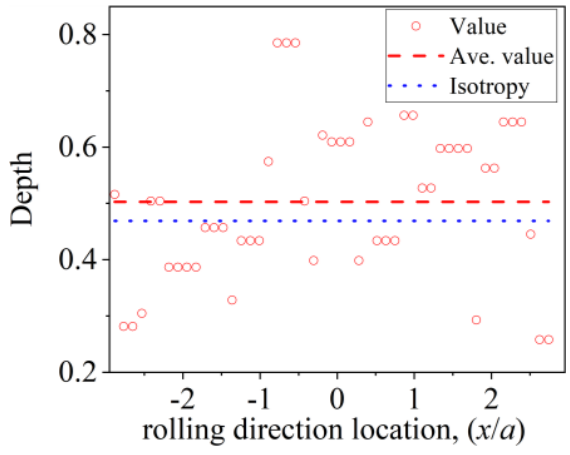

(b) Depth of the maximum VMS

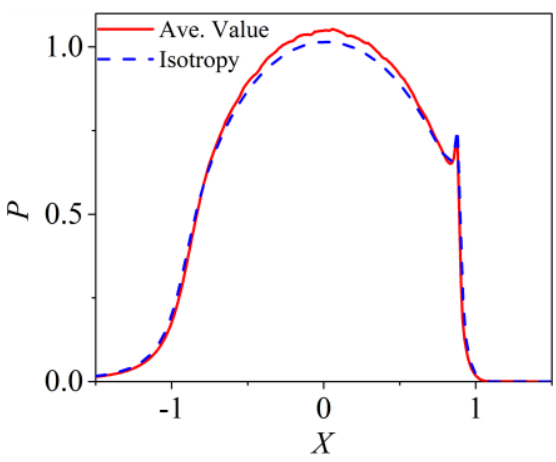

(c) Pressure comparison

Figure 9 The value and the depth of the maximum VMS and the averaged pressure for 49 microstructure domains

So far, the sphere is fixed to one contact location, which means the orientation angles and topology of the heterogeneous anisotropic material are the same as for the results already shown. Finally, the average effect of multiple randomly generated orientation angles and topologies is investigated with the anisotropy ratio $A$ equals 2.4074 . In total, 49 cases of different contact locations in rolling direction were solved. The value and location of the maximum VMS for each case are given in Fig. 9. The random nature in the orientation and topology is reflected in both the value and the depth of the maximum VMS, which shows significant variations from case to case. The overall average value of the maximum VMS is 1.0692 , which is significantly higher than the value predicted for isotropic material (0.6366). The average depth of the maximum VMS is 0.5027 , which is close to the value predicted for isotropic material 
(0.4688). The minimum depth is 0.2578 , when the corresponding value of maximum VMS exceeds the threshold of fatigue limit as well, these cases have higher potential to initiate cracks close to the surface. The standard deviation of the value and the depth of the maximum VMS is $2.44 \%$ and $13.77 \%$ respectively, which is of the same order of magnitude as the scatter observed in the fatigue life data obtained from RCF experiments [34]. The average of the EHL pressure distribution of the 49 cases is shown in Fig. 9(c) together with the pressure distribution for isotropic material. It can be seen that the average pressure curve is smooth and quite close to the result for isotropic material.

\section{Conclusions}

In this paper, multigrid techniques were shown to be very well suited for the numerical simulation of the pressure and film thickness distribution as well as the 3D stress distribution for an EHL contact with heterogeneous anisotropic material. Firstly, the developed 3D model was verified against conventional EHL models for homogeneous isotropic material with elastic half space, including a discussion of efficiency of numerical solution of 2D and 3D for different cases of dry and EHL contact. Next the effect of homogeneous anisotropic material was investigated. As anisotropic material exhibits different stiffness in the load direction depending on the orientation, it is seen that the orientation of the material significantly affects the predicted maximum VMS. Finally, the more computationally challenging case of 3D heterogeneous material with randomly varying anisotropy angles over the grains was studied. It was found that for polycrystalline anisotropic material, the stiffness variation between the grains leads to significant pressure fluctuations even when the contacting surfaces are smooth. This directly reflects in the subsurface stress distribution. However, whereas the material anisotropy clearly affects the pressure distribution and stresses, it has almost no influence on the EHL film thickness as this is determined in the inlet region where the deformation is still small. Analyzing cases of granular material with varying orientations and topologies, a standard deviation of the value and of the depth of the maximum VMS was observed of about $2.5 \%$ and $14 \%$ respectively. This qualitatively agrees well with the life scatter observed in RCF experiments. The average value of the maximum VMS of 49 cases of a statistically generated polycrystalline anisotropy distribution was $68 \%$ larger than that of isotropic material. This is a strong indication that also in real bearing applications the variations in anisotropy may have a significant effect on RCF life. Finally, the variations were shown to depend on the value of 
the anisotropic ratio of the material. The results presented stimulate further study into the effect of grain size and anisotropy variation on the actually predicted RCF life. Further developments will involve using the developed method to actual data from EBSD analysis of bearing material. Considering the lubricated contact equations extension to account for e.g. surface roughness effects is trivial, and extension to non-Newtonian lubricant behavior and to transient problems can be considered.

\section{Acknowledgements}

The authors would like to thank Mr. Bernie van Leeuwen, SKF Research and Technology Development Director, for his kind permission to publish this article. The first two authors acknowledge the China Scholarship Council (CSC) for providing the $\mathrm{PhD}$ scholarships. The authors would like to thank Dr. Guillermo E. Morales-Espejel (SKF), Dr. H. Boffy (SKF) and Prof. A.A. Lubrecht (INSA-Lyon, France) for the continuous interest and helpful discussions.

\section{Nomenclature}

$a$

$A$

$c_{11}, c_{12}, c_{44}$

$C_{i, j, k, l}$

$\bar{C}_{i, j, k, l}$

$E^{\prime}$

$F$

$h$

$h_{x}, h_{y}, h_{z}$

$H$

$h_{0}$

$p$

$P$ half width of Hertzian contact for homogeneous isotropic material, (m)

anisotropy material ratio, (-)

elastic constants for cubic material, $(\mathrm{Pa})$

elastic stiffness matrix, $(\mathrm{Pa})$

dimensionless of elastic stiffness matrix, $C_{i, j, k, l} / p_{\mathrm{h}}$

Reduced Young's modulus, (Pa)

applied load, (N)

film thickness, (m)

mesh space in $X, Y$ and $Z$ directions, (-)

dimensionless film thickness, $h /\left(a^{2} / R_{x}\right)$

mutual separation thickness, (m)

pressure, $(\mathrm{Pa})$

dimensionless pressure, $p / p_{\mathrm{h}}$ 


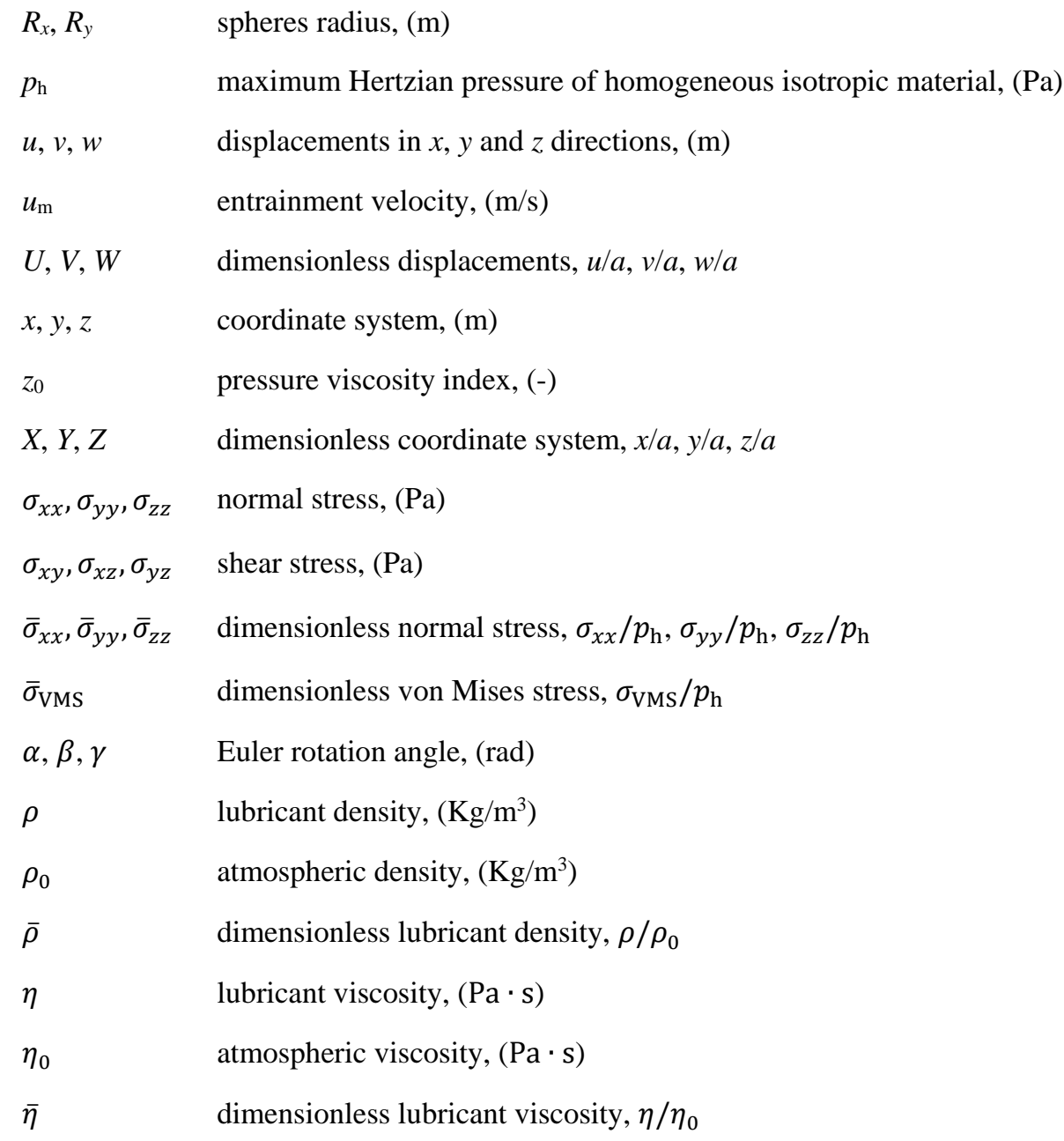

\section{References}

[1] Pierman A-P, Bouaziz O, Pardoen T, Jacques P, Brassart L. The influence of microstructure and composition on the plastic behaviour of dual-phase steels. Acta Materialia 2014; 73: 298-311. https://doi.org/10.1016/j.actamat.2014.04.015.

[2] Tasan C C, Diehl M, Yan D, Bechtold M, Roters F, Schemmann L, Zheng C, Peranio N, Ponge D, Koyama M. An overview of dual-phase steels: advances in microstructure-oriented processing and micromechanically guided design. Annual Review of Materials Research 2015; 45: 391-431. https://doi.org/10.1146/annurevmatsci-070214-021103.

[3] Aşik E, Perdahcıoğlu E, Van Den Boogaard A. Microscopic investigation of damage mechanisms and anisotropic evolution of damage in DP600. Materials Science and Engineering: A 2019; 739: 348-356. https://doi.org/10.1016/j.msea.2018.10.018. 
[4] Asik E. Damage in dual phase steels. PhD Thesis, University of Twente; 2019.

[5] Skylar-Scott M A, Mueller J, Visser C W, Lewis J A. Voxelated soft matter via multimaterial multinozzle 3D printing. Nature 2019; 575(7782): 330-335. https://doi.org/10.1038/s41586-019-1736-8.

[6] Bargmann S, Klusemann B, Markmannm J, Schnabel J E, Schneider K, Soyarslan C, Wilmers J. Generation of 3D representative volume elements for heterogeneous materials: A review. Progress in Materials Science 2018; 96:322-384. https://doi.org/10.1016/j.pmatsci.2018.02.003.

[7] Gu H, Réthore J, Baietto M-C, Sainsot P, Lecomte-Grosbras P, Venner C H, Lubrecht A A. An efficient MultiGrid solver for the 3D simulation of composite materials. Computational materials science 2016; 112: 230-237. https://doi.org/10.1016/j.commatsci.2015.10.025.

[8] Liu X, Réthoré J, Baietto M-C, Sainsot P, Lubrecht A A. An efficient strategy for large scale 3D simulation of heterogeneous materials to predict effective thermal conductivity. Computational materials science 2019; 166: 265-275. https://doi.org/10.1016/j.commatsci.2019.05.004.

[9] Venner C H, Lubrecht A A. Multi-level methods in lubrication. Amsterdam: Elsevier; 2000.

[10] Gohar R, Cameron A. Optical measurement of oil film thickness under elastohydrodynamic lubrication. Nature 1963; 200(4905): 458-459. https://doi.org/10.1038/200458b0.

[11] Cann P, Spikes H, Hutchinson J. The development of a spacer layer imaging method (SLIM) for mapping elastohydrodynamic contacts. Tribology Transactions 1996; 39(4): 915-921. https://doi.org/10.1080/10402009608983612.

[12] Li S, Guo F, Li X, Liu C. Numerical simulation of an oil droplet passing through an EHL contact. Tribology International 2017; 112: 58-67. https://doi.org/10.1016/j.triboint.2017.03.033.

[13] Alvarez W S. Microstructural degradation of bearing steels. PhD Thesis, University of Cambridge; 2014.

[14] Vorovich I, Ustinov I A. Pressure of a die on an elastic layer of finite thickness. Journal of Applied Mathematics and Mechanics 1959; 23(3): 637-650. https://doi.org/10.1016/0021-8928(59)90158-3.

[15] Kennedy F, Ling F. Elasto-plastic indentation of a layered medium. Journal of Engineering Material and Technology 1974; 96(2): 97-103. https://doi.org/10.1115/1.3443202.

[16] Plumet S, Dubourg M-C. A 3-D model for a multilayered body loaded normally and tangentially against a rigid body: application to specific coatings. Journal of Tribology 1998; 120(4): 668-676. https://doi.org/10.1115/1.2833764.

[17] Polonsky I, Keer L M. A fast and accurate method for numerical analysis of elastic layered contacts. Journal of Tribology 2000; 122(1): 30-35. https://doi.org/10.1115/1.555323.

[18] Cai S, Bhushan B. A numerical three-dimensional contact model for rough, 
multilayered elastic/plastic solid surfaces. Wear 2005; 259(7-12): 1408-1423. https://doi.org/10.1016/j.wear.2005.02.014.

[19] Watremetz B, Baietto-Dubourg M, Lubrecht A. Prediction of the thermomechanical contact behaviour of a Graded coating/substrate system using advanced numerical Techniques. World Tribology Congress III 2005; WTC2005-63335: 329-330. https://doi.org/10.1115/WTC2005-63335.

[20] Boffy H, Baietto M-C, Sainsot P, Lubrecht A A. An efficient 3d model of heterogeneous materials for elastic contact applications using multigrid methods. Journal of Tribology 2012; 134(2): 021401. https://doi.org/10.1115/1.4006296.

[21] Eshelby J D. The determination of the elastic field of an ellipsoidal inclusion, and related problems. Proceedings of the royal society of London. Series A. Mathematical and physical sciences 1957; 241(1226): 376-396. https://doi.org/10.1098/rspa.1957.0133.

[22] Eshelby J D. The elastic field outside an ellipsoidal inclusion. Proceedings of the royal society of London. Series A. Mathematical and physical sciences 1959; 252(1271): 561-569. https://doi.org/10.1098/rspa.1959.0173.

[23] Leroux J, Fulleringer B. Effects of the presence of multiple spherical inclusions within an elastic half-space in a circular point contact. International Joint Tribology Conference 2010; IJTC2010-41160: 423-426. https://doi.org/10.1115/IJTC201041160.

[24] Zhou K, Keer L M, Wang Q J. Semi-analytic solution for multiple interacting threedimensional inhomogeneous inclusions of arbitrary shape in an infinite space. International Journal for Numerical Methods in Engineering 2011; 87(7): 617-638. https://doi.org/10.1002/nme.3117

[25] Boffy H, Venner C H. Multigrid numerical simulation of contact mechanics of elastic materials with 3D heterogeneous subsurface topology. Tribology International 2015; 92: 233-245. https://doi.org/10.1016/j.triboint.2015.06.015.

[26] Slack T S, Raje N, Sadeghi F, Doll G, Hoeprich M R. EHL modeling for nonhomogeneous materials: the effect of material inclusions. $2007 ; 129(2)$ : 256273. https://doi.org/10.1115/1.2540234.

[27] Wang Z, Zhu D, Wang Q. Elastohydrodynamic lubrication of inhomogeneous materials using the equivalent inclusion method. Journal of Tribology 2014; 136(2): 021501. https://doi.org/10.1115/1.4025939.

[28] Zhang S G, Wang W Z, Zhao Z Q. Elastohydrodynamic lubrication analysis of point contacts with consideration of material inhomogeneity. Journal of Tribology 2014; 136(4): 041501. https://doi.org/10.1115/1.4027750.

[29] Dong Q, Yang J, Wang X, M Keer L, Zhou K. Heterogeneous structures with inhomogeneous inclusions under elastohydrodynamic lubrication contact with consideration of surface roughness. Proceedings of the Institution of Mechanical Engineers, Part J: Journal of Engineering Tribology 2016; 230(5): 571-582. https://doi.org/10.1177/1350650115606944. 
[30] Morales-Espejel G E, Boffy H, Venner C H. Effects of material heterogeneity on surface fatigue for rough lubricated rolling-sliding contacts. Proceedings of the Institution of Mechanical Engineers, Part J: Journal of Engineering Tribology 2017; 231(2): 274-290. https://doi.org/10.1177/1350650116650126.

[31] Félix Quiñonez A, Morales Espejel G E. Theoretical analysis of a rolling-sliding elastohydrodynamic lubrication line contact with a subsurface inclusion. Proceedings of the Institution of Mechanical Engineers, Part J: Journal of Engineering Tribology 2019; 233(8): 1197-1207. https://doi.org/10.1177/1350650119826440.

[32] Paulson N R, Bomidi J A, Sadeghi F, Evans R D. Effects of crystal elasticity on rolling contact fatigue. International journal of fatigue 2014; 61: 67-75. https://doi.org/10.1016/j.ijfatigue.2013.12.005.

[33] Noyel J-P, Ville F, Jacquet P, Gravouil A, Changenet C. Development of a granular cohesive model for rolling contact fatigue analysis: crystal anisotropy modeling. $\begin{array}{llll}\text { Tribology } & \text { Transactions } & \text { 2016; } & \text { 469-479) }\end{array}$ https://doi.org/10.1080/10402004.2015.1087076.

[34] Paulson N R, Sadeghi F. EHL modeling of nonhomogeneous materials: the effects of polycrystalline anisotropy on RCF. Tribology International 2017; 112: 137-146. https://doi.org/10.1016/j.triboint.2017.04.007.

[35] Zhang B B, Boffy H, Venner C H. Multigrid solution of 2D and 3D stress fields in contact mechanics of anisotropic inhomogeneous materials. Tribology International 2020. https://doi.org/10.1016/j.triboint.2019.02.044.

[36] Venner $\mathrm{C} \mathrm{H}$, Lubrecht A. Numerical simulation of a transverse ridge in a circular EHL contact under rolling/sliding. Journal of Tribology 1994; 116(4): 751-761. https://doi.org/10.1115/1.2927329.

[37] Bower A F. Applied mechanics of solids. United States: CRC press; 2009.

[38] Roelands C A. Correlational aspects of the viscosity temperature pressure relationship of lubricating oils. PhD Thesis, Technical University Delft; 1966.

[39] Dowson D, Higginson G R. Elastohydrodynamic lubrication, the fundamentals of roller and gear lubrication. Great Britain: Pergamon Press; 1966.

[40] Bair S. High pressure rheology for quantitative elastohydrodynamics. Elsevier; 2007.

[41] Venner C H, Bos J. Effects of lubricant compressibility on the film thickness in EHL line and circular contacts. Wear 1994; 173(1-2): 151-165. https://doi.org/10.1016/0043-1648(94)90268-2.

[42] Bair S, Mary C, Bouscharain N, Vergne P. An improved Yasutomi correlation for viscosity at high pressure. Proceedings of the Institution of Mechanical Engineers, Part J: Journal of Engineering Tribology 2013; 227(9): 1056-1060. https://doi.org/10.1177/1350650112474394.

[43] Brandt A. Multi-Level Adaptive Technique (MLAT) for fast numerical solutions to boundary value problems. Proceedings of the Third International Conference on Numerical Methods in Fluid Mechanics 1973; 82-89. 
[44] Brandt A, Lubrecht A. Multilevel matrix multiplication and fast solution of integral equations. Journal of Computational Physics 1990; 90(2): 348-370. https://doi.org/10.1016/0021-9991(90)90171-V.

[45] Lubrecht A, Ioannides E. A fast solution of the dry contact problem and the associated sub-surface stress field, using multilevel techniques. Journal of Tribology 1991; 113(1): 128-133. https://doi.org/10.1115/1.2920577.

[46] Hamilton G M, Goodman L. The stress field created by a circular sliding contact. Journal of Applied Mechanics 1966; 33(2): 371-376. https://doi.org/10.1115/1.3625051.

[47] Wang Q J, Chung Y-W. Encyclopedia of tribology. US: Springer; 2013.

\section{Appendix A: Discrete equations}

The discretization method of the interior and side boundary equations can be found in Refs. [25, 35]. Here, the discretization of the equations in the top boundary plane is given for the steady state case. The discretization of the Reynolds equation is done using a central second order discretization for the pressure flow terms and an upstream second order (SU2) discretization is for the wedge term, as in Ref. [9]. This gives the following discrete equation for the grid point with index $(i, j, 0)$ in the top surface:

$$
\begin{gathered}
\frac{\xi_{i-\frac{1}{2}, j} P_{i-1, j}-\left(\xi_{i-\frac{1}{2}, j}+\xi_{i+\frac{1}{2}, j}\right) P_{i, j}+\xi_{i+\frac{1}{2}, j} P_{i+1, j}}{h_{x}^{2}}+ \\
\frac{\xi_{i, j-\frac{1}{2}} P_{i, j-1}-\left(\xi_{i, j-\frac{1}{2}, 0}+\xi_{i, j+\frac{1}{2}}\right) P_{i, j}+\xi_{i, j+\frac{1}{2}, 0} P_{i, j+1}}{h_{y}^{2}}- \\
\frac{1.5(\bar{\rho} H)_{i, j}-2(\bar{\rho} H)_{i-1, j}+0.5(\bar{\rho} H)_{i-2, j}}{h_{x}}=0
\end{gathered}
$$

where $\xi=\frac{\bar{\rho} H^{3}}{\bar{\eta} \bar{\lambda}}, \bar{\lambda}=\frac{12 u_{\mathrm{m}} \eta_{0} R_{x}^{2}}{a^{3} p_{h}}$, as in Ref. [9]. The top boundary equations of the elastic problem are discretized using a second order central upstream discretization for the in plane displacement derivatives. For the $z$ derivatives, both a second order one sided discretization and first order discretization are used. The resulting discrete zero stress equations for the $x$ and $y$ directions are: 


$$
\begin{aligned}
\bar{C}_{1311(i, j, 0)} \frac{U_{i+1, j, 0}-}{2 h_{x}}+U_{i-1, j, 0} & \bar{C}_{1322(i, j, 0)} \frac{V_{i, j+1,0}-V_{i, j-1,0}}{2 h_{y}}+\bar{C}_{1333(i, j, 0)} \frac{W_{i, j, 0}-W_{i, j, 1}}{h_{z}} \\
+ & \bar{C}_{1323(i, j, 0)}\left(\frac{V_{i, j, 0}-V_{i, j, 1}}{h_{z}}+\frac{W_{i, j+1,0}-W_{i, j-1,0}}{2 h_{y}}\right) \\
+ & \bar{C}_{1313(i, j, 0)}\left(\frac{1.5 U_{i, j, 0}-2 U_{i, j, 1}+0.5 U_{i, j, 2}}{h_{z}}+\frac{W_{i+1, j, 0}-W_{i-1, j, 0}}{2 h_{x}}\right) \\
+ & \bar{C}_{1312(i, j, 0)}\left(\frac{U_{i, j+1,0}-U_{i, j-1,0}}{2 h_{y}}+\frac{V_{i+1, j, 0}-V_{i-1, j, 0}}{2 h_{x}}\right)=0 \\
\bar{C}_{2311(i, j, 0)} \frac{U_{i+1, j, 0}-}{2} & U_{i-1, j, 0}+\bar{C}_{2322(i, j, 0)} \frac{V_{i, j+1,0}-V_{i, j-1,0}}{2 h_{y}}+\bar{C}_{2333(i, j, 0)} \frac{W_{i, j, 0}-W_{i, j, 1}}{h_{z}} \\
+ & \bar{C}_{2323(i, j, 0)}\left(\frac{1.5 V_{i, j, 0}-2 V_{i, j, 1}+0.5 V_{i, j, 2}}{h_{z}}+\frac{W_{i, j+1,0}-W_{i, j-1,0}}{2 h_{y}}\right) \\
+ & \bar{C}_{2313(i, j, 0)}\left(\frac{U_{i, j, 0}-U_{i, j, 1}}{h_{z}}+\frac{W_{i+1, j, 0}-W_{i-1, j, 0}}{2 h_{x}}\right) \\
+ & \bar{C}_{2312(i, j, 0)}\left(\frac{U_{i, j+1,0}-U_{i, j-1,0}}{2 h_{y}}+\frac{V_{i+1, j, 0}-V_{i-1, j, 0}}{2 h_{x}}\right)=0
\end{aligned}
$$

Finally, the vertical normal stress should balance the pressure in the lubricant film:

$$
\begin{aligned}
\bar{C}_{3311(i, j, 0)} \frac{U_{i+1, j, 0}-}{2 h_{x}} & U_{i-1, j, 0}+\bar{C}_{3322(i, j, 0)} \frac{V_{i, j+1,0}-V_{i, j-1,0}}{2 h_{y}} \\
& +\bar{C}_{3333(i, j, 0)} \frac{1.5 W_{i, j, 0}-2 W_{i, j, 1}+0.5 W_{i, j, 2}}{h_{z}} \\
& +\bar{C}_{3323(i, j, 0)}\left(\frac{V_{i, j, 0}-V_{i, j, 1}}{h_{z}}+\frac{W_{i, j+1,0}-W_{i, j-1,0}}{2 h_{y}}\right) \\
& +\bar{C}_{3313(i, j, 0)}\left(\frac{U_{i, j, 0}-U_{i, j, 1}}{h_{z}}+\frac{W_{i+1, j, 0}-W_{i-1, j, 0}}{2 h_{x}}\right) \\
& +\bar{C}_{3312(i, j, 0)}\left(\frac{U_{i, j+1,0}-U_{i, j-1,0}}{2 h_{y}}+\frac{V_{i+1, j, 0}-V_{i-1, j, 0}}{2 h_{x}}\right)+P_{i, j}=0
\end{aligned}
$$

Summarizing, there are four equations for the variables $U, V, W$ and $P$ in each point. The solution is subject to the cavitation condition $P \geq 0$.

\section{Appendix B: Relaxation}

For the interior equations and the stress boundary conditions on the vertical faces of the cubic domain, Gauss-Seidel relaxation is used in lexicographic order, see also in Refs. [25][35]. Below the relaxation of the Reynolds equation and the stress boundary conditions in the top plane together with the lubricant cavitation condition is detailed. Due to the strong coupling between the discrete Reynolds equation (14) and the stress boundary Eq. (15)-Eq. (17), a sequential relaxation is not suited as when relaxing the next equation large disturbances are again introduced in the previous equation thus leading to a diverging process. The 
remedy is to use collective relaxation, that is to solve the equations for the different unknowns in each grid point simultaneously. This is explained below in section B.1, and was also used in Ref. [35] for the dry contact problem. A complication for the lubricated problem is that the Reynolds equation involves a strong coupling in the $x$ direction, which directly affects the equation for the vertical displacement. To ensure good error smoothing in pressure $P$ and multigrid efficiency, a line relaxation is needed in the direction of the strong coupling. This was also needed in the conventional EHL solver described in Ref. [9]. The line relaxation for the present problem is explained in section B.2.

\section{B.1 Collective relaxation}

The system of equations for the changes $\delta U, \delta V, \delta W$ and $\delta P$ to be applied to the variables in grid point $(i, j, 0)$ such that the Eq. (14)- Eq. (17) are satisfied after these changes are made:

$$
\left[\begin{array}{cccc}
\frac{1.5 \bar{C}_{1313(i, j)}}{h_{z}} & \frac{\bar{C}_{1323(i, j)}}{h_{z}} & \frac{\bar{C}_{1333(i, j)}}{h_{z}} & 0 \\
\frac{\bar{C}_{2313(i, j)}}{h_{z}} & \frac{1.5 \bar{C}_{2323(i, j)}}{h_{z}} & \frac{\bar{C}_{2333(i, j)}}{h_{z}} & 0 \\
\frac{\bar{C}_{3313(i, j)}}{h_{z}} & \frac{\bar{C}_{3323(i, j)}}{h_{z}} & \frac{1.5 \bar{C}_{3333(i, j)}}{h_{z}} & 1 \\
0 & 0 & \zeta \frac{2 \bar{\rho}_{i, j} R_{x}}{a h_{x}} & \frac{\xi_{i \pm \frac{1}{2}, j}}{h_{x}^{2}}+\frac{\xi_{i, j \pm \frac{1}{2}}}{h_{y}^{2}}
\end{array}\right]_{(i, j)}=\left[\begin{array}{c}
\delta U \\
\delta V \\
\delta W \\
\delta P
\end{array}\right]_{(i, j)}
$$

The right hand terms, $r_{U}, r_{V}, r_{W}$ and $r_{P}$ are the residuals of Eq. (14)- Eq. (17) in the grid point $(i, j, 0)$ before making the changes. The coefficients are the derivative of the respective discrete equation operator with respect to the variable to be changed. The value of $\zeta$ depends on the discretization used for the wedge term of the Reynolds equation. For the second order upstream (SU2) discretization, its value is 1.5. For a first order upstream discretization, it would be 1.0. The $4 \times 4$ system (Eq. (18)) can be quite easily solved by direct inversion. The complementarity condition is imposed by setting the pressure to zero when the computed new value for pressure $P$ is below zero. Subsequently, with $P$ set to zero, the system of $3 \times 3$ equations is solved for $\delta U, \delta V, \delta W$.

\section{B.2 Line relaxation}

The line relaxation ideally should scan the top surface $x$-line by $x$-line. For each line, construct the system of equations (Eq. (18)) for all points $i$ with the same $j$ and solve this system. Then apply all changes $\delta U, \delta V, \delta W$ and $\delta P$ solved 
for each $i$ simultaneously. The work involved for direct solution is $b^{2} n$ where $b$ is the bandwidth of the matrix. The storage requirements are of $O(b n)$. Hence, although significantly more expensive than point relaxation, it does not alter the $O(N)$ computational complexity of the Multigrid algorithm. However, as the coupling in $x$ direction mainly affects the equation (14) and (17), alternatively the collective point relaxation described in B.1 can be carried out and followed up by a line relaxation consisting only of the system of equations resulting from equation (14) and (17) for changes $\delta W$ and $\delta P$ for all points $i$ on a line $j$. As an illustration, for the case of a grid with 9 points, the system of equations for the 7 non-boundary points in the $i$ direction is:

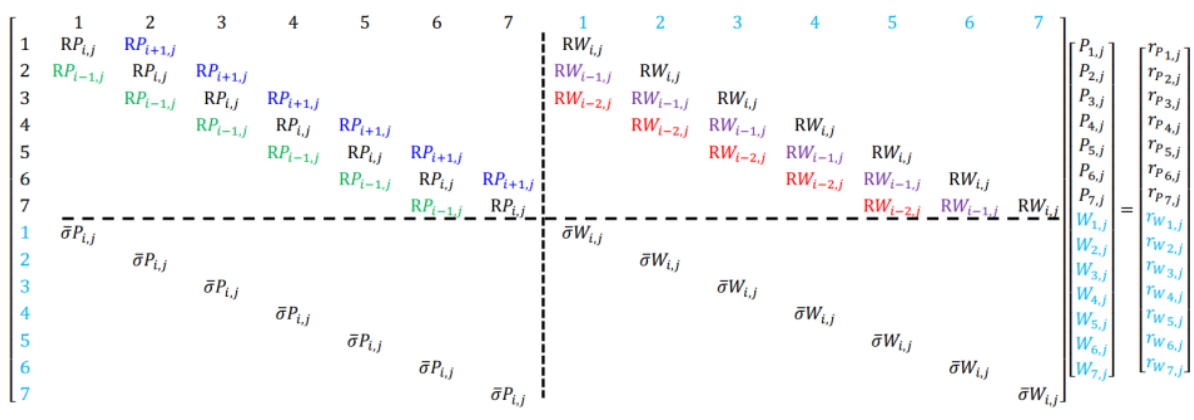

where the coefficients in the matrix are the derivatives of the operator with respect to the variable to be changed.

$$
\begin{aligned}
\mathrm{R} P_{i, j}=\frac{\partial(\mathrm{Reynolds})_{i, j}}{\partial P_{i, j}}, \mathrm{R} P_{i-1, j} & =\frac{\partial(\mathrm{Reynolds})_{i, j}}{\partial P_{i-1, j}}, \mathrm{R} P_{i+1, j}=\frac{\partial(\mathrm{Reynolds})_{i, j}}{\partial P_{i+1, j}} \\
\mathrm{R} W_{i, j}=\frac{\partial(\mathrm{Reynolds})_{i, j}}{\partial W_{i, j}}, \mathrm{R} W_{i-1, j} & =\frac{\partial(\mathrm{Reynolds})_{i, j}}{\partial W_{i-1, j}}, \mathrm{R} W_{i-2, j}=\frac{\partial(\mathrm{Reynolds})_{i, j}}{\partial W_{i-2, j}}, \\
\bar{\sigma} P_{i, j} & =\frac{\partial\left(\bar{\sigma}_{z z}+P\right)_{i, j}}{\partial P_{i, j}}, \\
\bar{\sigma} W_{i, j} & =\frac{\partial\left(\bar{\sigma}_{z z}+P\right)_{i, j}}{\partial W_{i, j}}
\end{aligned}
$$

Scanning the grid $j$-line by $j$-line, the system can be constructed and solved and the changes applied to $P$ and $W$. 

Appendix: Paper C 
Effect of material anisotropy on rolling contact fatigue life under dry and lubricated point contact conditions: a numerical study

Binbin Zhang ${ }^{a *}$, Armando Félix Quiñonez ${ }^{b}$, Cornelis H. Venner ${ }^{a}$

${ }^{a}$ Faculty of Engineering Technology, University of Twente, 7500AE Enschede, The Netherlands

${ }^{b}$ SKF Research and Technology Development, Meidoornkade 14, 3992AE Houten, The Netherlands

\begin{abstract}
Rolling bearings have to operate reliably and efficiently under increasingly severe conditions. Previously ignored effects of material inhomogeneity with varying crystallographic orientation may significantly affect rolling contact fatigue life. In this paper, it is demonstrated that Multigrid techniques allow the computational analysis of such effects in a full 3D setting. Using grain configurations created by Voronoi tessellation, the dependence of the maximum von Mises stress, and of a predicted fatigue life stress field integral with load, friction, mean grain size and crystallographic orientation distribution is shown. Crystallographic orientation variations are shown to potentially significantly reduce predicted rolling contact fatigue life relative to homogeneous isotropic material. The results contribute to material optimization and to computational diagnostics of criticality of material crystallographic (sub)structures.
\end{abstract}

\title{
Keywords
}

Fatigue life; Polycrystalline anisotropic material; Dry and lubricated contact; Multigrid method

\section{Introduction}

The motion of the rolling element relative to the raceway in a rolling bearing results in cyclic loading and an alternating stress field distribution in the raceway subsurface. After millions of cycles, cracks are usually initiated in regions where the local stress exceeds the threshold of the fatigue limit of the material. These cracks gradually propagate to form a network, eventually leading to material spalling and bearing failure. This type of failure is known as rolling contact fatigue (RCF), and also occurs in other applications such as gears, wheel-rail contacts and camshaft-follower mechanisms. 
Today's high reliability of rolling bearings is built on a fundament of extensive research over the past decades dating back to the middle of the twentieth century. At that time, a wide spread in fatigue life was observed even in rolling bearing series from the same batch. The observed differences between the longest and the shortest life were as much as a factor twenty or even larger, which was obviously below acceptable engineering reliability [1]. Since 1939, the Weibull statistical theory has been used to describe the probability distribution of fatigue life [2]. In this model, the probability of survival is a function of the maximum shear stress, the number of stress cycles and the stressed volume. In 1947, Lundberg and Palmgren [3] established a fatigue life model (the L-P model) based on the Weibull distribution, in which the depth and the value of the maximum orthogonal shear stress were introduced. Based on the L-P model, the Chiu-Tallian-Mccool (C-T-M) model [4, 5, 6], the IoannidesHarris (I-H) model [7], the Cheng-Cheng (C-C) model [8] and the Yu-Harris (YH) model [9] were proposed successively. In the C-T-M model $[4,5,6]$, the surface initiated fatigue due to so-called type B defects (such as furrows, digs and pits) and type $\mathrm{C}$ defects (secondary micro pits formed during running) was investigated. In the I-H model [7], a fatigue limit is introduced below which the material will not fail due to classical RCF. The stress criterion used is not limited to the maximum orthogonal shear stress, it can also be the shear stress or the von Mises stress (VMS). Another difference in the I-H model compared to other models is that the overall risk of failure is based on the integral over the entire stressed volume rather than only on the value at a single location such as the point of the maximum orthogonal stress in the L-P model. The C-C model [8] is similar to the I-H model, however, it is easier to use as no integrations are performed. In the Y-H model [9], the depth of the maximum orthogonal shear stress is eliminated and the three material constants $\left(e, c, h_{\mathrm{s}}\right)$ are reduced into two. The differentiation aspect of Zaretsky model [10] is the inclusion of some external conditions affecting bearing life, for example contamination, bearing steel, etc. This is done by superposition of a series of operating-conditions independent factors, which are then multiplied to the fatigue life term. To obtain a model applicable to a wide range of test data, in 1996, Tallian proposed a datafitted life prediction model for rolling bearings considering traction, lubricant film, surface roughness, bearing material, etc. [11, 12, 13]. The database contains 274 test groups from 25 sources ranging in date from 1950 to 1992. More recently, Morales-Espejel et al. [14] presented a rolling bearing life model, in 
which the surface initialized damage is explicitly formulated into the model instead of taken into account by means of a penalty factor as has been common practice so far.

With the developed models, the life of rolling bearings can be predicted more accurately. However, the trends in design and applications of downsizing, reduced material use, increased efficiency, leads to more severe operating conditions (e.g. higher temperature, larger loads, reduced lubricant supply and starvation) and often more complex material topology (e.g. coating [15], nonmetallic inclusions [16], roughness and so on) push engineers and scientists ahead to develop models which e.g. can take into account the detailed topological and crystallographic effects of the material. In order to know more about the surface and subsurface originated failures, a numerical analysis of the stress field is essential. Sina et al. [17] studied the size, depth and stiffness of inclusions (Type A defect) on the butterfly wing formation, crack initiation and its propagation. It was found that stiffer inclusions are more detrimental to the RCF when they are closer to the maximum shear stress reversal point. Zhou [18] used the micro-macro contact model and real contact surface textures (surface profile with waviness and roughness, type $\mathrm{C}$ defect) to study the effect of surface topology on RCF with different lambda ratios. The results explained why the life of enhanced-finish bearings is longer than that of standard-finish bearings. Bearings with good surface finish and macroscopically homogeneous material can be achieved by modern manufacturing technology. However, for further improvement of predictions, more detailed insight in failure causes, and for computational diagnostics, research interest is directed to develop models and computational methods to take into account actual tomographic and crystallographic information of the local material and its anisotropy for prediction of fatigue life. Different from homogeneous isotropic material, the heterogeneous material topology resulting from the grains of anisotropic material with varying crystallographic orientation causes local stress concentrations around grain boundaries [19, 20, 21]. Besides, these different local mechanical properties also affect the pressure distribution at the surface under the dry contact and lubricated condition [22]. Due to the variation of properties on the scale of the grain size, the stress field calculation for heterogeneous anisotropic material requires a dense discretization (grid) which for 3D problems leads to systems of equations with many millions of unknowns. This requires an excessive computational effort unless a very efficient algorithm 
is used for solving the contact problem and the associated stress field. In earlier work [21][28], the authors have demonstrated that the multigrid method is well suited for the simultaneous solution of the (lubricated) contact problem and the 3D displacement and stress field in heterogeneous anisotropic material. In this paper, the developed algorithm is used in a fatigue life analysis considering the influence of the applied load, coefficient of friction, material grain size and orientation angles. The variable nature of the microstructural topology and crystallographic orientations results in scattering which depends on the grain size and orientation angle variations. The predicted fatigue life may significantly be reduced compared to the result for homogeneous isotropic material.

\section{Theory}

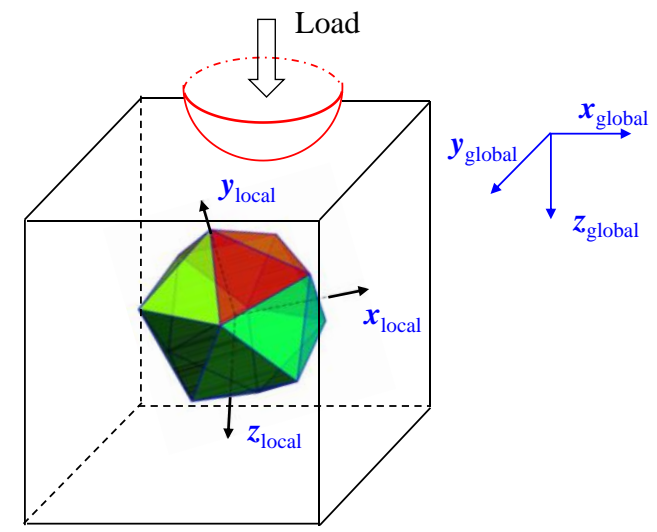

Figure 1 Schematic graph of 3D elastic contact

Figure 1 schematically shows the contact problem, a rigid ball loading against an elastic body. The contact pressure and the displacements on the top boundary can be solved with the Hertz-Signorini-Moreau condition [25]:

$$
\begin{cases}h(x, y)>0, p(x, y)=0 & \text { no contact } \\ h(x, y)=0, p(x, y)>0 & \text { contact }\end{cases}
$$

Alternatively, for a lubricated contact the Reynolds equation should be used as in Ref. [23]. The side boundary condition of the 3D elastic body is a stress free or Neumann boundary condition. At the bottom surface, zero displacement (Dirichlet boundary condition) is imposed. At the top surface: 


$$
\left\{\begin{array}{c}
\sigma_{z x}=\mu p \\
\sigma_{z y}=0 \\
\sigma_{z z}+p=0
\end{array}\right.
$$

with $p$ determined by Eq. (1) for a dry contact or by the Reynolds equation for a lubricated contact. For a lubricated contact, pure rolling condition is considered in this paper. So, the forces in $x$ and $y$ directions can be assumed to be zero compared to the normal stress in the $z$ direction. For a dry contact, both the rigid body and the elastic body keep still without relative motions. The effect of shear stress shown in Section 5.3 is obtained by applying shear force $(\mu p)$ in the $x$ direction. In other cases, the friction coefficient $\mu$ equals to zero if the shear stress is not considered for a dry contact. The stress equilibrium equations for the material are:

$$
\left\{\begin{array}{l}
\frac{\partial \sigma_{x x}}{\partial x}+\frac{\partial \sigma_{x y}}{\partial y}+\frac{\partial \sigma_{x z}}{\partial z}=0 \\
\frac{\partial \sigma_{y x}}{\partial x}+\frac{\partial \sigma_{y y}}{\partial y}+\frac{\partial \sigma_{y z}}{\partial z}=0 \\
\frac{\partial \sigma_{z x}}{\partial x}+\frac{\partial \sigma_{z y}}{\partial y}+\frac{\partial \sigma_{z z}}{\partial z}=0
\end{array}\right.
$$

where

$$
\left[\begin{array}{c}
\sigma_{x x} \\
\sigma_{y y} \\
\sigma_{z z} \\
\sigma_{y z} \\
\sigma_{x z} \\
\sigma_{x y}
\end{array}\right]=C\left[\begin{array}{c}
\partial u / \partial x \\
\partial v / \partial y \\
\partial w / \partial z \\
\partial v / \partial z+\partial w / \partial y \\
\partial u / \partial z+\partial w / \partial x \\
\partial u / \partial y+\partial v / \partial x
\end{array}\right]
$$

$C$ is the stiffness matrix in the global coordinate system $x_{\text {global, }}, y_{\text {global }}, z_{\text {global. }}$. It can be obtained from the stiffness matrix in the local grain coordinate system by:

$$
\left(C_{i, j, k, l}\right)_{\text {global }}=R_{x}(\alpha) R_{y}(\beta) R_{z}(\gamma)\left(C_{i, j, k, l}\right)_{\text {local }}\left(R_{x}(\alpha) R_{y}(\beta) R_{z}(\gamma)\right)^{T}
$$

$\alpha, \beta$ and $\gamma$ are the three Euler rotation angles, $R$ is the rotation matrix, and $C_{i, j, k, l}$ is the elastic stiffness matrix. For cubic anisotropic materials such as $\alpha$-Fe and $\gamma$-Fe, the local grain stiffness can be expressed in the following form [24]: 


$$
\left(C_{i, j, k, l}\right)_{\text {local }}=\left[\begin{array}{cccccc}
c_{11} & c_{12} & c_{12} & 0 & 0 & 0 \\
c_{12} & c_{11} & c_{12} & 0 & 0 & 0 \\
c_{12} & c_{12} & c_{11} & 0 & 0 & 0 \\
0 & 0 & 0 & c_{44} & 0 & 0 \\
0 & 0 & 0 & 0 & c_{44} & 0 \\
0 & 0 & 0 & 0 & 0 & c_{44}
\end{array}\right]
$$

in which $c_{11}, c_{12}$ and $c_{44}$ are three material constants. The ratio

$$
A=\frac{2 c_{44}}{c_{11}-c_{12}}
$$

is the anisotropy (Zener) ratio [24]. For isotropic materials $A=1$, the stiffness matrix keeps its original sparsity under rotation. For anisotropic materials, the matrix in the global coordinate system may become full. Substitution of Eq. (4) (with Eq. (5) and Eq. (6)) in Eq. (3) gives the Navier-Cauchy equations in terms of the displacements $u, v$ and $w$, see Ref. [21]. From the solution of displacements, the associated stresses can be obtained from Eq. (4).

Subsequently, the stress integral over the whole calculation domain can be taken according to the I-H fatigue life equation [7] with the fatigue limit set to zero. The VMS is chosen as the stress criterion [26] though it must be noted that any other criteria can be included with equal ease. The integral equation reads:

$$
\ln \frac{1}{S}=A_{\mathrm{s}} N^{e} \int \frac{\sigma^{c}}{z^{\prime h_{\mathrm{s}}}} \mathrm{d} v^{\prime}
$$

in which $S$ is the probability of survival of $N$ load cycles, with $e=10 / 9, c=31 / 3$, $h_{\mathrm{s}}=7 / 3$ [7]. The integral can be normalized using a reference case. This is taken as the same contact problem with a particular load for homogeneous isotropic material with the associated reference maximum Hertzian pressure:

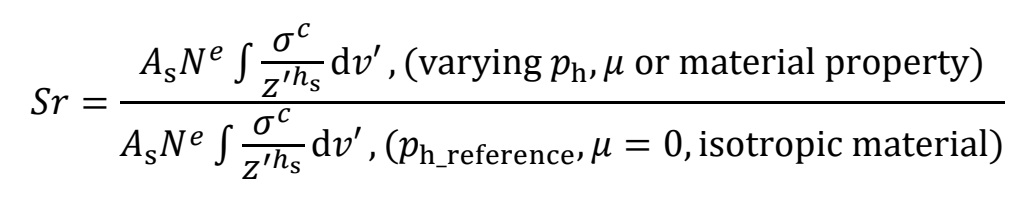

The variation of $S r$ with the material parameters and topology, e.g. grain topology, crystallographic details such as variation of anisotropy orientation angle over the grains, is studied by means of numerical calculations. All equations were made dimensionless using: 


$$
\begin{gathered}
X=\frac{x}{a}, Y=\frac{y}{a}, Z=\frac{z}{a}, U=\frac{u}{a}, V=\frac{v}{a}, W=\frac{w}{a}, \\
P=\frac{p}{p_{\mathrm{h}}}, \bar{\sigma}_{i j}=\frac{\sigma_{i j}}{p_{\mathrm{h}}}, \bar{C}_{i j k l}=\frac{c_{i j k l}}{p_{\mathrm{h}}}, H=\frac{h}{a}
\end{gathered}
$$

where $a=\sqrt[3]{\frac{3 F R\left(1-v^{2}\right)}{4 E}}, p_{\mathrm{h}}=\frac{3 F}{2 \pi a^{2}}$ are the values of the Hertzian contact radius and maximum contact pressure for the reference load condition with homogeneous isotropic material. For the contact and the material (isotropic) parameters, see Table 1.

Table 1 Contact and material parameters

\begin{tabular}{cc}
\hline Parameter & Value \\
\hline$F$ & $40.34 \mathrm{~N}$ \\
$R$ & $0.02 \mathrm{~m}$ \\
$p_{\mathrm{h} \_ \text {reference }}$ & $1.0 \mathrm{GPa}$ \\
$E$ & $206 \mathrm{GPa}$ \\
$\alpha, \beta, \gamma$ & $0 \sim \pi / 2$ \\
$X, Y$ & $-3 \sim 3$ \\
$Z$ & $0 \sim 6$ \\
$\nu$ & 0.3 \\
\hline
\end{tabular}

\section{Anisotropic material behaviour}

Before presenting the details of the numerical solutions, we elaborate on the relation between the anisotropy of the material and its compliance when loaded in a specific direction. Table 2 gives the chosen parameters for a cubic anisotropic material.

Table 2 Cubic anisotropic material parameters

\begin{tabular}{clll}
\hline Parameter & $2.4074^{[24]}$ & $2.4167^{[20]}$ & $3.77^{[22]}$ \\
\hline$c_{11}$ & $231.4 \mathrm{GPa}$ & $237 \mathrm{GPa}$ & $204.6 \mathrm{GPa}$ \\
$c_{12}$ & $134.7 \mathrm{GPa}$ & $141 \mathrm{GPa}$ & $137.7 \mathrm{GPa}$ \\
$c_{44}$ & $116.4 \mathrm{GPa}$ & $116 \mathrm{GPa}$ & $126.2 \mathrm{GPa}$ \\
\hline
\end{tabular}

Figure 2 (a) shows the elastic modulus in 3D according to Eq. (11) (Ref. [27]) for a cubic anisotropic grain with anisotropic ratio $A=2.4167$. 


$$
\frac{1}{E(l, m, n)}=s_{11}-\left[2\left(s_{11}-s_{12}\right)-s_{44}\right]\left(l^{2} m^{2}+m^{2} n^{2}+l^{2} n^{2}\right)
$$

in which $s_{11}, s_{12}$ and $s_{44}$ are elastic compliances of the material, $E(l, m, n)$ is Young's modulus along an arbitrary loading direction $[l, m, n]$ for cubic crystals. The norm of the vector from the origin to the point at the surface plane represents the elasticity. For isotropic material, the shape of the figure is a sphere. For cubic anisotropic material, it has eight rounded protuberances in the corners and six valleys at the centres of the faces. Its minimum value is $1 / s_{11}$ and the maximum value is $1 /\left(s_{11}-\left[2\left(s_{11}-s_{12}\right)-s_{44}\right] / 3\right)$. For an anisotropic grain with $A=2.4167$, the Young's modulus varies between $132.27 \mathrm{GPa}$ to $283.34 \mathrm{GPa}$ depending on the direction. When the grain is rotated, its stiffness tensor in the global coordinate system is changed according to Eq. (5).

As a result, the elastic moduli of anisotropic grains varies in the global coordinate system. Fig. 2 (b) compares the elasticity of anisotropic and isotropic material in the central $X Z$ plane. With an increase of the anisotropy ratio, the ratio between the largest and the smallest value of the elastic modulus increases. This implies that with increasing anisotropy ratio, the elastic modulus varies more significantly over the grains for a stressed material with a heterogeneous topology of anisotropic grains.

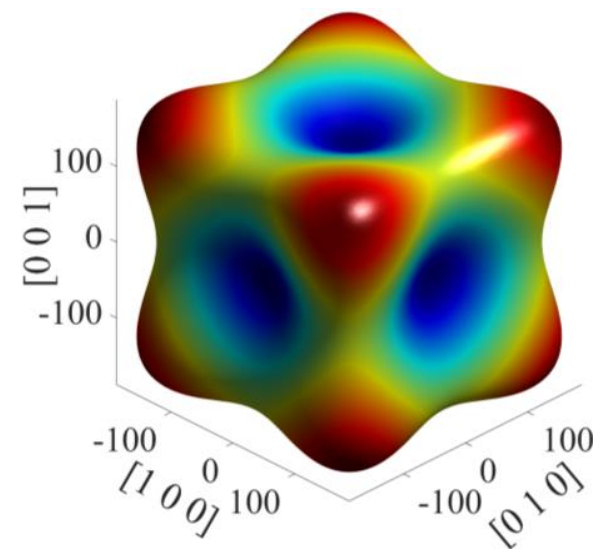

(a) 3D elasticity for an anisotropic grain $A=2.4167$

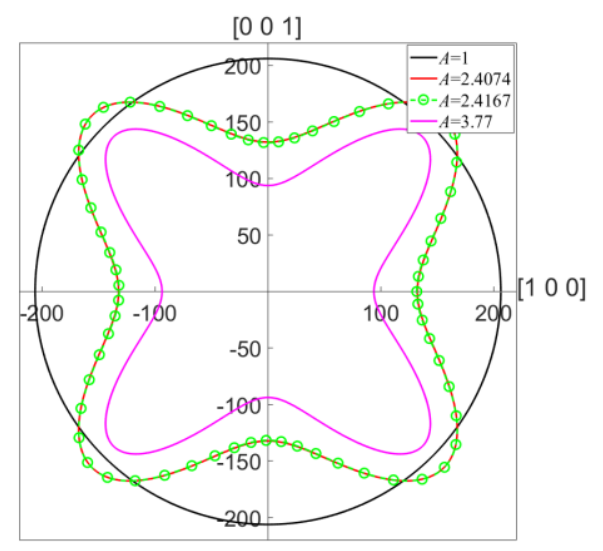

(b) 2D elasticity of $X Z$ plane $(Y=0)$

Figure 2 Young's modulus variation (GPa) on a single grain due to anisotropic elasticity 


\section{Numerical solution}

The resulting system of partial differential equations in terms of the displacements was discretized on a uniform grid with second order accuracy. A Gauss-Seidel lexicographic relaxation in sequential order is used for solving the displacement equations where solving the contact equation as boundary condition is integrated in the relaxation algorithm. Multigrid techniques are used to accelerate convergence. For details regarding the algorithm and demonstration of the numerical accuracy of the solutions see Ref. [21][28]. From the solution of the displacement field, the stress field was computed exploiting a second order discretization of the first derivatives in Eq. (4) in the interior domain and boundaries. The stress integral (Eq. (8), Eq. (9)) was discretized assuming cubic elements of constant stress surrounding each grid point where the stress values are defined, which is also a second order discretization. The subsurface topology was generated by means of Voronoi tessellation with randomly distributed crystal nucleus positions and orientation angles, i.e. a statistically uniform distribution.

\section{Results}

The reference load condition is as given in Table 1 . Table 2 gives the chosen parameters for a cubic anisotropic material. When not specifically indicated, otherwise the following parameters are used: (1) an average grain diameter of 15 $\mu \mathrm{m}$ for heterogeneous anisotropic material; (2) anisotropic material with a Zener ratio $A=\left(2 c_{44} /\left(c_{11}-c_{12}\right)\right)=2.4167$ [20]; (3) a contact load such that the maximum Hertzian contact pressure for homogeneous isotropic material would be $p_{\mathrm{h}}=1 \mathrm{GPa}$. Note that the choice of a relatively large material grain size is made for convenience. It is not intended to represent actual bearing steels but rather to show the effect of material inhomogeneities and their orientation.

\subsection{Comparison of dry contact and lubricated contact}

First for a typical 3D material topology, the stress fields under dry contact and under lubricated contact are compared for the reference load condition which, under isotropic material, would give a maximum Hertzian pressure of $1 \mathrm{GPa}$. The additional parameters for the lubricated point contact are an entrainment velocity $u_{\mathrm{m}}=0.5 \mathrm{~m} / \mathrm{s}, \eta_{0}=0.08 \mathrm{~Pa} \cdot \mathrm{s}, \alpha_{\text {oil }}=22 \mathrm{GPa}^{-1}$. In terms of the Moes dimensionless parameters for point contact $M=211.7, L=9.51$. The DowsonHigginson density-pressure equation and the Roelands viscosity-pressure 
equation are used to describe the density and viscosity as a function of pressure respectively. The dimensionless equations used and the discretization method of the Reynolds equation, which, as mentioned above, is now a boundary condition, is the same as that in Ref. [23]. Further details of the EHL solver considering 3D heterogeneous anisotropic material can be found in Ref. [28].

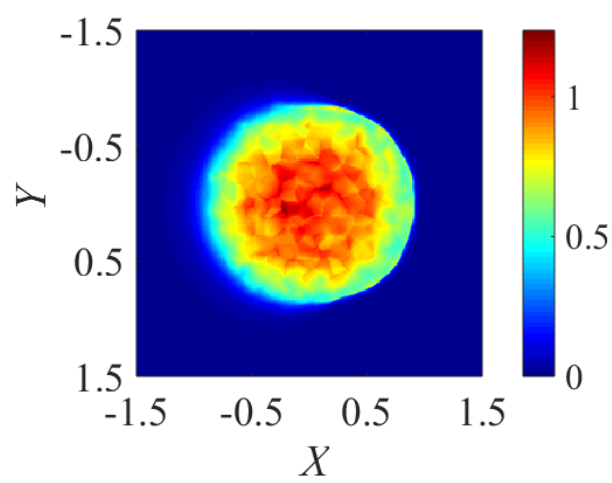

(a) EHL pressure

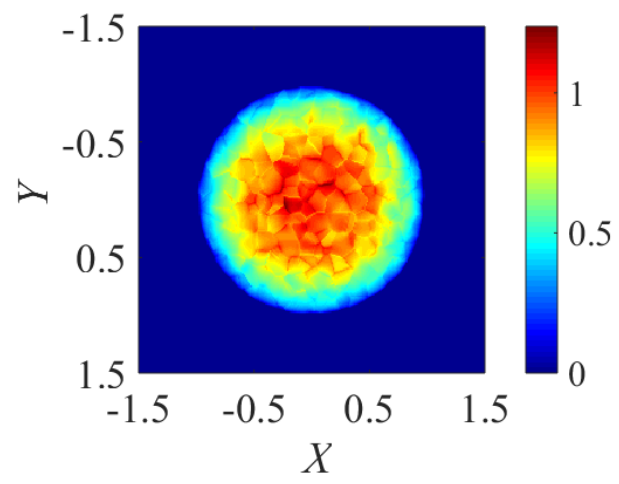

(b) Dry contact pressure

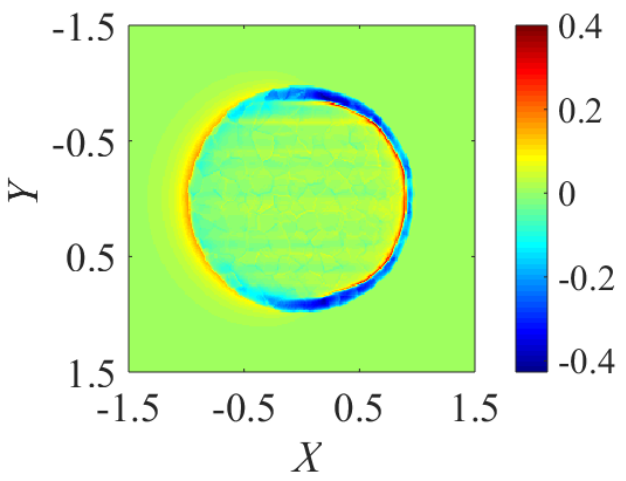

(c) Dimensionless pressure difference $P_{\text {EHL }}-P_{\text {Dry }}$ 


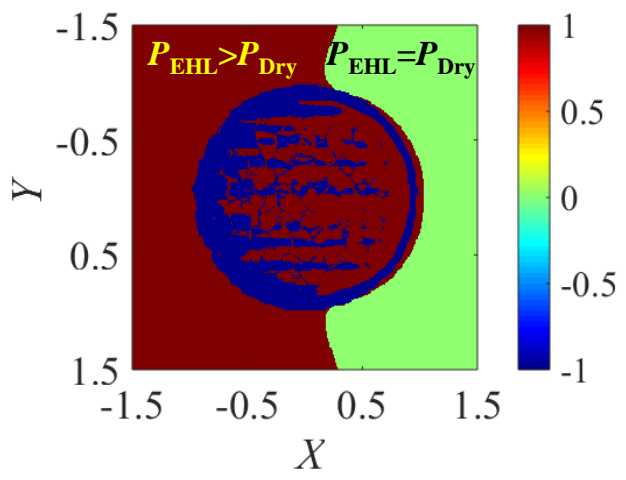

(d) Sign distribution of pressure difference $P_{\text {EHL }}-P_{\text {Dry }}$

Figure 3 Pressure comparison between (a) lubricated and (b) dry contacts for heterogeneous anisotropic material

Figure 3 shows the pressure distribution under lubricated (Fig. 3(a)) and dry contact (Fig. 3(b)) conditions. Relative to the well-known smooth (near) Hertzian semi-elliptic pressure distribution for homogeneous isotropic material, clearly pressure fluctuations are observed. These results are due to the effect of the heterogeneous anisotropic crystallography of the material, see also Ref. [22]. For the dry contact condition, the grain boundaries are much clearer, which means the variation of pressure between grain boundaries is less smooth compared to the lubricated case in Fig. 3(a). Fig. 3(c) shows the difference between the (dimensionless) EHL pressure and the (dimensionless) dry contact pressure. The differences are localized around the edge of the Hertzian contact region. Figure 3 (d) further emphasizes the pressure difference by the sign function:

$$
\operatorname{sign}\left(P_{\mathrm{EHL}}-P_{\text {Dry }}\right)= \begin{cases}1.0 & P_{\mathrm{EHL}}>P_{\text {Dry }} \\ 0 & P_{\mathrm{EHL}}=P_{\text {Dry }} \\ -1.0 & P_{\mathrm{EHL}}<P_{\text {Dry }}\end{cases}
$$

Obviously, the EHL pressure exceeds the dry contact pressure in the entire inlet region. In the outlet region, just after the outlet pressure spike it drops below the Hertzian pressure and decays subsequently to zero in this region. Inside the contact, the EHL pressure can either be smaller or larger. The transition points do not generally exactly coincide with the grain boundary as in the dry contact case, as the grain boundaries cannot be clearly observed in Fig. 3(d). For both 
cases, the VMS has been computed in the 3D volume below the surface. Fig. 4 shows the result in the central plane $Y=0$.

The VMS stress fields (Fig. 4(a) and (b)) for the lubricated and dry contact are almost identical. Fig. 4(c) and 4(d) aim to emphasize the differences. As can be seen in Fig. 4(c), these differences are concentrated near the edge of the contact region close to the surface where in Fig. 3 (c) also the pressure differences were observed. In Fig. 4 (d), the sign of the difference between the stress fields is shown using Eq. (12) by replacing $P$ with $\bar{\sigma}$. In the inlet region and in the contact region near the top surface, the VMS of the lubricated case is larger than that of dry contact at most areas.

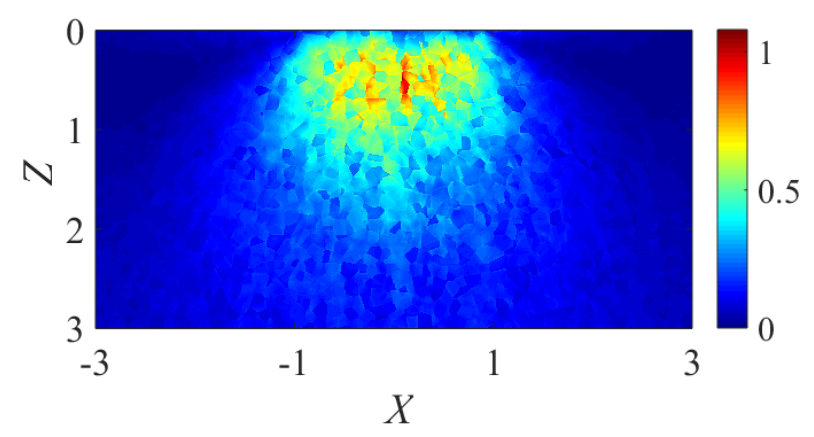

(a) VMS field lubricated contact

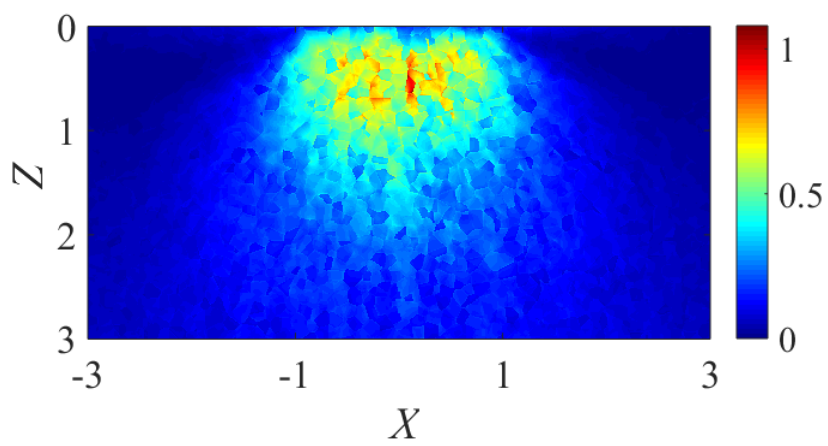

(b) VMS field dry contact

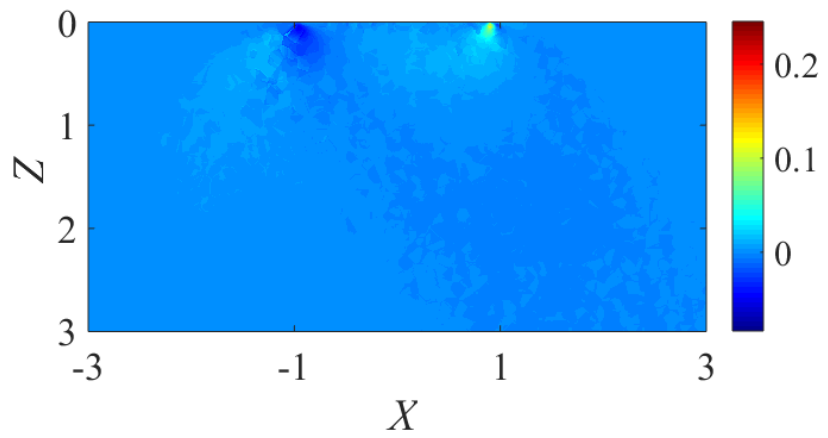

(c) $\bar{\sigma}_{\mathrm{EHL}}-\bar{\sigma}_{\mathrm{Dry}}$ 


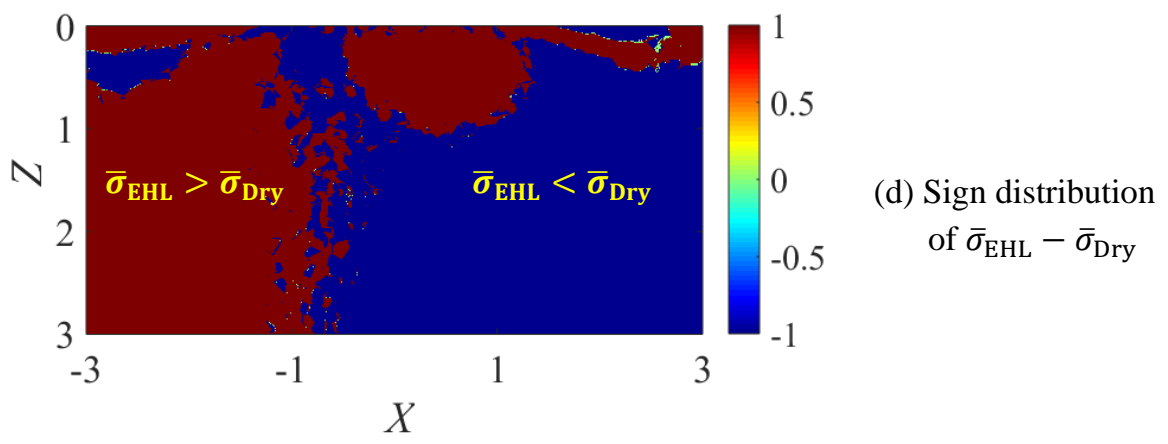

Figure 4 VMS in the central $X Z$ plane for heterogeneous anisotropic material: (a) lubricated contact; (b) dry contact; (c) difference between lubricated contact and dry contact; (d) sign of the difference between dry and lubricated VMS distribution.

The relative stress integral values according to Eq. (9) for the lubricated and the dry contact are 3.918 and 3.556 respectively for the studied cases. As this is the reference load case, the value for the dry contact with isotropic material is unity so the heterogeneity and anisotropy at the grain size/scale significantly reduces the predicted fatigue life. The value for the lubricated condition is about $10 \%$ larger than for the dry contact condition. The major differences originate from the regions near the outlet pressure spike(s) where also the largest difference between the dry and lubricated pressure profile is observed. The relatively small difference between the value of the fatigue life integral for the lubricated contact and the dry contact is not unexpected. For homogeneous isotropic material this is well known and justifies that most rolling contact fatigue life predictions at present are based on dry contact calculations. Note that for time varying solutions with roughness moving through the contact, this may be quite different. Nevertheless, under steady conditions also for the heterogeneous anisotropic material case it is justified to exploit dry contact calculations for fatigue life predictions provided the loads are sufficiently high. In view of the more severe operating conditions anticipated in the future, such as higher load, higher degree of starvation, higher temperature, the lubricant film will even become thinner and the EHL pressure will be even closer to that of dry contact. Besides, the time cost of dry contact (2h 8mins, Intel X5650 CPU at $2.66 \mathrm{GHz}, 2 \mathrm{~W}$ cycles) is around 0.6 (depending on the number of grains and cycles [28]) of the time cost of an EHL case. Thus, here we restrict ourselves to the pressure and the stresses of a dry contact for the following analyses. 
Regarding the specific effects of the heterogeneous anisotropic material on the film thickness, the reader is referred to reference [22][28].

\subsection{Effect of contact load}

Figure 5 shows the VMS in the central $X Z$ plane below the contact for a homogeneous anisotropic material aligned with the global coordinate system (Fig. 5(a)) and for a homogeneous isotropic material (Fig. 5(b)). The differences between the stress fields are visualized in the Figure 5(c) and 5(d). For the anisotropic material, the stress field extends over a wider region and decays more rapidly with depth. For the homogeneous isotropic material, the maximum dimensionless VMS is 0.62 and located in the centre at a dimensionless depth 0.47 below the surface. Quite differently, for the homogeneous anisotropic material aligned with the global coordinate system, the maximum VMS (0.5226) occurs at a circle below the surface near the Hertzian contact radius. This shows as two locations in the $X Z$ plane $(X=0.4688$ and $X=-0.4688)$ at a depth 0.4922 below the surface. This is related to the fact that for the aligned material the elastic modulus along the axis direction is the smallest and the material thus more compliant (see Fig.2).

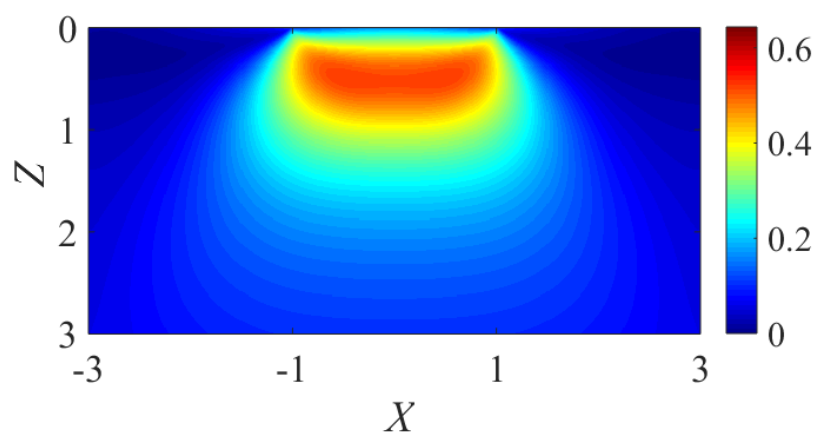

(a) VMS field of homogeneous anistropic material aligned with global coordinates

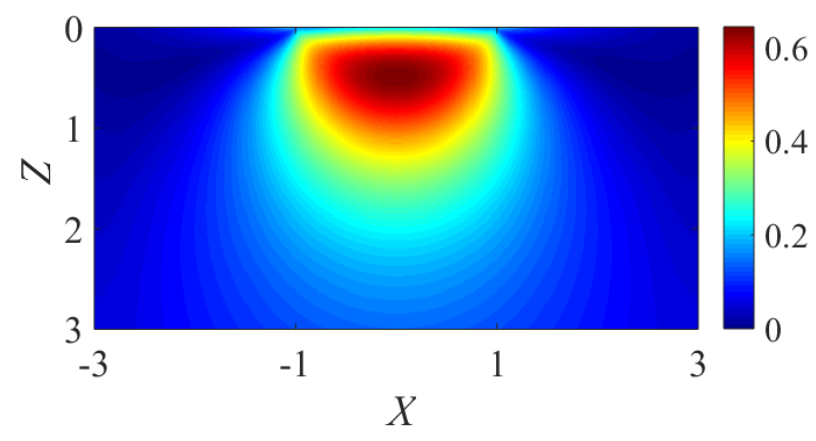

(b) VMS field of homogeneous isotropic material 

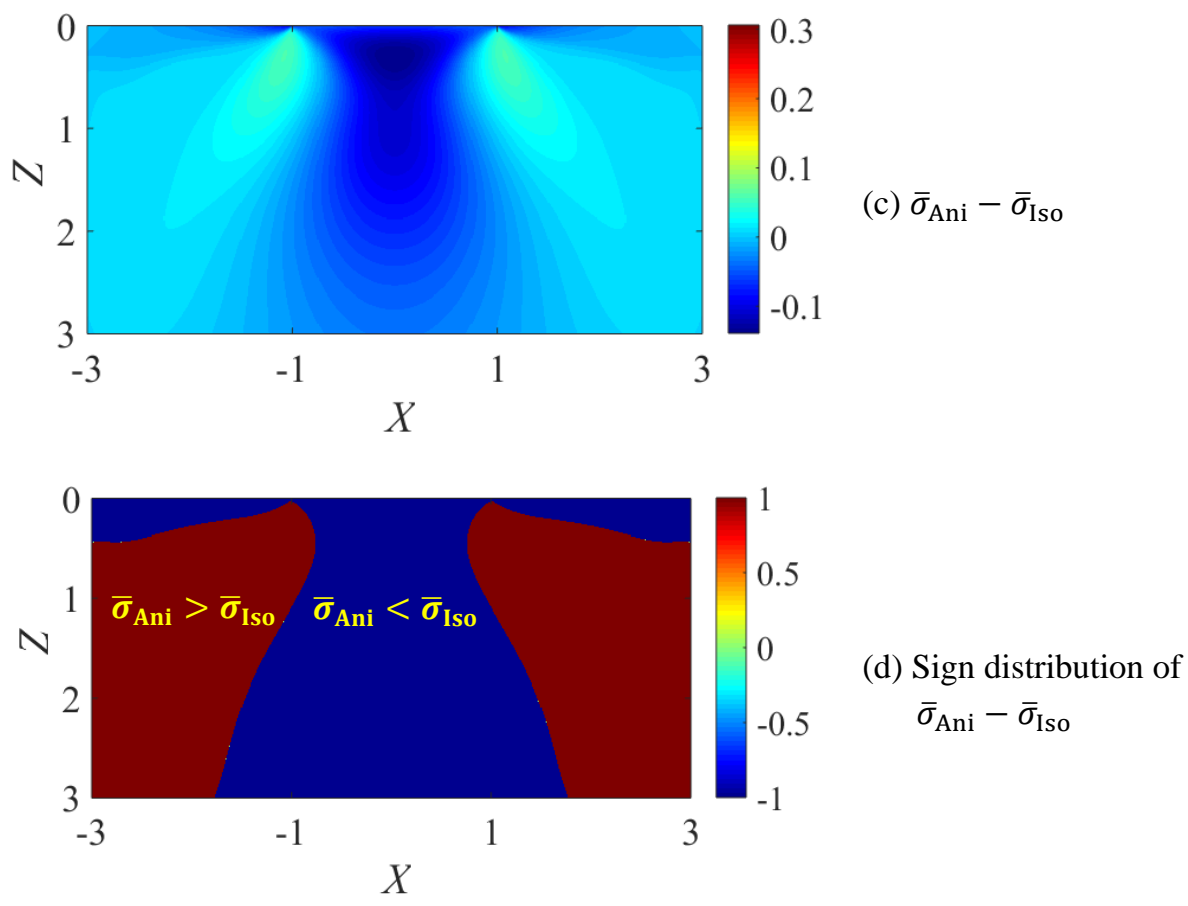

Figure 5 VMS in the central $X Z$ plane: (a) homogeneous anistropic aligned; (b) homogeneous isotropic; (c) diffrence in VMS between anistropic and istropic; (d) sign of diffrence inVMS between homogeneous aligned anisotropic and homogeneous isotropic.

In Fig. 6, the value of the relative fatigue life stress integral $\operatorname{Sr}$ (Eq. (9)) is given as a function of the contact load. Results are shown for several values of the Zener (anisotropy) ratio $A$ (Eq. (7)), including for the homogeneous isotropic material. Note that this latter curve has a value of unity for the reference load case with Hertzian pressure of $1 \mathrm{GPa}$. In the log-log plot, the relative integral value of both homogeneous anisotropic and isotropic material increases linearly with the increase of pressure. However, the values for the anisotropic material that is aligned with the global coordinate are lower than for the isotropic material. This is explained by the larger compliance in the load direction which is also reflected in the fact that the contact radius of for the anisotropic cases is 1.011 1.059 times larger than that of the isotropic case. When the homogeneous anisotropic material is not aligned with the global coordinate system $(0.5 \times \pi / 2$ in each direction), its global stiffness increases and results in a larger relative value compared to homogeneous isotropic material. 


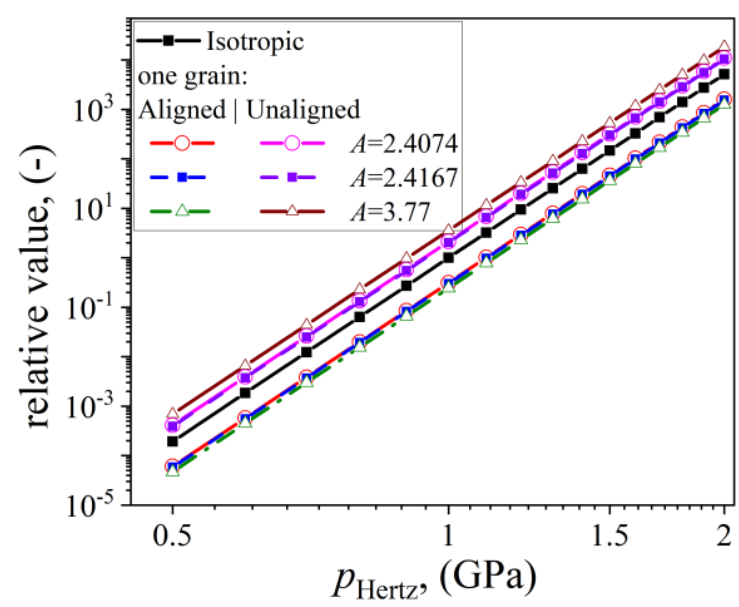

Figure 6 Effect of contact pressure on the relative stress integral $\mathrm{Sr}$ for homogeneous aligned anisotropic and isotropic material

Next the case is considered of a heterogeneous anisotropic material with the anisotropy direction randomly distributed over a granular structure defined by Voronoi tessellation. The average grain diameter is $15 \mu \mathrm{m}$ which is 10 times smaller than the Hertzian contact radius. The VMS field in the central $X Z$ plane shown in Fig. 7 (a) is significantly different from that of homogeneous material in Fig. 5. The variation of the crystallographic alignment effectively changes the elastic modulus of each grain in the global coordinate directions leading to a higher or lower stress. This effect can clearly be seen in Fig. 7(b) which shows the difference between the present case and the values for the homogeneous isotropic case. Stress concentrations and larger values of the VMS occur in the boundary regions of grains across which the largest variation in crystallographic orientation occurs. The maximum value of the VMS is higher than for the homogeneous isotropic case. These variations are detrimental for the fatigue life as is indicated by the value of 3.43 for $S r$. Note that for this case of a random distributed orientation and already quite small grains, the shape of the stressed region is quite similar to that for a homogeneous isotropic material. This is in line with the expectation that with decreasing grain size, one should eventually approximate the isotropic material. If these results were to be translated into a guideline for material crystallographic optimization to reduce the observed stress variations, one should consider: (1) reduce the grain size; (2) control the variation of rotation angles between adjacent grains. These effects will be discussed in more detail in section 5.4 and 5.5. This would gradually reduce the red and blue 
regions in Fig. 7(b) indicating large stress difference to the uniform into green (small stress difference).

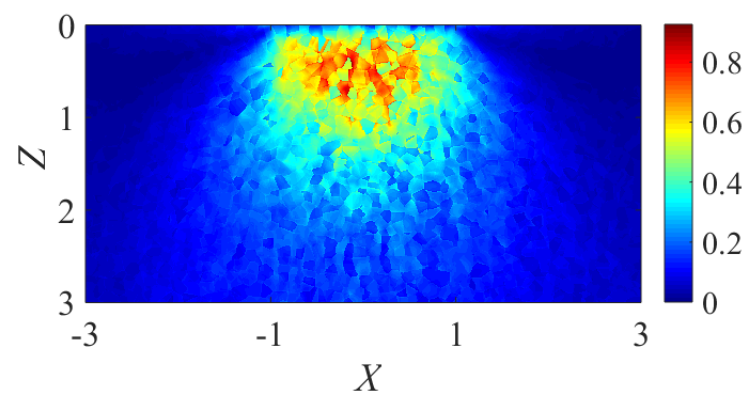

(a) Stress field of anisotropic material

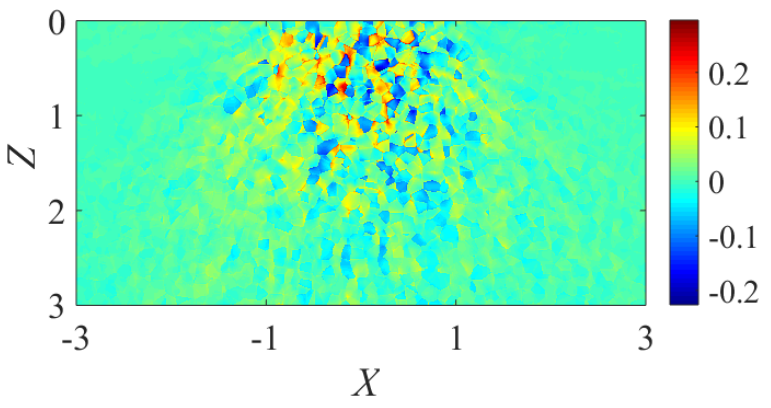

(b) $\bar{\sigma}_{\text {Ani }}-\bar{\sigma}_{\text {Iso }}$

Figure 7 VMS of $X Z$ plane comparison between heterogeneous anisotropic and isotropic material $(Y=0)$

Figure 8 (a) shows the influence of the contact load on the maximum VMS and the depth at which it occurs. Fig. 8 (b) shows the relative fatigue life integral value with the variation of contact load. The results for the homogeneous isotropic case match the theoretical values where the maximum VMS is $0.62 p_{\mathrm{h}}$ at a depth $0.47 a$, where $p_{\mathrm{h}}$ and $a$ are the actual values of the Hertzian contact pressure and radius. As in the present case the results are scaled on the $1 \mathrm{GPa}$ Hertzian pressure case one should see a linear increase of the maximum VMS value with slope 0.62 and a linear dependence of the depth at which it occurs with slope 0.47 for the homogeneous isotropic case. However, with the increase of load, the contact radius becomes larger and the side boundaries affect the stress field and thereby the stress integral value. As a result, the linear variation of the maximum VMS and its depth is affected. With an increasing large calculation domain, the effect of side boundaries decreases gradually and the linear variation with load could be observed. In Fig. 8(a) it can also be seen that with increasing load, the deviation of the maximum VMS from the value for the 
homogeneous isotropic case increases. The change of its depth with load is a stepwise function owing to the fact that with increasing load, the stressed region increases involving deeper laying grains. When a deeper grain whose strain and corresponding global stiffness can generate a larger stress is involved, this will become the location of the maximum VMS. With the increase of load, the relative integral value increases almost linearly on a log-log scale, see Fig. 8(b). For the grain structured material, the slope (on the log-log scale) is identical to the slope for the isotropic homogeneous material. However, due to the local stress concentrations around grain boundaries, the value of the relative stress integral is larger. The ratio varies between 2.76 and 4.65 . Interpreting the observed results in terms of rolling contact design, it is obvious that crystallographic structure and orientation may considerably affect rolling contact fatigue life calculations and thus should be studied and understood in detail.
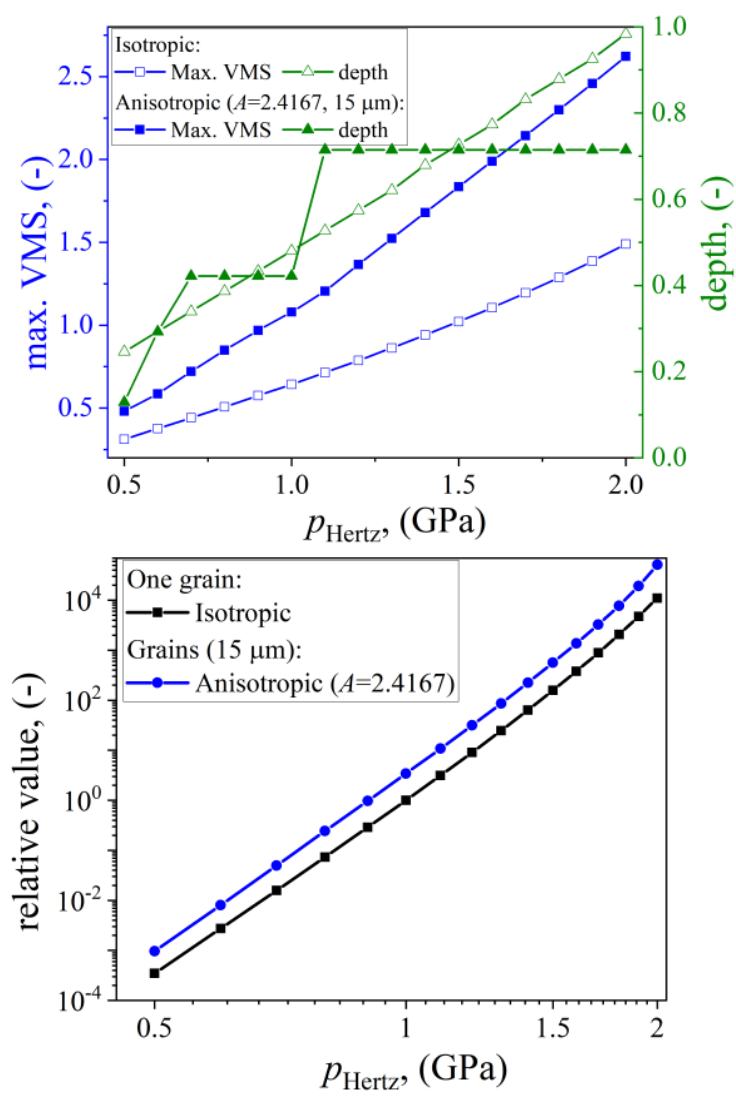

(a) Maximum VMS value and its depth (b) Relative stress integral value

Figure 8 Effect of load on the maximum VMS and the relative stress integral $\mathrm{Sr}$ for heterogeneous anisotropic material and homogeneous isotropic material 


\subsection{Effect of shear stress}

So far friction was neglected. First for homogeneous anisotropic crystallography aligned with the main coordinate system and subsequently for a grain structured heterogeneous material with randomly varying crystallographic orientation, the influence of the coefficient of friction on the relative fatigue life stress integral $\mathrm{Sr}$ is studied. Fig. 9 shows the results for the contact problem with friction for homogeneous anisotropic material aligned with the global grid, and for homogenous isotropic material as a function of the coefficient of friction for different values of the Zener ratio.

For small values $(\mu<0.1)$, the effect of the surface shear induced by friction on the integral value is small, although there is a clear difference between its value for the isotropic and the anisotropic case. For $\mu>0.1$, the effect of the shear stress becomes more evident, and for $\mu>0.2$, the effect of the value of the Zener ratio becomes visible. This is most likely related to the fact that for these values of the coefficient of friction, the stress distribution significantly differs from the reference case (without friction) as the maximum VMS now occurs at the surface. Although interesting from an academic point of view, these values of the friction coefficient are not representative for the lubricated roller-raceway contacts in rolling bearings as in these cases the friction is much lower.

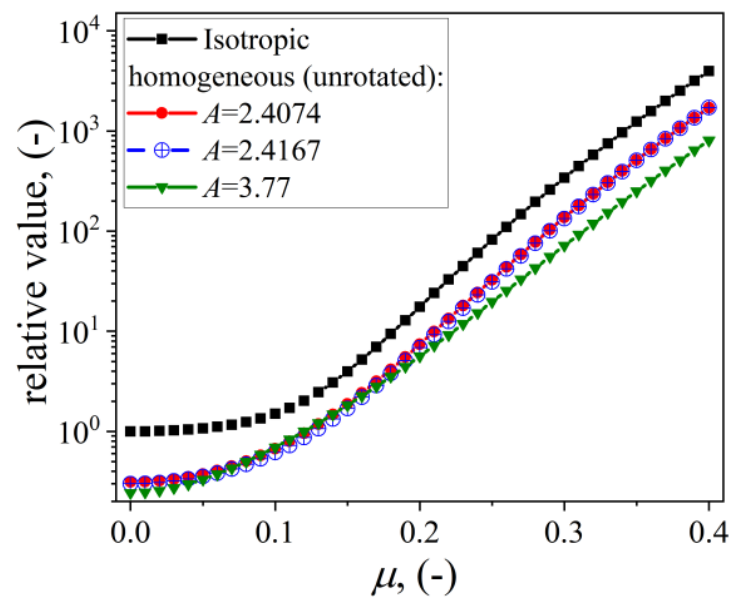

Figure 9 Effect of shear stress on the the relative stress integral $\mathrm{Sr}$ for homogeneous anisotropic and isotropic material

Figure 10 shows the effect of the shear stress due to friction on the VMS field for the case of the heterogeneous grain structured material with 
stochastically distributed crystallographic orientation as considered above. The figure shows the difference between the VMS field with and without friction in the central $X Z$ and the central $Y Z$ plane for the same case. In Fig. 10 (a) and (b), the difference in the VMS field for the frictionless case and for $\mu=0.1$ is shown. It can be seen that the main change is a strong asymmetry in the $X Z$ plane due to the friction with the maximum VMS moving closer to the surface on the inlet side. This trend adversely affects the RCF. Near surface stress concentrations of sufficient magnitude may induce surface cracks and pits close to the contact surface referred to as surface initiated RCF [29].

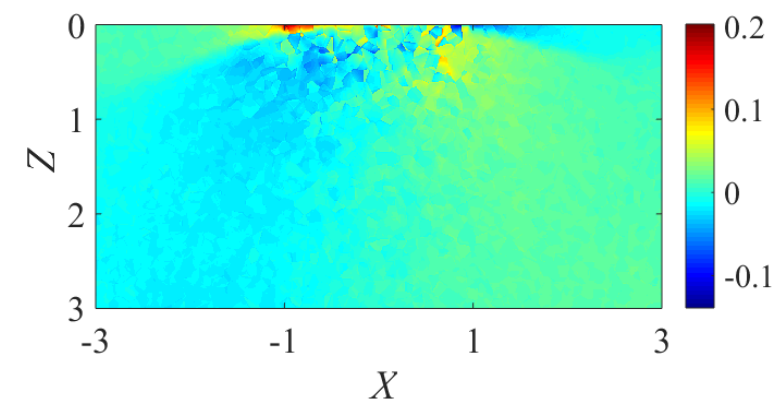

(a) $X Z$ plane of $\bar{\sigma}_{\mathrm{VMS}}(\mu=$ $0.1)-\bar{\sigma}_{\mathrm{VMS}}(\mu=0)$

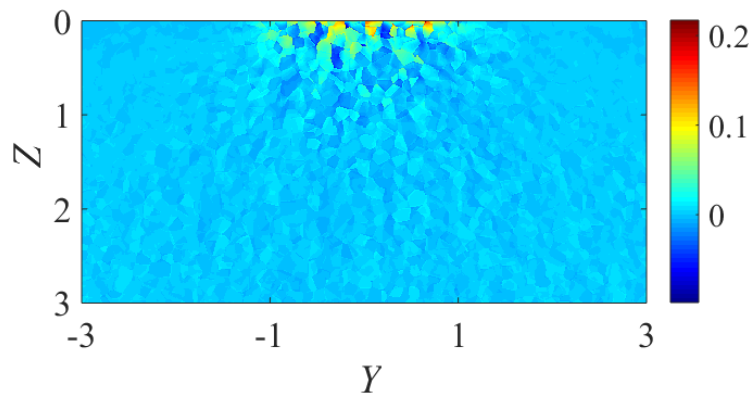

(b) $Y Z$ plane of $\bar{\sigma}_{\mathrm{VMS}}(\mu=$ $0.1)-\bar{\sigma}_{\mathrm{VMS}}(\mu=0)$

Figure 10 Effect of friction on the VMS field in the central planes of the contact for the case of heterogeneous material with randomly varying crystallographic orientation in a grain topology

The variation of the maximum VMS and the depth at which it occurs with the coefficient of friction is shown in Fig. 11 (a). The value of $S r$ is shown in Fig. 11 (b). For homogeneous isotropic material, the depth of the maximum VMS depends on the normal load (stress) and the coefficient of friction. For the grain topology with varying orientation, the variation of the crystallographic orientation affects the grain stiffness and thereby the location of the maximum VMS. The overall trend of the dependence on the coefficient of friction is the same for both cases: the larger shear stress increases the value of the maximum 
VMS and moves its location from the inner material to the contact surface. The difference between the two cases is in the small shear stress region. As for the heterogeneous anisotropic material, the location is unaffected until at a sufficiently high coefficient of friction to change it to the contact surface. The reason is that although the combined influence of normal stress and shear stress is the strongest, the variation of the stiffness from grain to grain (in the global coordinate system) still does not lead to a different overall maximum VMS value. Once occurring at the surface, the value of the maximum VMS strongly increases with friction. The ratio of the maximum VMS value between the two case is 1.66 1.85 (on average 1.71 \pm 0.065 ). In Fig. 11 (b), the effect of the coefficient of friction on the stress integral value is shown. Similar to the effect of the load, the stress integral value for the grain topology case with varying crystallographic orientation is larger than that for homogeneous isotropic material. The ratio between the two cases is 3.02 3.95 (on average 3.44 \pm 0.309 ).
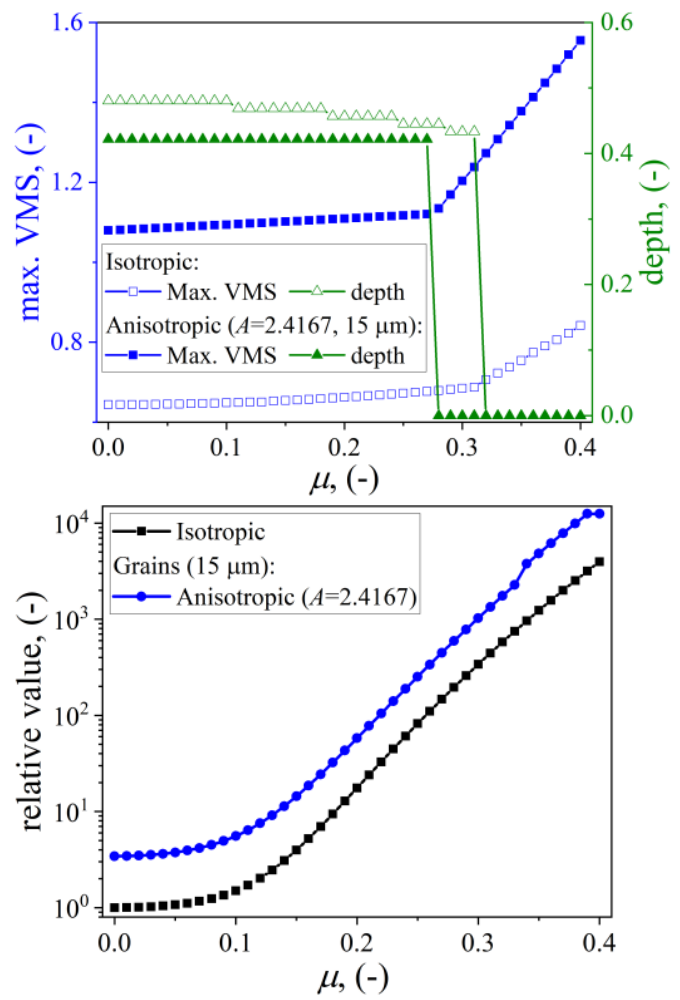

(a) Maximum VMS value and its depth (b) Relative stress integral value

Figure 11 Effect of shear stress on the maximum VMS and relative stress integral $\mathrm{Sr}$ for grain topology with varying crystallographic orientation compared with homogeneous isotropic material 


\subsection{Effect of mean grain size}

The material properties such as strength, stiffness, hardness, as well as the morphology of generated cracks in RCF are closely related to the crystallographic topology. For different values of the mean grain size in the Voronoi tessellation, two hundred microstructures were generated with randomly varying distribution of the orientation over the grains. The parameters for the Voronoi tessellation are given in Tab. 3. For each case, the contact problem was solved and the stress field evaluated.

Table 3 Configurations for the Voronoi tessellation

\begin{tabular}{cccc}
\hline $\begin{array}{c}\text { mean grain } \\
\text { size }(\boldsymbol{\mu m})\end{array}$ & $\begin{array}{c}\text { relation with Hertzian } \\
\text { contact width }\end{array}$ & $\begin{array}{c}\text { total grain } \\
\text { number }\end{array}$ & $\begin{array}{c}\text { mean grain number } \\
\text { in each direction }\end{array}$ \\
\hline 15 & $0.108 a$ & 171061 & 55.51 \\
20 & $0.144 a$ & 72166 & 41.63 \\
25 & $0.180 a$ & 36949 & 33.31 \\
30 & $0.216 a$ & 21383 & 27.76 \\
35 & $0.252 a$ & 13465 & 23.79 \\
40 & $0.288 a$ & 9021 & 20.82 \\
45 & $0.324 a$ & 6336 & 18.50 \\
50 & $0.360 a$ & 4619 & 16.65 \\
55 & $0.396 a$ & 3470 & 15.14 \\
60 & $0.432 a$ & 2673 & 13.88 \\
\hline
\end{tabular}

In Fig. 12(a), the variation of the contact area relative to the value for homogeneous isotropic material (Eq. (13)) is shown with the variation of the mean grain size. The spread of the value in the batch of two hundred generated cases for each grain size is also indicated.

$$
=\frac{\sum \sum P(>0),(\text { varying grain size and crystallographic topology })}{\sum \sum P(>0),\left(p_{\mathrm{h} \_ \text {reference }}, \mu=0, \text { isotropic material }\right)}
$$

With the decrease of grain size, the variation of the relative contact area in the batch decreases. From about $30 \mu \mathrm{m}$ downwards, the decreasing average grain size seems to reduce the contact area a little which means that the apparent stiffness of the base material increases and agrees with the Hall-Petch's Law [31]. 
In Fig. 12 (b), with finer mean grain size from $30 \mu \mathrm{m}$, it can be seen that the value of the relative fatigue life value decreases, i.e. the fatigue life increases with finer grain size. Also, the spread among the two hundred randomly generated cases reduces. This seems to align with the findings in the experimental study [30] that a fine grain size is beneficial to fatigue life and its dispersion would be smaller. The extension of fatigue life with finer grains can be explained as follows: The decrease of grain size introduces more grain boundaries and makes the stress field more continuous. The incidence of local stress concentration can be lowered. As a result, the integral value of stress field decreases (Fig. 12(b)) and the survival probability increases.

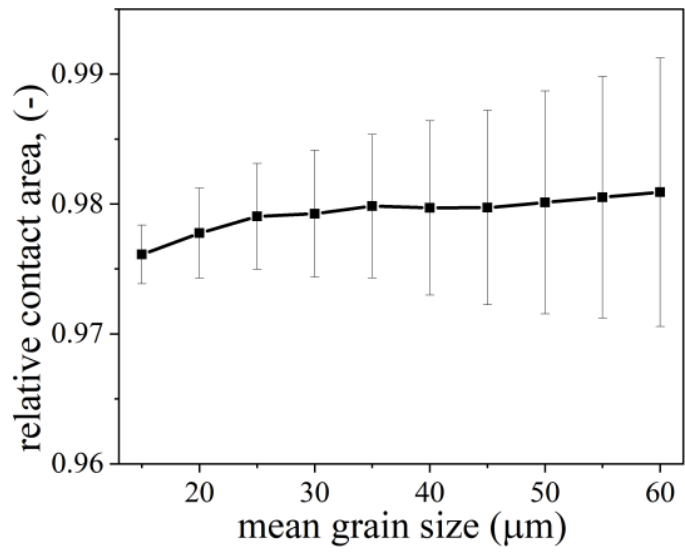

(a) Relative contact area

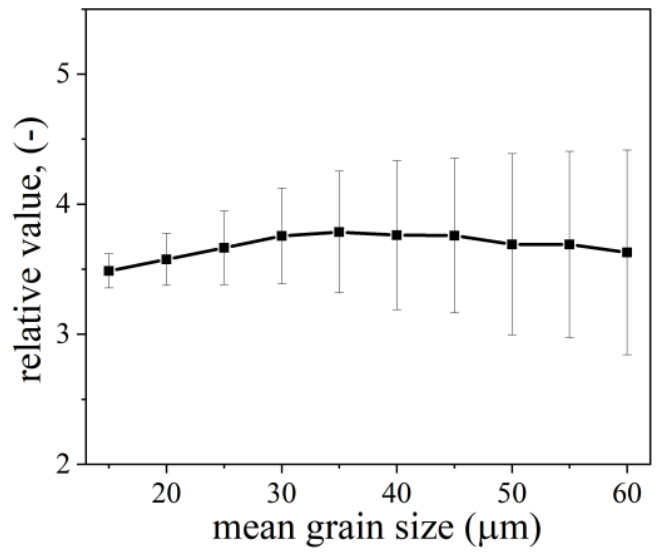

(b) Relative stress integral value

Figure 12 Effect of mean grain size on the relative contact area and the value of the relative fatigue life stress integral $\mathrm{Sr}$ for grain structured material with random variation of the crystallographic orientation

Figure 13 gives the influence of mean grain size on the maximum VMS and the depth at which it occurs. For the studied cases, the deviation of depth in Fig. 178 
13(b) is larger compared to the maximum VMS value in Fig. 13(a). The tendency found in Fig. 12 does not apply to the variation of maximum VMS. It can be explained as follows: compared to isotropic and homogeneous anisotropic material, the value and the location of the maximum VMS for heterogeneous anisotropic material depends both on the microstructure and on the rotation angles. Even with the same microstructure, the stress field can be different when the rotation angles are different. One example is shown in Fig. 14. The stress fields are different even though their Voronoi tessellations are the same. This implies that the fatigue life integrals only based on a local maximum stress as the fatigue criterium may not be accurate when the effect of grains with varying crystallographic orientation needs to be predicted.

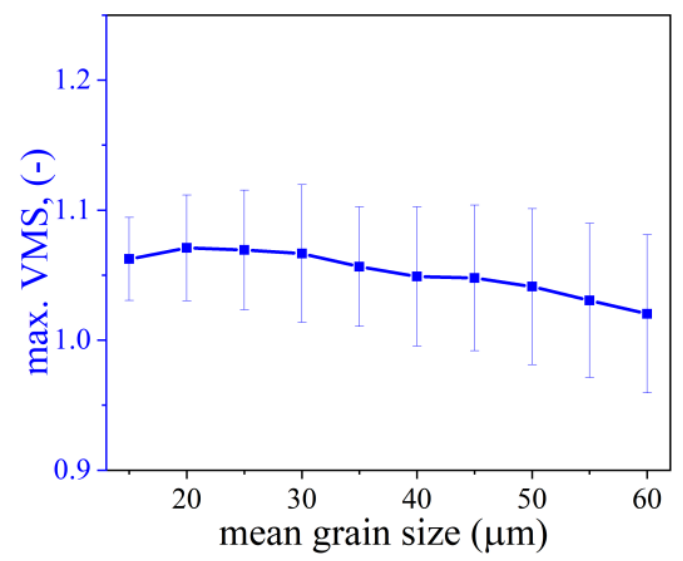

(a) Value of the maximum VMS

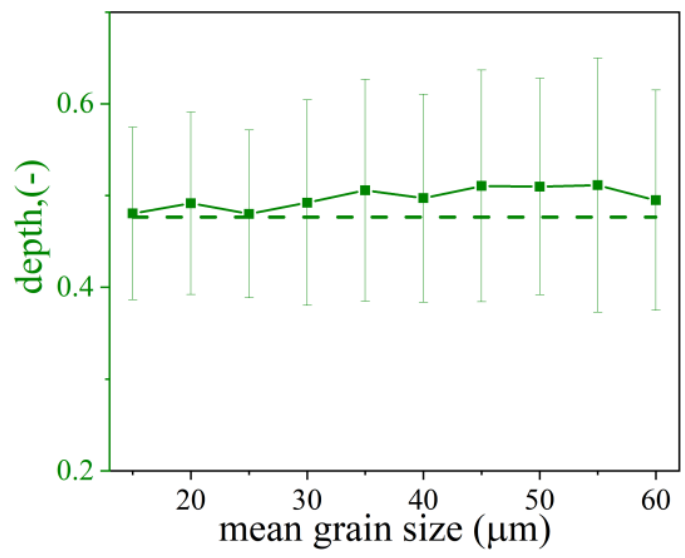

(b) Depth of the maximum VMS

Figure 13 Effect of average grain size on the VMS for heterogeneous anisotropic material 


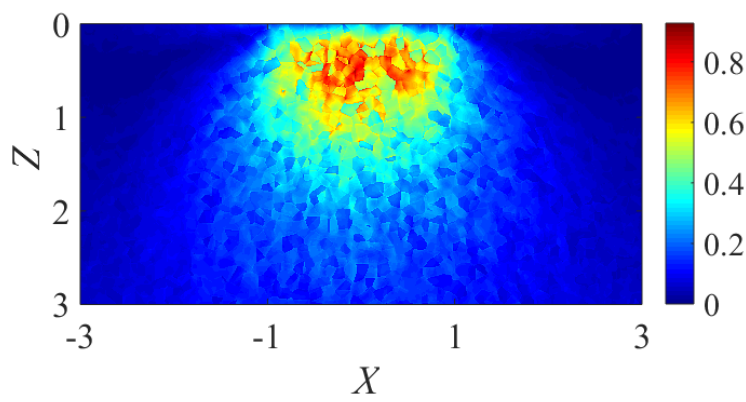

(a) Stress field of rotation angles 1

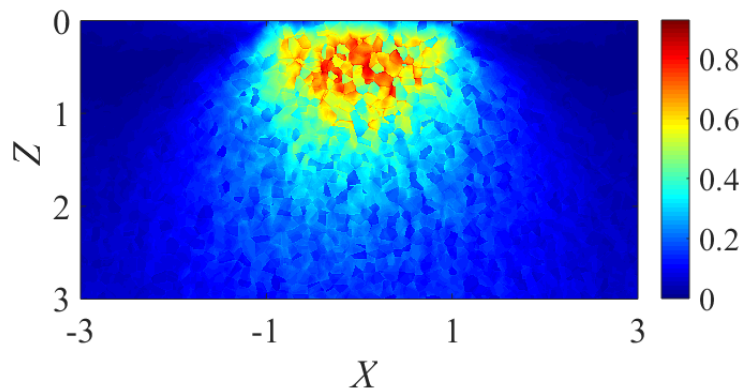

(b) Stress field of rotation angles 2

Figure 14 Effect of rotation angles on the stress field for heterogeneous anisotropic material

\subsection{Effect of rotation angle}

For the results shown before, the range of variation of the rotation angles $\alpha, \beta, \gamma$ is taken from 0 to $\pi / 2$. In this part, the effect of restricting this range is investigated. It should be pointed out that the rotation angle is uniformly distributed at each rotation range. Fig. 15 shows the influence of the rotation range on the relative contact area and the relative stress integral value. For each case, twenty randomly generated microstructures are employed to check the influence of range of rotation angles. With the increase of range, the relative contact area decreases at first and then increases. It means the stiffness of the 3D body increases at first and then decreases. For the relative stress integral value, its trend is inverse. This implies that the fatigue life of bearing material can be optimized by control of the crystallography variations. At around $0.7 \times \pi / 2$, the relative contact area and stress integral value reach the minimum and maximum value respectively. Different to the effect of the mean grain size shown in section 5.4, the stiffness and stress integral value show an opposite trend with the variation of range of rotation angle. 


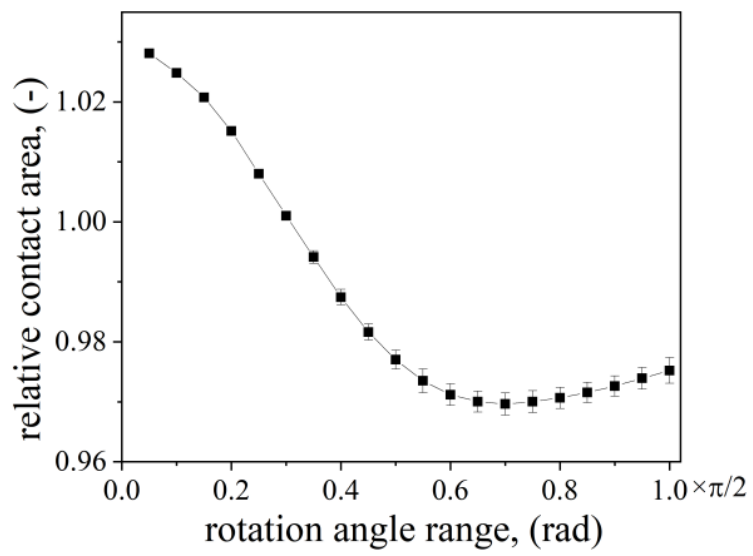

(a) Relative contact area

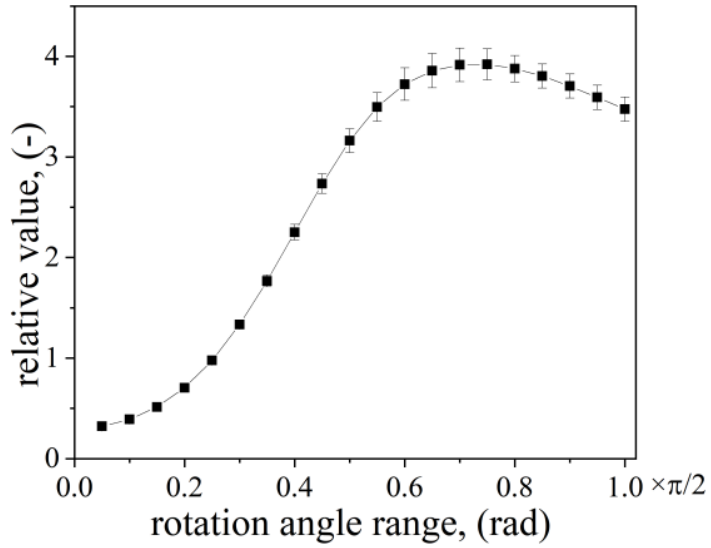

(b) Relative stress integral value

Figure 15 Effect of rotation angle range on the relative contact area and the stress integral value for heterogeneous anisotropic material

Figure 16 compares the stress fields with full rotation range $(0 \sim \pi / 2)$ and with restricted rotation $(0 \sim 0.7 \times \pi / 2)$ to that of isotropic material. The results are obtained for the same conditions and the same microstructure of grains. The stress integral value for the restricted rotation angle case (Fig. 16(b) and (d)) is larger than that of full rotation (Fig. 16(a) and (c)). When comparing the stress fields in the $X Z$ and $Y Z$ planes (Fig. 16(a) and (b), Fig. 16(c) and (d)), it is not easy to see which stress field would be more severe. A possible reason is that the total stiffness variation of adjacent grains has its maximum value when the rotation angle is restricted from 0 to $0.7 \times \pi / 2$. 


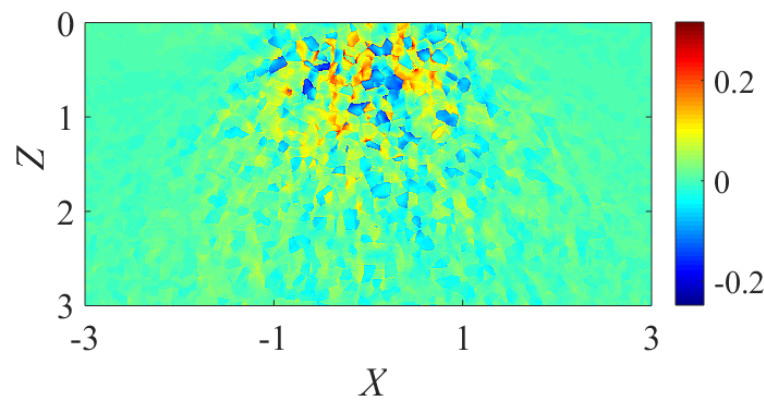

(a) $\bar{\sigma}_{\mathrm{VMS}}(0 \sim \pi / 2)-$ $\bar{\sigma}_{\mathrm{VMS}}$ (iso) of $X Z$ plane

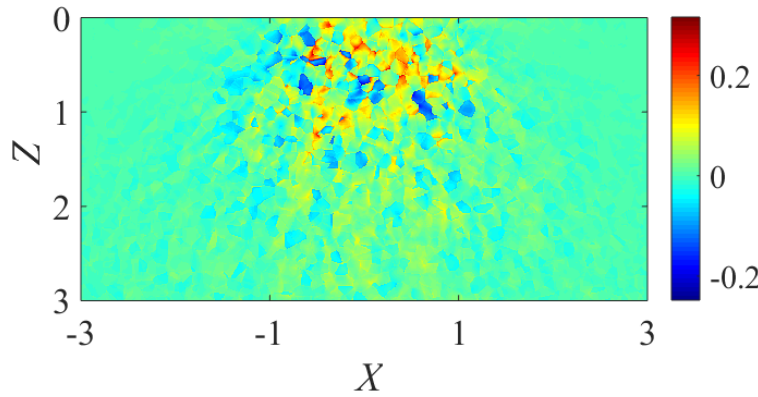

(b) $\bar{\sigma}_{\mathrm{VMS}}(0 \sim 0.7 \times \pi / 2)-$ $\bar{\sigma}_{\mathrm{VMS}}$ (iso) of $X Z$ plane

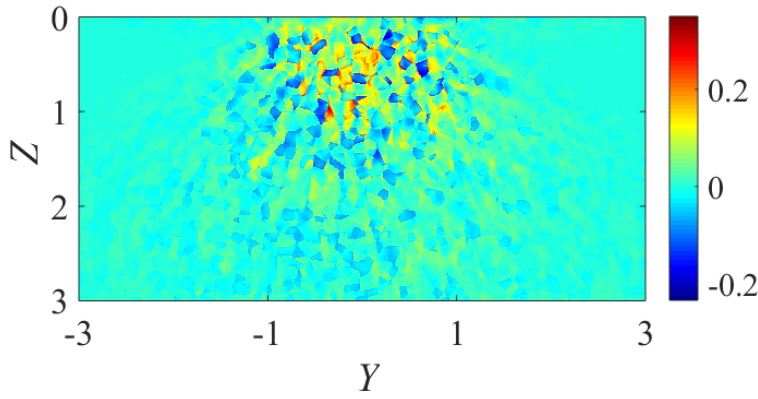

(c) $\bar{\sigma}_{\mathrm{VMS}}(0 \sim \pi / 2)-$ $\bar{\sigma}_{\mathrm{VMS}}$ (iso) of $Y Z$ plane

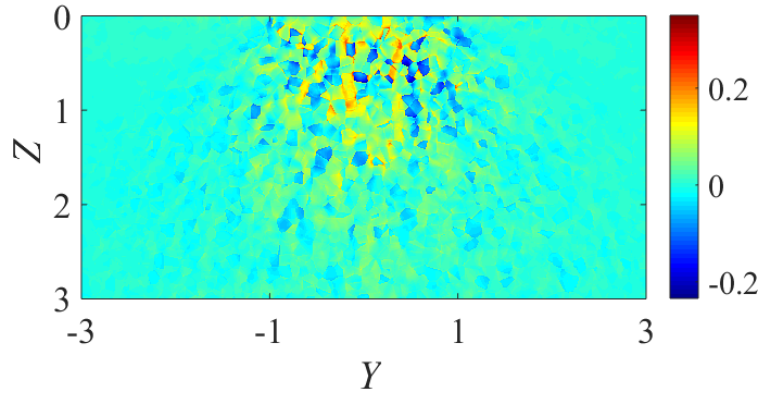

(d) $\bar{\sigma}_{\mathrm{VMS}}(0 \sim 0.7 \times \pi / 2)-$ $\bar{\sigma}_{\mathrm{VMS}}($ iso) of $Y Z$ plane

Figure 16 Effect of rotation angle on the stress field for heterogeneous anisotropic material

\section{Conclusion}

In this paper, a developed multigrid method for the numerical simulation of dry and lubricated contacts for the case of 3D elastic heterogeneous material with 182 
varying crystallographic orientation [21][28] was used to analyse the effects of various parameters on the predicted fatigue life using an Ioannides-Harris [7] based analysis. First uniform anisotropic cases were considered. Subsequently using Voronoi tessellation grain topologies where the crystallographic orientation was randomly varied with a uniform distribution. The effect of contact load (pressure), friction coefficient, mean grain size and effects of distribution of rotation angles on the stress field and the fatigue life stress integral value were investigated. It was shown that the developed numerical method is well suited to study the effects of crystallographic orientation induced anisotropy both for uniform as well as for granular topology with randomly varying orientation over the grains. The results show that mean grain size and crystallographic orientation variation significantly affect predicted fatigue life. Whereas the fatigue life integral value of homogeneous (aligned) anisotropic material under increasing pressure or tangential shear stress conditions is smaller than that of isotropic material, a granular topology with varying crystallographic orientation results in some local stress concentrations, and as a result, for the cases considered the fatigue life stress integral value is some 3-5 times larger than that of homogeneous isotropic material which could imply a significant reduction of the RCF. The study was conducted for grain sizes down to $15 \mu \mathrm{m}$. The effects are strongest for the larger grains and with larger stress variation between neighbouring grains. With decreasing mean grain size, the detrimental effect is reduced. The results show that the developed method has excellent prospect to help assess criticality of heterogeneous material topology and crystallographic orientation variations down to a grain size that is about 10 times smaller than the Hertzian contact radius. It should be noted that this grain size is most likely still too large to approach both the structure of bearing steels and the anticipated limiting behaviour of an homogenous isotropic material. This limit will anyhow numerically be very challenging to clearly demonstrate as a reduced grain size requires a finer grid to maintain comparable numerical accuracy. Parallelization of the solver to further decrease the grain sizes that can sufficiently accurately be computed as well as use of local grid refinement approaches where a particular structure is embedded in a homogeneous bulk are topics of current development. Nevertheless, the presented results already show an excellent capability to investigate the effects of varying crystallographic orientation in 3D. The developed method can be a very useful tool to aid 
microstructural criticality assessment, to perform computational diagnostics, and to help optimize EHL contact and bearing performance.

\section{Acknowledgements}

The authors would like to thank Mr. Bernie van Leeuwen, SKF Research and Technology Development Director, for his kind permission to publish this article. The first author acknowledges the China Scholarship Council (CSC) for providing the $\mathrm{PhD}$ scholarship. The authors would like to thank prof. A.A. Lubrecht for the helpful discussion.

\section{Nomenclature}

$a$

$A_{\mathrm{S}}$

A

$c_{11}, c_{12}, c_{44}$

$e, c, h_{\mathrm{s}}$

$C_{i, j, k, l}$

$\bar{C}_{i j k l}$

E

F

$h$

$H$

$l, m, n$

$L, M$

$N$

$p$

$P$

$p_{\mathrm{h}}$

$R$

$\mathrm{RCF}$ half width of Hertzian contact (m)

probability normalization factor, (-)

anisotropy ratio, $2 \mathrm{c}_{44} /\left(\mathrm{c}_{11}-\mathrm{c}_{12}\right),(-)$

elastic constants for cubic material, $(\mathrm{Pa})$

Lundberg-Palmgren exponents, (-)

elastic stiffness matrix, $(\mathrm{Pa})$

dimensionless of elastic stiffness matrix, $C_{i, j, k, l} / p_{\mathrm{h}}$

Young's modulus, $(\mathrm{Pa})$

applied load, (N)

gap distance, $(\mathrm{m})$

dimensionless gap distance, $h / a$

direction cosines, $(-)$

Moes dimensionless parameters, (-)

number of cycles, (-)

pressure, $(\mathrm{Pa})$

dimensionless pressure, $p / p_{\mathrm{h}}$

maximum Hertzian pressure, $(\mathrm{Pa})$

spheres radius, (m)

rolling contact fatigue 


\begin{tabular}{|c|c|}
\hline$S$ & survival probability \\
\hline $\mathrm{Sr}$ & relative value of fatigue life integral \\
\hline$s_{11}, s_{12}, s_{44}$ & elastic compliances of material, $\left(\mathrm{Pa}^{-1}\right)$ \\
\hline$u, v, w$ & displacements in $x, y, z$ directions, (m) \\
\hline$u_{\mathrm{m}}$ & entrainment velocity, $(\mathrm{m} / \mathrm{s})$ \\
\hline$v^{\prime}$ & volume, $\left(\mathrm{m}^{3}\right)$ \\
\hline$U, V, W$ & dimensionless displacements, $u / a, v / a, w / a$ \\
\hline VMS & von Mises stress \\
\hline$x, y, z$ & coordinate system, (m) \\
\hline$z^{\prime}$ & stress weighted average depth, (m) \\
\hline$X, Y, Z$ & dimensionless coordinate system, $x / a, y / a, z / a$ \\
\hline$\sigma_{i j}$ & normal and shear stress, $(\mathrm{Pa})$ \\
\hline $\bar{\sigma}_{i j}$ & dimensionless normal and shear stress, $\sigma_{i j} / p_{\mathrm{h}}$ \\
\hline $\bar{\sigma}_{\mathrm{VMS}}$ & dimensionless Von Mises stress, $\sigma_{\mathrm{VMS}} / p_{\mathrm{h}}$ \\
\hline$\alpha, \beta, \gamma$ & Euler rotation angle, $(\mathrm{rad})$ \\
\hline$\mu$ & friction coefficient, $(-)$ \\
\hline$v$ & Poisson ratio, (-) \\
\hline$\eta_{0}$ & lubricant viscosity, (Pas) \\
\hline$\alpha_{\text {oil }}$ & pressure viscosity coefficient, $\mathrm{Pa}^{-1}$ \\
\hline
\end{tabular}

\section{References}

[1] Zaretsky Erwin V. STLE life factors for rolling bearings. 2nd ed. Park Ridge: Society of Tribologists and Lubrication Engineers; 1992.

[2] Weibull W. A statistical theory of strength of materials. Stockholm: Generalstabens litografiska anstalts förlag; 1939.

[3] Lundberg G, Arvid P. Dynamic capacity of rolling bearings. Stockholm: Generalstabens litografiska anstalts förlag; 1947. 
[4] Chiu Y P, Tallian T E, McCool J I. An engineering model of spalling fatigue failure in rolling contact: I. The subsurface model. Wear 1971; 17(5-6): 433446. https://doi.org/10.1016/0043-1648(71)90049-4.

[5] Tallian T E, McCool J I. An engineering model of spalling fatigue failure in rolling contact: II. The surface model. Wear 1971; 17(5-6): 447-461. https://doi.org/10.1016/0043-1648(71)90050-0.

[6] Tallian T E. An engineering model of spalling fatigue failure in rolling contact: III. Engineering discussion and illustrative examples. Wear 1971; 17(5-6): 463-480. https://doi.org/10.1016/0043-1648(71)90051-2.

[7] Ioannides E, Harris T A. A new fatigue life model for rolling bearings. Journal of Tribology, 1985; 107(3): 367-377. https://doi.org/10.1115/1.3261081.

[8] Cheng W, Cheng H S. Semi-analytical modeling of crack initiation dominant contact fatigue life for roller bearings. Journal of Tribology 1997; 119(2): 233-240. https://doi.org/10.1115/1.2833163.

[9] Yu W K, Harris T A. A new stress-based fatigue life model for ball bearings. Tribology transactions 2001; 44(1):11-18. https://doi.org/10.1080/10402000108982420.

[10] Zaretsky E V. STLE life factors for rolling bearings. Park Ridge: Society of Tribologists and Lubrication Engineers; 1992.

[11] Tallian T E. A data-fitted rolling bearing life prediction model--Part I: mathematical model. Tribology transactions 1996; 39(2): 249-258. https://doi.org/10.1080/10402009608983527.

[12] Tallian T E. A data-fitted rolling bearing life prediction model--Part II: model fit to the historical experimental database. Tribology transactions 1996; 39(2): 259-268. https://doi.org/10.1080/10402009608983527.

[13] Tallian T E. A data-fitted rolling bearing life prediction model-Part III: parametric study, comparison to published models and engineering review. Tribology transactions 1996; 39(2): 269-275. https://doi.org/10.1080/10402009608983528.

[14] Morales-Espejel G E, Gabelli A, De Vries A J. A model for rolling bearing life with surface and subsurface survival-tribological effects. Tribology Transactions 2015; 58(5): 894-906. https://doi.org/10.1080/10402004.2015.1025932.

[15] Stewart S, Ahmed R. Rolling contact fatigue of surface coatings - a review. Wear 2002; 253(11-12): 1132-1144. https://doi.org/10.1016/S00431648(02)00234-X. 
[16] Hashimoto K, Hiraoka K, Kida K, Costa Santos E. Effect of sulphide inclusions on rolling contact fatigue life of bearing steels. Materials science and Technology 2012; 28(1): 39-43. https://doi.org/10.1179/1743284711Y.0000000062.

[17] Moghaddam S M, Sadeghi F, Paulson K, Weinzapfel N, Correns M, Bakolas V, Dinkel M. Effect of non-metallic inclusions on butterfly wing initiation, crack formation, and spall geometry in bearing steels. International Journal of Fatigue 2015; 203-215. https://doi.org/10.1016/j.ijfatigue.2015.05.010.

[18] Zhou R S. Surface topography and fatigue life of rolling contact bearing. Tribology Transactions 1993; 36(3): 329-340. https://doi.org/10.1080/10402009308983167.

[19] Paulson N R, Bomidi J A, Sadeghi F, Evans R D. Effects of crystal elasticity on rolling contact fatigue. International Journal of Fatigue 2014; 61: 67-75. https://doi.org/10.1016/j.ijfatigue.2013.12.005.

[20] Noyel J P, Ville F, Jacquet P, Gravouil A, Changenet C. Development of a granular cohesive model for rolling contact fatigue analysis: crystal anisotropy modelling. Tribology Transactions 2016; 59(3): 469-479. https://doi.org/10.1080/10402004.2015.1087076.

[21] Zhang B B, Boffy H, Venner C H. Multigrid solution of 2D and 3D stress fields in contact mechanics of anisotropic inhomogeneous materials. Tribology International 2020. https://doi.org/10.1016/j.triboint.2019.02.044.

[22] Paulson N R, Sadeghi F. EHL modeling of nonhomogeneous materials: The effects of polycrystalline anisotropy on RCF. Tribology International 2017; 112: 137-146. https://doi.org/10.1016/j.triboint.2017.04.007.

[23] Venner C H, Lubrecht A A. (Eds.). Multi-level methods in lubrication (Vol. 37). Amsterdam: Elsevier; 2000.

[24] Bower A F. Applied mechanics of solids. Florida: CRC press; 2009.

[25] Boffy H, Venner C H. Multigrid numerical simulation of contact mechanics of elastic materials with 3D heterogeneous subsurface topology. Tribology international 2015; $233-245$. https://doi.org/10.1016/j.triboint.2015.06.015.

[26] Zaretsky E V, Poplawski J V, Peters S M. Comparison of life theories for rolling-element bearings. Tribology transactions 1996; 39(2): 237-248. https://doi.org/10.1080/10402009608983525.

[27] Zhang J M, Zhang Y, Xu K W, Ji V. Young's modulus surface and Poisson's ratio curve for cubic metals. Journal of Physics and Chemistry of Solids 2007; 68(4): 503-510. https://doi.org/10.1016/j.jpcs.2007.01.025. 
[28] Zhang B B, Liu H C, Félix Quiñonez A, Venner C H. Effects of 3D anisotropic heterogeneous subsurface topology on film thickness and subsurface stresses in elasto-hydrodynamically lubricated point contact. $\begin{array}{llll}\text { Tribology International 2020; } & 151 .\end{array}$ https://doi.org/10.1016/j.triboint.2020.106471.

[29] Soda N, Yamamoto T. Effect of tangential traction and roughness on crack initiation/propagation during rolling contact. ASLE Transactions 1982; 25(2): 198-206. https://doi.org/10.1080/05698198208983081.

[30] Ooki C, Maeda K, Nakashima H. Improving rolling contact fatigue life of bearing steels through grain refinement. SAE Technical Paper 2004; No. 2004-01-0634.

[31] Petch N J. The cleavage strength of polycrystals. Journal of the Iron and Steel Institute 1953; 174: 25-28. 